University of San Diego

Digital USD

2016-1

\title{
"Intonations of their Own Language": An Analysis of Leadership and Resonance in Two Progressive Young-Adult-Filled Congregations in the Pacific Northwest.
}

D. Bethan Theunissen

University of San Diego

Follow this and additional works at: https://digital.sandiego.edu/dissertations

Part of the Organizational Behavior and Theory Commons, and the Organization Development Commons

\section{Digital USD Citation}

Theunissen, D. Bethan, "'Intonations of their Own Language": An Analysis of Leadership and Resonance in Two Progressive Young-Adult-Filled Congregations in the Pacific Northwest." (2016). Dissertations. 26. https://digital.sandiego.edu/dissertations/26 Digital USD. It has been accepted for inclusion in Dissertations by an authorized administrator of Digital USD. For more information, please contact digital@sandiego.edu. 


\title{
"INTONATIONS OF THEIR OWN LANGUAGE": AN ANALYSIS OF LEADERSHIP AND RESONANCE IN TWO YOUNG-ADULT-FILLED PROGRESSIVE MAINSTREAM CONGREGATIONS IN THE PACIFIC NORTHWEST
}

\author{
by \\ D. Bethan Theunissen \\ A dissertation submitted in partial fulfillment \\ of the requirements for the degree of \\ Doctor of Philosophy
}

January 2016

\author{
Dissertation Committee \\ Robert Donmoyer, Ph.D. \\ Laura Deitrick, Ph.D. \\ Evelyn Kirkley, Ph.D.
}

University of San Diego 
(C) Copyright by D. Bethan Theunissen, 2016

All Rights Reserved 


\begin{abstract}
Christendom in Canada and the United States is in decline, and young adults are leaving the church in considerable numbers. This exodus is especially noticeable in mainstream religious denominations, although evangelical groups are beginning to experience a similar waning. The fastest-growing "religious" group consists of those who identify with no religion.
\end{abstract}

Simultaneously, young adults are experiencing a far longer entry process into adulthood after adolescence than those who went before them. They also experience the world as unstable and impermanent. Their needs and the church's needs could converge but instead seem to be antithetical to each other in ways that further contribute to the numerical decline.

This qualitative study focused on two progressive mainstream congregations in the Pacific Northwest. Both congregations were outliers in that they attracted substantial numbers of participants aged 18 to 35 . The study focused on how congregations and their leaders created webs of significance and intonations of language (Weber, as cited in Hopewell, 1987, p. 6) that resonated with those seeking a spiritual home.

The research strategy, by design, was emergent. Data were gathered in this focused ethnography by conducting individual and focus group interviews with leaders and members that encouraged storytelling; by observing worship services and other church-related interactions; and by analyzing websites, bulletins/PowerPoints, and documents.

Although both congregations were located in progressive young-adult-filled neighborhoods, they had almost opposite leadership, liturgical, and music styles. 
Consequently, two case-studies were initially constructed to portray the dynamics within each location. A subsequent cross-case analysis however, revealed that analogous sources of resonance between young adults and congregations emerged when visionary leaders freed and empowered young adults to encounter the divine through tradition, innovation, and questioning. The sources of resonance were categorized under the sociocultural milieu, leadership preferences, and developmental needs of young adults.

Despite the limitations of case-study research, this study provides insight into what aspects of these religious congregations resonated with the young adults who found a home there. It offers new thought categories and working hypotheses for denominations, seminaries, clergy, congregations, young adults, and others interested in religious experience and affiliation among younger people. 
To Naomi, who loved and supported me throughout!

To the Divine Mystery, the Presence in the Midst

for beginning this good work in me and carrying it to completion, quite often despite me. 


\section{ACKNOWLEDGEMENTS}

It took a village to complete this dissertation and I am immensely grateful to these “villagers.” In particular I would like to thank my committee. My supervisor Dr. Robert (Bob) Donmoyer is a social scientist/practitioner with the academic versatility and range to effortlessly supervise students from a wide range of disciplines, even pastor/theologians! His advice made my writing and the structure of this dissertation infinitely better. Dr. Evelyn Kirkley from USD's Department of Theology and Religious Studies asked incisive questions and alerted me to some of my imprecise theological and historical thinking. Dr. Laura Deitrick, fortuitously Episcopalian, late in the journey, generously agreed to replace Dr. David Herrera whose health unfortunately required that he step aside.

The faculty members in the SOLES department at the University of San Diego were a superb resource. Dr. Robert Donmoyer, Dr. Fred Galloway, Dr. Cheryl Getz, Dr. Zachary Green, Dr. Terri Monroe, and Dr. George Reed taught outstanding courses and I was fortunate to serve as teaching assistant for a few. Dr. Mary-Rose Mueller, nursing professor, further fortified my qualitative research sensibility. My fellow students were a rich source of dialogue, both encouraging and goading me into new learning. I am grateful to the Caster Family Center for Nonprofit and Philanthropic Research where I

worked as a research assistant. Here the directors Prof. Pat Libby and Dr. Laura Deitrick with faculty member Dr. Mary McDonald tried valiantly to help this pastor become a researcher. Fellow research assistants, now Dr. Heather Carpenter, Dr. Lindsay McDougle, Dr. Melanie Hitchcock, Dr. Taylor Payton-Roberts, and soon-to-be Dr. Tom Cesarani became academic models and family. Assistant Dean Linda Dews, Dr. Paula 
Krist, and the exceptional staff in the dean's office played an invaluable role guiding me through the intricacies of being an international student. I would also like to thank Beth Garofalo, Annie Guanciale, Heather Gibbs and the staff at Soles who kept me on track with cheerful determination. In Linda Vista nearby, Kathy Marpe, Cyndy Guy and their neighbor Marty Becerril offered me accommodation and much-needed logistical support.

I am grateful to those who helped me financially in large or small ways: the SOLES merit awards, scholarships, and loans; Pearl Wong; Marj Parker; Shiloh-Sixth United Church; the Victor Blatherwick Memorial Bursary; John and Joanne Lougheed; and Judy Dixon made this work possible. I am also indebted to my colleagues and former congregants for their encouragement along the way. Trinity United generously attempted to create space for me to complete my writing.

During the research phase of my dissertation the doors to both the sites I studied were opened to me by Bishop Greg Rickel and the leaders and boards of both churches. Ned and Jeannette Olson, and Sarah and Paul Brown provided gracious hospitality during my month at each of the two sites. During the writing phase I received important software, transcription, and editing help from Jeanie Wolfe, Denise Hankin, Dorothy Wiebe, Leenane Shiels, Nathaniel Dunigan, Naomi Lloyd, Jane Power, Cameron Duder, Karen Segal, and just this last weekend from Linda Murray, Anna Christy, Linda Henderson, Emily Rautenbach, and Bruce McCandless Davis.

I am most thankful to the young adults and others from COTA and St. Paul who shared their spiritual journeys with me and trusted me to tell their stories. My greatest hope is that I have done justice to their narrative. I trust that this work will provoke stimulating thinking and conversations within and outside of the church. 


\section{TABLE OF CONTENTS}

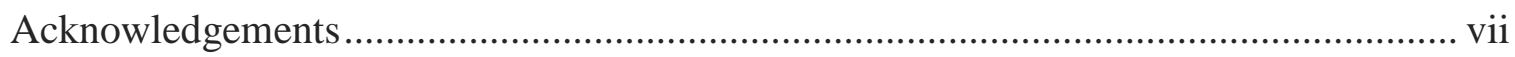

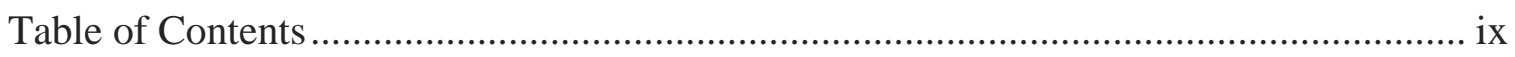

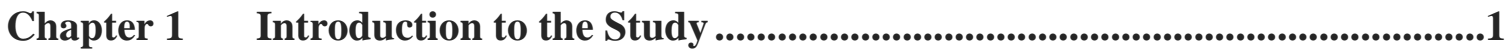

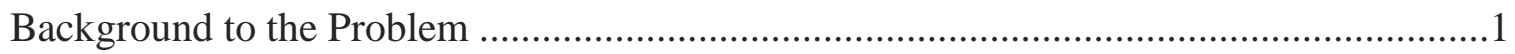

Studies Concerning Religious Decline and Young Adults ....................................

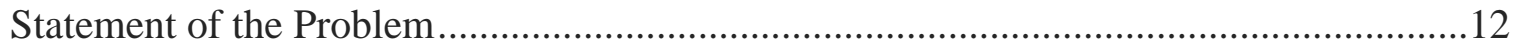

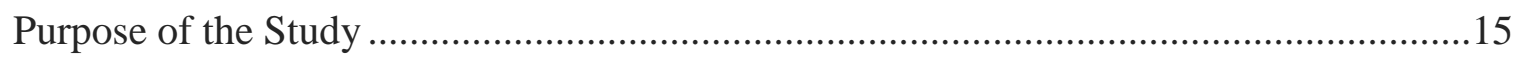

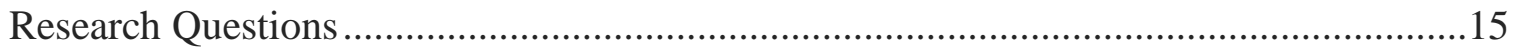

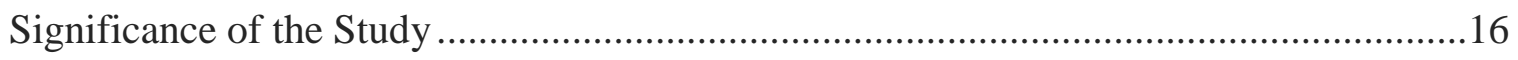

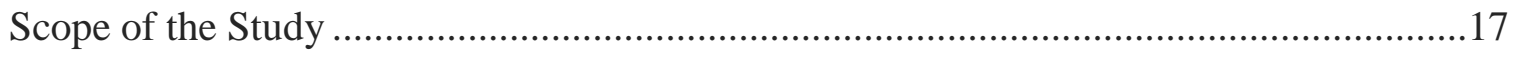

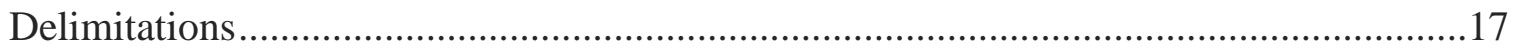

Membership Role of Researcher..................................................................... 18

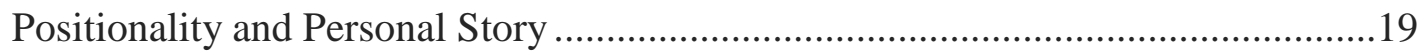

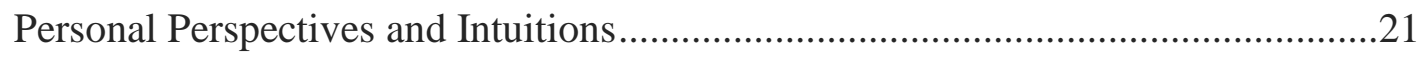

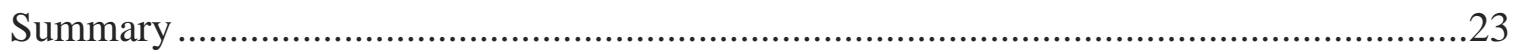

Chapter 2 Literature Review ................................................................................................24

Studies of Religious Participation of Young Adults in the United States .......................25

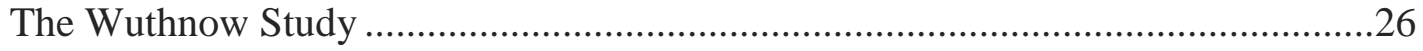

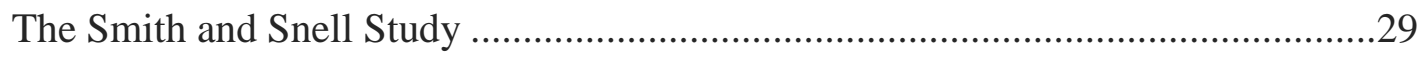

The Norris and Inglehart, and the Welzel Studies ...............................................33

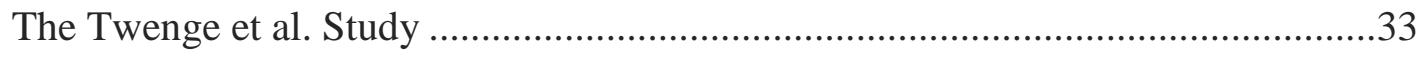


The Barna Group Study

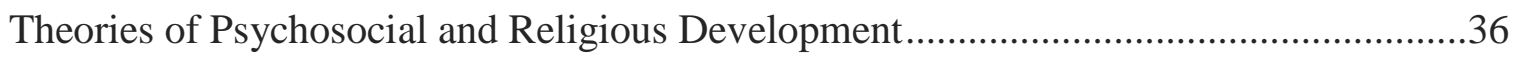

The Life Cycle and Stage Theories of Development...........................................37

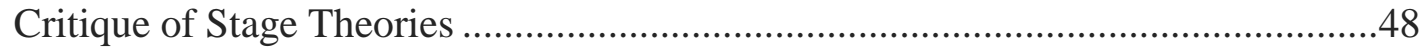

The Significant Challenges Facing Young Adults......................................................53

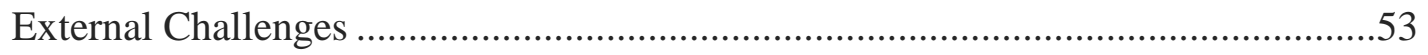

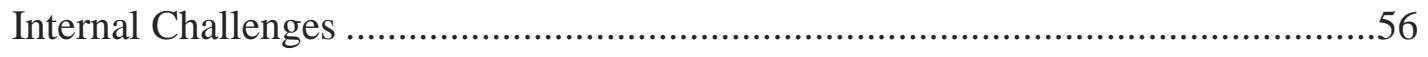

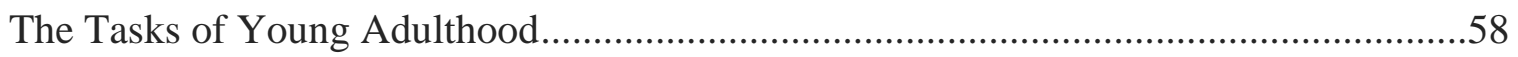

Ego Development Through Separation/Individuation ........................................59

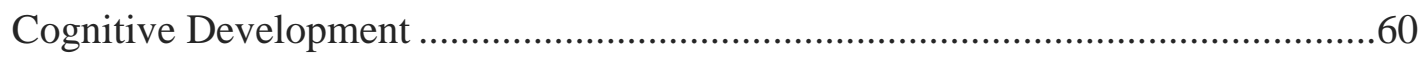

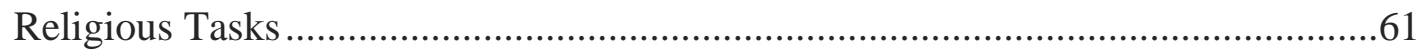

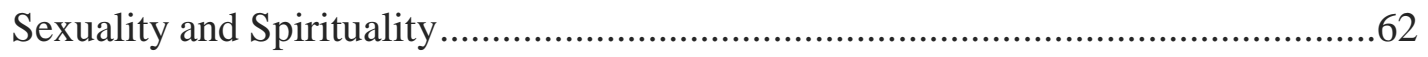

Studies of Young-Adult-Rich Churches .............................................................63

The "Congregations that Get It" Study ........................................................63

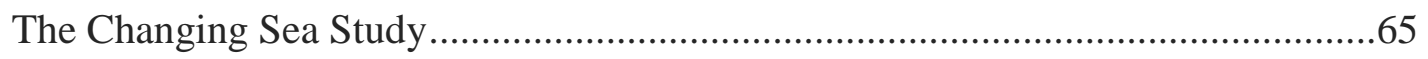

A Typology of Congregations of Religious Young Adults ................................67

Some Recurring Themes in the Studies of Young-Adult Religious Affiliation ...............69

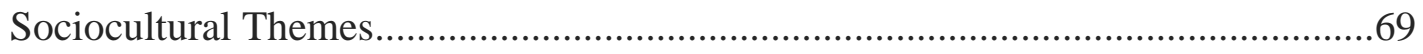

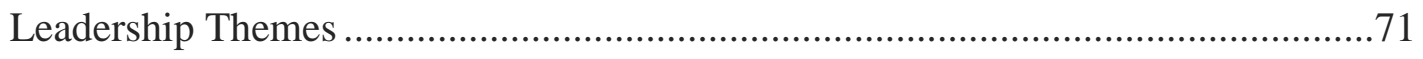

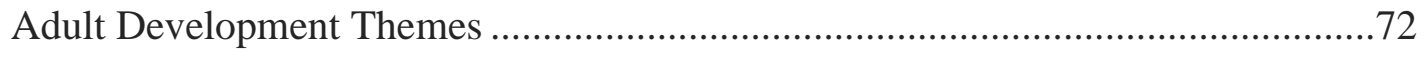

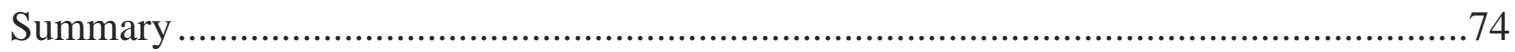


Chapter 3 Research Methodology ....................................................................................76

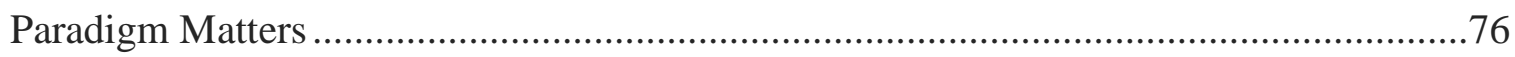

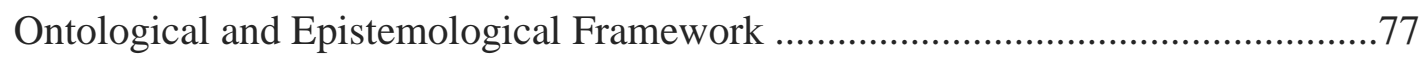

Congregational Studies Perspective .........................................................................78

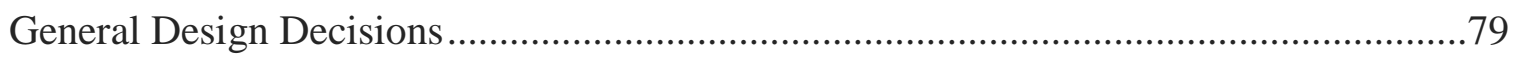

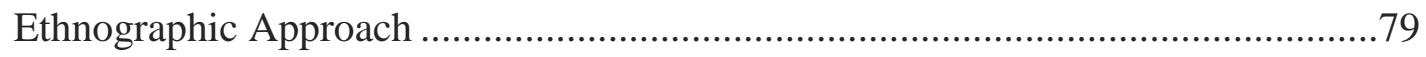

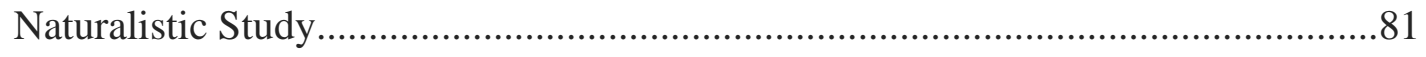

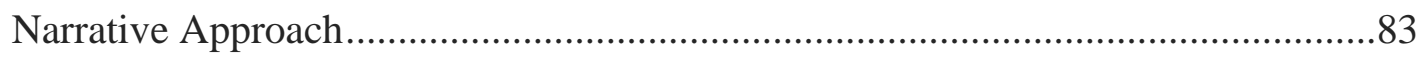

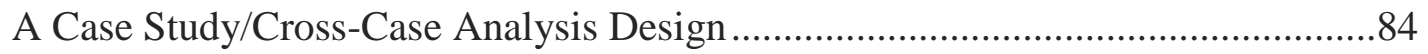

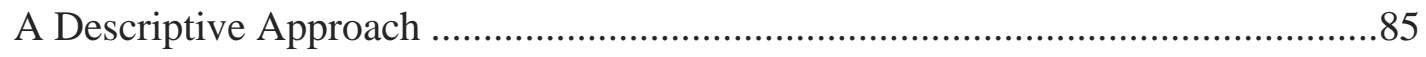

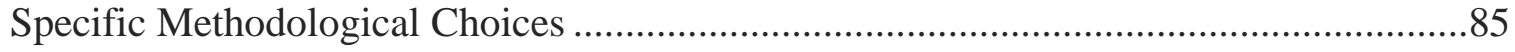

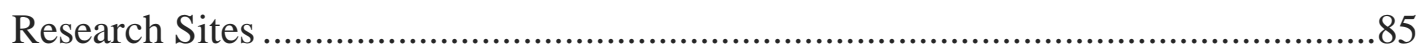

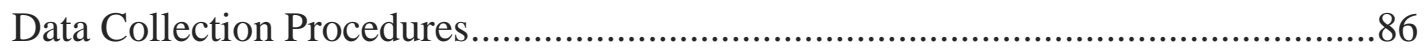

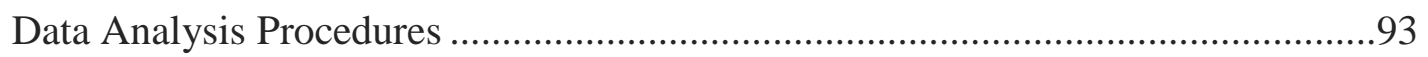

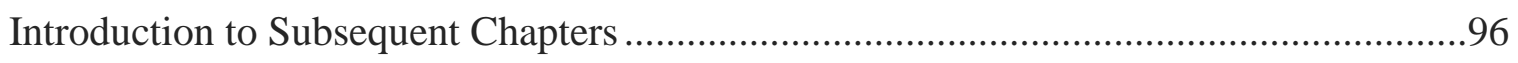

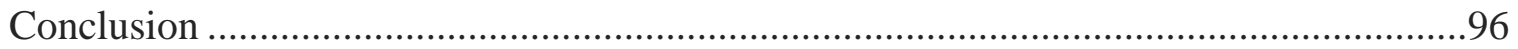

Chapter 4 COTA: A Completely Different Kind of Church......................................97

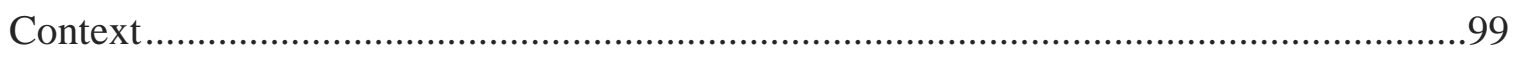

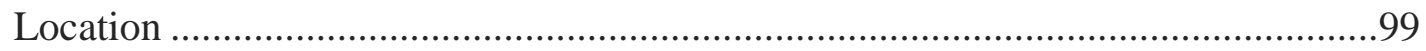

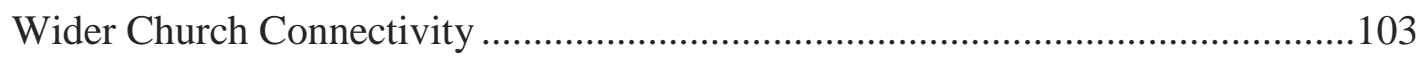

Creation of Welcoming Space for Young Adults ...........................................................108

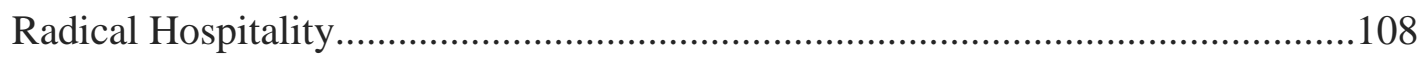

The Ambiguity and Ambivalence about Being Welcoming ...................................110 
The Center and the Periphery: A Place to Belong ..............................................112

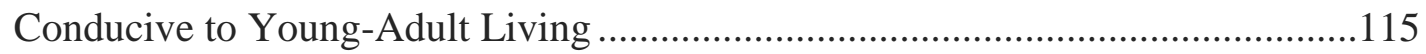

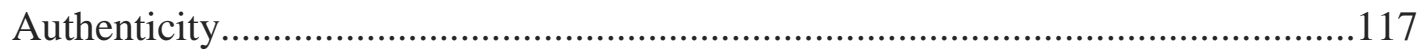

Translation of Ancient Christian Wisdom or Rituals ................................................124

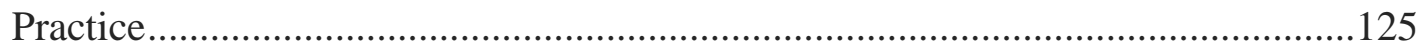

Liturgy: "A Little Bit of Scripted Theater, A Little Bit of Improv" (Noah)...........126

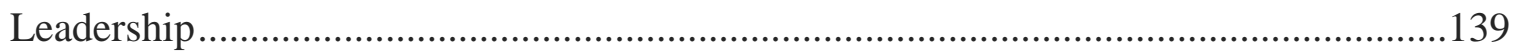

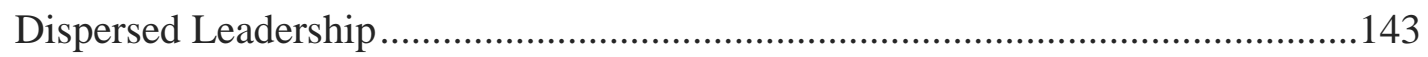

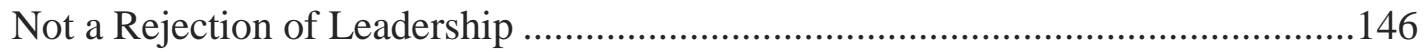

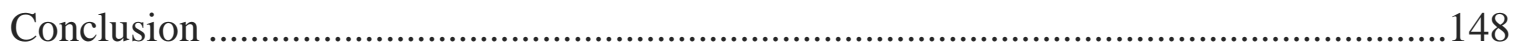

Chapter 5 St. Paul's: A Vibrant, Progressive Anglo-Catholic Parish..................149

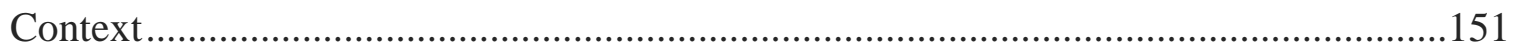

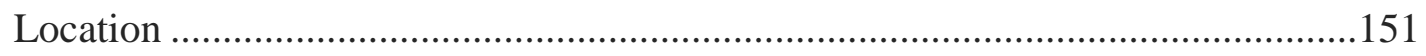

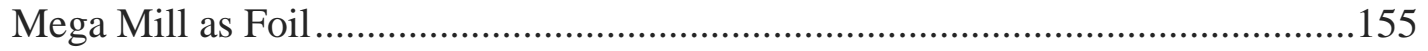

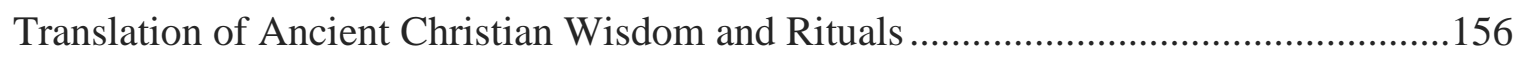

Anglo-Catholic Liturgy: Ancient, Mysterious, and Vibrant .................................158

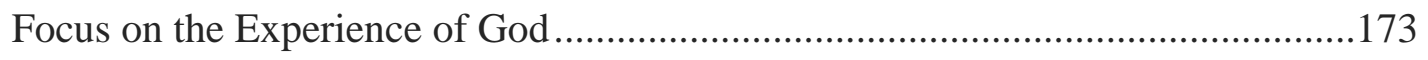

Creation of Welcoming Space for Young Adults ....................................................174

Welcome Through Radical Hospitality ........................................................ 174

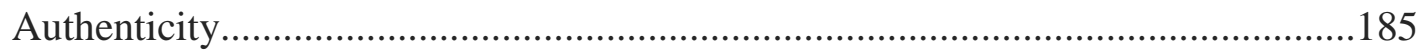

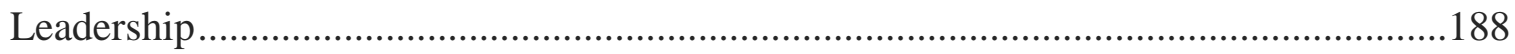

Dispersed and Centralized Leadership.........................................................188

Non-Coercive Leadership: Walking Alongside ...............................................190 
Leadership and Empowerment: A Healthy Tension

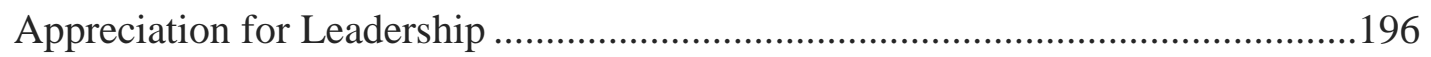

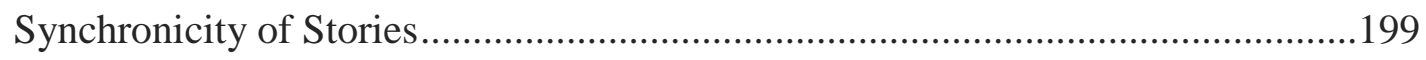

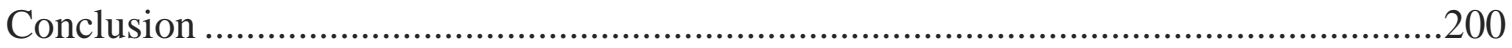

Chapter 6 Cross-Case Analysis.........................................................................202

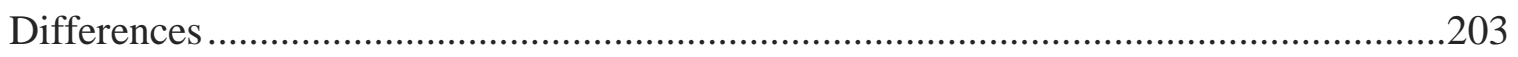

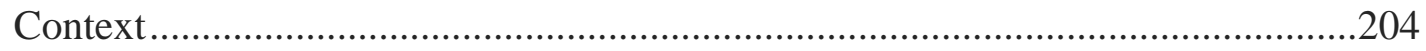

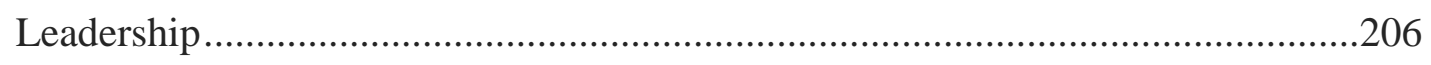

Translation of Ancient Wisdom and Rituals ..................................................211

The Creation of Welcoming Space ...............................................................215

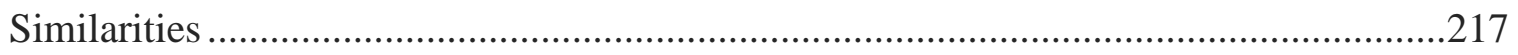

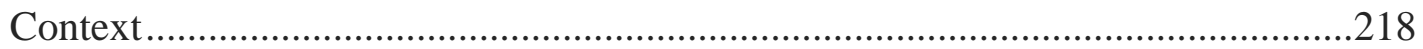

Translation of Ancient Rituals and Wisdom...................................................219

The Creation of Welcoming Space ................................................................222

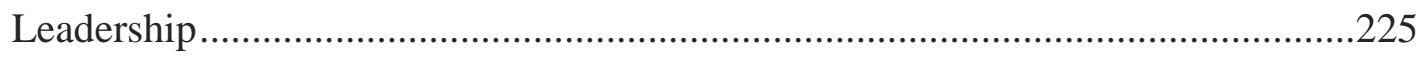

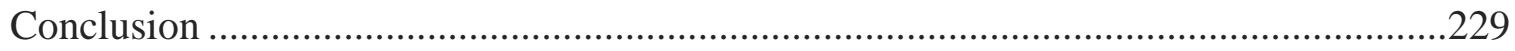

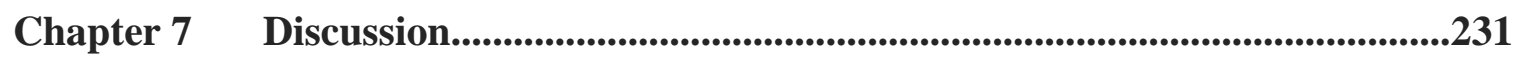

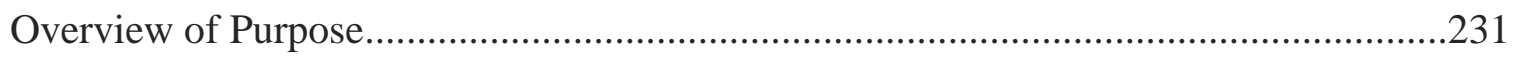

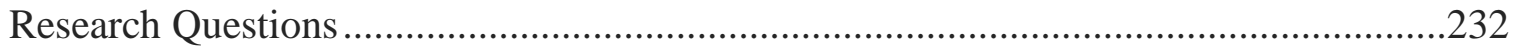

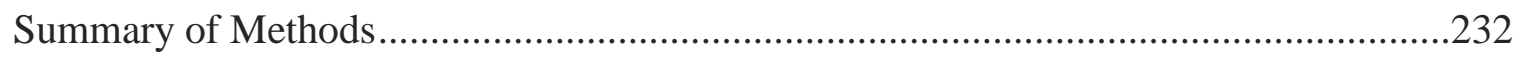

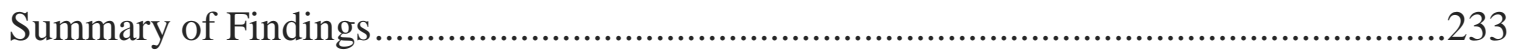

Discussion of Findings with Regard to the Literature ...........................................236 
Question 1. What aspects of leadership and translation, if any, were/are exercised to make ancient wisdom or rituals relevant to, and create a welcoming space for young adults?

Question 2. What kinds of resonance, if any, emerged between the leaders and the group (both individual participants and the whole congregation)?. .245

Question 3. What kinds of associations, if any, exist between the narratives of participants and theory about the developmental and maturational work of young adulthood? .251

Back to the Barna Research .256

Summary .258

Limitations .259

Implications for Young Adults, Congregations, and Denominations .262

Developmental Needs of Young Adults .263

Leadership .265

Implications for Further Research .265

Conclusion .267

References .269

Appendix A E-Mail to Congregational Leaders to Follow Initial Contact .281

Appendix B Research Participant Consent Form ...............................................283

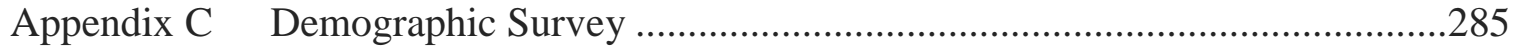

Appendix D Open-Ended Interview Questions: Original and revised ......................287

Appendix E. Demographic Details for COTA and St. Paul's ....................................290 xiv 


\section{CHAPTER 1}

\section{INTRODUCTION TO THE STUDY}

It is the hope and desire of most religious people that each generation will pass the faith and values of their community to the next. For instance, Jewish and Christian worshippers regularly sing or say this Psalm:

I will open my mouth in parables, I will utter things hidden from of old - the things we have heard and known, things our ancestors have told us. We will not hide them from our children; we will tell the next generation. We will tell them of your praiseworthy deeds, YHWH, your power, and the wonders you have performed. You set up statutes for our forebears, and established the law in Israel, which you commanded our ancestors to teach their children, so the next generation would know them - children yet to be born - and as they come up, they would tell their own children. Then they would put their trust in you and not forget your deeds, but keep your commandments. (Psalm 78:2-7. The Inclusive Bible)

\section{Background to the Problem}

The United Church of Canada - of which I am a minister - is passionate about its social justice work, progressive theology, and conciliar ${ }^{1}$ decision-making style. While there are several vital, thriving congregations in the denomination, the more pervasive scenario is of declining churches that are struggling financially, with a decreasing number of participants, or both. Some congregations with significant financial resources have disbanded because the elderly participants are simply too tired to carry on. Most young adults raised in the United Church of Canada, particularly those in their twenties and early thirties, do not continue to participate in United Church congregations.

${ }^{1}$ Conciliar denotes two aspects of church governance in the United Church of Canada. First, decisionmaking occurs through groups rather than individuals. Second, individual congregations send representatives to presbytery/district meetings, who then collectively meet with other presbyteries once a year to form (geographically based) conferences, which sends representatives to the General Council every two or three years (United Church of Canada, 2013). 
Research on the demographics of congregations in Canada and the United States has suggested that the situation in the United Church of Canada is not unique (Olson, 2008). One out of every one hundred Christian congregations closes each year in the United States (Adler, Chaves, Anderson, Martinez, \& Hoegeman, 2008), which translates into about 280 congregational closings a month. Adler et al. argued that many congregations are only nominally functioning and in what could be considered a permanently failing performance state. This decline is obvious in the Pacific Northwest in the U.S. (or the Pacific Southwest of Canada) which is also called Cascadia. This area held the distinction for decades of being the least religious region in North America, before (with the exception of parts of Oregon) losing this status in the U.S. to the Northeast coast (Kosmin \& Keysar, 2008; Newport, 2014).

Although young adults in many congregations in the U.S. and Canada are a tiny minority or absent altogether, until recently there has been little investigation into the relationship between young adults and congregations. Sociologist of religion Robert Wuthnow (2010), in discussing the realities of young adults, asserted only five years ago that:

Their lifestyles have seldom been scrutinized, and little is known about the church going habits, their spiritual interests and needs, and how their faith affects their families, their politics, and their communities. The need for better information on young adults is thus urgent for the present as well as the future. (p. 2)

At least one aspect of this failure by churches to engage more quickly in a "missing-persons investigation" is because the decades-long numerical decline was often attributed to the failure of clergy to be sufficiently magnetic to draw in young families. 
The church has been slow to grasp that Christianity is no longer the default religion of Western society. Most mainstream ${ }^{2}$ Christian clergy are finding themselves in a situation for which they are not trained, that is, leading congregations in a time of increased secularism, pluralism, and rapid religious decline. Furthermore, although existing members would love to pass their faith tradition on to the next generation, the dramatic decline in church membership and attendance in general has left many aging congregations somewhat incapacitated. Both church members and church leaders often feel weak, fearful, and ill-equipped to provide young adults with the kind of sacred space and community they might need to traverse the difficult social, economic, and emotional terrain of an extended young adulthood. Although many might argue that young adults are simply finding other ways to practice their spirituality outside of Christian congregations, as someone who is particularly committed to congregations as a collective spiritual form, it is the relationship of young adults to congregations that interests me and that I explore in this study.

Former professor of Religion and the Church at the Candler School of Theology, James F. Hopewell (1987) asserted that it was not inevitable that local congregations would become the primary form through which the Christian religion shifted from one generation to another. He depicted various different ways religion has been both experienced and passed on in various cultures. Families and clans have religious

2 Instead of using the term mainline which does not include Catholic churches in the USA, I have stipulated the use of the word mainstream as inclusive of Catholics. Religious historian, William Hutchison, (1960) associated the following seven U.S. denominations as mainline: American Baptists, Christian Church (Disciples of Christ), United Church of Christ, Episcopal Church in the United States of America, Lutheranism, Methodism, and Presbyterianism during the period between 1900 and 1960. In Canada, we use the acronym PLURA - that includes Presbyterian, Lutheran, United Church of Canada, Roman Catholic, and Anglican churches as the mainline. 
practices such as family shrines and meals or feasts. Civic societies have religious celebrations such as Memorial Day services or political inaugurations. Religious communities provide sites for religious activity, such as shrines and other holy places, which require more or less commitment from laity.

In Judaism, however, after two temples were destroyed in $586 \mathrm{BCE}$ and $70 \mathrm{CE}$, the physical congregation became an effective way to practice the Jewish faith. Christian spirituality, which was birthed within Judaism, followed suit. Since biblical faith was not simply a relationship between an individual and the divine, but also had communal and social implications, the congregation was a uniquely suited form for the expression of biblically-oriented faith. In my own experience, congregations provide a place of belonging where people can learn to get along with others, develop decision-making routines and leadership/followership styles, acquire communal spiritual practices, and collaborate in collective service and action in the community.

John Wesley, the founder of Methodism, said that there was "no holiness but social holiness" (United Methodist Communications, 2015), and numerous passages of Scripture encourage believers not to give up meeting with other believers (Hebrews 10:25. The Inclusive Bible). Unless Christian disciples could practice not only giving "glory to God in the highest" but also embodying and creating "peace among the people on earth," their faith was untested and incomplete. The marks of the church, according to Bosch (2003), namely kerygma (proclamation), leitourgia (worship liturgy), koinonia (fellowship), didache (teaching and education), diakonia (service in the church or to the community), and martyria (witness to the larger community) were particularly possible in, although perhaps not exclusive to, a physically gathered congregation. 
Congregations are thus small microcosms of society in which spirituality and human belonging can be experienced collectively, not only at Sunday worship and weekday prayer but also through the nitty-gritty things of life such as the management of finances and renting or owning a building. Hopewell (1987) asserted that through these mundane realities, the congregation could "deepen its sense of commonality with efforts of human societies throughout the world to gain their own shalom" (p. 15). Despite the abundance of Internet resources for spiritual nurture, many Christians are still attached to the gathered congregation as their primary faith vehicle.

Hopewell (1987) compared those seeking a congregation to house hunters, who were interested in a potential home's context (neighborhood location), mechanisms (plumbing and electricity), and organic issues (familial style, cohesion, and social interaction). House hunters do a symbolic intuitive analysis, testing consciously and unconsciously whether a place is a match with their own identity, values, and worldview. They thus ask the question, "Is this house me?" I believe that this "house hunting" analogy may be useful for discerning resonance that young adults either do or do not experience in potential home congregations.

Hopewell (1987) did not address the issue of young adults in his book but he did say, "Congregations have an extraordinary ability to weave together a network of construable signs that shape their identity" (p. 5). Congregations can be seen as "coherent systems whose structural logic was narrative" and as congregations come into being, "they attract those who resonate with the unique local drama enacted there" (p. 5). Drawing from the work of sociologist Max Weber cited by anthropologist Clifford Geertz (1973), Hopewell asserted that congregations also were constituted by "webs of 
significance" or in his own words, "intonations of language" that may include words, but are not limited to words. Rituals, symbols, artifacts, ambience, and various invisible psychological and sociocultural forces may all be included in the language of the congregation.

Hopewell suggested that potential church members (and thus, I would argue, young adults) instinctively sense whether the congregations' construable signs resonate, or to use his own words, whether they are compatible with the "intonations of their own language" (p. 6). Ministers moving from one context to another take a while to adapt to the new idiom and master the particular "language" of the new congregation, Hopewell explained, and must spend time weighing words so that what they say matches the congregation's idiom. Hopewell's argument can be applied to the relationship between young adults and the church, I believe, and could thus be an answer to the question of why young adults are not involved in the churches of which they are aware. In order for young adults to feel at home in a congregation, they need to feel some kind of resonance, some kind of sense that "this is me."

This notion of people finding or not finding in a congregation the "intonations of their own language" (Hopewell, 1987) has become the primary conceptual frame for this study. The idea that congregations and groups of people have a 'language" or "idiom," metaphorically speaking, along with Hopewell's notion that congregations have a structural logic of narrative, led me to posit my interview questions as "requests for stories" from and about the congregation, individuals, and leaders. 


\section{Studies Concerning Religious Decline and Young Adults}

Although until recently there has been little systematic study of why young adults are not attending churches and what can be done about it, the problem itself is now being discussed by scholars from a variety of disciplines, particularly sociology, psychology, political science, and religion. Some of these scholars have begun to describe the realities faced by young adults in society today, and the implications of these realities for religious life (Arnett, 2000; Côté, 2006; Smith, Christoffersen, \& Davidson, 2011; Smith \& Denton, 2005; Twenge, Exline, Grubbs, Sastry, \& Campbell, 2015; Wuthnow, 2010). The variety of reasons offered to explain the absence of young people from religious congregations, and the particular reasons offered, depend on the disciplinary lens being used by the scholars in question. Sociologists and political scientists tend to observe the impact of larger sociocultural and political forces, whereas psychologists might look for inner motivations and values. In the Barna research mentioned below, young adults themselves give answers that generally do not include such inner and outer forces.

Studies in church and society. According to Christian scholars of church and society Eddie Gibbs and Ryan Bolger (2005), who look at the religious involvement of young adults through a more societal lens, two cultural shifts have affected Western society and thus the church since the 1950s. The first is the transition from Christendom to Post-Christendom. Christendom is a term they use to describe the period after Roman emperor Constantine legalized and respectabilized various religions in the fourth century after which Christianity slowly became the central and default religion of Western Society. Post-Christendom is that period after the 1950s when the church as an institution began to lose its privileged position and increasingly occupied a place on the 
margins of society alongside other recreational and non-profit organizations. The second, they argue, is the shift from modernity to postmodernity. Modernity, according to Gibbs and Bolger began prior to the Renaissance, and provided epistemological certainty based on foundationalism, a certainty which began to disintegrate in the twentieth century. Postmodernity, they say, is exemplified by pluralism and a radical relativism, where religion is understood in terms of its sociological and psychological significance rather than claims of absolute truth. These authors believe that congregations that are not aware of these shifts and fail to address postmodern culture will not resonate with young adults in a Post-Christendom and postmodern world (p. 17-18).

Studies from the sociology of religion. Sociologist Robert Wuthnow (2010), in his enlightening account, After the Baby Boomers: How Twenty- and Thirty-Somethings are Shaping the Future of American Religion, observed that the extended life span experienced in post-industrial nations over the last century has had a considerable impact on the typical trajectories of people's lives, particularly the lives of retirees and young adults. The longer period during retirement means that individuals have more time in later life to do things such as start a second career or travel, and this provides a significant membership and volunteer pool for congregations. Wuthnow (2010) similarly argued that for young adults there is more time to do things that used to be compressed into a smaller number of years. For example, whereas previously it was important to start a family earlier in order to see one's children grow to maturity by the time one died, people can now wait longer. They can also take longer to decide on a line of work, and it may take them longer to achieve financial independence. The extended period of young 
adulthood, however, is correlated for Wuthnow with a withdrawal of young adults from their church connections.

Half the adult population of the U.S. fits into Wuthnow's (2010) young-adult agespan of 18-45, with a new midpoint to the lifespan of age 49. Wuthnow discussed the implications of this extension of young adulthood for both young adults and congregations. In the 1950s, he asserted, congregations that arranged age-specific programming only for teenagers would have easily met the needs of young adults who would move rather quickly into marriage and childbearing within a congregational life that supported young families. However, with such adulthood tasks now often deferred, an adolescent/young adult might leave a congregation and feel no need to participate again until they become a parent in their later twenties or thirties, if ever.

Religious congregations, Wuthnow (2010) observed, typically plan their programs based on the old view of lifecycle development, in which confirmation classes took place during the teenage years followed by some kind of youth group experience, after which people married young and often stayed in the same congregation. The dividing line in congregations, in previous decades, was between those participants who were single or married without children and those who were married and raising children. Childless or single young adults were a smaller group than the "real adults" - those who had settled down. Clearly, ministry decisions based on this understanding of the typical lifecycle are no longer helpful, according to Wuthnow. Congregations have not understood the new "language," broadly defined, of young adulthood, part of which at least is that most young adults stay single for much longer than those of previous generations. 
Studies from the political sciences. Political scientists Pippa Norris and Ronald Inglehart (2011) attributed the decline in religious affiliation, among other things to a sense of existential security within post-industrial societies which they define as "the feeling that survival is secure enough that it can be taken for granted" (p. 4). Christian Welzel (2014), also a political scientist, argued that a decline in religious involvement can be observed in nations that have increased in emancipation values (the desire to be free of domination), because religion may more easily be perceived as a dominating force that restricts freedom and enforces social rules.

Studies from psychology. These sociological and political approaches have been complemented by the psychological approach of scholars Jean Twenge, Julie Exline, Joshua Grubbs, and Keith Campbell in their article "Generational and Time Period Differences in American Adolescents' Religious Orientation" (2015). They attributed the decline to two societal aspects: First, more teens have nonreligious parents. Four times as many college students in the 2010s (versus the early 1970s) said their mother had no religious affiliation. Second, the tendency for young people to leave religious congregations as they become young adults has become more pronounced over time.

With regard to the interior aspects of young adulthood, they found that religious involvement was low when indicators of individualism were high (more positive selfviews, materialism, individualistic language, and need for uniqueness), and when social support was low. Such disproportionate individualism is, according to Wuthnow (2010), an obvious outcome of the fact that society and mainstream religious communities have left young adults to navigate their journey to adulthood on their own 
Study by the Barna Christian Research Institute. According to the Barna Group (Kinnaman \& Hawkins, 2011) there are six main reasons given by young adults themselves for their diminished relationship with Christian churches, namely: 1) churches seem overprotective; 2) teens and twenty-somethings feel their experience of Christianity is shallow; 3) churches come across as antagonistic to science; 4) young Christians experience the church's understanding of sexuality as simplistic and judgmental; 5) they wrestle with the exclusive nature of Christianity; and 6) the church feels unfriendly to those who doubt.

Societal change affecting young adults. The explosion of information technology, increased sexual liberty, immigration, and globalization particularly affect the lives of young adults which are increasingly fraught with uncertainties regarding job security, changes in accommodation, on-and-off relationships, crime, gun violence, terrorism, and issues of identity and spirituality (Arnett, 2000; Smith \& Snell, 2009; Wuthnow, 2010). The accumulation of such uncertainties makes the young-adult period an unstable one.

Although faith communities could provide a space that is both a refuge from a tumultuous world and a place to acquire the tools with which to navigate it, there seems to be a gaping chasm between young adults and religious congregations. In fact, the needs of an aging and declining mainstream church that requires new members and the needs of young adults in a time of uncertainty seem to be playing out in incompatible ways. Congregations and the church at large have been hoping that young adults will return and save them, rather than asking what kinds of support young adults might want and need in a rapidly changing society. This is presumably, at least in part, because they 
themselves feel so needy. On the other hand, many young adults are barely coping with all the instability in their own lives; they are not attracted to what seems to be a failing organization that does not speak "their language." Part of this language would seem to involve a rugged individualism, a determination to be their own authority, to determine their own morality, to think their own thoughts, and to make their own rules.

As societies change and new periods of human development emerge, new institutional supports usually arise. For example, when the period we call now adolescence was "discovered" at the turn of the twentieth century, it was accompanied by the rise of the now ubiquitous and usually free high school, for purposes of education, support, and socialization (Kett, 2003). The only significant national institutions that currently provide structures for young adults who are past high school age but continue to need support are college, prisons, and the military (Wuthnow, 2010). Once adolescents pass eighteen years of age, they generally are left to their own devices. Congregations are no longer the primary places for young adults to gather; in ever-increasing ways, bars, parties, the internet, meet-up groups, and work places fill the vacuum. Young adults have to make major decisions and do all kinds of developmental work without sufficient societal support.

\section{Statement of the Problem}

Churches are only starting to understand that young adults are living in a fundamentally different era than generations before them. What some observers have unsympathetically named the "failure-to-launch" syndrome may, in fact, not identify a problem to be solved so much as describe the reality young adults now face as a result of global economic and social forces that might hinder their journey to financial 
independence. If this is the "new normal," churches need to engage with this population in ways that are more helpful. Of course, doing this will be difficult given that many churches are struggling to keep the lights on and the church building safe and sound. Is it possible for a congregation facing the crisis of its own demise to be nimble and responsive to problems created by changes in the society beyond the church doors?

The six reasons that young adults no longer attend church, according to the Barna Group's findings (Kinnaman \& Hawkins, 2011) are problematic for progressive mainstream congregations, first because the reasons, for the most part, do not seem to apply to them. Progressive mainstream congregations, for instance, are not often antiscience. Yet, in his study Hackett (2014) found that although young adults between the ages 18 to 29 made up at least one tenth of the church in $59 \%$ of evangelical and $31 \%$ of Catholic congregations, this was only the case in $10 \%$ of mainline Protestant churches. If mainline congregations are hardest hit by the decline, but the reasons given by young adults for leaving the church do not apply to them, the reasons for the demise of the Protestant mainline have not been adequately addressed by the Barna research.

Second, the answers young adults give in the Barna survey seem based on theirvalid and important — conscious perceptions, but the survey does not speak to the various political, sociocultural and psychological forces that may be imperceptibly impacting them and influencing their "language." For instance:

- An improved health care system has extended the human lifespan in postindustrial countries.

- Changes to career paths brought by a global economy have made it more difficult for young adults to find stable work and become financially secure. 
- The resulting delay in settling down, marrying, and having a family, along with other unseen impacts of young-adult development in the third decade, has weakened ties to the congregations of their adolescence, for those who were so affiliated.

Finally, the Barna Group's (Kinnaman \& Hawkins, 2011) results speak to why those young adults believe that they do not connect with the church, but they do not in any way address the reasons that those young adults who do attend churches give for their participation. Scholars of religion have only recently begun to take up the question of why some young adults $d o$ in fact find homes in religious congregations (Belzer, Flory, Roumani, \& Loskota, 2009; Pogorelc, 2008).

Furthermore, Christian denominations and seminaries have been slow to realize that changes in the religious landscape require a different set of leadership skills than those offered to people training for ministry in times past. Most ministers no longer serve in localities where the inhabitants are, almost by default, Christians interested in congregational life. The decline in religion places pressures on Christian congregations and their leaders to come to terms with environmental changes and to determine whether to close the doors, adapt, move, or start a new type of religious community.

Organizational ecology theory suggests that inertia can limit the adaptability of existing congregations, and that although starting new congregational forms is not easy, it may be easier than trying to turn existing congregations around (DiMaggio, 1998). Mainstream seminaries, however, are only beginning to understand the need to train clergy to start new congregations, or to engage specifically with the needs and dreams of young adults (Foster, 2006). 
There are remarkably few studies of congregations that are successfully attracting and retaining young adults, and none that focus exclusively on progressive mainstream congregations. In the last few years, two nationwide studies of congregations that resonate with young adults have taken place. The "Congregations That Get It!" study conducted in 2009 was an interfaith effort among Christians, Jews, and Muslims, and the “Changing Sea" study undertaken between 2008 and 2013 was initiated by the Catholic Church, but included certain Protestant congregations. Both studied a range of congregations from liberal to conservative. I am unaware of any studies that provide insight into leadership and translation in progressive Christian congregations with which young adults resonate. There is a need for further such studies, and this dissertation is one modest attempt to respond to this need.

\section{Purpose of the Study}

The specific purpose of the study was two-fold. First, I wanted to gather stories in progressive mainstream congregations with significant numbers of participants aged 18 to 35 (who had been there for two years or longer), which might explain why these young adults experienced in these congregations "the intonations of their own language." Second, my goal was to identify and analyze any aspects of leadership and translation that led to the resonance between individual participants and the congregation.

\section{Research Questions}

Although this was a naturalistic study where I constantly adapted my research plans to the situations being studied, the initial intent was to structure my investigation around answering the following questions: 
1. What aspects of leadership and translation, if any, were exercised to make ancient wisdom or rituals relevant to, and create a welcoming space for, young adults?

2. What kinds of resonance, if any, emerged between the leaders and the group (both individual participants and the whole congregation)?

3. What kinds of associations, if any, exist between the narratives of participants and theory about the developmental and maturational work of young adulthood?

\section{Significance of the Study}

This study contributes to the nascent body of literature on young adulthood and religious affiliation (Barry \& Abo-Zena, 2014; Barry \& Nelson, 2005; Belzer et al., 2009; Dyson, 2011; Heft, 2009; Pogorelc, 2008; Smith \& Snell, 2009; Wuthnow, 2010). As a focused ethnography aiming to explore leadership and resonance in two progressive mainstream congregations in which young adults are present and thriving, I hope it will provide a unique perspective on the nature of these sources of resonance. It is also a particular attempt to explain some of (a) the resonance experienced between the leaders, participants, and the whole congregation, (b) the qualities and skills of leaders found in these outlier congregations, and to (c) explore the correspondence between the stories of young adults in these congregations and what developmental theorists describe as the tasks of young adulthood.

Although it is impossible to generalize findings from an $n$ of 2 study in a traditional social science sense, psychological generalizability, that is, the expansion of 
possible interpretations or new cognitive schema is possible (Donmoyer, 1990). A number of different practitioner audiences might find such new cognitive schema helpful. Some of these are seminaries training clergy, denominational staff looking at how to minister to young adults, clergy, and/or congregations who wish to provide ministry with this constituency, and young adults seeking to start new congregations or to make sense of their own experience.

\section{Scope of the Study}

This study focuses on two relatively small progressive mainstream congregations in Seattle during the first half of 2012. While I was gathering data, COTA generally had between $40-80$ people in their Sunday afternoon worship, and St. Paul's had about 150 people over four Sunday services. Each congregation included a significant number of participants aged 18 to 35 , especially when compared with otherwise similar congregations. (I was not able to interview all the young adults in the two congregations but was able to interview 22 young adults at COTA and 21 at St. Paul's). I spent a month with each congregation, the first from April 1 through April 30, and the second from May 20 through June 20, 2012. I also did one interview with a couple from St. Paul's by using Skype once I arrived home.

\section{Delimitations}

I will address the limitations of the study in chapter 7, but will here discuss some aspects of my role, my positionality, my personal story, and some of the intuitions I had before undertaking the study. 


\section{Membership Role of Researcher}

In a naturalistic study and focused ethnography in which the researcher is the primary or, in many cases, the only research instrument, it is important to recognize and acknowledge a priori perspectives and assumptions that have influenced the researcher's informal conceptual framework, and to locate the researcher in the study (Knoblauch, 2005). My own story had an influence not only in the sites I selected, but also in what I saw there.

Adler and Adler (1987, as cited in Dwyer \& Buckly, 2009) identified three "membership roles" of qualitative researchers engaged in observational methods: (a) peripheral member researchers, who do not partake of the primary activities of group participants; (b) active member researchers, who become involved with the vital activities of the group without fully binding themselves to the participants' ideals and ends; and (c) complete member researchers, who are already members of the group or who become fully associated during the course of the research (p. 55). My own role was a combination of the latter two, depending on where the boundaries of group membership are drawn. As a Christian from a progressive mainstream congregation in the Pacific Northwest, I could be seen as a "complete member researcher," or insider. This may have opened some doors and provided people with a level of comfort in talking to me. At the same time, I was not a member of either congregation. I was not Episcopal or Lutheran. I was not from Seattle. I was studying the sites as part of a doctoral program in a university in a different city, giving me an outsider role. I was thus participant in the central activities of the group (such as taking communion, participating in groups and 
events), and visibly video-recording events and services. Both may have had an indefinable impact on participants.

\section{Positionality and Personal Story}

For the purposes of positioning myself in this study, it might be appropriate to briefly describe my own faith story. I began my journey of faith when baptized as an infant in the Vereeniging Methodist Church in South Africa, and by attending Methodist Sunday school throughout my childhood. As a teenager, I left the church and went through a period where I was a convinced atheist. At age sixteen, I had a conversion experience within a fundamentalist evangelical group, which shaped my Christian experience around a love of Scripture and the person and story of Jesus. Between the ages of eighteen and thirty, I held leadership positions in two congregations in South Africa, one in which I was the only young adult and one in which I was one of many. I had also done several mission trips with a young-adult evangelical organization. I was familiar with the culture of evangelicalism internationally, and knew of most of the prominent leaders.

As a result of the engagement of my particular personality with the biblical story, my commitment in the South African context to social and racial justice grew. I became a progressive evangelical and very active in the anti-apartheid struggle. During my graduate studies in a Mennonite seminary, I came to understand and accept my own sexual orientation as a lesbian and to seek and then to help build communities of acceptance and hospitality to all, including LGBTQ-identified people. Over the course of time, I became a progressive liberal Christian, although one with an enduring bond to the person and teachings of Jesus, and a great affection for Scripture. 
As I became more acculturated into the progressive mainstream, I began to appreciate certain liturgical forms such as the seasons of the church year; the four-part movement within a worship service of a) gathering, b) engaging the Scripture, c) response, and d) sending; and the use of the Revised Common Lectionary, which uses four readings each week over the course of a three-year cycle, two from the Hebrew Bible and two from the New Testament. This appreciation informed my worship leadership within the United Church of Canada, although it was crucially complemented (for me at least) by the freedom to create the particular liturgy for each week based on the lectionary and church year, using inclusive language, progressive theology, and a critical approach to scripture, rather than using prescribed liturgies from a book.

Because of my personal history and role as minister, I brought both insight and potential blindness to this study. On the one hand, I might have read my former involvement and cultural experience into the experience of the young adults in my study. On the other hand, there are very different degrees of religious saturation within South African and North American cultures. South Africa was a country still steeped in Christendom, whereas the Pacific Northwest of North America could hardly be less Christian. Furthermore, when I conducted this study, I was a middle-aged minister and $\mathrm{PhD}$ student. These roles presumably helped me avoid conflating the experiences of those I was interviewing with my own experiences. On the other hand, they also could have influenced the questions I asked and the type and extent of responses people offered. It is also important to acknowledge that my journey from evangelicalism into a more progressive mainstream tradition was a result of subjective change, and I am now clearly more partial toward the latter. 


\section{Personal Perspectives and Intuitions}

Although I sought both confirming and disconfirming evidence along the way, I will mention some of the hunches and ideas that I named in my proposal so that I could monitor myself as I gathered and analyzed data.

Developmental issues: Rumspringa or premature confirmation of faith. My understanding, through previous study and reading in psychology and through my own personal experience, was that there might be a developmental reason for the exodus of young adults from congregations. These young adults might simply feel a need for time away from church to form their own identities and develop their own spiritual convictions. Paradoxically, certain Amish Christians understand and allow for such a need. They encourage their young adults to take time away from their highly restrictive community before making a lifetime commitment to it. During this rumspringa (translated literally: "running around" period), young Amish people may leave their communities and go out into the world to explore life in ways not available or permissible back home (Shachtman, 2006). They are expected to take the time they need to determine whether to return and be baptized or to leave their community altogether. Curiously, although the Amish community is very restrictive, Shachtman noted that most of its young adults do return and take their place alongside their elders in their community of faith.

By contrast, in many churches in Canada and the United States, teenagers are instead encouraged to go through a confirmation ritual, in which they confirm the baptismal vows made by their parents and officially become members, before having had time to test their own religious identities. Ministers ruefully jest that teens see this ritual 
not as a confirmation of faith so much as a graduation from faith. One of my hunches was that congregations might need to find ways to recognize this need for some equivalent of the Amish rumspringa period and provide support for this stage of development. My conclusion that both congregations did this was based on a substantial amount of evidence gathered in both congregations (and by the absence of the disconfirming evidence that was sought). There is no doubt, however, that the impetus to look for and gather this sort of evidence was prompted by my prior education and my own need at times to take time away from church, although not God, along the way.

\section{Difficulties with conflating evangelical and mainstream congregations. My}

journey from the Christian mainstream into fundamentalism and then back out again led to my sense that there was a stark difference between mainstream and evangelical congregations. This perception affected my site selection criteria. Because evangelical churches are more successful in drawing young adults than are mainstream congregations, many would argue that those in mainstream churches need simply to emulate such evangelical churches. My faith journey, however, had shaped my understanding that evangelical and liberal/progressive congregations are so different culturally that the one cannot simply emulate the other.

More progressive mainstream churches, for instance, do not share the more conservative theology of some of their evangelical siblings. This means, first, that mainstream churches do not make use of the characteristic biblical literalism (and the resultant fear of hell) that exists in many evangelical churches, which can motivate and encourage young adults to attend and commit themselves to their congregations. Second, there is a different relationship between congregants and leaders in mainstream 
congregations. Mainstream leaders simply would not claim the kind of authority that evangelical leaders might assume based on a more literal reading of the Biblical verse Hebrews 13:17, “Obey your leaders and submit to them, for they keep watch over your souls as those who will give an account." Third, evangelical churches have very clear principles of morality and ethical behavior that are often more ambiguous in mainstream churches. This ethical clarity may fit those young people drawn to evangelical churches well, but would not work in most mainstream congregations. I thus believed that those progressive mainstream congregations that attracted young adults resonated with them for very different reasons, and it was these churches specifically that I sought to study.

An overarching preliminary assumption. Finally, my tentative sense about the sites that I was about to study was quite simply that leaders and participants in these young adult-filled congregations were knowingly or unknowingly providing opportunities for young adults to meet their spiritual and developmental needs. I assumed they were doing this in ways that resonated with their young people's stories and identities, their developmental stage(s), and their meaning-making capabilities, which together with certain socio- political and cultural realities made up the "language" of young adulthood. I worked hard through memo writing and analysis to ensure that any assumptions did not blind me to other possibilities.

\section{Summary}

In summary, this chapter provided an introduction to the study. Specifically, it provided the background to the study, the statement of the problem, the research purpose and questions, the significance and scope of the study. The chapter also provided details of some of the delimitations of the study. The limitations are discussed in chapter 7. 


\section{CHAPTER 2}

\section{LITERATURE REVIEW}

Due to the naturalistic nature of this research, I chose to do the literature review after the initial analysis and write up of the findings chapters. I hoped to ensure that I was approaching the analysis as naively as possible to avoid imposing already existing categories onto the young adults and congregations in the study. There were of course a multitude of possible directions for the literature review, and I had to make choices, in consultation with my dissertation chair and committee, about which areas I was going to explore.

This review is based on the following bodies of literature. First, I will discuss literature relating to the religious affiliation and attitudes of young adults (as mentioned in the Statement of the Problem in Chapter 1), which was generated by the analysis of nationwide quantitative surveys focused on religious participation of young adults in the United States. Second, I will describe and reflect on various stage theories of psychosocial and religious development in young adults. I will pay particular attention to the controversy about emerging adulthood as a new life stage. Third, I will explore the scholarship on the significant challenges, both internal and external, facing those who are aged 18 to 35 . Fourth, I will discuss the tasks of young adulthood described in the developmental psychology literature. Finally, I will consider three recent studies about young adult-filled congregations, including a study that provides a typology of religious young adults, before looking at a few recurring themes in that literature. In all cases, when I use the word "religion," I am referring to religion in general and not to any 
specific religious tradition. When discussing a particular religious tradition, I will specify Christianity or Judaism or Islam, and so on.

One of the challenges faced by comparing these studies is that they are not all discussing the same cohort of people when they talk about young adults: sometimes because the studies are written during different time periods; sometimes because they calculate the period they call young- or emerging-adulthood differently; and sometimes because they do not believe in the notion of generational difference, thinking instead that all those who fall into the category of young adult would simply find themselves dealing with the same issues, regardless of their birth years. A distinction also must thus be made between generic characteristics of "young adulthood" across generations - e.g., young adults are usually more idealistic than their parents and grandparents - and the particular characteristics of the cohort of young adults in this study, who were born between 1977 and 1994. To this end Twenge makes a distinction between generational differences based in a particular time period and developmental differences based what happens to people as they reach a particular age (2015).

\section{Studies of Religious Participation of Young Adults in the United States}

In two separate nationwide multiple-survey studies, renowned sociologists of religion Robert Wuthnow (2010) and Christian Smith and Patricia Snell (2009) analyzed sizable data sets with regard to religious involvement. Their research covered a variety of religious groups and they drew conclusions about religion in general. They were also able to discuss findings related to specific traditions when required. Their findings differed at times because, for Wuthnow, young adulthood could stretch into the fourth decade of a person's life, whereas Smith and Snell's research consisted of a longitudinal 
study of young adults who had only reached age 23 at the time of their writing. Almost all studies of young adults and religion have used the sociological data provided by Wuthnow (2010) and Smith and Snell (2009) as their basis. I will thus begin with their work.

\section{The Wuthnow Study}

In Religion After the Baby Boomers, Wuthnow (2010) discussed his National Young Adults and Religion Study (NYRS) analysis of national survey data ${ }^{1}$ from thirteen different sources taken over numerous decades and included a qualitative study he commissioned, which took place in 2005. The qualitative study was built around one hundred in-depth interviews about religion and spirituality conducted with clergy and with young adults aged 21 through 45 (born between the 1960s and the mid-1980s) from various traditions and positions on the spectrum of religious involvement. His analysis allowed him to describe the cultural shifts that had led to a significant decrease in youngadult involvement in religious institutions. For example, Wuthnow noted that, in the early twentieth century, adulthood was marked by a chronology of demographic markers such as completing school, leaving home, starting a career, marrying, and having children. He then identified seven trends necessary to understanding the changing life worlds of today's young adults:

1 The National Young adults and Religion Survey used the following existing surveys of U.S. adults: Arts and Religion Survey; Civic Involvement Survey; DDB Neeham Survey; Forgiveness Survey; General Social Surveys; Liberal-Conservative Survey; National Congregation Study; Pew Internet and American Life Religion Callback Survey; Public Use Microdata Samples; Religion and Diversity Survey; Religion and Ethics Newsweekly Survey; Religion and Politics Survey; Social Capital Community Benchmark Survey; and World Values Survey. 
- Delayed marriage (few research participants were married in the early years of young adulthood, but nearly all were married by their late forties).

- Delayed interest in having children (fewer young adults were focused on raising children or on the values they would want their children to learn).

- Work and fiscal uncertainties (young adults' scramble to get on their feet economically shaped almost every aspect of their lives).

- Higher education (increasing numbers of young adults go to college and then on to graduate study).

- Loosening relationships (the high mobility necessary for employment leads to shallower roots in communities).

- Globalization (young adults were part of, and impacted by, a global economy).

- The information explosion and its impact (gathering information from a variety of sources, for example, has resulted in a greater respect for diverse groups and lifestyles).

While recognising the declining relationship between young adults and religious involvement, Wuthnow (2010) rejected the notion that young adults as a group formed "a distinct generation with an identity shaped by the confluence of their coming of age and developments in the wider world" (p. 4). He argued that even those born after the first and second world wars, i.e., the baby boomers and builders respectively, were influenced less by the wars of their generation than by the extensive effects of these earlier wars on their personal and family lives. These effects, in turn, shaped how young adults participated in religious communities.

Wuthnow (2010) also reminded his readers that generational cohorts could be quite diverse, with cohort members often differing from one another more than they 
differed from their parents. In fact, he argued that those who use generational labels such as Generation $X$, Generation $Y$, or millennials frequently have to strain to draw contrasts and, as a result, such contrasts are often misleading. Wuthnow also noted that assertions once made about boomers in the past are similar to those made about the young adults of today. Specifically, Wuthnow emphasized variability among younger adults and continuities between the present and the past. Instead of using distinctive generational language such as millennials, Wuthnow used the term young or younger adults to describe his population of interest, those between the ages of 21 and 45 in 2005 (i.e. born between 1960 and 1984). His 45-year marker was based on the national survey data concerning when most life tasks of marriage, childbearing, purchasing a home, and so on had been completed.

Wuthnow (2010) argued that marital status and number of children were the two strongest predictors of church attendance among people aged 21 to 45 . Declining attendance rates (and differences in rates of decline across denominations) could almost entirely be explained by the recent delays in marriage and childbearing, he argued. Smith and Snell (2009), who studied young adults between the ages of 18 and 23 as part of a longitudinal study, corroborated this, arguing that other demographic considerations, such as gender, educational attainment, and income had had little effect on the trajectory of declining attendance rates. This notion was contradicted by Twenge et al. (2015) who found that a decline in religious affiliation among adolescents attending high school and college over the last three decades was most prominent among females, Caucasians, political liberals, those of lower socioeconomic status, and those in the Northeast of the 
country. They further found a lower rate of decline among African Americans and a nonexistent decline among politically conservative participants.

Wuthnow bemoaned the fact that even those congregations that connected with young adults did not connect with single young adults, who were the least likely to go to church. Wuthnow also asserted that the size of congregations had little bearing on young-adult attendance. He suggested that the location of churches played a greater role. Youthful congregations, which he defined as congregations where $35 \%$ of regularly attending adults aged 35 years old or younger, were located in metropolitan areas where so many young adults lived. Most were racially or ethnically mixed, with at least a small minority of African Americans, Hispanics, and Asian Americans.

Thus, for Wuthnow (2010), who used a sociological approach, religious attendance was a matter of demographics_-location as well as age of marriage and procreation, which were increasingly delayed in the young adults in his study — rather than agreements or disagreements about religious issues. Wuthnow also lamented the fact that this new prolonged journey to adulthood was accompanied by almost no societal support structures. Unless young adults were in the military, in college, or in prison, they were left to their own devices at a particularly challenging time in their lives. Wuthnow called for greater societal support structures, but he also suggested that innovative congregations from any tradition could offer the social and institutional support that society was largely failing to provide to single or childless younger adults.

\section{The Smith and Snell Study}

In their longitudinal study of over 3000 Americans from varied or no religious traditions, discussed in the book Souls in Transition: The Religious and Spiritual Lives of 
Emerging Adults, Smith and Snell (2009) characterized what they saw as the shape and texture of the dominant religious culture among newly minted emerging adults (a term they adopt from Arnett), although they clarify that the cohort they are studying are the younger emerging adults aged only 18 to 23 at the point of their research in 2007/8. The young adults they studied produced the following religious cultural themes (which are the headings in their chapter 5).

- Religion (generally) was "not a very threatening topic.” (p. 144)

- Their attitude to religion was "indifferent." (p. 145)

- “The shared central principles of religions are good.” (p. 145)

- "Religious particularities are peripheral" (p. 146), i.e., unimportant, not the essence of religion.

- "Religion is for making good people." (p. 148)

- "Religious congregations are 'elementary schools for morals."' (p. 149)

- "Family's faith is associated with dependence" (p. 150) and they are trying to stand on their own two feet.

- Congregations are "not a place of real belonging." (p. 152)

- "Friends hardly talk about religion." (p. 153)

- "Religious beliefs are cognitive assents, not life-drivers." (p. 154), i.e., the repondents don't organize their lives around them.

Smith and Snell (2009) see the following characteristics as the "real, tacit, de facto religion" (p. 155) of the majority of American emerging adults:

- “'What seems right to me' is my authority." (p. 156) 
- "Take or leave what you want" (p. 157) suggests a cafeteria approach to religious traditions.

- "Evidence and proof trump blind faith" (p. 158) when evidence is available.

- "Mainstream religion is fine, probably" (p. 160), but I don't really know much about it.

- Religion is "personal — not social or institutional" (p. 162), i.e., it is up to the individual.

- "There is no way to finally know (sic) what is true" (p. 163), i.e., everyone sees things differently, and that is fine.

Smith and Snell (2009) used the term moralistic therapeutic deism to explain this attitude to religion which can be formulated in the following way:

- A god exists who created and ordered the world and watches over human life on earth.

- God wants people to be good, nice, and fair to each other, as taught in the Bible and by most world religions.

- The central goal of life is to be happy and to feel good about oneself.

- God does not need to be particularly involved in one's life except when God is needed to resolve a problem.

- Good people go to heaven when they die.

Daloz Parks (2011) suggested that the extreme cultural relativism many young adults express is a useful but typically impermanent phase in the course of becoming a self-actualized adult.

The reluctance on the part of many to embrace beliefs and commitments, according to Smith and Snell (2009), did not mean that the young adults were against 
religion. In fact, young adults in the study no longer succumbed to outright modernist rejections of religion in the name of "universal rationality, liberal progress, and scientific objectivity" (p. 101). Instead, within a postmodern era,

that stressed difference over unity, relativity over universals, subjective experience over rational authorities, situated perspectives over objectivity, and general skepticism over all "master narratives" rather than just the religious ones, religion may have lost any authoritative standing to make truth claims, but now enjoyed a more level playing field among all ideologies and movements. (p. 101)

The result, according to Smith and Snell, was that "many young adults had a greater openness to and comfort with religious and spiritual matters" (p. 101). Smith and Snell divided their research sample of young adults into six major types based on their relationship to religion:

- $15 \%$ were committed traditionalists: these embraced a strong religious identity, knew religious doctrine, and practiced somewhat regularly;

- $30 \%$ were selective adherents: these adopted some religious practices from a tradition, rejected what they saw as outdated, and practiced only sporadically;

- $15 \%$ considered themselves spiritually open: these were not committed, but open to the idea of religious faith and practice while skeptical about some but not all forms;

- $25 \%$ identified as religiously indifferent: these neither practiced nor opposed religion, they were simply too distracted with other things;

- 5\% identified as religiously disconnected: these had little or no interest or exposure to religion and didn't plan to have any;

- $10 \%$ identified as irreligious: these were secular and probably critical of religion. 
Smith and Snell (2009) suggested that vital teenage religious experience and religiously committed and practicing parents (or other significant adults) were the most significant factors in determining continuing religions affiliation of young adults. They argued, however, that most congregations had not understood young adulthood and had certainly not thought of what a faithful response to young adults would look and be like. They noted that when congregations did engage with young adults, they tended to focus on settled young adults, i.e., those who were married with children. This was partly because the latter group had themselves turned to the church in its role as the "elementary school for morals" (p. 149) for their children's education.

\section{The Norris and Inglehart, and the Welzel Studies}

As mentioned in chapter 1, political scientists also have theories about religious decline. Pippa Norris and Ronald Inglehart (2011) attribute religious decline in postindustrial societies to a general sense of existential security, namely "the feeling that survival is secure enough that it can be taken for granted" (p. 4). Christian Welzel (2014) argued that in nations with a strong desire to be free of domination, that is, nations with high emancipation values, if religion is perceived as a dominating force that restricts freedom and enforces social rules, a decline in religious involvement will be observed.

\section{The Twenge et al. Study}

These sociological and political approaches have been complemented by the psychological approach of scholars Jean Twenge, Julie Exline, Joshua Grubbs, and Keith Campbell (2015), in their article "Generational and Time Period Differences in American Adolescents' Religious Orientation," which examined participants of the same age at different points in time so that any changes must be due to time period or generation, 
rather than age or development. Twenge et al. analyzed the Monitoring the Future survey (MTF) of high school students and the American Freshmen (AF) survey from 1966 to 2014, as well as individualistic versus communal words ${ }^{2}$ or phrases $^{3}$ found in the Google Books database ${ }^{4}$ over the period. They found that religious involvement was low when indicators of individualism were high (more positive self-views, materialism, individualistic language, and need for uniqueness) and when social supports for young adults were low (as in the case of young adults living alone).

Careful to distinguish between correlation and causation, Twenge et al. (2015) nevertheless submitted that the increasing individualism of the American culture could be at odds with the nature of religious congregations, which generally involve:

- some level of commitment to an organized group,

- assent to group beliefs, opinions, and practices,

- some rule following and submission to authority,

- a focus on others and some self-sacrifice, and

2 The 20 top-rated individualistic words, chosen and evaluated by two panels of diverse adult Americans respectively, included: independent, individual, individually, unique, uniqueness, self, independence, oneself, soloist, identity, personalized, solo, solitary, personalize, loner, standout, single, personal, sole, and singularity. The 20 top-rated communal words were: communal, community, commune, unity, communitarian, united, teamwork, team, collective, village, tribe, collectivization, group, collectivism, everyone, family, share, socialism, tribal, and union (Twenge et al., 2012).

3 The 20 top-rated individualistic phrases were: all about me, captain of my ship, focus on the self, I am special, I am the greatest, I can do it myself, I come first, I get what I want, I have my own style, I love me, I'm the best, looking out for number one, me against the world, me first, my needs, self-love, selfreliance, self-sufficient, and there's only one you. The 20 top-rated communal phrases were: all in this together, band together, community spirit, common good, communal living, concern for the group, contribute to your community, it takes a village, sense of community, sharing of resources, strength through unity, the group is very important, the needs of all, together we are strong, united we stand, we are one, we can do it together, work as a team, and working for the whole (Twenge et al., 2012).

4 The Google Books Ngram Viewer allows users to search a corpus of 5 million books for words and phrases up to 5 words long. The corpus is so large that it would take 80 years for someone to read all of the books for the year 2000 alone (Twenge et al., 2015). 
- a search for meaning.

Such aspects of religious groups could, they suggest, repel these most recent inheritors of a culture that values freedom of choice, personal exploration, and assertion of independent opinions and practices pleasure-seeking, stimulation, and self-direction.

On the other hand, several scholars corroborated Smith and Snell's (2009) finding that, despite a move away from religious institutions, young adults generally still valued religious beliefs and practices (Astin \& Astin, 2003; DeHaan, Yonker, \& Affholter, 2011; Funk \& Smith, 2012; Greenberg, 2014; Smith \& Snell, 2009; Valpy, 2010). For example, the 2004 College Students' Beliefs and Values Survey (Lindholm, 2009) found that $80 \%$ of entering first-year students claimed to have an interest in spirituality and $47 \%$ said it was "very important" or "essential" to look for opportunities to grow spiritually (pp. 82-83). When in the National Study of Youth and Religion (NSYR) researchers asked young adults aged 18 to 23 if they had become more religious, less religious, or stayed about the same over the past two years, $59 \%$ reported staying the same and $24 \%$ reported becoming more religious (Smith \& Snell, 2009). It would seem that there is a greater decline in religious institutional affiliation than there is in religious interest or belief.

\section{The Barna Group Study}

According to the Barna Group (Kinnaman \& Hawkins, 2011) which studied young adults aged 18 to 29 between 2007 and 2011, (those born between 1978 and 1989), there are six main reasons given by young adults themselves for their diminished relationship with Christian churches, namely:

1) churches seem overprotective, 
2) teens and twenty-somethings feel their experience of Christianity is shallow,

3) churches come across as antagonistic to science,

4) young adults experience the church's understanding of sexuality as simplistic and judgmental,

5) they wrestle with the exclusive nature of Christianity, and

6) the church feels unfriendly to those who doubt.

It is important to note that according to Kinnaman \& Hawkins (2011), this trend of young adults moving away from congregational life after leaving home is found in evangelical as well as in mainstream churches, (although the latter are experiencing this to a greater extent), and only $20 \%$ of 20 -somethings maintain a level of spiritual activity consistent with their high school experiences in religious organizations.

What scholars see in their research depends very much on the particular lens they are using to survey their data. Sociologists, economists, and political scientists will notice broad social, economic, and political forces that affect young adults, whereas psychologists may be more interested in what young adults think and feel. Rather than seeing these findings as contradictory, it is more helpful to see each of them as a single window into or out of the world of young adulthood.

\section{Theories of Psychosocial and Religious Development}

Since one of my research questions concerned the relationship between young adults' resonance with congregations and their developmental and maturational work, I 
will now review some of the seminal theories that have bearing on young-adult development as part of the life cycle, including a new theory by Jeffrey Arnett.

\section{The Life Cycle and Stage Theories of Development}

From antiquity, societies have generally recognized just three phases to life: childhood, adulthood, and old age (Gollnick, 2008). Early in the last century, Carl Jung was especially influential in bringing to the fore an incipient notion of a psychological life cycle. In his 1930 essay Stages of Life, Jung (as cited in Gollnick, 2008) simply distinguished the morning from the afternoon of life. In the morning, the individual developed a stable ego and adapted to the external world; in the afternoon, s/he experienced fully, and investigated thoroughly, the inner world of the psyche (through dreams and intuitions, for example). Jung also called attention to a mid-life transition, when individuals shifted from an outer to inner orientation. He argued that this transition was accompanied by a psychological disorientation, which Erikson (1968) later named an identity crisis. As life span theories developed, stage theories came to the fore and various critiques emerged. I will now discuss key stage theories and the critiques of each and consider their implications for understanding young-adult development.

In the latter half of the twentieth century, a plethora of stage theories, too many to be reviewed, emerged. Because the findings of my study seemed to require an engagement with the theories of cognitive and identity development of young adults so as to understand their faith journeys, I will limit my focus to five stage theorists who have been seminal in the areas of cognitive, identity, moral, and faith development. The first four theorists are Piaget (1977), Erikson (1968), Kohlberg (1977), and Fowler (1984). Erik Erikson, who was born in 1902 and died in 1994, and Jean Piaget, who lived from 
1896 to 1980 , were somewhat contemporaneous, but Piaget developed his theory of cognitive development based on observation and research undertaken in the 1920s, whereas Erikson developed his theory mid-century. Kohlberg was born in 1927 and died in 1987. Fowler, who was born much later, in 1940, is still living. His theory of the stages of faith development was influenced by the stage theories of both Erikson and Piaget. The fifth theorist is Jeffrey Arnett, currently a research professor in the department of psychology at Clark University in Worcester, Massachusetts.

Piaget's theory of cognitive development. Piaget's (1977) ground-breaking theory of cognitive development has been particularly influential among life stage theorists. Piaget described development as an active process during which learners engage with their surroundings and construct their own understandings. The four stages described in Piaget's theory are:

1. The sensorimotor stage (birth to two years).

2. The preoperational stage (2-7 years).

3. The concrete operational stage (7-12 years).

4. The formal operational stage (12 years and up).

Each subsequent stage, Piaget argued, builds on the one before, resulting in the development of a more advanced set of mental conceptions as a child matures.

Piaget also argued that substantial cognitive transformations occurred during adolescence and young adulthood. Starting at the age of 11 and ending between ages 15 and 20, there was a shift from concrete operations that is, thinking within concrete, immediate contexts, to formal operations, where thinking becomes more scientific, 
abstract, and complex. Meta-cognitive awareness also comes into play at this time. Neurologists Fischer and Rose (2006) later provided physiological support for Piaget's theory by examining the development of the brain. They provided evidence that the frontal cortex develops physically during adolescence and young adulthood, allowing for the advent of more advanced cognitive skills. They proposed thirteen levels of simultaneous neurological and cognitive spurts, the twelfth of which occurred in young adulthood from ages 18 to 20, and the thirteenth of which occurred when a young adult was between ages 23 and 25 .

Isquith, Gioia, and Espy (2004) further noted that frontal lobe development supported a cognitive skill set known as executive function processes, that is, the control, supervisory, or self-regulatory functions that organize and direct all cognitive activity, emotional response, and overt behavior. More recently Hartmann and Swartz (2006) suggested that the consolidation of identity, the task of young adulthood, may in fact rely upon the increasing meta-cognitive capacities of this age, namely, the ability to think reflexively, and explain one's own thinking to others.

In summary, cognitive changes in adolescence, such as being able to think about one's own thought process, set the stage for the development of critical thinking ability and for identity development in early adulthood. The literature suggested that cognitive and identity development are connected at the heart of young adulthood; one might assume that these findings have bearing on spiritual and faith development also.

Erikson's theory of identity development. Erikson's (1968) life stage theory has been judged groundbreaking by developmental theorists. Influenced by Freud and by psychoanalytic thought, Erikson identified a series of eight crises that characterized the 
growth of personality. A crisis is a challenge to the ego, that sense of self which we develop through social interaction and which is continually shifting due to new experiences and information acquired. Such a crisis could be a threat and/or an opportunity to develop and progress. Erikson argued that this series of crises defined what he called psychosocial stages. Each of the eight stages had a main task, and the strengths that developed in each stage equipped the person for the challenges of the next stage. The stages, among others, included a fifth stage during ages 12 through 18, which involved establishing identity, as opposed to the earlier diffusion of identity, and a sixth stage during ages 18 through 40, which involved learning intimacy as opposed to experiencing isolation. In these stages, individuals gain a sense of reliable identity and then an ability to love and be loved. Any unresolved stage would affect ego health in subsequent stages. Erikson argued that, although the psychosocial task of identity construction was a normative event occurring throughout the life span, it was most prevalent in adolescence. Furthermore, he posited that love, work, and ideology/worldview constituted the three primary arenas, over the life course, in which the work of identity formation was undertaken.

Scholars no longer embrace Erikson's (1968) idea that identity exploration was largely the developmental task of adolescence. In fact, Erikson himself had noted instances of delayed adulthood in a few cases. In his chapter "Emerging Adulthood as an Institutionalized Moratorium," Côté (2006) built on this thread of Erikson's work in the light of the scholarly finding that, with the increase in the life span (and because of other social forces), there is presently a moratorium on achieving full adulthood among almost all young adults in post-industrial contexts. Like Wuthnow (2010), he argued that the 
journey to adulthood was now taking longer than ever before for almost all young adults, rather than in just a few rare cases.

Côté (2006) noted that, in the past, only the sons of certain elite socio-economic classes were given periods of unencumbered foot-looseness prior to taking up the responsibilities of adulthood. Wealthy young Germans at the height of the Romantic Movement were allowed a wanderschaft, a period of travel, for example, and elite young men in Britain undertook the Grand Tour through Europe (2006). Erikson (as cited in Côté, 2006) had called these periods institutionalized moratoria, where "societies offer, as individuals require, a more or less sanctioned intermediary period between childhood and adulthood, institutionalized moratoria, during which a lasting pattern of inner identity is scheduled for relative completion" (p. 87).

Côté (2006) suggested that identity formation was now the key characteristic of young adulthood during what, with an expanded lifespan, had become a far more widely experienced institutionalized moratorium, which he defined as "structured contexts for working through identity confusion and resolving an identity crisis" (p. 85). Young adults had license to experiment with certain roles without having to take on permanent responsibilities and commitments. Côté argued though, that prolonging the onset of adulthood also had the capacity to aggravate the identity crisis, create identity confusion, and interfere with the process of creating stable ego development.

Kohlberg and Gilligan's debate over his theory of moral development.

Kohlberg (1976) was inspired by Piaget and Gabain's (1965) book The Moral Development of the Child. He was particularly intrigued by the notion that there was a relationship between the individual's level of moral reasoning and their level of cognitive 
development, and by the descriptions of children's reactions to moral dilemmas. Kohlberg (1977) studied moral reasoning by presenting 72 Chicago boys aged 10 to 16 with moral dilemmas and analyzing the reasoning used in the responses. He found that as cognitively developing children encounter a sequence of broader social circles, they can develop greater decision-making abilities and handle dilemmas that are more complex. He classified the responses to the dilemmas he posed into six distinct stages, grouped into three levels: pre-conventional, conventional, and post-conventional.

In the preconventional level (most children aged nine and younger, some over nine), adult authority is given most importance. Punishment and reward define whether something is wrong or right. Authority does not reside in the child, but in their authority figures, and reasoning is based on what happens to them as a result of their actions. In the second stage of this level, children recognize that there is not just one right view and that people in authority have different viewpoints.

In the conventional level (most adolescents and adults), the individual becomes aware that while rules exist for the good of the many, they sometimes harm innocent individuals. As time passes, individuals begin to internalize the moral standards of their role models, without yet questioning the norms of the group to which they belong.

In the postconventional level (10-15\% of adults, after their mid-30s), rules are still useful, but not absolute. As the individual matures, moral reasoning is based on individual rights and justice. Moral authority has been internalized, individuals become more adaptable, and what is right may mean resisting what is acceptable in society. The individual may have to pay the price of societal disapproval and/or imprisonment. Kohlberg expected few individuals to reach the postconventional stage. According to 
him, the evolution of moral development continued throughout the lifespan and was chiefly related to questions of justice.

Colby and Fischer (1983) studied 58 of Kohlberg's research subjects at three-year intervals for 20 years. After the subjects had been tested six times over a span of 27 years, these researchers found support for Kohlberg's original conclusion that people pass through the stages of moral development in the same order.

Perhaps the best known critique of Kohlberg's study came from his colleague Carol Gilligan (1982; 1979), who concluded that Kohlberg's theory showed a gender bias, not only because all the subjects were boys, but because Kohlberg did not recognise that women approach moral problems from an "ethic of care" rather than an "ethic of justice." In her groundbreaking book, In a Different Voice: Psychological Theory and Women's Development (1982), Gilligan investigated the perspectives of women. She argued that women are socialized on principles of compassion and care, and men on abstract principles of law and justice. She lamented that the very qualities that have defined the goodness of women, their care and compassion, had been seen by theoreticians as a mark of moral deficiency. Gilligan noted that the gender bias in the above-mentioned seminal theories of development resulted in the failure to recognize the value of connection, not just individuation, in the moral socialization of boys and girls. As a result, the voices of compassion, love, and non-violence were not valued as much as were the voices of willpower, individuation, and justice.

Fowler's theory of faith development. In his book, Becoming Adult, Becoming Christian: Adult Development and Christian Faith, James Fowler (1984) advanced the idea of a developmental process in human faith building that was heavily influenced by 
Piaget's (1977) theory of cognitive development and Kohlberg's (1977) theory of moral development. Fowler (1984) posited six stages of faith, the first three pertaining to childhood (ages 0 through the early 20s); I will describe these only briefly. Stage 1 is the Intuitive-predictive, Stage 2 the Mythic, literal (symbols, beliefs, moral rules, and attitudes are comprehended in a literal manner). Incongruities in the stories lead to musing about the meaning of the stories and symbols, which thus propels individuals into Stage 3, the Synthetic-conventional. Those who do not experience and engage with such discrepancies remain in Stage 2, even as adults.

The transition into Stage 3 usually takes place at puberty, according to Fowler's theory. The individual resolves the contradictions of Stage 2 by accepting an external authority—namely, official leaders. Religious concepts are tacitly held; the person is not fully conscious of having chosen to believe. Anyone trying to reason about or demythologize beliefs is perceived as a threat. The label conventional means that people believe that everybody else believes what they themselves believe, and they are disinclined to doubt because they fear isolation. Fowler argued that most adults in traditional churches are at this third stage. He suggested wryly that religious institutions function optimally when the majority of their members are in Stage 3 because few people question authority.

The transition to Stage 4 happens when a contradiction or conflict between the individual's beliefs and those of the authority source forces the individual to doubt their authority figure/s. Stage 4, Individual-reflective faith, ideally takes place when individuals are in their early to mid-twenties and are in a better socioeconomic, emotional, and intellectual position to interrupt their dependence on outside authority. 
Then the source of authority can be relocated to the individual themselves, forming an executive ego. They can govern themselves without external rules. Meanings in stories are separated from the symbols; stories are demythologized. Despite the grief sometimes experienced with the loss or demythologization of story and symbol, individuals experience the freedom associated with their ability to reflect on their experience and to unpack their tacit beliefs. Fowler (1984) proposed that many religious institutions discourage individuals from reflecting on their faith because they believe it would threaten the viability of the group.

The strength of Stage 4 is in the capacity for critical reflection or rational inquiry and for being able to face ideas that might be uncomfortable or painful. The potential weakness is in excessive confidence in the rational, conscious mind and a discounting of unconscious forces. When an individual is ready (rarely before mid-life) to attend to the "anarchic and disturbing inner voices" (p. 5) of the unconscious mind, Stage 5, conjunctive faith, is reached. In Stage 5, rational analysis and the literal meaning of symbols are replaced by more metaphorical interpretations. Drawing on Ricoeur's (as cited in Fowler, 1984) concept of second naiveté, Fowler described this stage as a "postcritical receptivity and readiness for participation in the reality brought to expression in symbol and myth" (p. 65). Furthermore, at this stage, an individual is ready for encounters with other traditions than their own, understanding that truths disclosed in those traditions can complement or correct their own. Justice for those outside the confines of tribe, class, religious community, or nation is embraced - if doing so does not threaten the individual's own comfort and well-being. Very few individuals reach the sixth subversive universalizing faith stage, where they overcome the self-interested 
barriers to action of Stage 5 and become willing to sacrifice their own well-being to that of their cause, an attitude radically different from the self-interested views of the rest of society.

Arnett's theory of emerging adulthood. While most scholars have embraced the notion of institutionalized moratoria as a defining feature of young adulthood, there have been fierce disagreements about the causes, nature, and outcomes of contemporary delays in reaching full adulthood (Arnett \& Tanner, 2006; Côté, 2014). Some scholars argue that there is actually a new life or developmental stage emerging (Arnett, 2000; Tanner, 2006), whereas others tend to see the delay as an involuntary halt caused by social and economic factors (Côté, 2014; Furstenberg, 1999).

Differing terms have thus been used to define this period: e.g., transition to adulthood, the frontier of adulthood (Settersten, Furstenberg, \& Rumbaut, 2008), early adulthood (Hendry \& Kloep, 2007), the odyssey years (Brooks, 2007). Researchers also conceptualized the timing of this period in different ways. All scholars agreed that it begins at the age of 18 , but the end could be seen as $25,29,34$, or as late as the mid- to late 40s (Furstenberg, 1999; Schoeni \& Ross, 2004; Settersten et al., 2008; Vaidyanathan, 2011; Wuthnow, 2010).

Emerging Adulthood was a term introduced by psychologist Jeffrey Arnett (2000). His theory found traction in both the media and the academy. He brought into dialogue previously discrete bodies of scholarship on childhood and adolescence, on the one hand, and adulthood, on the other. Between 1993 and 1999, Arnett questioned young adults aged 18 through 25 (born between 1968 and 1981) about, among other things, whether they felt they had achieved adulthood, after which he proposed emerging 
adulthood as a new developmental stage. Many in their late 20s and early 30 s felt they were reaching adulthood, but $30 \%$ still felt in-between, according to Arnett. They characterized adulthood not in terms of the demographic markers of the past—-finishing their education or even getting married-but as accepting responsibility for themselves, making independent decisions, and being financially independent, all of which they felt, they were only accomplishing gradually.

Jennifer Lynn Tanner (2006), an applied developmental psychologist with an emphasis on mental health in emerging adults, argued that Arnett's theory of emerging adulthood also brought together the previously distinct work of psychologists and sociologists. Where psychologists had examined the life span of the individual, focusing on the development of maturity (as cognitive, ego, identity, and moral development); sociologists had addressed life course theory, which emphasized transitions to adult roles in the light of the multiplicity of transactions between individuals and contexts. According to Tanner (2006), Arnett's contribution was to integrate the two schools of research by integrating the psychological study of identity with the sociological investigation of geographical and work-related factors affecting young adults.

Arnett (2006) described emerging adulthood as heterogeneous, but believed it could be characterized in a general way as:

- an age of identity explorations during which young adults were continually trying out different options in an attempt to figure out who they were and who they'd like to become, particularly in the areas of romantic relationships and careers, 
- an age of instability, in which young adults were forced to revise their grand life plan as it encountered complications along the way, often changing majors, partners, jobs, and especially residences,

- a self-focused age when young adults tended to focus on themselves and their own personal needs and to delay significant adult responsibilities, such as marriage and parenthood, in an effort to enjoy the opportunity to exercise the freedom they now had since their parents were no longer overseeing their every move,

- an age of feeling in-between, when they didn't feel they were at the stage where they could accept responsibility for themselves, make independent decisions, and be financially independent in order to be considered fully adult, but did feel a great deal more independent and mature than when they were adolescents,

- an age of possibilities, when they characteristically held very optimistic views of the future and were convinced they would accomplish their dreams and overcome past circumstances in an effort to become the person they'd like to be.

Arnett believed that identity formation was a defining process during emerging adulthood and, following Erikson (1968, as cited in Arnett, 2006), suggested that work, love, and world-view development were the three main domains in which it took place. He presented emerging adulthood in a singularly positive light, suggesting, for example, that the fluidity of this phase meant that young adults no longer needed to fear being interminably stuck in a problematic job or premature marriage.

\section{Critique of Stage Theories}

Stage theories have offered exciting insights to all those who work with people at various stages of the lifespan, and have had a significant impact on numerous academic 
fields, but they have also received a fair amount of justified criticism. In an essay Gilligan (2011) noted:

In the theories of Freud, Erikson, Piaget, Kohlberg, and their contemporary offshoots in psychoanalysis and cognitive psychology, the separation of the self from relationships and the elevation of mind over body, reason over emotion, appear as milestones along a developmental path, markers of progress toward maturity. The splits themselves have become naturalized and mistaken for development, or seen as a requisite of civilization. The loss of relationship suffered along the way is deemed necessary, part of the price we pay for growing up. (p. 6)

Gilligan's gender critique is one of various such challenges. Within the scholarship on religious development, the use of such stage models as Fowler's (1984) structural theory of faith development, has similarly been criticized for assuming an invariant and culturally universal sequence of meaning-making across the life span (Barry \& Abo-Zena, 2014). Another critique concerning religious stage theories is that they tend to see a progression toward an end point or telos. Those with this linear orientation are thus seen as inherently biased against particular religions with more cyclical notions of reality (Murray-Swank, Pargament, \& Mahoney, 2005 as cited in Barry \& Abo-Zena, 2014). At the same time, stage theories have been seen as helpful in drawing attention to the broader context of the individual's religious or spiritual development.

Gollnick (2008) observed that more recent scholarship has concentrated less on a fixed sequence of irreversible phases and cyclical patterns across generations, and more on an individual's continuous need to adjust to variation and discontinuity in their daily life. For example, Anthony Giddens (1991, as cited in Gollnick, 2008) argued that the life cycle idea applied more accurately to non-modern societies, where renewal occurred 
as each generation rediscovered and relived the ways of their predecessors. Settersten (2008, p. 16) agreed that stage theories were too rigid to embrace the diversity of current post-industrial life experience. He pointed to many changes in personal and social patterns, such as shrinking family size, non-traditional forms of family, divorce in record numbers, children returning to re-occupy the "empty nest," and the lengthening of life expectancy. He preferred the terms life span, a psychological term emphasizing interior phenomena, and life course, a sociological term that highlights the influence of external social forces on the lives of individuals, to the term life stage.

Numerous scholars have disagreed with Arnett's (2006) theory that this period was a developmental stage. First, Hendry and Kloep (2007) argued that young adulthood was not a developmental period as nothing actually developed in this stage; developmental tasks were, instead, delayed. Second, Schoon and Schulenberg (2015) argued that Arnett's notion of emerging adulthood did not take into account the social and economic conditions that had produced extended transitions; instead, it offered a psychological model of free choice focused on the deferment of obligations. They suggested that transition outcomes were reliant on structural opportunities and constraints as well as individual resources and capabilities. Third, although Smith and Snell (2009) used Arnett's research on emerging adulthood and adopted the term, they admitted that when a young adult married and had children, they in effect pressed the eject button on emerging adulthood and were immediately full adults. This would defy the notion that young adulthood was a full-fledged developmental life stage in favor of something more circumstantial. 
Côté (2014) on the other hand, took issue with what he saw as Arnett's romanticism and the oversimplification of emerging adulthood. First, he challenged Arnett's methodology, pointing out that he did not describe his analytic strategy in extracting the five features of emerging adulthood; he might thus be vulnerable to confirmation bias. Côté suggested further that, in creating his young adulthood metanarrative, Arnett might well have missed other narratives. While Arnett had posited the theory as if it applied to all young Americans regardless of social class, economic circumstances, or educational status, Côté argued that there was no evidence that Arnett's concept of emerging adulthood applied to young adults across social classes. He drew attention to the forgotten half, a term (coined by a study sponsored by the William T Grant Foundation in 1988), describing the plight of young Americans who didn't go to college, and whom scholars generally overlooked. Côté believed that Arnett had not taken this large group sufficiently into account.

Côté (2014) noted the extensive influence of Arnett's (2000) article on emerging adulthood on the study of young adulthood, but suggested that there was a growing chorus of dissenters of whom he was one. He challenged Arnett's theory as a romanticized myth that, in fact, applied only to those with financial means, talent, or good fortune.

In a different article, Côté (2002) argued that the capacity to flourish during young adulthood depended on the amount of identity capital a person had. Identity capital involved a tangible and intangible network of resources available to an individual. Tangible resources included possessions, social networks, financial resources, credentials, group memberships, and social status. Intangible resources included such 
personality attributes as ego strength, critical thinking skills, and sense of purpose. It was possible, even likely, that young adults facing numerous challenges with insufficient identity capital might flounder during this period.

In challenging Arnett's evidence for emerging adulthood as a life stage, Côté (2014) distinguished between the empirically validated period of life between 18 and 30 (the moratorium), and Arnett's formulation of emerging adulthood, which he believed scholars were conflating. Côté (2014) suggested that since the delay in assuming adult roles had actually become increasingly involuntary, Arnett's notion of emerging adulthood as a positive life stage was dangerous because it covered up the causes and consequences of some young adults' disadvantages. For Côté, these assumptions were harmful if, as a result, policy makers were misinformed about what it was that was causing the transition to be protracted. He argued that, if the causes of this new life course phase were better understood, it might be possible to learn how to ameliorate its negative consequences, with special attention given to disadvantaged and disenfranchised groups such as the forgotten half, minorities and immigrants, the disabled, and the socially marginalized.

He, along with many other scholars, did acknowledge that the tasks of this period were unique - they were not the same as those of either adolescence or the adulthood that replaces young adulthood (Tanner, 2006; Twenge, 2008), and agreed with Arnett and Tanner's (2006) assertion that scholars and practitioners should treat young adulthood as a discrete phenomenon to prevent it from being neglected in research (2014). 


\section{The Significant Challenges Facing Young Adults}

Regardless of whether young adulthood is a developmental stage, a moratorium on achieving adulthood, or a socially and economically enforced period of destabilization, young adults are no longer expected to proceed from adolescence directly to being an adult. Instead they find themselves on a less distinct, but multifaceted, extended, and bumpy progression toward adulthood than did their parents and grandparents. There is no doubt that young adults today are facing unique challenges. This section focuses first on external, and then, internal challenges identified in the literature.

\section{External Challenges}

The economic insecurity challenge. Settersten (2008) challenged the notion of economic freedom that some scholars claim is a characteristic of young adulthood. He reflected on the experience of young adults in labor markets. In the 1980s, the youth labor market collapsed in most advanced countries. Many well-paying manufacturing jobs for young adults gave way to fewer more poorly paid service jobs. As a result, youth participation in the workforce decreased and unemployment increased. Young adults now frequently face dead-end, low-paying jobs, many of which are part-time and on a contract basis, which made it very difficult to attain financial self-sufficiency, one of the tasks of becoming an adult. In order to resolve this problem, many young adults go on to university, hoping to find better paying jobs later. While in the 1950 s only $5 \%$ of those in their early 20s were in higher education institutions, in 2000, 40\% of those aged 20 to 25 were. By 2006 the figure had risen to $50 \%$. 
The forgotten half who either choose not to, or can't afford to attend college, have also been adversely affected (Côté, 2014). Their earning power dropped continually and substantially from 1980 through 2000. Jobs once held by those who had not gone on to higher education were now often taken by college graduates who could not find work in their fields of study. At the same time, there was little motivation in the society as a whole to change the situation. Mainstream society was benefitting from the delay of full adulthood because these young adults provided an important source of cheap labor.

The lack-of-scaffolding challenge. Scholars have also described the crumbling over recent decades of established societal structures, such as the easier entry into the job market before globalization sent jobs overseas; young people marrying early and thus automatically being welcomed into adult communities; young married couples having children and enjoying the social systems that were in place for parental support; normative structures, such as religious traditions, with accepted rules, that had traditionally facilitated a smooth transition to adulthood (Cote, 2006). Tanner (2006) suggested that while children and adolescents were offered scaffolding for their transitions to succeeding stages, young adults now have to build their own scaffolding for their transition from adolescence to adulthood. Self-socialization is required, according to Côté (2006), because structured socialization formations have diminished. This lack of social supports is particularly challenging for vulnerable populations. Côté (2002) suggested that this decline in established structures and supports for young adults has contributed to the shift toward the exploratory nature of these years. He argued that the freedom of choice young adults supposedly experience was actually something far 
grimmer. With fewer guiding structures for the many choices they face, realistic and informed choices become onerous for many young adults.

The lack-of-continuity challenge. Wuthnow noted that American young adults faced a loss of continuity (2010). He suggested that current post-industrial societies generally did not encourage continuity because they undervalued history. These societies encouraged choices geared to the future instead of the past. As a result, "everything a young adult experiences in his or her twenties and thirties calls for consideration, choice, and change" (p. 215). Wuthnow also argued that American culture's disavowal of continuity did not "diminish the need we all experience for personal coherenceincluding a connection between our present and our past” (p. 215). Giddens (as cited in Gollnick, 2008) suggested that the links between individual lives and the cycle of generations were no longer apparent. The cycle of generations had less meaning if the practices of earlier generations were pursued only as long as there were current rational grounds for engaging in these practices. Other scholars challenged Giddens, though, arguing that in modern society there were still forces that connected the individual to the experience of previous generations, such as assumptions about child rearing, care of the elderly, and norms for career development (Coupland \& Nussbaum, 1993 as cited in Gollnick, 2005).

The increased mobility challenge. Related to economic uncertainty was an increase in mobility, sometimes unchosen, facing young adults. Young adulthood was, as Arnett (2006) asserted, an age of instability. Young adults left home, moved to college and moved into a dorm, moved into separate housing, moved in with a lover, broke up and moved out, moved back with parents while seeking a job, moved overseas to teach 
English, returned to take up jobs, and left them for better opportunities. It is not always possible to distinguish which of such moves are voluntary and which are involuntary.

The collapse of norms and standards challenge. Not only were young adults facing economic uncertainties and the challenges of frequent uninvited mobility as the power of religious and other societal institutions diminished, according to Côté (2006), they were also facing the collapse of norms, values, or standards, which in past eras had undergirded and steadied the transition period to adulthood. This, combined with emotional immaturity (which the moratorium could exacerbate), could result in young adults making poorer choices and lead to youthhood - Côté's term for a perpetual lifestyle of young adulthood, an open-ended identity moratorium. Those who delayed occupational preparations for economically autonomous adulthood for too long might find the route to adulthood more difficult to navigate when they eventually faced the need to surrender long-pursued playful activities. Even college students did not inevitably experience progress in undertaking the tasks of young adulthood.

\section{Internal Challenges}

The overinflated self-esteem challenge. In her controversial popular book, Generation Me: Why Today's Young Americans are more Confident, Assertive, Entitledand more Miserable than Ever Before, psychology scholar Jean Twenge (2015) asserted that the current young adult cohort born in the 1980s and 1990s represent the culmination of decades of increasing individualism and a sense of entitlement, in many cases even narcissism. Twenge spent 14 years of research comparing the results of personality tests, including the Narcissistic Personality Inventory, given to boomers when they were under 30 and those given to young adults today. The positive finding of her study is that young 
adults are generally tolerant, self-assured, open-minded, and motivated; the shadow side is that they are also generally detached, self-absorbed, distrustful, and anxious. Twenge attributed the unrealistic self-image of current young adults to the sociocultural belief in the importance of self-regard, something most evident in parents who are determined to boost the self-esteem of their children by instilling in them the notion that they are special and can do anything to which they set their minds. This, she believes, leads to depression and disappointment when the grandiose vision young adults have for their life does not materialize. Although Twenge did not find that the majority of young adults were narcissistic, she did find that $58 \%$ more college students scored high on a narcissism scale in 2009 than in 1982, and the incidence of narcissistic personality disorder was nearly three times as high for people in their 20s as for those aged 65 or older.

Scholars in the field of psychology and sociology (Arnett, Trzesniewski, \& Donnellan, 2013) have vigorously challenged Twenge's generalizations about this cohort of young adults, however. Scholars of psychology Kali Trzesniewski, Brent Donnellan, and Richard Robins (2008) who analyzed the same data, argued that there had in fact been very few changes in the thoughts, feelings, and behaviors of youth over the last 30 years. Arnett (2010) further suggested that young adults are seen to have increased narcissistic traits because of further misperceptions - the biases of older adults, the lack of nuance in certain psychological surveys - along with such external factors as shifting social principles, the media's emphasis on celebrity, and the increase in social networking sites where self-absorption is the norm. He argued that what Twenge sees as narcissism is merely the self-focus necessary for individuation in young adulthood. 
The tendency to label any group of people with a term as derogatory as narcissist is troubling. Regardless, many young adults do find themselves at the zenith of an everincreasing hyper-individualism and self-absorption that has evolved over previous decades, leaving them ill prepared for the social, psychological, and economic challenges named above.

The challenge of solitude. Although social isolation may in many cases be mitigated by technology and social networking, the flip side of freedom is the large amount of time young adults spend alone. The literature suggested that those aged 19 to 29 spent more time alone than any other section of the population, except for the elderly (Arnett \& Tanner, 2006).

\section{The Tasks of Young Adulthood}

Even as current young adults face a variety of challenges that developed over the last decades, they are also in a process of separation and individuation as they journey toward full adulthood. During this critical time, they continue to develop their sense of self, their cognitive and social abilities, their sexuality, and in many cases, their religious or spiritual lives. Tanner (2006) assessed Arnett's notion of emerging adulthood within the language and concepts of life span development theory. At pains to emphasize the heterogeneity among young adults, she presented emerging adulthood as a critical turning point, rather than just one phase, in life development. Extending Arnett's cross-

disciplinary approach, she affirmed Lerner's (as cited in Tanner, 2006) developmental systems perspective, in which "the person was not biologized, psychologized, socialized, nor culturalized; rather, the individual was systematized - that is, his or her development was embedded within an integrated matrix of variables derived from multiple levels of 
organization" (p. 26). I will consider four kinds of developmental tasks that young adults are working on, often unconsciously, in and around their third decade: ego development through separation/individuation, cognitive development, religious development, and sexual development.

\section{Ego Development Through Separation/Individuation}

Tanner (2006) presented the concept of recentering as the defining process in emerging adulthood. Recentering has traditionally been understood as ego development through separation/individuation. Tanner perceived recentering as a three-stage process in which the goal was relational autonomy, being separated from but still in a good relationship with parents. Systems theory was central to Tanner's analysis. In Stage 1, the launching position, adolescents were embedded in the family home; the systems of the family and the child's systems were identical. During Stage 2, emerging adulthood proper, individuals began to develop new relationships and systems outside the family while they were still connected to the family. They were lightly tied to childhood/adolescent identities and roles and, at the same time, increasingly committed to the evolving identities and roles of adulthood. This stage was characterized by a renegotiation of the relationship with their parents and a clearer definition of the boundaries between themselves and their families. The model was that the young adult let go of their reliance on parents without a collapse of familial relationships. In Stage 3, young adulthood, individuals developed their own autonomous associations and systems. They were still allied with the family system, but had recentered in their own distinct world. They had embraced a lasting identity and role commitments and were able to maintain a consistent self, rather than an experimental self. They had exchanged the 
freedom of the investigational self and its accompanying instability for the constancy that was the goal which inspired the stimulus to adulthood (pp. 27-30)

\section{Cognitive Development}

If Tanner focused on the ego developmental tasks of young adulthood, University of Geneva psychologist and specialist in socio-emotional development Gisela LabouvieVief (2006; 2015) addressed the cognitive tasks. She suggested the existence of a transition from adolescent hypothetical thought (a preoccupation with possibilities or hypotheses) to practical or pragmatic thought. Pragmatic thinkers could entertain inconsistencies, imperfection, and compromise (2015). For Labouvie-Vief, early adulthood constituted an important intermediate phase where creative and critical thinking came to the fore. By the late 30s, individuals are able to verbalize new, significant problems and to ask questions they had not posed before.

As mentioned earlier, Piaget pointed to the shift that happens in late adolescence from thinking within concrete, immediate contexts, to thinking that is more scientific, abstract, and complex and neurologists. Fischer and Rose (2006) provided physiological evidence that the frontal cortex develops physically during adolescence and young adulthood, allowing for the advent of more advanced cognitive skills. Of thirteen levels of simultaneous neurological and cognitive spurts that occur, the twelfth takes place between ages 18 to 20, and the thirteenth occurs when a young adult is aged 23 to 25 . Isquith, Gioia, and Espy (2004) further noted that frontal lobe development supported a cognitive skill set known as executive function processes, that is, the control, supervisory, or self-regulatory functions that organize and direct all cognitive activity, emotional response, and overt behavior. More recently Hartmann and Swartz (2006) suggested that 
the consolidation of identity, the task of young adulthood, may in fact rely upon the increasing meta-cognitive capacities of this age, namely, the ability to think reflexively, and explain one's own thinking to others.

\section{Religious Tasks}

In their review of the literature on religiousness and spirituality of young adults, Carolyn McNamara Barry and Mona Abo-Zena (2014), professors of psychology and sociology respectively, drew attention to the religious tasks of young adulthood. They suggested that many young adults valued religiousness and spirituality and explored such beliefs as they developed their identities; young adults sought to create a set of values, beliefs, and world views uniquely their own. Some explored differing faiths and later rediscovered their faith of origin in a fresh way.

Drawing on the work of cognitive psychologists, including Labouvie-Vief's work addressed above, Barry (2014) pointed out that young adults' evolving ability to engage in higher levels of metacognition, planning, and abstract thinking meant that they could also sustain a more complex understanding of religious, theological, philosophical, and epistemological questions. Barry made the observation that all domains of young adulthood - physical, cognitive, emotional, and social — converged to inform the religious beliefs and influence the practices of young adults, and vice versa (p. 29).

In her study Big Questions, Worthy Dreams: Mentoring Emerging Adults in Their Search for Meaning, Purpose, and Faith, leadership and education scholar Sharon Daloz Parks (2011) defined faith, as did Fowler (1984), as something beyond propositional religious belief. It was "the activity of seeking and discovering meaning in the most comprehensive dimensions of our experience" (p. 10). She suggested that a primary 
developmental task of young adulthood was to learn how to ask big enough questions and to cultivate dreams that were not simply ambitious, but societally worthwhile. She outlined praxes of mentoring that aimed to draw out these dreams and suggested several potential mentoring communities, including congregations, where such mentoring relationships might thrive. Other scholars support her focus on mentoring. Handel (1990), for example, suggested that a single good relationship with a mentor could influence an emerging adult's trajectory toward success. This was especially true of the forgotten half, those who lack some of the support provided by post-secondary institutions.

\section{Sexuality and Spirituality}

Scholars considered sexuality an important social factor influencing young-adult faith development. Associate professor of religion at Hofstra University, Donna Freitas (2008) in the study described in her book Sex and the Soul: Juggling Sexuality, Spirituality, Romance, and Religion on America's College Campuses, explored the sexual and spiritual lives of college students through personal interviews at a variety of public and private, secular and religious American colleges and universities across the country. She found there a pervasive hook-up culture. Students struggle with the lack of connection between sex and religion, but hope for one between sex and spirituality. Of all the religious schools she visited, only at evangelical colleges was faith important in making choices about sexual activity.

Freitas (2008) discovered that regardless of the type of college they were attending, students were uneasy with the hook-up culture of casual sex, and longed for a greater connection between their spiritual or faith lives and their sexuality. She found 
that students' quest for a life partner could often result in the dissociation of their moral compass from their sexual behavior, which left them sexually and emotionally unsatisfied. She found that when sexuality was integrated with spirituality in the hallowing of sex in loving relationships, there was greater sexual satisfaction. For young adults, resolving tensions between religious belief and sexual desire could thus lead to more positive sexual experience.

In sum, there was in the literature a mixture of developmental factors that come together to inform the individual's adult development and their religious experience. When these factors were connected with the realities of the social context, more nuanced portrayals of young adulthood were created.

\section{Studies of Young-Adult-Rich Churches}

Despite widespread young-adult indifference to religious congregations, three recent collections outlined some effective congregational responses to the changing social worlds of young adults. These reflect a growing scholarly interest in religious young adults and the churches they attend. I will describe the findings of three studies which researched young adult-rich churches from both liberal and conservative congregations across the United States, one of which proposed a typology of young-adult congregations.

\section{The "Congregations that Get It" Study}

The book Passing on the Faith: Transforming Traditions for the Next Generation of Jews, Christians, and Muslims (Heft, 2009) included papers from a 2004 conference and material from three additional studies. The conference titled Faith, Fear, and 
Indifference: Constructing the Religious Identity of the Next Generation, ${ }^{5}$ was part of the "Abrahamic Dialogues Series." In addition to the conference papers, the book included discussion of two existing studies: Smith's longitudinal National Study of Youth and Religion (NSYR) (which was then at the point when its participants were teenagers) and Sandy Aston's study on The Interior Lives of American College Students (CSBV). Since at that time, neither of these, nor any other studies specifically addressed the relationship between young adults and congregations, the conference organizers went on to commission the national study (Belzer et al., 2009) called "Congregations that get it: Understanding religious identities in the next generation" (described in chapter 5 of Passing on the Faith).

The new study was based on qualitative interviews and participant observation conducted by a research team in fifteen congregations from four faith traditions: Jewish, Muslim, Protestant, and Catholic. Each congregation studied was urban and intergenerational, but the sample represented a broad theological spectrum within each faith tradition. The Christian congregations included two evangelical, three Catholic, and three mainline congregations, all in urban settings. Six were large and included a substantial minority of young adults; two were small, largely young-adult congregations, which relied heavily on larger, supportive congregations for funding and worship space. To explore how these congregations passed their faith to their children, the researchers analyzed the congregations and the individuals within them. They then highlighted

5 The conference was sponsored by the Institute of Religion at Hebrew Union College-Jewish, the Institute for Advanced Catholic Studies, the Omar Ibn Al Khattab Foundation, and the University of Southern California. 
similarities and differences among and between individuals and congregations across the faith traditions. Belzer et al. (2009, pp. 119-122) offered the following lessons learned, namely that young adults in these Christian congregations:

- wanted a sense of ownership in their congregations,

- had multifaceted interests in religion, including an interest in finding community, emotional support and guidance, a social network, and a life partner,

- thrived when they were "met where they were,"

- welcomed opportunities to feel emotionally affected, and

- responded to a theoretical and practical balance between the particular and the universal.

In her summation of the conference in the last chapter of the book, historian/journalist

Diane Winston (2006) stated that:

The gold standard for organized religion (and a model for enabling and promoting its continuity) was: (a) an encounter that participants experience as authentic (rooted in a particular historical tradition which can be expressed through language, ritual, art, and music), (b) accessible (welcoming worshippers at different stages of their religious journeys), and (c) animating (providing an experience of reflection, revitalization, and renewal). (p. 266)

\section{The Changing Sea Study}

“The Changing Spirituality of Emerging Adults (or Changing SEA) Project” (Pogorelc, 2008) was started in 2008 by Dr. Dean R. Hoge of the Department of Sociology at the Catholic University of America. It included nine case studies, conducted over periods of nine months to one year, in which researchers examined the success of selected Christian (Catholic and Protestant) churches that had attracted and maintained emerging adults as members. 
Father Pogorelc (n.d.) who oversaw the Changing Sea project, summarised the findings in an interview about the study. During a very transient time, he said, when families and groups of friends that nurtured young adults earlier are no longer available, congregations can provide a sense of community for them. He made the following observations based on the Changing Sea congregational study:

- Congregations can provide a "home" for emerging adults by welcoming them and offering opportunities for short-term leadership

- Congregations that appreciate the ideas, work, and prayers of younger people, as well as their financial and time limits will be attractive. Long range projects are problematic, but short term, significant things — ad hoc projects — are welcomed.

- Young adults like diverse and inclusive communities, and abhor the combination of church and right wing politics.

- Media and the use of social networking and a good congregational webpage is good, but he warned leaders not to use technology as a gimmick because young adults are wary of gimmicks and those who use them.

- Young adults enjoy a strong pastor - one who is parental in a nurturing way. They like good preaching and teaching, and pastors with a vision who can address problems and also assemble teams of people to meet challenges.

- Young adults respond well to worship at times they can come - a late Sunday afternoon mass or a late morning service with hospitality times accompanying — wine and cheese after a late afternoon mass, for example, or some breakfast or brunch after a morning time of worship.

- Young adults like to be where there are other emerging adults, so it can take a "critical mass" in their cohort and word that they are welcome. Set up the opportunity for people to meet one another. 
- Things off campus in a coffee house or a home or dorm are popular. "Theology on tap" is something held in a bar. Off campus, people who are more religious can invite those less religious to share equally in the events on neutral ground.

In 2013, the project (currently found in the online archives of the Catholic University of America) surveyed young adults aged 20 through 29. The results, along with former study findings, are to be made into a book for the use of young-adult ministers in Catholic and Protestant churches.

\section{A Typology of Congregations of Religious Young Adults}

Flory and Miller, whose study can be found in the book Finding Faith: The Spiritual Quest of the Post-Boomer Generation (2008), had originally intended to produce a book about "the recovery of liturgy" (pp. viii-ix). They planned to analyze something they were noticing in faith communities they visited, namely, post-boomer Christians "giving up on the relatively sterile, rationalistic worship they were experiencing in their churches" and "making a radical switch" to congregations where they could experience the "full-bodied experience of a worship service" in an Episcopal, Catholic, or Orthodox church (p. vii). They visited Christian congregations led by and filled with post-boomers at ten urban sites (primarily in southern California, but also in St. Louis, Chicago, and New York City), undertook one hundred recorded interviews with post-boomers in these sites, and investigated each group's activities on the Internet. Unexpectedly they discovered that certain Christians were not just leaving Baptist or Presbyterian churches to become Orthodox or Episcopalian. In fact, congregations that had never done so before were inventing, importing, and adapting rituals for their own worship services. Rather than only encouraging individualistic spiritual quests, they were 
now fleshing out their faith commitments in the larger community through service, outreach, the arts, and social justice action. Flory and Miller thus found through their research a common desire among post-boomers for a healthy interplay between the personal and the social, and for worship that engaged both mind and body. They believed that the emphasis was on experiential, even sensory religion, and also otheroriented local/global service. Flory and Miller (2008) divided the congregations they studied into four types.

- Innovators (p. 19) were congregations that represented a constantly evolving approach to religious and spiritual beliefs and practices, with an emphasis on newness and innovation.

- Appropriators (p. 52) were those churches and ministries seeking to provide a compelling and culturally relevant experience for participants through imitating or appropriating trends found in the larger culture, creating a popChristian culture.

- Resisters (p. 84) were congregations, usually fundamentalist, that opposed postmodern culture and sought to restore the status of the written text and rational belief in spirituality and practice, seeking a return to right doctrine.

- Reclaimers (p. 124) were congregations that sought to renew their experiences of Christianity through the history, symbolism and practices of ancient forms of liturgical faith, reclaiming the liturgical traditions.

This typology has not yet been tested in subsequent research, so its reliability and validity as a measure of meaningful intra-generational difference remains uncertain. 


\section{Some Recurring Themes in the Studies of Young-Adult Religious Affiliation}

According to Probasco (n.d.), three congregational best practices were particularly inspiring for young adults: dynamic, participatory, and emotionally engaging worship; invested clergy; and opportunities to serve (p. 9). Certainly, in the literature pertaining to congregations that were attractive to young adults, various themes do seem to recur. I list these under the following: sociocultural, leadership, and adult development themes.

\section{Sociocultural Themes}

The importance of music and the arts. Middle Collegiate Church (Yukich, 2010), in the Changing Sea Study, valued the artistic aspects of their culture, as evident in the rich musical program that included regular performances by professional musicians. Younger members named the emotional resonance of its music and arts as key to the congregation's appeal. Wuthnow (2010) reported that congregations with active youngadult memberships often emphasized arts and music and that young adults frequently pointed to art and music as sources of inspiration. When creeds and doctrines fail them, he noted, they turn to the more intuitive lessons from the arts.

He also noted some seemingly contradictory findings. On the one hand, religious young adults are often associated with contemporary styles of worship, and between a tenth and a quarter would like to see some experimentation with contemporary music in church. On the other hand, Wuthnow (2007), along with Flory and Miller (2008), asserted that many of the characteristics associated with contemporary worship — such as praise music and an informal setting — appealed more to the Baby Boomer generation than to the young adults who are often absent from contemporary church pews. Indeed, 
in his 2010 publication, Wuthnow noted that numbers of young adults were as interested in preserving traditional worship and music as they were in changing it.

This claim is consistent with findings reported in the Hymnal Revision Feasibility Study (Price, Darves-Bornoz, Erdey, Hurst, \& Walker, 2011) created for the Episcopal Church. This study indicated that by a large percentage, those who were most resistant to the idea of revising the hymnal were under 29 years of age; those in this age group often eschewed the notion that sacred music should reflect their secular musical tastes.

Diversity as the new normal. Compared to older cohorts, those aged 18 through 29 supported interracial dating, affirmative action, and gay marriage at higher rates (Yukich, 2010). Young adults were drawn to an inclusive, diverse faith community, but the forms of diversity differed from one church to another, based on race in one case, or LGBTQ inclusion, or women in leadership, or all of these. What was essentially consistent was the intentional effort to embrace diversity in some form.

Middle Collegiate Church (Yukich, 2010) was a progressive Protestant congregation in New York City that expressed the congregation's identity with four words: welcoming, inclusive, bold, and artistic. These appeared prominently on the church website, ads, and documents. An active Gay, Lesbian, Bisexual, Transgender, and Intersex ministry was intrinsic to the congregation's life. Younger members appreciated the emotional resonance of its music and arts.

When New Life Evangelical Fellowship in Elmhurst, Queens, New York intentionally built a racially diverse congregation, they found themselves also attracting 
younger members (Cimino, 2010). At The Crossing, a small emergent ${ }^{6}$ Christian church in Boston, progressive theology and a "radical welcome" were embodied by a congregation and leadership board with half straight and half LGBTQ-identified people (Kaell, 2010).

\section{Leadership Themes}

The clarity of a strong identity. Young adults often feel their own identities to be fluid, and appreciate those individuals and organizations who are clear about who or what they are and where they stand, in order to test whether there is a good fit between them. John Roberto (of LifelongFaith Associates) and Mike Hayes (author of Googling God) argued that congregations that resonate with young adults had a clear identity (2007). They asserted that vital congregations provide a community for spiritual seekers:

- in the context of a clearly defined faith tradition,

- imbued with a strong leader's vision, and

- responsive to local contexts. (p. 11)

Some congregations fostered inquiry while accentuating their traditions. St.

Ann's Roman Catholic Parish, a mega-parish with more than 28,000 members and seven masses a week, found that much of the allure for young-adult parishioners came from the church's emphasis on being unapologetically Catholic (Bruce, 2010).

${ }^{6}$ Formed mostly by evangelical, along with relatively few mainstream leaders and congregations disillusioned with the organized and institutional church, the emerging church movement is characterized by conversations that transcend such "modernist" labels and binaries as conservative and liberal. Eddie Gibbs and Ryan Bolger, in their book Emerging Churches: Creating Christian Community in Postmodern Cultures (2005), explain that emerging churches are communities that practice the way of Jesus within postmodern cultures. This definition encompasses nine practices. Emerging churches (1) identify with the life of Jesus, (2) transform the secular realm, and (3) live highly communal lives. Because of these three activities, they (4) welcome the stranger, (5) serve with generosity, (6) participate as producers, (7) create as created beings, (8) lead as a body, and (9) take part in spiritual activities. 
Young adults and leadership. All of the congregations in the Changing SEA and Congregations That Get It! studies included young adults in noticeable leadership roles within the church that involved various degrees of commitment—from occasionally reading, to helping with music, to planning worship, to chairing committees, to being clergy (Belzer et al., 2009; Pogorelc, 2008). This was true even in congregations with transitory young adults, such as those in college and university towns. There was a focus on nurturing young-adult leadership. At St. Peter's Catholic Student Center in Waco, TX, the core leadership of the congregation was made up entirely of such transient young adults. A small group of older adults joined students in worship in a secondary or mentoring role, appreciating the chance to see young adults test themselves by putting aspiring ministry ideas into practice. Relationships grounded in mutual trust were key to sharing the power and responsibilities that come with leadership roles (Palmer, 2010).

In addition young adults learned from other leaders, and resonated with having clergy available as mentors. Congregations with large, diverse young-adult programming told stories of clergy with vision who made things happen (Probasco, n.d.). Such accessible leaders can make the environment a learning one for young adults.

\section{Adult Development Themes}

Accepted just as you are. Young adults on their journey to full adulthood have to get there through a process of trial and error, sometimes succeeding and sometimes failing. They need places that allow them to be wherever they are. Congregations met young adults where they were in their faith journey (and were thus perceived to be accessible). With regard to religious knowledge and commitment (Belzer et al., 2009), the more typical congregations provided entry points for newcomers-joining small 
groups, serving on committees, making financial pledges — which assumed a familiarity with religion and time availability that were challenging for younger adults. Such assumptions can no longer be made. Today's young adults have dissimilar religious backgrounds. Almost half of those aged 18 through 23 had disinvested from the customs of a particular denomination or faith tradition and were attracted to interfaith exploration; one-third of those aged 21 through 45 had attended services at a non-Christian place of worship. Congregations able to allow young adults to learn along the way, and not have to know anything to start with, are more appealing. Young adults are also juggling a great many competing commitments in order to get by and get ahead, and need congregations that understand their time limitations.

No pressure to commit. Young adults are anxious about commitment - whether that be to a congregation, a romantic partner, or a job (Cunningham, 2009). Congregations that adjusted their expectations — that avoided embarrassing young adults about erratic attendance or reluctance to assume church-related tasks—resonated with young adults. Rabbi J. Rolondo Matalon (2009) of Congregation Bnai Jeshurun in Manhattan said that in a community, there had to be room for "asymmetric exchanges of support" (p. 132). His congregation aimed to balance non-judgmental welcome with invitations to deeper involvement.

Dynamic ancient-future worship. The 1,200 members at non-denominational New Life Fellowship in Queens, New York mixed an evangelical mission and theology with neo-monastic and contemplative practices to foster an emotionally healthy spirituality (Belzer et al., 2009). Flory and Miller (2008) reminded us that many postboomers are eschewing sterile, rationalistic worship in favour of the full-bodied 
experience of Episcopal, Catholic, or Orthodox church worship, or some moderation of these (p. vii).

\section{Summary}

The traditional tasks of adulthood are delayed for most of today's young adults, with a corresponding decline in religious attendance. Society provides few institutional supports during this extended period of instability and change, and supports that existed before are no longer effective.

Marriage and childbearing are the greatest predictors of church attendance, and the delays in both for most young adults have resulted in fewer young parents seeking a place to nurture the faith and morality of their children. Few young adults attend church on a regular basis, and those who do tend to be urban and to join city churches. Although the cultural milieu leans away from congregational faith practices, only $10-15 \%$ of young adults, at most, were opposed to religion. Most were still interested in beliefs and practices of faith but were reluctant to commit to anything too early. Strong predictors of ongoing religious attendance were religious parents who talked about and lived their faith at home and personal experience of faith and practice as teenagers.

The extended period between adolescence and adulthood has created an elongated period of identity clarification. Frontal lobe development creates new cognitive capabilities and promotes identity consolidation for young adults. Many psychologists and sociologists, among others, are endeavoring to comprehend this new reality. Some believe a new life stage is emerging, and others believe the stage is an enforced moratorium because of economic and social forces. Young adults themselves feel in- 
between, not accepting themselves as fully adult until they are independent decision makers, are independent financially, and feel responsible for their own lives.

All theorists, however, believe that young adults face considerable challenges, such as vocational/locational instability, financial hardship, lack of continuity, loneliness, the tyranny of freedom, and some may have been unintentionally misled by their parents into feeling over-confident and entitled, resulting in conflict at school and work. During this period of recentering, young adults, generally left to their own devices, have to build their own scaffolding. Single young adults are the most vulnerable.

According to theorists, congregations that resonate with young adults find ways to engage both mind and body through interactive, sensory, and experiential worship. Such congregations also have a clear identity, inspire their people, and innovate around worship. Young adults in congregations particularly appreciate the inclusion of diverse voices, the invitation to practice leadership, the availability of mentoring, and the blending of the social with the sacred. Studies of various congregations have concluded that young adult-filled congregations pay attention to music and the arts, celebrate diversity, inspire young adults to lead and to serve, accept people as they are, do not pressure young adults to commit, have strong group identities, and are both traditional and innovative. Young adults are facing immense challenges on their journey to adulthood, and far too few congregations are finding ways to be an alluring spiritual home for them. 


\section{CHAPTER 3}

\section{RESEARCH METHODOLOGY}

I begin with a few observations about my qualitative paradigm, from the broadest ontological and epistemological perspectives that influenced my study to the particular lens within congregational studies through which I analyzed my findings. I then describe the general design choices I made, namely, a focused ethnography within a naturalistic and narrative approach. This strategy consists of an analysis of narrative to construct two cases followed by a cross-case analysis process that allowed me to compare and contrast the two cases. Finally, I discuss specific methodological decisions, including decisions about data sources, collection procedures, and the specific data analysis strategies I employed, along with a discussion of the ethical considerations that came into play in the course of doing the dissertation research.

\section{Paradigm Matters}

Qualitative research methodologist and educational anthropologist Corrine Glesne (2011) classifies the multitude of overarching theories and philosophies that guide the work of social scientists into four major paradigmatic families: positivism, interpretivism, critical theory, and post-structuralism (p. 6). Although there were certainly things of interest in my data that could be observed and measured (measurement is a defining characteristic of positivism), emancipatory issues to be considered (as would be considered in a critical theory approach), and considerable participant references to postmodernity by clergy and participants (i.e., a defining characteristic of poststructuralism), my primary framework for making sense of the world is interpretivism. I 
am motivated to understand how people, both as individuals and as groups, construe and make meaning of their experience. As a result, my purpose for this research was that of contextualization, understanding, and interpretation, rather than generating the generalizations, causal explanations, or prediction power that is characteristic of a more positivist approach (2011). I also eschewed the critique orientations that characterize critical theory and post-structuralist approaches.

\section{Ontological and Epistemological Framework}

I begin from an understanding that no one can claim to have a completely objective point of view. Our world is known through the mind and, more specifically, through the interpretations our minds make. It was thus the interpretations that study participants made of their experience, the interpretations that I made of my experience, and the subsequent conversation between these in my own mind that constituted the essence of this study. While I began the study with several vague hunches, I did not have a particular idea or theory to guide me and was not intending to come up with one. My approach reflected a naturalistic, inductive, and contextual methodology; I sought to discover and describe "another country heard from" (Geertz, 1973, p. 23) through thick description $^{1}$ of emic ${ }^{2}$ perspectives. I expected to find complexity and then search for patterns within it, and indeed, I did.

1 Thick description refers to the researcher's detailed and contextualized description of patterns of cultural and social relationships (Holloway, 1997).

2 In an emic approach, a researcher tries to put aside prior theories and assumptions so that themes, patterns, and concepts emerge from the participants and the data themselves (Presidents and Fellows Harvard University, 2008). 


\section{Congregational Studies Perspective}

Although this dissertation was produced within a school of leadership studies and based in the social sciences, I studied two congregations. This dissertation might thus be of interest to those who work in the area of practical theology. I therefore offer here a brief comment on where in the field of congregational studies I would locate this study if that were my discipline.

As mentioned in chapter one of this dissertation, Hopewell (1987) in his book Congregation, compared those seeking a spiritual community to homebuyers who view potential homes as textures, mechanisms, organisms, or means of signification (p. 5). Hopewell argued that most scholarship in congregational studies utilized the contextual, mechanical, and organic approaches, but that there was insufficient research done within a symbolic framework. In Studying Congregations: A New Handbook, edited by key scholars of religion Nancy Ammerman, Jackson Carroll, Carl Dudley, and William McKinney (1998), Hopewell's original work has been reconsidered, resulting in a revision of the four primary frameworks for studying congregations. The new frameworks are: the ecological frame (seeing a congregation as one organism surrounded by many other social, political, economic, and religious organisms); the resource frame (which focuses on various forms of capital such as money, buildings, reputation, that can allow a congregation to meet its goals); the process frame (a frame that emphasizes the various informal and formal processes and procedures that a congregation adopts); and the cultural frame, which I will now describe, since it is the one that informs this study (p. 15). 
According to Ammerman et al. (1998), "To look at a congregation engaging in its unique rituals, showing off the things with which it has surrounded itself, and telling the tales of the group is to use a cultural frame for understanding its life together" (p. 15). They go on to say that the cultural frame includes the unique ways a group has invented for being together-its identity. This identity is discovered through the lens of culture, which includes the habits, artifacts, and places of being, as well as the ways people describe the group - "its stories and heroes, symbols and myths, its jargon, and its jokes" (p. 15). It is within the cultural frame that this dissertation finds its home.

\section{General Design Decisions}

\section{Ethnographic Approach}

At the core of ethnography, the earliest form of qualitative inquiry is a desire to understand and describe the culture of a group of people (Patton, 2002, p. 81). The primary way that culture is studied is through participant observation, and early ethnographers usually spent years in an entirely different culture in order to comprehend the complexity that makes up that particular culture. Although this approach is widely criticized, and rightly so, because of the unequal power dynamics between the researcher(s) and the researched (Brewer, 1994), it has been taken up by sociologists studying their own complex and highly differentiated societies where power differentials may be somewhat less problematic.

German sociologist Hubert Knoblauch (2005), known for his work on the sociology of knowledge, sociology of religion, and qualitative research described newer forms of sociologically based ethnographic research in his seminal article, "Focused Ethnography," in which researchers, rather than going into a completely foreign culture 
where almost everything is new, study particular field sectors or specific parts of more familiar cultures. He gathered these new forms under the umbrella term focused ethnography.

Since the researcher in a focused ethnography is familiar with much of the culture and is only studying a part of it, Knoblauch (2005) explained that data collection occurs in shorter, more intensive survey phases, and numerous emergent modes of documentation are used for generating data. The use of video, audio, and memos is common, he noted, so that the bulk of the analysis can take place after the concentrated visit. While this process is still subjective, he suggested that the unrestrained subjectivity of the classical ethnographer taking field notes is somewhat mitigated by the ability the researcher has to return to the recording over and over again, and by other researchers being able to see the same events and hear the same words (p. 4).

Rather than needing to reconstruct a whole culture, Knoblauch (2005) noted that the researcher in focused ethnography starts out with considerable prior knowledge of the society being studied. Then they seek to understand the particular background knowledge of some aspect of that society, that is a specific field, or more particular social practices and the emic perspectives of insiders. This constructivist recreation of the participants' structures of knowledge and experience, and thus the meaning of their actions, Knoblauch said, is also based on the researcher's sense of what was happening in the group and illustrated with quotes from field participants.

Knoblauch (2005) observed that in ethnography, particularly that of the anthropological ethnographer, the encounter with the other is characterized by strangeness in a situation of unfamiliarity not only with specific situations, but also with 
the general culture that holds the clues to their meanings. In a focused ethnography, more the domain of the sociological ethnographer, he continued, the encounter with the other is characterized by alterity. The other may be a different actor, may even know different things, but is accessible because of a backdrop of common, shared knowledge (p. 4).

For Knoblauch (2005), standards of scholarship are achieved by understanding that the sociological ethnographic process actively produces rather than simply distills data from reality, because the researcher is subjective. He therefore emphasized the importance of continuous reflexivity through self-awareness and the naming of previous knowledge and expectations through journaling and memos to moderate personal bias. He also reminded researchers that those being interviewed and observed, particularly when recording equipment is being used, respond to the researchers and assign roles and perspectives which influence their answers and actions.

\section{Naturalistic Study}

Although focused ethnographers often choose a highly differentiated focus such as the impact of a new technology on a particular group of workers, this study sought to explore why young adults resonated with two particular congregations. Since the resonance between congregations and young adults is complex, subjective, and socially constructed, this study required the description and disentangling of a plethora of "webs of significance" (Weber, as cited in Geertz, 1973, p. 5) that individual participants within congregations each hinted at in the course of interacting with me. I therefore believed that this research required an emergent rather than a fixed design, and I developed this through careful listening and observation within each congregational context, trying not 
to thoughtlessly impose a priori theoretical assumptions onto the young adults I studied. I thus tried to name and reflect on those things I felt I already suspected or knew about young adults in congregations. (See Chapter 1 under Delimitations).

I hoped to meet the participants on their own terms and to be myself-a reflexive and open self. I expected the process to be an interactive one in which both parties were involved in shaping the research process. The design and methods I initially posited were not blueprints for action, but, rather, my best sense of a useful starting point. They evolved in consultation with congregational leaders and research participants as the study progressed. This was, in fact, a helpful choice. Some young adults, particularly at the first site, were somewhat weary of being researched and indicated they found the more emergent and collaborative approach I employed more authentic and refreshing.

One young man seemed to head off in the opposite direction whenever I arrived. I mentioned that to him one day, and he confessed that he sometimes felt as though the congregation was an exotic island constantly being studied by both insiders (usually members who were seminary students) and outsiders. He nevertheless agreed to meet, and we set up a time to talk near his workplace during his lunch hour. After he shared some initial thoughts about postmodernity, I introduced the study and explained that in a naturalistic study, the questions were simply a guide and that if someone said, "I hate your questions, and I want to actually go in this direction," I might actually change the questions a little. He responded with some enthusiasm, "Yeah, that's good! That's good research!" He then responded by challenging one of the interview questions: "Well, there's an issue with the bottom question, 'Why do you think this congregation attracts young adults?' and part of that was never using language of attracting anyone, so that 
kind of speaks to the dualism [of modernity] as well. We don't attract people-we just are." What followed seemed to be a mutually enjoyable interview. I was grateful that, because of this naturalistic research approach, some interviewees were more willing to engage in the process, and I was able to refine my questions to suit emerging understandings.

\section{Narrative Approach}

The biographical turn in the social sciences influenced my data gathering and analysis. Since resonance functions mostly on an unconscious level, Patton's (2002) suggestion that "stories and narratives offer especially translucent windows into cultural and social meanings" (p. 116) was helpful. Often people find it easier to tell stories than answer propositional questions. That "stories can often serve as a half-way house between tacit personal knowledge and formal propositional thought" (Donmoyer, 1990, p. 186) was evident in the richness of the storied data, information that I might not have evoked through propositional questions that solicited propositional (as opposed to storied) answers.

Building on the work of Bruner, professor emeritus of psychology and research methodology Donald Polkinghorne's (1995) work on narrative provided a useful context for my approach to the study. Polkinghorne distinguished between paradigmatic and narrative cognition (p. 5). According to Polkinghorne, a researcher engaging with a narrative can do so paradigmatically by drawing out categories and themes from the story by means of an analysis of narrative. On the other hand, a researcher engaging with actions, events, and happenings can also reconstruct stories, such as biographies, histories, by means of a process Polkinghorne calls narrative analysis. My intention was 
to gather and compare stories of leaders and participants in each group and to observe congregations engaging in their collective life, and then, through an analysis of narrative, to seek draw out those webs of significance, those themes and categories from individual stories that could provide insight into the resonance between individuals and their congregations.

\section{A Case Study/Cross-Case Analysis Design}

Most researchers have traditionally had low regard for individual or low $n$ case studies, maintaining that, since individual units of analysis are unique, they cannot be regarded as typical. Donmoyer (1990), however, argued for a more psychological conception of generalizability, based in schema theory, as more helpful to practitioners (p. 182). He contended that it is in the very uniqueness of an individual case study that its value lies, and that the purpose of social science research today is to expand the range of interpretations available to the research consumer. Since expanding cognitive structures is the aim of qualitative research, he argued, an outlier could have great heuristic value. This study thus employed a case study/cross-case analysis design with two information-rich congregations. I treated each congregation participating in the study as a case. After the construction of each of the case studies, I compared and contrasted the cases with each other to seek common themes.

Another critique of the case study and focused ethnography is that the focus on the particular can in some cases cut the research off from greater societal concerns. Knoblauch (2005) argues that social relations, networks, and even milieux depend on the particular events, encounters and situations that are the basic segments of social life (p. 12). Focused ethnographies not only demonstrate the particularity of such segments, he 
contended, but also provide far more grounded descriptions of the ways such field sectors might be related to other aspects of society.

\section{A Descriptive Approach}

My approach when observing COTA and St. Paul's as well as the young adult interviewees was a descriptive rather than an evaluative one, in keeping with my ethnographic approach. My purpose was not to critique but to understand what it was about the congregations that resonated with their young adult participants, and what aspects of leadership facilitated this resonance.

\section{Specific Methodological Choices}

\section{Research Sites}

I initially studied three sites but after being unable to gather sufficient data from one of them, ${ }^{3}$ I used a purposive sample of only two information-rich, extreme-case progressive mainstream congregations. These included, in 2012, a significant proportion of people aged eighteen to thirty five, (young adults born between 1977 and 1994). The two sites studied were the Church of the Apostles, more commonly called COTA, and St. Paul's Episcopal Church. The criteria for choosing these congregations were that they:

- were progressive mainstream congregations in the Pacific Northwest;

- had at least thirty young adults in regular attendance;

- were open to and welcoming of people of all sexual orientations; and

${ }^{3}$ The third site was not a congregation as such, but sanctuary where unacquainted hundreds of people came on a Sunday night to listen to the chanting of a choir. There were no announcements made, and people arrived and left quickly. I was given permission to do research there, but people's anonymity was to be respected. Because it was difficult to find interviewees without bothering people as they arrived or left, I was unable to interview enough young adult attendees. I hope to complete this study later. 
- were willing to provide a letter of permission for me to do interviews and focus groups, observe on-site, and review congregational websites and social media.

I chose these sites because they had the greatest capacity to illuminate the phenomena being studied, namely, resonance in progressive, young adult-filled mainstream congregations and those aspects of leadership that contributed to this resonance. I had visited COTA several times after hearing the founding priest speak in Canada, and had heard about the third site also through her presentation.

I contacted the primary clergyperson or leader at each site by phone and email (Appendix A). Each gave permission to conduct research at their site. Because both initial sites were Episcopalian, I also spoke by telephone to the local Episcopal bishop and received permission from him to do this research in churches under his care. It was the bishop who encouraged me to study not only COTA but also St. Paul's Episcopal Church. I was unaware that these two final congregations would be so very different in their understandings of leadership and their liturgical and musical styles. The significant differences between them enabled me to maximize variation between congregations to some degree so that any common patterns that emerged would be of particular interest (Patton, 2002).

\section{Data Collection Procedures}

The data gathered included recorded interviews and focus groups with leaders and participants (29 from COTA and 31 from St. Paul's), participant observation and recording of worship and other events I had been given permission to study, and some analysis of websites and worship PowerPoint slides (COTA) as well as bulletins (St. Paul's), and congregational documents produced by each site. The primary source of 
data was qualitative interviewing and naturalistic observation, and I was the primary research instrument.

Congregational participants were interviewed on a voluntary basis, and requests for interviewees were made during church announcement times or in bulletins. I also directly asked those with whom I had casual conversations whether they would be willing to be interviewed. Some agreed, and some did not. In each congregation, I also asked members who were ensconced in the life of the congregation to suggest people to interview. I then emailed or spoke to those people directly and asked if they might be willing to participate in a focus group or individual interview. Some snowball interviewing also took place, as I asked interviewees "Whom else should I interview? Who might see this differently?"

Of the 29 people I interviewed at COTA, 2 clergy, 2 staff, and 18 participants were in the 18-through-35 age range. Of the 31 people I interviewed at St. Paul's, 20 of the participants, but neither clergy nor postulants, ${ }^{4}$ were young adults in this range. (For demographic tables characterizing participants, see Appendix E).

At COTA I interviewed thirteen people individually (two clergy, two staff, one postulant, and eight participants, six of whom were young adults), and sixteen people in four focus groups (of five, four, four, and three people respectively) for a total of twentynine interviewees, as well as two staff members who were associated with the Fremont Center for the Arts that shared space with the congregation and was loosely affiliated with the church.

${ }^{4}$ Postulants are candidates for membership in a religious order, in this case, clergy leadership. 
At St. Paul's, I interviewed ten people individually (two clergy, one deacon, three postulants, one treasurer, and five young adults), ten people in five groups of two, and ten people in three focus groups (of three, three, and four people) for a total of thirty interviewees. The interviews and focus groups were ninety minutes long; in three cases, with the permission of the interviewees, they were longer.

It is difficult to ascertain the extent to which my presence and the presence of the recording equipment influenced interviewees. To minimize reactivity bias, I sought to assure participants that there was no right or best answer, their material would be both confidential and helpful, and that I would be the only one who would ever watch the video. I invited them to be as open and honest as they could. I assured them that their identities would be protected. I was delighted that the young adults I spoke with seemed quite willing to share their stories and dispute my questions.

I felt a little awkward using the video camera in services and events, and one person at each site expressed some discomfort when I did this. They seemed reassured in both cases when I reminded them that the video was for my eyes only. For the most part, all other participants not only appeared to be unperturbed; a number at COTA specifically mentioned that they were quite used to being recorded.

Patton (2002) suggested that researchers choose from a range of interviewing strategies, from informal conversations to highly structured interviews. The approach of this study was a mixture of casual conversations, informal interviews, and focus groups utilizing a semi-structured guide to evoke stories that would enable an analysis of narrative. Focus groups included congregation attendees who were willing to participate in such groups. Some preferred to be interviewed on their own. The number of focus 
groups and interviewees depended on the willingness of people to participate in a group interview and on the amount of time available. Interviews and focus groups occurred more slowly at first, and then as people became more familiar with me, and as the deadline for my leaving approached, the number increased significantly. I also made brief field memos every day because of the time needed to transfer large amounts of data from the video, audio, and Livescribe recording pen onto both hard drives and DVDs to ensure data security. When transcribing and watching the video back home, I made brief descriptive, reflexive, and analytical memos (which included pictures).

I adjusted the questions according to their effectiveness with the initial interviewees. The questions were focused on storytelling rather than soliciting propositional statements because, like Hopewell (1987) I believe that a congregation's experience and identity "are essentially storied" (p. 84) and that stories could lead to thick description from emic perspectives. Like Donmoyer (1990) I believe that "stories can often serve as a half-way house between tacit personal knowledge and formal propositional thought" (p. 186) and that eliciting stories could result in an analysis of both conscious and unconscious sources of resonance between young adults and the two congregations. The initial questions were adjusted on site, because of feedback from interviewees, in the following ways (Appendix D):

1. "Tell me the story of how you came to be part of this congregation" became "Could you tell me the story of your spiritual/faith/God journey and how that connected you to XXX?" (I made this change because it became clear that for the person to share more fully, they 
needed to go further back than directly before they arrived at this congregation).

2. "Can you tell me what you know of the story of how this congregation came to be?" became "Can you tell me the XXX story as you know it?" When participants had no idea of the story, I would ask, "How would you explain XXX if you wanted to describe it to someone?" (I made this change to encourage answers from some who did not feel they knew enough about the history of the congregation).

3. "Do any of these words (written up on a sheet of paper handed to each participant) have bearing on your story of coming to this congregation, either by their presence or by absence?" The list originally included Bible, leaders, music, people-like-me, theology, parents, friends, location, time of day, ritual, liturgy, special events. Along the way, people added ethos, Eucharist, God, authenticity to the list. (This question was designed to ensure that there was some connection and coherence among the various narratives).

4. "Tell me the story of your experience of any leaders (as you define leadership), past or present, who were part of why you came to this congregation." This question became, "Are there any leaders in the story of why you are connected to XXX, and who were they, or what did they do to have an impact on you?" (This change was to mitigate the resistance, particularly at COTA, to the idea that leaders might be the reason they were there.) 
5. "Can you tell me any stories of how the leaders of this congregation helped/help young adults feel at home here, or met your needs?" became "Are there any aspects of how leadership is expressed or not expressed at XXX that resonate with you?" (See the explanation in question 4).

6. A new question was added between questions \#5 and \#6, and so the previous \#6 became \#7. It was "Can you think of a metaphor for $\mathrm{XXX}$ or your experience of it?" (This change was to provide ways for people so inclined to explain in symbolic terms how they understood the congregation).

7. "Why do you think young adults are drawn to this congregation?" This question received some strong feedback, and as a result, it became instead, "Why do you think so many young adults resonate with XXX?" XXX was changed by site to COTA or St. Paul's. (Neither of the sites felt that they were doing anything to "attract" young adults, and in fact balked at the implication that they were trying to attract any particular age group).

Interview/focus group procedures. After the interviewees read and signed the consent form (Appendix B), they filled out a brief demographic survey (Appendix C). Some of the demographic data about interviewees at COTA and St. Paul's are summarized in Appendix E. The majority of participants, both staff and younger interviewees, were Caucasian and highly educated, and had grown up in devout Christian 
families. Of the young-adult participants, most were single, and most had attended church regularly as children. The interim clergy leaders at COTA were young adults, whereas the clergy at St. Paul's were much older. In keeping with the demographics of the city and the two neighborhoods, both congregations included only a small number of biracial or Hispanic participants, and one included an African.

I interviewed each clergyperson or lay pastor individually for up to ninety minutes at a site of their choosing. Due to time constraints, one of the lay leaders was interviewed when I was back in Canada, using Skype and a free Skype recording application. I interviewed participants in focus groups where possible, but some people preferred to be interviewed individually.

As mentioned, I recorded the data three ways: 1) with a digital recorder, 2) with a Livescribe note-taking pen that records sound as it writes, and 3) with a camcorder. The interviewees were informed that I would be using these recording methods before the day of the interview. Multiple recording devices were used to ensure that the interviews would be effectively captured in case of any technological failures. This was important because, from time to time, one of the recorders failed.

Naturalistic observation. Naturalistic observation greatly enriched the interview findings. For a month in each case, I attended worship services and after-service coffee times, as well as other events in each congregation's life to experience the sacred space and culture of the congregation. My role was more that of observer than participant, although I was warmly welcomed into each site and, as a progressive Christian myself, was quite comfortable participating in the Eucharist and prayers. I tried to pay particular attention to symbols, rituals, and interactions between leaders and participants and took 
brief analytic notes directly afterward. With the permission of the sites' leaders, I also took photos of the congregations' buildings and the empty worship spaces. I also video recorded any events for which I had permission to do so.

Document analysis. I spent time looking at the congregational websites and collected and reflected on worship PowerPoint slides or bulletins. I gained access to the draft constitution of COTA, which was being discussed at a board meeting I attended. At that time, curiously, neither congregation made extensive collective use of such social media as Facebook, Twitter, or Instagram.

\section{Data Analysis Procedures}

A recursive, inductive approach to the analysis of data was undertaken. In inductive analysis, "findings emerge out of the data, through the analyst's interaction with the data, in contrast to deductive analysis where the data are analyzed according to an existing framework" (Patton, 2002, p. 453). Data collection, analysis, and validity checking occurred simultaneously to some degree as the study evolved, although the process of interviewing and of saving large amounts of video was so time-consuming and intense that much of the in-depth analysis happened later.

I analyzed each case separately. Starting with COTA, all interviews or focus groups of leaders and people aged 18-35 were transcribed word for word using audio or video recordings. In some cases, others transcribed the interview, and I checked it by listening to the video/audio and correcting any mistakes that had been made. I then submitted the documents to the interviewees for member checking. In a few cases, I did not transcribe the interviews of individual older adult interviewees but simply listened or watched them again because they often provided rich historical background. After 
incorporating the feedback from interviewees, I loaded the documents into AtlasTi software. Starting with COTA, I began the process of line-by-line inductive coding. I attempted, so far as was possible, to approach the data naïvely, without imposing theory onto the coding process. I was genuinely curious about what was actually in the data. To this end, I did not do the literature review until after I had done the analysis. After coding the interviews and focus groups for the COTA case, I had over 700 codes, all of which seemed relevant, under the following umbrella categories: context, individual, site, welcome, leader, theology, and liturgy. Although certain themes began to flicker through, the stories were so rich and the "webs of significance" so dense that it was very difficult to know what to focus on and what to leave out.

After reviewing word counts, analyzing codes, reading and rereading and listening to the interviews, I concluded that the only order that could be imposed on the wealth of data from COTA was that of the research questions themselves. I would initially use the categories of (a) context, (b) translation of ancient rituals and wisdom, (c) creation of welcoming space for young adults, and (d) leadership, to analyze each site.

With the help of field memos, I carefully considered my a priori assumptions along the way, so that I could seek and analyze contradictory evidence. Memos written after each event or interview included descriptive, analytical, and reflexive thoughts. Along with the interview and focus group data coding, I also paid careful attention to these analytic memos in order to document changing perceptions and counter-evidence.

Reflexive analysis was important. I remember feeling very annoyed, for instance, that I had taken the time to interview a visitor to St. Paul's who it seemed had not enjoyed the service and was openly critical. The music was not to his taste. I reckoned I 
had wasted my time. After some self-reflection, I realized that this interview was, in fact, a gift. While interviewing only young adults who liked the church, I was forgetting that there were likely as many young adults who would not resonate with either of these congregations, as there are young adults who would.

Then, through an "analysis of narrative" process (Polkinghorne, 1995, p. 5) I analyzed all the stories within each site. I constructed each case study independently. I then undertook a cross-case analysis where I compared similarities and differences between the sites in a search for common themes and patterns, lack of patterns, and variations in patterns

Triangulation took place through analysis of (a) casual conversations and individual, leader, and group interviews/focus groups followed by member checking; (b) websites, service bulletins/PowerPoint presentations; (c) and my own participant observation of worship services and other events at each site. Because my focus was on the emic perspectives of participants, I named only those "webs of significance" regularly mentioned by participants as well as any rare counter evidence to these commonly held notions. In all cases, however, they echoed my own observations and experience.

Member checking/findings. In addition to sending the transcribed interviews back to each participant for member checking, I gave both congregations' leaders an opportunity to read and comment on the findings chapter related to their congregation. I asked them to point out any factual errors, and also offer any feedback they would like to give. All feedback offered were "friendly amendments" and I incorporated them into the chapters. 
Ethical considerations during data analysis. Keeping the sites confidential had been important during data collection because every participant wanted to know which other sites I was studying. Once leaders had read their chapter, I asked and received written permission to use the name of the congregation, while using pseudonyms for participants. Participants also had been guaranteed anonymity as part of their granting of consent. During the writing of the chapters, it became clear that if there was more than one quote by a particular person, certain things people said could identify them. Once identified, all other uses of the same pseudonym failed to protect them. I determined in certain cases to give people more than one pseudonym.

\section{Introduction to Subsequent Chapters}

The methodology employed in this dissertation study produced findings about each site that were exceedingly rich and dense. As a result, each site has its own findings chapter. The findings and the discussion of the findings that are often presented in a single findings chapter will instead be presented in the following format:

- Chapter 4. Findings from COTA.

- Chapter 5. Findings from St. Paul's Episcopal Church.

- Chapter 6. The Cross-Case Analysis Results.

- Chapter 7. Summary, Discussion, and Concluding Comments.

\section{Conclusion}

In summary, this chapter discussed methodological issues. Specifically, it provided discussions of general paradigm and design matters. The chapter also provided details of the specific research methods employed. 


\section{CHAPTER 4}

\section{COTA: A COMPLETELY DIFFERENT KIND OF CHURCH}

I still have respect for my parents' church and where I came from, but it didn't fit me anymore. I've got to go build my own thing and our generation has to build our own thing. (Dylan)

The Church of the Apostles (COTA) is a Christian congregation with a short but rich 10-year history filled with somewhat unconventional and imaginative leaders, many of whom had come and gone. I spent the month of April 2012 at COTA engaging in participant observation, document analysis, and interviews with individuals and focus groups in order to discover and describe those webs of significance that were spun by the congregants and leaders in which young adults found the "intonations of their own language." The data generated were infinitely rich and thick. In a congregation entwined with innumerable nuances, subtle (and not so subtle) processes, and fascinating individuals, endeavors to sort or classify the data seemed artificial and reductionist. The ideas within the first research question, "What aspects of leadership and translation, if any, were/are exercised to create welcoming space for young adults, and make ancient Christian wisdom and rituals relevant to them?" and the second, "What kinds of resonance, if any, emerged between the leaders and the group?" provide the framework for this findings chapter. ${ }^{13}$ The young-adult participants' experience of resonance with COTA — as discovered directly through interviews and participant observation will unfold under the following headings: (a) context of the congregation, (b) the creation of

13 This chapter will consider the findings from COTA, and the findings from the second site of study, St. Paul's, will be described in the chapter 5. For a description of the flow of the chapters, please see the section "write-up of findings" at the end of the methodology chapter 3. 
welcoming space, (c) the translation of ancient wisdom and rituals, and (d) leadership. I will address the third research question about the developmental and maturational work of young adulthood in chapter 7 , where the data will be brought into dialogue with the literature, which I read only after the initial data analysis.

A separate book could be written just about the founding of the congregation and the role of its visionary founding priest, Carolyn (a pseudonym). I did not interview her, but she was very much part of the COTA narrative, and the origin of many of the webs of significance within the congregation. I learned much about her from stories told by interviewees, from articles she had written, and from copies of interviews and workshops she did about COTA during and after her time there. The community she created and left behind has been a place of resonance for many young adults. Ethan, a current member of the congregation, said after acknowledging his appreciation for Carolyn:

Although Carolyn had a powerful vision for COTA, we weren't attracted to what her vision of it was. We were attracted to what it turned into. So we were attracted to the embodiment of being an honest expression of something. Where Carolyn succeeded was, you know, in creating a community that sustains itself and you've seen some of that since you've been here-how the community goes on regardless of who's in whatever leadership. It has a life of its own.

In working only with "what it turned into," I will write in the past tense, so that it is clear that what I experienced and learned was true at the time I visited the congregation and talked with its members; the congregation may have moved in different directions since then, particularly since the interim priests have been replaced by the new priest. COTA was, in fact, quite distinctive. Sensitive to tensions and contradictions throughout the breadth of the Christian tradition, COTA following the lead of its founder, relished paradox, and found innovative ways to create a Christian congregation that was 
both rooted in tradition, yet sensitive to the nuances of the less-than-traditional culture and community in which the church was intentionally located. As a result, it walked a path that distinguished it both from the evangelical or megachurches at one end of the church-type continuum, and from most liturgical ${ }^{14}$ or mainstream churches at the other. COTA employed a song from here, a sacred practice from there, an icon from somewhere else, and found ways to weave them together, not through an amorphous blending, but as a celebration of contradiction: the ability to hold contrasting things in the same space and yet allow them to remain their distinct selves.

\section{Context}

\section{Location}

When asked to tell the COTA story participants generally shared that from its inception, COTA was an integral part of the emerging church movement/conversation. ${ }^{15}$ In fact, Carolyn was credited with coming up with the term "emerging church" (Gibbs \& Bolger, 2005, p. 320). This is a late twentieth- and early twenty-first century movement, primarily in the Western world, crossing various theological and denominational

14 Liturgy usually relates to traditional, ritualized, formally structured ways of worshiping. This may include such aspects as the procession of clergy and lay servers wearing albs up the center aisle at the beginning of the service, the use of incense, the incorporation of religious symbols, the communal recitation of such prayers as the Lord's Prayer and the creed, call and response prayers, petitions read aloud, the observation of the church year, the following of a lectionary, and performance of the sacraments, which all mark the worship practices typical of a liturgical church.

15 Formed mostly by evangelical, along with relatively few mainstream leaders and congregations disillusioned with the organized and institutional church, the emerging church movement is characterized by conversations that transcend such "modernist" labels and binaries as conservative and liberal. Eddie Gibbs and Ryan Bolger, in their book Emerging Churches: Creating Christian Community in Postmodern Cultures (2005), define the emerging church in this way: Emerging churches are communities that practice the way of Jesus within postmodern cultures. This definition encompasses nine practices. Emerging churches (1) identify with the life of Jesus, (2) transform the secular realm, and (3) live highly communal lives. Because of these three activities, they (4) welcome the stranger, (5) serve with generosity, (6) participate as producers, (7) create as created beings, (8) lead as a body, and (9) take part in spiritual activities. 
boundaries in response to the notion of the postmodern ${ }^{16}$ society that has emerged at the tail end of modernity and Christendom. In contrast to many fundamentalist evangelicals who believe that being a faithful Christian means eschewing "the world" and its "worldly" culture, emerging churches tend to embrace today's culture as an important conversation partner for the Christian gospel.

Consequently, COTA was intended to be postmodern, culturally attuned, and distinct from other liturgical churches. Many interviewees recounted the story of how Carolyn had envisioned this congregation during times spent in a pub in Chicago with friends and neighbors who did not have any relationship with the church. After being invited to Seattle by a forward-thinking bishop who had heard her speak, she had very intentionally chosen secular Fremont as a place in which to create a church for those who would not usually come to a church.

Fremont cool. When COTA began in 2002, Seattle was the city that had the fewest religious people in the country, and Fremont was the bohemian neighborhood that arguably most exemplified Seattle's lack of interest in religion. While many would have balked at trying to start a religious congregation in this community, Carolyn wanted to "plant a church among the postmoderns [sic]" and found a neighborhood in Seattle she knew would be "just right." It was "where the artists hang out, with lots of singles, art, and cafes. I knew the church needed to be right there. There were no churches in the area" (Gibbs \& Bolger, 2005, p. 320). Thus when a Lutheran church in another

16 According to Gibbs and Bolger (2005), postmodern Christians see the contemporary church as being shaped by modernity and Christendom, and in reaction adjust their thinking and practice to the new postmodern cultural situation. 
neighborhood offered COTA space, Kathryn remembered that Carolyn "was like, 'Wow this is nice and generous but this is, like, isn't our neighborhood.' She really felt like she needed to be in Fremont "somehow, some way."' At the time I collected data there, Fremont's just over 1300 residents (who call themselves Fremonsters) enjoyed a vital nightlife, regular and unconventional community festivals, pubs, restaurants, cafes, and small, independent stores. A diversity of age groups live in Fremont, but the predominant group was between 18 and 35 years old. Approximately $88 \%$ were Caucasian, the majority of whom were single and college-educated.

College-rich neighborhoods. Although there were no colleges in Fremont per se, COTA was just over the Fremont Cut (part of the Lake Washington Ship Canal) from Seattle Pacific University (SPU), and only a few blocks from the University of Washington (UW or less formally, U-Dub). It was not too far from the Seattle School of Theology and Psychology and Northeastern University. Many residents of Fremont were students who attended nearby colleges and seminaries. This college-rich environment certainly set the stage for the creation of a congregation with an average age of 27 , something that would be unlikely in a small town or suburb with an older demographic profile. In particular, SPU, which was a relatively progressive Christian institution, appeared to be a good place for younger people to work through identity issues. Dylan, for example, described SPU as "a really great place to process [issues of identity] and go through my multi-racial identity crisis, my sexuality identity crisis, my faith identity crisis, and put all of that together." There was, in fact, something of a symbiotic relationship between this college and the COTA congregation, and the congregation was 
mentioned regularly by interviewees as a supportive environment for Christian college students and others wrestling with issues of faith and doubt.

Although the abundance of college-age young adults in the neighborhood provided a good environment for a young adult-filled congregation, I know of numerous progressive mainstream congregations in college-rich neighborhoods in the Pacific Northwest that do not resonate in any striking way with young adults. In short, being in a young adult-rich neighborhood was not the only variable that occasioned a congregation with an average age of 27 at COTA.

The congregation in context. After the congregation began to form in a nearby neighborhood, it moved to Fremont and had begun to fashion its "sacred space," first in a café called The Living Room where deliberate connections were made with the arts community. The Living Room displayed the work of local artists and hosted performing arts events. Carolyn, in collaboration with others, oversaw the formation of a Center for the Arts. When the congregation moved from the Living Room into the Lutheran church building across the road, which they rented and renovated by means of a loan into what is now known as the Abbey, they were accompanied by that Arts Center, whose director played a large role in the building's renovation. The Abbey thus became simultaneously the home of both the Fremont Center for the Arts and COTA, although they were now two separate entities. The church had a couple of offices, a small chapel, and the rest of the building was shared. The primary public space known as the Great Hall was used by the Fremont Center for the Arts for performances and gatherings, and as worship space for the congregation. Despite occasional tensions, most people saw the Fremont Center for the Arts as beneficial for the congregation. The Abbey, through the Fremont Center 
for the Arts, provided an intriguing way to offer space to people who were not "churchy," and this idea of creating such artistic space for the neighborhood was part of the COTA mission, as Evan noted:

I think this need for mission is something that resonates, and it's the quirkiness of the mission we chose that also feeds not just into 18 to 30-year-olds, but the feeling that something is being done, this [is] work being done that I can feel closely associated with. "This is how I know that this community is good for me, because I'm part of something."

Although this congregation was always deeply connected to its

Seattle/Fremont/Abbey location, not many of the congregants that I interviewed actually lived in Fremont itself. However, they did appreciate the fact that the church was in that particular neighborhood, because some of the hipster, unchurched Fremont folk attended and become part of the congregation.

\section{Wider Church Connectivity}

Lutheran, Anglican, and emerging church families. The COTA congregation had solid mainstream denomination affiliations. Indeed, it was affiliated with both the Evangelical Lutheran Church in America (ELCA) and the Episcopal Church of America, which enabled it to draw from two unique traditions and to have a greater degree of freedom than did congregations with only one denominational identity. Furthermore, as has already been noted, it was also affiliated with the emerging church movement through Carolyn's involvement in conferences and workshops, and COTA's connection with the Northwest Hothouse, an alliance of local emerging church communities.

The shift beyond evangelicalism. During my previous visits to COTA some years before coming to engage in formal data collection, I was struck by the fact that so many of the individuals involved seemed to come from evangelical backgrounds. 
Although during my data collection I interviewed two people who had little church background, or none whatsoever, a far greater percentage of COTANS might not have been the particular niche group — those secular bohemian "postmoderns" [sic]—-that Carolyn had in mind when she started COTA. These were the evangelicals, perhaps the most "churched" of all, that joined COTA. In fact, many interviewees had been, or still were, evangelicals who were rethinking, remaking, reimagining their faith, or else were in the process of letting go of it altogether. Thus people without church backgrounds and ex-evangelicals, along with a handful of Lutherans, Catholics, and former members of other mainstream denominations, were drawn to a church that was intentionally attempting to be a different kind of church, an emerging church congregation in a postmodern world.

Evangelicals incorporate a wide range of theologies and practices ranging from conservative to more progressive. Historian David Bebbington (2003) created a fourfold definition, in which he advances that evangelicals are Christians who hold to the principles of crucicentrism (seeing the death and resurrection of Jesus, as Son of God, as central to human history and individual destiny); conversionism (believing that people need to be born again or converted, which involves a complete change of life); biblicism (having high regard for biblical authority as a rule of faith and life); and activism (either through good works, social justice, or sharing the gospel). Perhaps most commonly they are characterized by a conviction that they need to share their faith in the hope of converting others to their particular form of Christianity.

I became aware that COTA, for many of its participants, provided a way to move beyond evangelicalism. Certainly LGBTQ-identified people/allies had been badly hurt 
by the outright condemnation or ambivalence about their sexual orientations in their former congregations. Yet it was not only LGBTQ-identified people who saw themselves as "recovering evangelicals" or the emotionally and spiritually battered and bruised of certain evangelical streams. Ken, a married heterosexual man explained:

The best thing about it [COTA], I think, is that I don't get angry when going to church anymore, which is nice, "cause I was going to Church and the pastor was just infuriating, and I would spend [the] whole drive home just kind of venting about how difficult I found the experience.

Others were evangelicals who had not had a negative evangelical experience but had found themselves increasingly drawn to the more emerging church and liturgical nature of what COTA had to offer. Of the 18 young adults I interviewed, 15 were former evangelicals. Of the remaining three, one came from a Lutheran background, one had no religious background at all, and one had spent a part of his childhood in a Unitarian Church.

Of the four staff I interviewed, three were mainstream Christians, and one had an Evangelical Orthodox Church ${ }^{17}$ upbringing. Of the seven older adults I interviewed (over the age of 40), four came from evangelical and two from mainstream churches, and one was a former Catholic who had become evangelical before joining COTA. I interviewed roughly one third of congregants in attendance during my month at COTA so these numbers can be seen as a representative sample of the data.

${ }^{17}$ The Evangelical Orthodox Church (also known as the EOC) is a group with roots in evangelical Protestantism which incorporates elements of Orthodoxy (Antiochian) as well as Roman Catholicism, Lutheranism, and Anglicanism in its worship and doctrine. Further information may be found at http://www.evangelicalorthodox.org/. 
It was clearly not only those who were unchurched who might enjoy a more culturally attuned kind of church; many young adults who had grown up Christian were also longing for something in which they could hear "the intonations of their own language." Curiously, both those with no religious background and those who came from more evangelical traditions seemed to have found something deeply resonant in the innovative ritual, and in the Episcopal and Lutheran traditions at COTA.

For many evangelicals the discovery of the more progressive liturgical traditions provided a theological breath of fresh air, a sense of the mysterious, as well as a sustained connection to their former Christian faith. Dylan, who had tried a non-denominational church prior to attending COTA, had found a comforting tether in liturgies that are more traditional. "We hold onto those traditions because the traditions are where we came from. That's why I like being a part of a mainstream church versus a non-denominational church,"18 he explained.

The congregation was sensitive to where individuals were coming from and were careful about what they offered in terms of music and prayers. The music director explained:

I think a lot of people who go to COTA are a little bit wounded from the evangelical church, like the less liturgical, more conservative [church]. And I think we're just aware of that, and so I won't for example go and play some

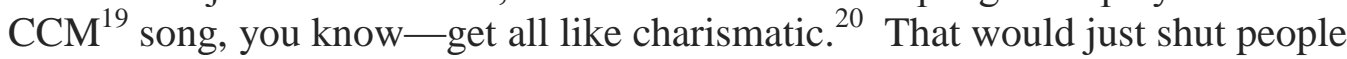
off. So, it's just being aware of, being sensitive to who's here.

18 Non-denominational churches are usually evangelical communities that prefer not to affiliate with such evangelical denominations as the Baptists or Assemblies of God, but may network with other likeminded groups.

19 CCM stands for the contemporary Christian music genre and also for a licensing agency for such music. 
Mega Mill as foil. The mild tension between COTA, a progressive mainstream liturgical congregation on the one hand, and evangelicalism on the other, was encapsulated in the contrast the COTA interviewees constantly drew between themselves and Mega Mill, ${ }^{21}$ a nearby evangelical megachurch that drew thousands of young adults. Three of the four focus groups, two participants, and one of the leaders (14 people in all) raised the issue of Mega Mill in their interviews. When interviewees tried to explain why COTA resonated with young adults, they acknowledged often with some bewilderment, that Mega Mill drew many more young adults than did COTA. Yet Mega Mill had an almost diametrically opposed set of values about the practice of leadership and congregational participation, as well as a very different liturgical sensibility, from the values and sensibility of COTA. Mega Mill was an evangelical congregation with a dominant, fundamentalist pastor (who was later disciplined for his over-controlling style and left). The music program was culturally attuned in that it drew on contemporary music forms and bands, but it was far more professional and polished than the music program at COTA. Young adults, including students, flocked to Mega Mill in droves. Mega Mill seemed to be the local success story in terms of young adults and the church.

That COTA was radically different from Mega Mill was a sharp reminder that all young adults are not the same. Nick explained:

${ }^{20}$ Charismatic Christian spirituality involves the adoption of Pentecostal ways of worshipping in mainstream churches. It is usually more emotional than customary mainstream practice and reliant on supernatural aspects of faith, such as healing and special revelation.

${ }^{21}$ This is a pseudonym for a nearby megachurch that was drawing thousands of young adults into a number of large congregations in the Seattle area, and a couple of other cities, and doing so in a more typically evangelical way. 
They [Mega Mill] try to be culturally relevant in a way that is hip and cool, and it's really, for someone like me, it's really entertaining to see how that happens. The pastors are dressed in cool clothes, and cool haircuts. It's sort of like a video that's put together, the bands are phenomenal, and it's like going to a decent rock show. There's this band, that's been a major band in the last ten years and the girl who sings with them fronts one of the bands at Mega Mill. She's amazing, and, like, it's really impressive and I hate it so much. I know that I'm not gonna like it, yet I'm so enthralled by the machine that is that church, and I have a lot of friends who go there and, like, so it continues to interest me to no end; why people like it and why I don't.

Clearly, where young adults find resonance with congregations is a complex issue and broad generalizations cannot be made.

\section{Creation of Welcoming Space for Young Adults}

\section{Radical Hospitality}

COTANS placed a high value on what they call "radical hospitality," i.e., creating a space that is welcoming to everybody, particularly those who would not usually feel welcome in a church. This emphasis on creating a welcoming space is consistent with the longing and need for community that many young adults feel and express. Those who long to belong, however, want to belong where they can be who they really are. For many young adults, belonging is only real if people can participate authentically without having to pretend to be something they are not.

COTANS prided themselves on the fact that whether in the Abbey during the week, or in the Abbey on Sunday (when the main area, the Great Hall, was transformed into a worship space), there was a sincere welcome for people who were believers and people who were not; for people of all ages, ethnicities, genders, sizes, and shapes, income and mental health levels; for LGBTQ-identified people, and for people who were still figuring out what radical hospitality was, and why it was important. This was not 
only true of those exploring and creating for themselves a religious identity, or moving beyond one, but also of those dealing with complex identity issues around race or sexual orientation. Although I did not gather demographic data on sexual orientation at COTA itself, seven young-adult interviewees identified as LGBTQ during storytelling. Twentytwo interviewees were under the age of 35 , and the other seven ranged from ages 44 to 72. Although most interviewees were Caucasian, among the young adults there were four interviewees of color.

Several interviewees mentioned that COTA was a place where you could be single and not feel marginalized. Logan explained:

I like the fact that COTA is not openly a family church. And for me, being single and being gay, going to a church as a young person where half of the year is not spent on how to be the best husband, and how to like raise your children, and these are the ministry options for your children. And you know, all of the structure of the church isn't around the idea that you are in a family, you have kids, and you're married. I'm not in that category in my life. And that doesn't detract me from being involved in community. I'm not unwelcome just because I'm single.

Logan's point is that when any congregation focuses on a particular demographic, such as young families, it is easy to exclude others, such as singles. Initially COTA tended to draw in more single people, and when some married and started having children, parents in the congregation had to develop a more family oriented service, which then developed into a separate Sunday breakfast liturgy.

The welcome to partnered or single individuals of all sexual orientations was significant for many. For LGBTQ-identified people, finding a congregation that would enable to them to be themselves, and bring their partner, was a relief. Penny, hurt by the 
ambivalent approach to LGBTQ issues in a former congregation, found such a haven at

COTA. She explained:

I left really wounded [by another church] and because of the proximity of SPU to COTA, I found myself, like, coming up here. I could, you know, bus or walk, and I came with my girlfriend. This is the first place that we ever held hands; it was the place that felt safe.

Dylan was particularly glad that the welcome was there, but that it was not the

focus of the church.

And I liked that it was an accepting community of all sexualities but not defined by that. I didn't want to go to any church that flew a rainbow flag or that was their sole conversation because that is not the purpose of church for me.

I heard no desire expressed, at that time, for the congregation to become an official affirming ${ }^{22}$ congregation. In conversation with the interim priest and others, it became clear to me that for young evangelicals just beginning to explore their sexual identity issues, this low-key welcome of LGBTQ-identified folk actually felt safer than a louder, more public welcome would.

\section{The Ambiguity and Ambivalence about Being Welcoming}

There was an espoused desire on the part of the congregation to be a welcoming place, and also a desire on the part of individuals to find a sense of belonging in community. At the same time, there was, on the part of the congregation as a whole, some ambivalence and ambiguity around being a self-consciously welcoming community. Sometimes the congregation members were too wrapped up in greeting and

\footnotetext{
${ }^{22}$ An affirming parish that publicly welcomes and affirms LGBTQ-identified people and that has completed a simple, multi-step process. Once registered, the congregation is listed on a national database of welcoming and affirming faith communities. In different denominations, the term may be welcoming, or reconciling, or some other word.
} 
chatting with their friends to meet and greet visitors. Core members might be traveling, and staff might be busy talking to people or organizing things. I had experienced this benign inattention myself on former visits, so it was no surprise that I heard from several people that newcomers could feel quite alone when few actually took the time to welcome them or get to know them.

I was not able to talk to anyone who had failed to return because they had not received a warm welcome, but curiously, this dynamic of benign neglect was sometimes intriguing to young adults who felt that in other churches that they had been welcomed too ardently. They had experienced the overly enthusiastic welcome as off-putting, inauthentic, or as an unwelcome pressure. It is perhaps only natural that in declining congregations, for instance, when a rare young adult walks in the door, they were welcomed as if the cavalry had arrived.

There is, of course, a sense of ambivalence for many young adults about entering a church at all, particularly if that young adult comes from a tradition they have found stifling, or if they were unsure about what the church might have to offer or might require from them. The juxtaposition of the church's ambiguous welcome, on the one hand, and newcomers' ambivalence around entering, on the other, sometimes resulted in a surprising resonance. Sarah described her experience:

I came and I really liked it, and I also felt like no one welcomed me, because I think it was like around the time everything was kind of a transition, it was the summer, and no one really knew who was visiting and who wasn't. And so, in other churches, you know someone's ready up there waiting to shake your handit's like so fake, and "We can't wait to have you here?" And I'm going, "You don't like me, you [are] just trying to drag me into church." That didn't happen here, [and] because I so badly needed to make friends and was mainly at church to make friends, I was like, "Oh shoot, I want to make friends instantly." 


\section{The Center and the Periphery: A Place to Belong}

Even those who were unabashedly seeking a spiritual home might simultaneously

feel ambivalent about whether or not they really wanted to belong. A young gay man,

Evan, described his concerns around belonging:So, like, I went in certain that it wasn't going to be somewhere where I would feel comfortable. Like I said, I was, "Well, we'll see. They have a cool arts center. They won't really actually want me there, but, I'll go in and say "Hi," and do whatever. And I didn't feel that way-I didn't feel like I didn't belong. And so then I sort of had sort of a breaking-in period when I sort of felt whether I felt ok with the idea of belonging, now that we'd established that I didn't affirmatively not belong [laughter]!

If the center represents those who have found a home, who belong, and the

periphery denotes those who are skirting the edges, feeling marginal and unsure of what they are doing and, often, who they are, COTA sought to gently "hold space",23 at the center and the periphery simultaneously. Evan elaborated on this concept:

There is a sort of space in the center of our community that none of us can hold, or colonize, or claim for our own. And this idea of sort of a center and a periphery-I think in most communities you have the idea of sort of a concrete center, a strong center, and then you get less and less associated as you get to the periphery - I think of COTA as, we're trying to hold space at the periphery.

In contrast to most evangelical communities, where there is an expectation of a high commitment to attendance and connection, and even though the regular attendance of some was essential for the health of the congregation and the participatory nature of the worship services, belonging to the COTA community did not require any commitment to regular attendance. The pressure to push for high commitment was

\footnotetext{
${ }^{23}$ Holding space connotes the activity of creating an impartial, stable, secure physical or psychological context for one or more people to utilize such time and space to resolve whatever they're going through. Ideally, in this space, people can be wherever they are psychologically without judgment, criticism, or blame. The facilitator works from the assumption that the person for whom they are holding space has what they need already to work things out.
} 
resisted so that boundaries could remain permeable. The attendance of many was sporadic for periods of time, as Lauren, now a more regular attender, said about her college years:

You can walk away; people don't get mad, like if you don't show up for a week or for a month or something like that. They're just, sort of, you come back and then you are here again, and, and that's, it's sort of just this, this preserve, like this reserve space that's open, that is flexible, and you can be there or not be there, and it's going to be held.

Daniel appreciated the freedom to come and go during the worship service itself, and the lack of spoken or unspoken rules and regulations about what is appropriate behavior during the services:

I can get up in the middle. You know, I can slide out of the service, if I need to go do something in the middle of the service or whatever, you know, and nobody's really going to pay attention 'cause they're ah, you know, they're not focused on that. Whereas, in a lot of other churches, you know, any distraction, everyone turns around and stares. You know. And I don't know, there's (sic) just not, not as many, there's (sic) not really any rules to it.

Some attendees brought partners who didn't feel comfortable participating in the worship in the circle of chairs that made up the worship space. Madison (a pseudonym) remembered:

We had a, we called it an atheist corner, we had [some spouse who came along, and] then he was like, "Nah," but he kept coming. Mostly because I think [his partner] was there and he could sit on the couch. So this corner grew, and people were just there, part of the service; it wasn't a threatening place for them to be. We just let them be.

Again, as there was in the ambiguity of welcome, there was a kind of paradox at play here. In order to create a sense of belonging, people had to be free to leave and return later, or to leave and stay away, or to stay without believing. 
Numerous people talked about how they eventually knew they belonged at COTA. Various participants mentioned that they thought of themselves as marginal until others explained that they saw them as part of the community; in other words, that they belonged was a bit of a surprise to them. Many experienced a sense of belonging after they were invited to a meal after the 5 p.m. service, perhaps at the pub or a community house. For others, developing a sense of belonging involved little tasks they were invited to do. Lauren, for example, said:

We have a lot of people who are doing leadership fairly humbly, and that's something that's really attractive. And, being invited into that is also something that affirms my place in the community; that I have something to give, that I can belong here. Those, it's those, those other little moments when you're helping do things, too, that you begin to have friendships with people.

Many in the congregation were artistic and/or musical. One third of the young adults I interviewed were part of the music ministry. Making music together, arranging pieces in different ways or composing new pieces was a significant part of why the congregation was meaningful to them and a major source of their sense of belonging. Some congregants also performed at the Fremont Center for the Arts, and there was a team of COTANS called the A-Team that helped set up and take down before and after performances in the Great Hall. This sort of activity also helped individuals feel an ownership of what was happening at the Abbey all week, and added to their sense of belonging to the congregation, and through the congregation to the community beyond the Abbey's doors.

There were also other opportunities to connect in places that were more secular, and on other days of the week. Holding space at the periphery involved providing such ways to connect as the theology pub, or other small groups, where individuals could have 
conversations about spiritual issues or theological questions completely outside of the church environment, and without coming to "church." Daniel, particularly, appreciated these opportunities:

I knew I wanted to get involved in COTA, but I didn't know if I wanted to go to services because I just hadn't had good experiences with services and that kind of stuff, so I didn't know if service was what I wanted to do. Well, I heard about Theology Pub and I was like, "That sounds like fun. Let's go drink beer, hang out with people. Cool."

Some described the tension between the center and the periphery using the metaphor of a whirlpool. Being pulled into the center could result in overexposure and overwork, requiring the person to move back to the periphery or take a break altogether for a while. There has also been a history of congregational burnout, particularly among leaders and board members. Interim priests were working on stabilizing the core of the congregation to prevent such fatigue. Nevertheless, there would always be a tremendous amount of transition because students were constantly coming to and leaving the city.

\section{Conducive to Young-Adult Living}

When young adults are providing leadership in a congregation, they tend to do things that resonate with other young adults. For instance, COTA threw great parties which made it easier for young adults to connect with them. COTA used culturally familiar church holiday parties to build community and engage with the neighborhood. Madison reminisced, "We used to throw a lot of parties; a Day of the Dead party, and a RISE party, we did like a posada. Is that what it's called? That was super fun." Parties and other social events also provided an opportunity to work with local musicians and others to create the kind of space that would bring people together to celebrate life. 
These parties took religious themes like the resurrection, or All Saints Day, and created opportunities to get together and let off steam, as Ethan remembered:

And so I went to COTA and it was Rise four years ago now, and it was a giant party for Easter. It's not anything like I've experienced with, you know, kegs, and dancing, live music. And on Easter, which is when Christians are supposedly happy, so I liked that. That's what told me that I was kinda safe here.

Although the afternoon service time, first on Saturday and then on Sunday, started as a pragmatic way to share space, for many COTANS the afternoon time was part of what made the congregation seem more welcoming than other mainstream churches. They often mentioned the service time as a key factor in why they were there.

For some, Sunday was the only day they could sleep in, and the service was a good pivot point to end the weekend and to start the new week. As Dylan mentioned:

Yeah, I get up early every day of the week and it's like I want to sleep in one day, so it's kind of nicer than coming in early. I like ending my week with church, or starting, I don't know however you want to view that, it just seems very appropriate.

For others, it was part of their social life to meet with their friends at church and afterward. COTA had initially met on Saturday at 5 p.m. and many enjoyed this even more than the late Sunday afternoon time slot, because they could go out afterward with people from church and still have some of the weekend left to rest. Noah explained:

Time of day; that's really big for me. It's just lame having to get up early. I'm not a morning person. I'm not at my best, I'm not at my most thoughtful, or my most able to be open to things, so having in the evenings is a, is actually one of the things I liked most about it when I first came, especially back when it was on Saturday night; having to not really plan things for Sunday night. I'm at the time of my life [when] I don't have kids yet. Friends are very important part. But you know friends really have become a huge part of the support group.

The change from Saturday to Sunday afternoon came about because of the needs of the Fremont Center for the Arts, but the later time of day remained appealing. Some people 
thought mornings would not feel as worshipful as evenings. Zoe explained, "I also cannot imagine being at church in the morning, that doesn't sound like a worshipful experience. It sounds like I'll just want more coffee, and think of what I want for lunch. So the evening, I really enjoy that."

Another common theme was that although the congregation did not demand longterm commitment, it did provide short-term and small ways for people to participate, from the day they arrived. People talked about how they started to feel at home through helping with the breakdown of the worship space, such as putting away chairs, an invitation to read scripture, helping to bake bread for the Eucharist, bringing food, washing dishes, or helping to cook a meal. In summary, then, choosing a conducive time of day, finding culturally familiar ways of celebrating religious themes, and offering small and short term ways to help, were ingenious ways of welcoming other young adults (and others) to COTA's life.

\section{Authenticity}

One of the words I heard most often during my interviews with young adults about COTA, and their experience of being there, was authenticity. This term, in this context at least, seemed to refer to being able to be who they were rather than some idealized person or group. Not "having it all together" was more than acceptable at COTA.

Imperfection acceptable, "coming as you are" essential. Madison was a curious participant at the very first COTA service she attended. She described for me some of the others who came to the very first service: "There's this guy, long hair down his back, earrings, parachute pants, dream catcher tattoo. There's this other kid, long 
hair, plaid shirt. [They) didn't look like they would go into a church. And they were there. So cool!"

From the beginning, the worship involved many different kinds of individuals, and their imperfections were, in fact, part of COTA's appeal for Madison:

It was awesome. It was very unorganized, messy, casual; endearing is the word for it. These people were endearing, really sincere, but they didn't kind of have their act together, they didn't really know what they're doing yet, but really sincere, heartfelt, and I just thought that was awesome. Really Carolyn had a lapel mic and it kept brushing up against her hair. It was funny. She was unaware of it the whole time. The readers would not be quite sure what to read. Yeah, I saw potential in it. I liked how people were really like being themselves, just kind of all out there.

This acceptance of imperfection, some measure of messiness, and the preference for authenticity over sophistication were essential for the fiercely participatory nature of this congregation. These qualities also served to demarcate COTA clearly from the slick sophistication of Mega Mill. Extreme perfectionists and those with a need for control were unlikely to be drawn to COTA. To facilitate high levels of participation, individuals were given a chance to learn, grow, and make mistakes. The fact that most in the congregation found some scrappiness endearing and sincere helped newcomers feel that they too could participate without being embarrassed. Noah explained:

It's really community led. We, we've got the Liturgy Guild. ${ }^{24}$ We don't really do hired guns for, for the band or for worship, you know. It's all like, "This is what we wanna do. This is what gifts we have to offer. Let's do that." And so even when it's not top notch or the best, it means more because we do it, you know.

Another strongly held conviction was that people needed to be able to be authentically themselves. Individuals were welcomed regardless of belief, mood, or state

${ }^{24}$ The Liturgy Guild was a group of congregants who would commit themselves over a Christian season to help plan and implement the weekly 5 p.m. liturgies. 
of mind. There was no need to "put on your COTA face" or be "a shiny, happy person." People talked about being able to cry through a breakup, or to sit on the atheist couch when not psychologically able to participate in worship. While raising one's hands to signal devotion to God was perfectly fine for those from more charismatic backgrounds, it was not required or expected. Eccentricity was appreciated. "I remember when I first started coming," Penny said. “This, like, interpretive dancer man come, and he would just, like, the whole service he would just dance in the corner. And I was like, 'This is awesome!"',

Such idiosyncratic responses during worship time were facilitated by the fact that there was not just one confined area in the sacred space. In the Abbey's Great Hall, there were open areas outside of wherever the chairs were placed that Sunday, including stations $^{25}$ around the walls. There were also comfortable chairs, cushions, a side room, and the steps outside. Through the doors, and also part of the stations, were a library, office, and small chapel. There were no obvious rules around worship practices, and there was plenty of space for some COTANS to be unconventional without being in someone else's space.

Freedom to doubt and question. At the core of this open and welcoming space was the conviction that people needed to be able to belong even if they were unsure about

${ }^{25}$ Originally the Stations of the Cross refers to a series of artistic representations during Lent, often sculptural, typically placed at intervals along the side walls of the nave; or small plaques with reliefs or paintings. The tradition of moving around the Stations to commemorate the Passion of Christ began with St. Francis of Assisi and extended throughout the Roman Catholic Church in the medieval period. COTA has adapted this practice to include different kinds of stations that people can stop at before or after the service or during the Open Space time, to meditate, write, pray, etc. Such stations might include candles and cushions around an icon, prayer beads, a way to engage with a text on the wall by writing on cards, and other similar invitations. 
what they believed, even if they didn't believe in anything in particular, and even if they were angry with God or the church. Noah felt particularly supported by this conviction:

I needed a place to be angry at questions, and be angry at God, be angry at myself. I needed a place to be questioning, and reaching, and trying to find what I would hold on to and what I wouldn't. And I was very hesitant, very skeptical about that. But I kinda felt like every little step that I took, "Oh, that's okay. Oh, that's okay. Oh, that's okay."

During one of the services I attended, a young woman who no longer felt she was Christian and was no longer present most Sundays was nevertheless invited during worship to share her poetry, even poetry about her lack of belief. The result was much appreciated by the COTANS because critical thinking was not merely tolerated; it was valued.

COTA thus provided a safe place for young adults and others to explore, question, and investigate personal and religious identity. Space was created for individuals to hear, encounter, and express their doubts, faith, and questions. In contrast to many evangelical congregations, COTA did not make right belief a prerequisite for belonging. Madison observed:

That's, like, one of the most amazing things about this place. Because in service we're not afraid to talk about what we're not sure of, and it's just like a great place to question, to bounce things off other people. You're not really looked down upon or people aren't guilting (sic) you. So [it is] just a super forgiving, welcoming place.

Here, individuals who had left their more rigid faith traditions had an opportunity to decide which parts of faith they wanted to hold on to, which new things should be tried, and which parts could safely be relinquished. Ethan explained:

I slowly stepped away from the church in my early years of college and, eventually, stopped going entirely. But then I had one of these experiences of faith that was undeniable to me, that was personal to me, where I actually did 
believe the things that I grew up believing - that was so in conflict with the other things I believed to be true - that I was in a rough spot. I couldn't accept a lot of the other things [I had been taught as a kid by the church]. I couldn't just black and white it. "Because this is true, then all this other stuff is true?" So, that put me in a weird spot. And so, when I was looking for a church, I was looking for a place where I could explore that — me in this place of doubt.

To resonate with this aspect of questioning and doubt, individuals who were comfortable at COTA had to have, or had to cultivate, a high tolerance for ambiguity. Fortunately, both the Lutheran and Episcopal traditions, but particularly the latter, not only value good theology and the human intellect, but also theological diversity or what Episcopalians called Anglican Comprehensiveness. ${ }^{26}$ Valuing a diversity of opinion and the ability to freely question was integral to COTA's identity. Young adults at COTA felt they could be authentically themselves, trying on and taking off and then retrying beliefs in order to determine their new identity. For many, COTA seemed to function as a halfway house between faith and doubt, between belonging and leaving. Noah explained:

One of the things that I liked; initially they talked about COTA as the people's last stop at Church on their way out the door. And I was kind of, "You know what? I don't know if I'm quite there, but I was definitely leaning that way at least for this, at this moment in my life." And this is sort of like the, this is the halfway house.

Curiously, despite its tolerance for, and even encouragement of doubt, compared with my own United Church of Canada, COTA was theologically relatively orthodox ${ }^{27}$ using traditional language and pronouns for God, and faithfully repeating the Apostles'

\footnotetext{
${ }^{26}$ Anglican comprehensiveness describes the way the church ideally allows for all kinds of Christians to belong, affably debating non-essentials on the basis of their agreement about basics, although in reality there is much disagreement about what the basics constitute.

${ }^{27}$ By orthodox I mean conforming to the faith as expressed in early church creeds.
} 
and Nicene creeds during worship. The prevalent idea, though, that the whole community together held the creed — that is, if one person was not able to affirm each point, there were others who could do so for them—-provided an anchor that created a great freedom for individuals to question, doubt, and explore their faith, or lack thereof. COTANS created space where it was possible to embrace the mystery and the questions, and, even, as happened in some cases, leave the faith altogether.

Honest congregational conversations. Another strong place of resonance with young-adult congregants was the ability to move through difficult times together as a congregation. This sense of moving together occurred despite strongly held and differing opinions on questions of staffing and decision-making processes. These differences were managed by engaging in honest, thoughtfully facilitated congregational conversations.

My month at COTA in April 2012 coincided with the ending of the interim ministry term, ${ }^{28}$ which had been shared by two part-time priests. I was able to observe a congregational conversation in which the interim priests' time with the congregation, some of the residual anxiety around the reasons for the interim ministry, and hopes and concerns about the imminent arrival of the new priest were discussed. As someone who has either participated in, or served numbers of congregations for over 40 years, I knew of very few congregations where such a conversation could have occurred with such grace, vulnerability, and honesty. The ability of the COTA board both to be candid with the congregation about why they made difficult staffing decisions, and to create a safe

\footnotetext{
${ }^{28}$ Interim ministry often happens when a long-term clergy person leaves, or after a congregational conflict,
} so that the congregation has some time to go through a process of preparation for the next stage in its life. 
space where individuals could disagree and yet listen to each other, was profoundly important to those young-adult interviewees who valued authenticity so highly.

No advertising, gimmicks, or games. Ethan immediately objected when he read question six, in its initial configuration-Why do you think this congregation attracts young adults? - in the interview guide:

Well, there's another issue with the bottom question. "Why do you think this congregation attracts young adults," and part of that is never using language of attracting anyone. We don't attract people-we, we just are. And if what we are is an honest expression of faith, then don't worry about the rest.

Perhaps because of a reaction to the more forceful proselytizing in the evangelical congregations that had once been the faith homes of some COTA members, there was resistance to intentionally trying to bring individuals into the congregation. At this time, there was not even signage on the building to indicate that it was a meeting place for the congregation, although at worship times a COTA sandwich board sign was placed next to the sidewalk at the bottom of the stairs. Apparently, the absence of a sign was not simply because the Abbey was also an art center in a somewhat religion-phobic context. The absence of a sign might have suited the sensibility of a congregation that prided itself on employing an understated welcome and was reluctant to advertise or use other gimmicks to attract people. The feeling was that authentic faith and community were enough to draw in those who were interested. Ethan offered the following analogy:

Yeah, it's the same as, like, the appeal to like monastic life or something. I only use that as an example because the monasteries will never do any marketing, but there are still people who are drawn to that, because it's an honest expression of faith.

Nick mentioned those fatigued by consumer culture to make the same point: 
Now, we are so used to being sold things on television and internet and everywhere, and so used to being manipulated, you know, persuaded, that there's a built-in weariness or skepticism. It is so much more appealing, when you feel like you're not being tricked, you're not being convinced, you're not being persuaded I guess. I think that's really attractive to people.

Penny also acknowledged a secret reluctance to have too many people know about COTA. "We want to be like the hidden gem in the Fremont neighborhood, you know," she said. "It's like you don't want to be Starbucks, you want to be the, like, the independent coffee shop."

\section{Translation of Ancient Christian Wisdom or Rituals}

Each generation has an opportunity to be shaped by and reshape the Christian tradition. Despite all the questioning and theological openness of the congregation, the young-adult participants were longing for ways to connect more broadly to a Christian identity that was not embarrassing. Evan explained:

But, also, we own this Christian identity that's deeper than a lot of us realize, so I think that for a lot of us, what makes us feel that we belong at COTA is not just that we belong at COTA, that we fit in here, but that COTA makes us feel that we fit in with the [wider] Christian identity that a lot of us didn't necessarily feel like we did.

As a counterbalance to the freedom of thought and openness to doubt, COTA stayed connected to orthodox Christian thought through the creedal liturgy and weekly

Eucharistic practice. The consistency of the liturgy (the church year, the lectionary texts, the Eucharist, and open space, and so on) was the anchor that enabled individuals to explore their doubts and questions. Ethan described this as follows:

The liturgy keeps us rooted in a faith that's lasted thousands of years, so the liturgy is important for the realization that the faith is bigger than you as the individual. And without the liturgy we wouldn't see those truths, right - which are important for getting to the other side of doubt. 
At the same time, COTA was a congregation consisting primarily of young adults, and not surprisingly, this was reflected in some of the congregational terminology. Some of the vernacular used and some of the music and dress at COTA strongly reflected popular culture and a young-adult idiom. Announcements during the service were called "Family Biz," the sermons were called "Reverbs" and during one of the reverbs, the speaker likened the resurrection to the Tupac hologram. I never had the sense, however, that this language was contrived. People were not trying to sound hip to make the words more relevant. Rather it seemed that there was simply an idiom that was indigenous to this group. There was an interplay between the ancient liturgy and the present cultural idiom and experience of people that played out in COTA worship. In order to understand how COTA's worship services and culture resonated with young adults, I will look at that resonance as it was reflected through practice, liturgy, participation, Open Space, ${ }^{29}$ the presence or absence of the Bible, and music.

\section{Practice}

I think the way we use the liturgy and ritual provides a space, not just for [ages] 18-30, but for anyone who comes in. It's a very open way, and it's a very Episcopal/Lutheran way, but it's a very open way in which to provide the space, because you're not being told what to believe, you're being given the experience of enacting belief and ritualizing belief.

There was no attempt ever at COTA to use apologetics or persuasion to convince people of the efficacy of Christian faith. Instead, individuals were provided with multiple

\footnotetext{
${ }^{29}$ Open Space has a number other of meanings in our culture, including being an organizational technology for group discernment, but in the context of COTA it usually involves a hiatus in the service for individual reflection where people could stay in their seats, move, or visit various stations.
} 
opportunities to experience Christian wisdom and ritual in real time. The Daily Office, ${ }^{30}$ liturgies written for certain times of the day, could be experienced collectively during evening vespers ${ }^{31}$ in the chapel on Wednesday evenings. A rule of life $e^{32}$ was created so that interested people could live together and explore living it out, sometimes in communal houses. Sacred texts were explored through interactive liturgies. Liturgy was created and shaped by the Liturgy Guild for people to embody. The stations during Open Space helped individuals use spiritual practices like meditation and prayer. The Eucharist had become the central practice and primary metaphor for radical welcome in sacred space, simply through the community experiencing it together week by week. The way that these congregants discovered ancient Christian wisdom and rituals was through the innovative practice of them. Through this practical enactment, tradition was made relevant.

\section{Liturgy: "A Little Bit of Scripted Theater, A Little Bit of Improv” (Noah)}

COTA walked a unique liturgical path that distinguished it both from most evangelical churches and from most liturgical churches. What distinguished COTA from

\footnotetext{
${ }^{30}$ This is an ancient practice that uses daily prayers to mark the times of the day. For Anglicans, this generally comes in the form of the two main offices of Daily Morning Prayer and Daily Evening Prayer. They may be led by lay people and are said communally or individually. Other Offices as set forth in the Book of Common Prayer include Noonday Prayer and Compline (at the end of the day).

${ }^{31}$ Vespers is the sunset evening prayer service in the Orthodox, Western Catholic, Eastern Catholic, Anglican, and Lutheran liturgies of the canonical hours. When I was at COTA one could attend vespers in the chapel on Wednesday evening.

${ }^{32}$ A set of guidelines and commitments chosen for one's life. A rule may be worked out with a spiritual director, or one may follow a shortened or modified version of the rule of a particular religious order. Some people commit to a rule that is basically a resolve to live with a certain disposition of prayer, study, and charity. Participation in the Daily Office is at the heart of Anglican spirituality and included in many rules of life.
} 
more evangelical churches was a love for the full history ${ }^{33}$ and traditions of Christianity (not just the witness of the earliest church) including the seasons of the church year, the four-part liturgy, and certain forms within the service such as call-and-response prayers. Penny elucidated this point, as did virtually every other interviewee, in one way or another:

What really brings me here, and what I most resonate with, is liturgy and ritual. Because coming from like a non-denominational background, coming from an evangelical megachurch, when I started learning about church history, and I started, yeah, when I started tuning into the meaning behind liturgy and ritual, it, like, had fed me in a way that I had never been fed before.

The liturgy, including creeds, the Eucharist, and call-and-response prayers added a sense of formality and gravitas. Noah explained, "I think it's also that there's enough formality in the way we do certain things to make me feel like there's a certain solemnity, a certain majesty in some of these things." On the other hand, what distinguished COTA from most liturgical churches was the informality, playfulness, and experimentation with which the liturgy was engaged. As Nick put it, "I love the liturgy and ritual and the, like, creative spins we, like, put on those things so that they're not stale or dry or repetitive, but really come to life." Instead of simply using liturgy found in a book, a liturgy was newly created for each service around the lectionary texts. This recreating process resulted in a lively take on ancient things, and the people who were drawn to COTA found the slant refreshing. Noah continued:

${ }^{33}$ Numbers of interviewees mentioned that they perceived evangelical churches as viewing the Christian tradition in an ahistorical way. Their former congregations tended to see Christian history as starting with a heroic early church, and then millennia of darkness before the Protestant reformation. Other parts of church history, and tradition in particular, were considered irrelevant, if not problematic.

Episcopalians saw themselves as part of a lineage that could be traced back in a line of succession to the earliest apostles. 
But there's also enough, you know, like the way we do offering is completely bonkers. It's always just like somebody's getting up pounding random off the cuff stuff. ... You've got a blend of those two kinds of things that can make you feel; it's just like you get a little peek behind the curtain maybe. So, you know, there's a little bit of scripted theater; there's a little bit of improv.

The words liturgy or ritual evoke notions of mindless repetition and the boredom that comes from reading set prayers or singing "lame" (Zoe) hymns. Many boomers, during and after the 1960s, had left liturgical churches they considered dead or boring. For Otis, one of the members in his late fifties, COTA's embrace of and approach to ritual was an important rediscovery after spending several decades in evangelical churches, although born into a Lutheran family. He noted, "Ritual had a connotation of being repetitive, and I've discovered here that that's not necessarily the case." That their children or grandchildren find comfort in liturgy and other historical Christian practices might seem mystifying to boomers who left such liturgical churches because they perceived them as lifeless and repetitive. That the appreciation for ancient liturgy is accompanied by the impish reshaping of this liturgy to speak to a new generation might be more understandable. Nevertheless, for the COTA participants I interviewed, tradition was exciting. Evan observed:

We can draw on so many things from Christian history, because COTA has this ancient-future, emergent approach — where we are able to sort of find these mystics and saints and really quirky figures from Christian history-instead of having this evangelical ahistorical approach.

Noah, from an evangelical background, described the way that the innovative take on ancient rituals enhanced his sense of belonging:

So, I was, like, finding ways to mark the things that are important in, in the Church's life. To this day, I think the most moving baptisms I've ever seen have been at COTA. The most moving Lord's Suppers I've ever had had been at COTA just because, you know, we'll do something special, or something unique, 
or something that's just very us, and I'm like, “I'm part, I'm doing this, you know."

COTA's attempts to make liturgy relevant to people's experience could take some interesting turns with experiments that worked, some that failed, and many that pushed the envelope. Penny explained:

I remember when we were having like brownies and milk for communion. The theme was like "Through the Looking Glass" and they were doing all these like Alice in Wonderland metaphors, and people were wearing like Mad Hatter's hats, and I was like "Oh my God, all these people are high! Like, it's a cult!" We dance on the edges of, yeah, I don't know, sacred-profane. We're not really too afraid to play with the ritual that's here.

The experiment Penny described in this quote might startle some more sedate traditionalists who believe that any interference with sacred ritual, as they know it, might be sacrilegious. Yet it was this dialectic between being shaped by the tradition through liturgy, and reshaping the tradition through innovative liturgy that created resonance for these congregants. There was an appeal to things that were ancient which was reassuring in this transient, plastic, throwaway world. At the same time, the ancient was connected to the here and now in engaging ways, as was apparent in this conversation about ancientfuture approaches to liturgy.

Ethan asserted, "I really think that's why people like liturgy. It's the crux of things." I asked for clarification: "Keeping the ancient and the new together?" And he responded, "Yeah. Otherwise, it's just a fetish for old things! There's more than that to it. They're experiencing that they are rooted in something timeless, and I truly believe that it is timeless, it's working!"

Noah explained the innovation - tradition continuum: 
I think the fact that it is both traditional and completely uncategorizable. I think that's a draw. I think there are enough familiar elements for people who come from liturgical traditions that there's something to latch on to, but because of the way we do liturgy, and the way it is very kind of loosey-goosey and you never know what you gonna get, it's always kind of like, "Oh, I'm gonna unwrap the present this week. What's it gonna be?"

Appreciation for the liturgy was a recurrent, almost dominant theme in the interviews I conducted. Some participants came from liturgical traditions; others came from other traditions but became interested in liturgy before coming to COTA; others had to adjust and get used to liturgy, having had no previous experience. Evan described his first negative reaction to the liturgy:

So, then I got here and they were doing sort of the high liturgy, which I don't really like. I don't like the call-and-response, or I didn't. I have come to appreciate it, but I was absolutely certain that this was not how I would design worship, and that was sort of, coming from my background, which had a very prescribed, "This is what you do."

This healthy tension between the appreciation for ancient rituals and the innovation that allowed people to discover them anew created both stability and amazement, keeping people just enough on edge not to get too comfortable (and, consequently, numb to the content). Liturgy was appreciated even more as it was reinvented and reshaped into something that spoke to people in that place and time in compelling ways.

Some Christian congregations I am aware of have two services, one considered traditional for the traditionalists, and one called "contemporary" for those so inclined. In a workshop at Baylor University (Baylor University, 2012), Carolyn rejected this model. Her fascination lay in the simultaneous juxtaposition of the ancient and the new, and the placing of these in contrast to each other in service of the biblical text and theme. 
Making worship the "work of the people." The heart of the practice of making people feel welcome at COTA was an invitation (without pressure) to participate, to use their gifts and time, and be their authentic selves. This was the result of not only the Lutheran and Protestant belief in the priesthood of all believers, ${ }^{34}$ but also a strong belief that liturgy, which is quite often translated as the "work of the people," should be something in which all who wanted to could participate. Liturgy was not a performance that individuals watched, but an interactive experience in which all were participants.

Furthermore, participants were not only those who planned and engaged in the reading of Scripture, or managed the PowerPoint or sound system, or rang the bell, although, as Nick affirmed: "You know, different people are doing the reverbs, different people are setting up the stations, different people are writing the prayers—and that's really important." The liturgy also involved everyone in the room who wished to be part of the experience, not only through corporate singing or call and response prayers, but also through exploring the text or theme for themselves during the Open Space period. This involvement was evident in the way that individuals were actively engaged with the ritual, living themselves into the experience of encountering God. Otis explained, "We try to put ourselves into the liturgy, the work of the people. We declare ourselves to be a people, how can I say, living into the way of Jesus.” Daniel, who attended theology pub more often than the Sunday services, described the liturgy this way:

\footnotetext{
${ }^{34}$ This is the notion held by all Christians, even Catholics, that the priesthood is practiced by all Christians as explained in 1 Peter 2: "But you are a chosen race, a royal priesthood, a holy nation, God's own people." Some traditions may also recognize the ordained priesthood of some set apart for ministry, while some do not have any clergy in order to guard the notion of the priesthood of all believers.
} 
I think there's a difference in COTA. It's more what I call active ritual because, you know, you're part of it. You know, I don't know how many times in my life I've said the Lord's Prayer, but I've gotten more out of it the seven times I've done it at COTA the last two years, or whatever, than I have the rest of the time because there's something about COTA's space and the just the way they do things, that I just seem to hang upon every word of whatever you're saying or whatever you're singing.

Music. The synergy of the music and liturgy, created by the musicians who sign up for particular Sundays at COTA under the guidance of the music director, was a significant dimension of COTA worship. One of the interim priests said, "I would say music is huge. It's probably the single most clear distinguishing characteristic of the congregation. It's also something that a lot of members of the congregation are involved in creating. Yeah, that's, I think, COTA's signature." Music was certainly the most striking thing when I walked into the Abbey on Sundays, and the music I heard seemed very much native to the Fremont and Seattle area. A set of drums, electric guitars, and various other instruments were visible in the sanctuary. It would thus be easy, at first glance, to conclude that COTA had gone the way of the stereotypical worship band in many Caucasian congregations. However, COTA did music differently than any other congregation I have ever encountered. Nick, a musician who did not come from a Christian background, mentioned how much he disliked the typical church contemporary music band, and how different the music at COTA was:

Actually, it's a harsh statement, but I for the most part, abhor [contemporary] worship music. It literally makes my stomach turn. Like it makes me want to leave, step outside for a while, and then come back in when it's over. It is canned and artificial. It feels so unbelievably insincere and discohesive (sic), you know. My experience at COTA has been the opposite. Instead what I feel is, sort of a basic, non-flashy, authenticity. 
In the same way that COTA services bridge the liturgical/non-liturgical divide, drawing from both ancient and future sources, COTA's music also combined tradition and improvisation. Ken explained, "And so it's nice to be able to go to Church where I appreciated the way they did music. It was modern, but yet sacramental." Indeed, music was named over and over again as a meaningful part of COTA worship, often in contrast to more emotionally demanding worship in some evangelical or charismatic congregations. Owen explained:

I don't know what kind of magic we put in the music, 'cause I've always had a difficult relationship with music in churches I've gone to, because [in] most of the churches I've gone to, it's like, you know, you got to get into the music. It's really quite an intense experience. And somehow, the music at COTA just really works. I've even seen Madison take songs that, you know, I've sang [sic] before at other churches, and then we sing them here, and I'm just like, "Why does this feel different?"

The musician who coordinated worship drew from a wide variety of resources in an attempt to serve both the liturgy and this diverse community. Madison described her approach:

We try to do a mix of things, first off, and a lot of hymns that don't sound totally [like] block chords (hums), something for everybody. I do a lot of Taizé; meditative, contemplative. Repetitive music really helps. It kind of goes with our Open Space, free-form of liturgy style I guess. People can just let it sink in. I'm really sensitive to what kind of language we use, "Does it make sense. Do people understand it?"

Madison also commissioned people within the congregation to write songs. She

added:

There's something about singing my friend's song in worship that's so powerful. I do a lot of original music, $80 \%$ maybe. It's either written by community members, or friends of the community, or arrangements of hymns that I've done. About $40 \%$ of the music is original music written from within the community. There are numbers of musicians that are part of the congregation, and they play and offer their gifts for worship in the congregation. 
In her music filing system, she told me she had "Taizé, Hymns, COTA, Church of the Beloved [a new church in a nearby city started by COTA], Chant, "Enter the Worship Circle," and different U.K. friends, as well as "regular songs." She explained, "We do what I call like "regular songs;" I do, like, "Penitent" by Suzanne Vega." Again, rather than blending different forms into some kind of broth, the music brings into contradiction the different forms, sacred and secular, quiet and loud, meditative and rousing, in service of the liturgy and theme. Secular ("regular") songs were used if they supported the sacred text or theme, drawing people into the divine through their own idiom. Noah explained how this spoke to him:

It was an Advent service, but we concentrated on motherhood all throughout Advent. And so we played, we, so Madison started this song, that I found out later was a Sinead O'Connor song. It's a song called "To Mother You." It is amazing. And it was just so much like, "This is, this has got to be a gospel song." But the fact that it came from this other source but fits so perfectly made it mean even more, kind of like, this is - whether they may intend it that way or not - this is totally how, how it's fitting us.

Those who did not enjoy the music were less likely to stay at COTA. For those who liked it, and particularly for those who participated in the music ministry, it became an important magnet. For example, Noah remembered, "That was one of the first things that really got me. Just the atmosphere of the service and how tasteful the music was; I was like, 'Oh, this is great."' He went on to say:

And, you know, I was just really blown away by how well everything was put together. I know you're not supposed to Church shop, you know. But, but it is something that I've come to realize that part of, part of what's important to me is having a way I can express myself that's really meaningful.

One of the volunteer musicians, Ethan, found that the musicians were able to provide an authentic expression of their faith without becoming the center of attention: 
Yeah. The music at COTA is an honest expression of worship. I don't play in worship bands, although I play in a couple of bands. For a long time I would never do that, but COTA's been a place where you don't have to feel like that guy when you do it, you know, so, there's no stage in the front. A lot of times it's in the back. I actually prefer when it's in the back. Because it's not about you, you know.

What was so compelling about the music was not just that it drew from so many sources and was produced collectively by musicians ably led by the music director, but also the way that it served the worship and the theme, flowing seamlessly into and out of the liturgy. Owen noted:

We don't have this extended period of music that you might see at other churches. Perhaps it's the fact that the music just sort of works, you know. Like the Psalms. We might do a song during the Psalm, might do a song during the Eucharist, and so on, so it sort of fits in rather than being a music time. That's, that's one thing I haven't completely figured out: why do I like music here so much, as opposed to other places that I went to.

The music's appeal to interviewees was that it was carried by, and carried the liturgy, enhanced sacred moments, accompanied the Eucharistic prayer, and supported what was happening without ever being intrusive or glitzy. There was no doubt that the music was a vital part of the resonance that these young adults found at COTA. Ethan felt, though, that music alone was not the reason anyone was drawn to COTA it was reflective of a generally more postmodern approach:

People say, "Oh I love the music at COTA, so I keep coming back." I doubt that's why they really do. The church at large can't handle the fact that people don't believe a lot of the crazy shit that they say. It doesn't make any sense. You need to leave space for people to say, "That doesn't make any sense" or else you're basically trying to brainwash them. We grew up with things like evolution in the schools and the height of modern rationalism. And so postmodernity is a lot about the emptiness at the end of rationalism. It is kind of a spiritual awakening; but it doesn't look like "you can't doubt" in a shame-based system of the church. That is in a nutshell why young adults are here. People will say the music, and they just discovered liturgy and those are all pieces of this bigger thing, which is authentic, open, honest, room for doubt. So through liturgical 
traditions and through music and through theology, we find something beyond what we've got so far.

Clearly one cannot take one aspect of the life of COTA, such as the music, and see it as a single attractor. The gestalt is greater than the sum of the parts, and it is also the freedom to question and doubt or to believe, the ability to be both deeply spiritual and deeply rational, along with the embrace of other paradoxes that makes COTA uniquely attractive to the young adults who attend.

Open space. Open Space is not a typical part of most Christian worship services, whether evangelical or mainstream. At COTA, Open Space had been a part of the liturgy from the beginning in 2002. It was a period for individual reflection during the liturgy, often with music playing in the background, and usually about eight minutes long. The way the time was used was up to the individual, but someone would stand up and invite people to a variety of opportunities to encounter the holy that had been prepared beforehand. It often took place just before or just after the reverb. Individuals in the congregation could stay still or move about and reflect on, or in, a number of stations around the Abbey. They could pray, engage more deeply with the theme, or take a break. Madison, who was at the very first service, expressed her enjoyment of it. "Open Space was [an] awesome, mind-blowing experience for me," she said. "Just to have a pause in the middle of a service, and go about the space, go and get a cup of coffee. Yeah, I just thought that was so cool." Different modalities were used to engage different personalities or needs during Open Space time. Stations that were set up for Open Space activity that I encountered during my time there included walking the labyrinth, praying with icons, and literally shredding (in the office) written records of mistakes and flaws. 
There was also usually a station where people could engage in very specific ways with the text or themes for the day. For example, on "Doubting Thomas" Sunday, at one of the stations, individuals were invited to write down an expression of doubt and slip it into a box. They were given notice that these would be read during the prayers of the people. The anonymous expressions of doubt were very honest and vulnerable, variously describing doubt in oneself, in God, in a relationship; each statement reflected the very real life circumstances congregants faced. During the prayers of the people, these expressions were read, along with the refrain, “O God, I believe, please help my unbelief." This was an extraordinary meeting of the real vulnerabilities of people with the strength of a prayer that acknowledged the sense of vulnerability, and yet provided a common affirmation of each person's reality and a hope for a different experience going forward. For COTA congregants, it was about being authentic, open, and honest. As Noah explained:

We have Open Space and people have, you know, like a piece of paper on the wall where they can write something that's meaningful to them or something really good about the reverb. And you always got such a mix of platitudes, and Scripture, and direct quotes, and quotes I've never heard of, and really dark places, and places that are shot through with hope. It's always just like a, it's just like a buffet of human emotions.

Some had to get used to this different aspect of a service. Fred noted:

When I first came to COTA I found it to be annoying and just disruptive in the context of the service and now I value it tremendously, and partially because it's a time when I am given place in the service to just do it. Like the rest of it isn't imposed. I mean like I can sit there and reflect on what has just been spoken, take care of what I need to take care of.

For some, the Open Space might be more mundane: a time to get a cup of coffee, or take a breath, or stay right in their seat. Nevertheless it was deeply resonant for many. 
Bibles absent yet present. There was a recurring joke at COTA that there were no Bibles to be found in the Abbey. Individuals did not bring their Bibles with them to church, a practice typical in most evangelical congregations. There was a different approach to Scripture than in churches where Bibles are treated as a manual for living.

As Makayla explained:

Many of us have come [from] where you would never go to church without your Bible under your arm, and now, if you're that type of person, you'd feel uncomfortable at COTA. And nobody tells you to turn the page to 1 Corinthians 13 in your Bible.

Logan also compared COTA to his former experience:

Coming from a very evangelical background, I was thinking that the Scripture is very present - more present in our liturgy, and there's more reading of Scripture, I think, than you'd ever absolutely get in an evangelical setting, but on the flip side, what I was thinking about the absence is, is there's almost this absence of the [idea] that the Bible is the reason we're there, like that we have to have every little thing that we're doing, like proof texted, and that you should bring your Bible with you to every service. There's almost an absence, like, of the worship of the Bible, but also there's a deeper presence of the Scripture in our expression of the church.

The liturgy during Sunday services was drenched with Scripture, including four

Bible passages read most Sundays, but the Bible was not used to keep people in line, or exposited line by line, as Penny described:

I remember one time I was sitting around with a group of people in this room and we were like "Well, we should look that up in a Bible." And we're like "Ok, where are they?" We had to like go try to find one. Yeah, so I think that for some folks who have been deeply wounded by the church that not having like a three point sermon where it's like "This is what the Scripture means and how we live it out in point one, two, and three," with clearly defined, you know. There's not that kind of preaching in front of a pulpit. People feel less intimidated when there's, you know, there aren't Bibles visible.

The Bible was instead something that people engaged with in very interactive ways, particularly in the Open Space. For example, one Sunday the text from Matthew 
15:27 onward was used about the woman who argued with Jesus when he initially refused her request to heal her child, inexplicably calling her a dog (a gentile). The woman challenged Jesus and told him that even dogs were able to receive the crumbs from under the table. Lauren described the liturgy:

There was like a bowl of crumbs, and you were supposed to take a crumb, and take it up to the altar. And then, Carolyn took that down, and then like replaced it with the elements. And then we did Eucharist. So there was like this, interplay between Open Space and Eucharist, and like the, the lectionary text and all this stuff, and it was really great, really powerful, and I was like, "I like this way of playing with [the text]. It was the first time that I really engaged with one of those open stations, because they tied it to the Eucharist ritual, but I think we try to do that, we try to do that, we try to play with ritual as we share space together.

This different approach to Scripture, interactive and open-ended rather than Scripture-asrule-book, was very appealing to those who had experienced the Bible in oppressive ways. This approach was, I believe, a powerful factor in why young adults resonated with this congregation.

\section{Leadership}

COTANS enjoyed the fact that there was no individual leader visible during services. This was likely due to the fact that Carolyn understood the priestly role as that of curator. Rather than being a focal point, her perceived task as priest was to facilitate an experience of God for congregants, much as an art museum curator created an experience of art for visitors.

A curator, Carolyn argued, is not necessarily visible when people are having the experiences that the curator arranges. Carolyn's unique ability to create time and space for others to shine was seen by Frank and others as a large part of why young adults found resonance in this congregation. Carolyn not only made space for young adults to 
be the leaders of the congregation, but also, in various subtle ways, required it and provided numerous ways for this to happen. Clergy leaders were not there to "pull the strings," but to help the group move forward together. Lauren explained:

Within the church, people have a place and a role, like you know who to ask for certain things. Some people have more information than others, but we don't have the sense of anyone pulling the strings. We don't want someone who is running the show, and that has a lot to do with our sense that we are all at this place and time and history, so there's leadership and responsibility is really dispersed, and everyone can be really independent and still give to this community.

During the month I spent with this congregation, there was never a single "upfront person" (clergy or lay) at any of the worship services, meetings, or other gatherings. Usually, while there was organization behind the scenes, different individuals took on particular roles (inviting people to the open space time, making announcements, announcing the offering, reading, doing the reverb, and so on) momentarily within any particular service, and then simply merged back into the group. I had attended a couple of services years before and noticed this phenomenon, so I knew it was not new. The only time one saw the priest seemed to be during the sacraments, such as the Eucharist and baptisms, which traditionally have to be performed by an ordained priest.

Some individuals had a strong negative reaction to the notion that leaders or a leadership style might have something to do with why young adults were there, or that leaders were interested in attracting young adults. This came up most often when we reached question \#5 in my interview guide-Can you tell me any stories of how the leaders of this congregation helped/help young adults feel at home here or met your needs? - Interviewees objected to the idea that any kind of leadership, particularly the leadership of one person, would play a role in why they were there. As Lauren put it, "I 
think we have, like, sort of an innate distrust of leadership and dislike of people calling themselves leaders here." The very practice of leadership at COTA, as experienced by the interviewees, led to a rephrasing of the question so that it de-emphasized leaders. I changed the question to "Are there any aspects of how leadership is expressed or not expressed at COTA that resonate with you?"

The intensity of belief that leaders were not important to why people were in the congregation, and the notion that leadership was something everyone possessed, could partly have been the result of the particular situation in which the congregation found itself. The congregation and the leadership were in a state of flux. Their founding priest and their community architect, who fulfilled visionary and developing roles respectively, had left, in what had been a difficult process for all concerned. There were two interim priests, both on a part-time basis, and COTA's incoming priest was to arrive in a month. Numbers of individuals who had played significant roles had come and gone, and a few of the significant lay people were about to enter the priesthood and move away. As a result of all these factors, the congregation's members had taken even more ownership of their life together than usual and were very much enjoying their sense of dispersed leadership. One of the interim priests quipped at the Rise Party - a time of celebration Easter and of the previous year - that it was hard for a priest at COTA to figure out what exactly their role was, since congregants did almost everything.

On the other hand, for Dylan, this lack of an observable single authority figure took some getting used to, and needed some explanation:

Yeah, now it's what I appreciate in a sense, but at first it threw me off, and I sat down with Kenneth who was the architect here, and we had a conversation over a beer - and I thought "Wow, having a beer with a church person is kind of cool 
too," because coming from my background I just didn't— but we talked about what her [the lead priest's curator] role was, so when I finally understood what was going on, the conversation made sense, but as a newcomer it was a little bit [of] "where is my focal point?" and I didn't understand that. "And where is the authority or the accountability?"

One of the newer people, Theresa, who attended a focus group and had been part of the formal congregational conversation the previous Sunday about the imminent arrival of the new priest said:

You know, that's one of the things that impressed me was the way the leadership is just spread all around. It's not all focused on clergy, the priest. Everybody's giving the message. So I was happy to hear at that community meeting that people didn't want to lose that.

Although I did not interview Carolyn, I was able to transcribe a couple of interviews and lectures she gave that were in books written about the emerging church and posted on the Internet, and we did have a brief email correspondence. In this material, she identified a couple of realities that played into COTA's dispersed leadership sensibility. First, she was a self-proclaimed "true introvert," and not particularly interested in being the person at the forefront of the congregation's life. Second, she had strong theological convictions about leadership. One was the notion of "the priesthood of all believers" which meant that the both the priesthood and the Bible belonged to the whole community, even if the sacramental authority was held by an ordained person. The other was the curatorship metaphor, a metaphor that encouraged leaders to make sure that an experience happened for others, rather than seeking a visible central role themselves. 


\section{Dispersed Leadership}

Penny affirmed that COTA was a place where dispersed leadership was practiced. There was, in fact, a strong sense that everyone is, or could be, a leader in the congregation. There was no need for someone to be an expert or experienced before they could try something. Young adults took leadership in every sphere and learned on the job. Individuals were free to experiment, start things, make mistakes, and learn from them.

Leadership in the Episcopal Church is often less dogmatic or directive than in many evangelical churches, although more so than in my denomination. Homilies or reverbs have more of a devotional or inspirational focus than a directive one, and at COTA, this tendency was taken even further. The liturgy itself, with its various parts, tended to disperse people into a variety of roles, mitigating the need for a single leader. As mentioned earlier, individuals were not told how to think or act as much as encouraged to think for themselves and make their own decisions. This leadership style allowed young adults to develop their own beliefs, values, and identity and their leadership skills. It was helpful in making young adults, particularly recovering evangelicals, feel at home.

The Lutheran side of the congregation, from which the founding minister originally came, had from its inception strongly valued the idea of the priesthood of all believers. In the second week of the "orientation" class for new members, the question was asked, "How do you feel about being a priest?" That you understand yourself to be a priest was an expectation at COTA. 
Finding and freeing the right individuals to take on roles. According to many

I interviewed, part of Carolyn's genius was the ability to woo individuals into

participation in the congregation, and to empower them to take on particular roles in keeping with their gifts. The best example of this was her mentoring of the young woman who was just a college student when they met, and who later became COTA's music director. Madison remembered:

I was just sort of like a lot younger at the time. Things were happening fast, and I was drawn to [Carolyn]. She dreams. She's a dreamer. Yeah. She also really trusted me and empowered me to do my job. [She] didn't micro-manage me. She always was like, "There's this that you might want to do, but I'll leave that up to you." She always gave me the last word on music stuff. And at that age, just being fresh out of undergrad, I think I was really lucky to have this mentor empowering me like that.

This courage to give responsibility and authority to young adults to try things, to experiment and to learn, seems to have been a major force in creating this young adultfilled congregation.

Let the one who thinks we need something start it themselves. The role of leaders was seen to be not one of control, but of theological accompaniment, particularly in inspiring others to do things. COTA preferred more organic or laissez-faire organizational development. Rather than officially designated leaders starting and driving various groups and ministries, congregants were encouraged to imagine and start things based on their own energy and gifts, as Owen described:

The other thing that Carolyn would say a lot is if you have an idea of something that the church should be doing, do it. Don't wait for the church to start it. A lot of people come from evangelical backgrounds here and wonder why we don't have small groups here at COTA. Well it's like if you want one you have to start one, and I remember thinking "Well I don't want to start one, so I guess we won't have any at COTA, so let's just see what happens." Then when I heard other 
people were gonna try it out, I thought "That's the energy, that's the spirit, and that's how things happen here at COTA!"

No sole preacher, non-doctrinaire: The case of reverbs. Something else that was rather unusual about COTA was that preaching was not predominantly the domain of the clergy. Throughout the times I spent at COTA, whether during data collection for this research or previously, I heard only one reverb by a clergy person. Because the service was so experimental and experiential, the reverb was not the focal point of the service as it was in many mainstream and evangelical congregations. What was shared was simply seen as that person's point of view, and simply because they had that point of view did not mean others needed to share it.

Carolyn had the idea that "the Word of God belongs to the whole people of God, not to a few experts" (Red Herring, 2006). Thus the "reverbs," the sermon-like reflections, were offered by individuals in the congregation, who did not exhibit any need to convince anyone to do or believe anything in particular. As Dylan explained, "You have to realize that you could learn from others but you have to know what you really truly believe." Daniel added:

I always thought it was weird that there wasn't the one guy that stood up and talked at me for 45 minutes, but I think there's more preaching done in the hour and a half at COTA than there ever has been in 45 minutes every Sunday that I listened to someone else get up and talk, because I'm more engaged. I'm more interested in what's going on. You know, it's not like a lecture. I'm actually involved in becoming part of the preaching, so I've gained more from the COTA services than from the white dude that got up there and tried to be hip (laughter) and dissect three Bible verses for 45 minutes.

The reverbs, or the preaching of Scripture, were not the focal point of the service, even though the liturgy was built around the lectionary texts for that Sunday. The Eucharist was the focal point, and there were numerous parts of the journey during the 
service on the way to the Eucharist. There were so many ways to engage with the

Scripture text/theme during the liturgy that if the person doing the reverb did not do so in a way that spoke to someone, it did not matter all that much.

\section{Not a Rejection of Leadership}

The reluctance of the congregation to attribute the presence of young adults in the congregation to the charisma of a leader did not mean that clergy leadership was not appreciated. Nor did it mean that clergy leadership was disempowered. Ken explained:

I do think there's this level of [congregational] engagement [that] is important. And the level of organic engagement is important. If it is too top down it doesn't work. And yet we need the guidance and administration of a pastor. Just hope that we are gaining that soon. It's, it's a tricky balance.

There was much appreciation of the gifts of Carolyn in visioning, making things happen, and raising funds to get things going, freeing others to explore and find their gifts, being a "theological center," and so on. The interim priests were also valued for their role in stabilizing the congregation and getting some of the chaos of a church startup sorted out. As Nick observed:

It's not to say that there can't be someone, a particular person, giving you the input, or giving you thoughts, or whatever. I mean, some of my favorite moments in there were some of those reverbs given by the interim pastors, preachers, priests, whatever it is. So it's not as if I feel like you can't have someone giving you ideas, or giving you their take, or telling you things about, the Bible or Jesus, or Christianity, but it's the way that you do that.

Longer-term members I interviewed reminisced about Carolyn's visionary and rainmaking capacity, which brought the congregation into being. Fred was one of a several interviewees who talked about how he missed having her in her role as the "theological center" when she left, and he went on to say: 
She had a gift for attracting very talented people to her because she gave them the space to shine. So she had a vision. She has a deep understanding of the Christian tradition but is Lutheran in the sense that she loves paradox. So she's doing this paradoxical thing like taking this ancient faith and making it modern.

Clearly, without Carolyn's love of paradox and contradiction, her understanding of postmodernity, ancient-future liturgy, arts and culture, and ability to make space for others to discover their gifts and ministries, the congregation would not have existed. Similarly, other leaders were appreciated for their particular gifts and administrative skills. The music director had been part of the congregation from the start and was a significant part of the health and ongoing life and ethos of the congregation. While she was clearly an integral part of the musical experience at COTA, like the founding priest, she did her work as a servant leader, empowering the gifts of others.

The dispersed leadership style of COTA continued even after Carolyn left. Perhaps fortuitously, this brings into clear light her vision of leadership, which she (Ward, 2010) described in this way:

When all is said and done, the greatest test of leadership is what happens when the leader is not around. Instead of cultivating a culture of dependence, a leader cultivates a culture of apprenticeship, which calls for leading something while others observe, leading it with others, having others lead it while you observe, then going on your way to apprentice others who will go in peace to love and serve the Lord. (p. 173)

In summary, the leadership at COTA was fiercely egalitarian and dispersed. A founding priest, who had seen herself not as person up front but as a curator behind the scenes, had reinforced in the congregation a strong sense that they were the leaders. Her task was to be a theological center that enabled others to discover and use their gifts within the liturgical traditions of the Lutheran and Episcopal Churches. 
Rather than a centrally controlled organization, COTA had a more laissez-faire approach to leadership. If someone wanted to try something, they were encouraged to do

so. If it did not work, it could simply wither. Numerous people preached on Sundays, no individual, clergy or lay, led the whole service, and there was a strong sense that the congregation together, rather than some individual, was pulling the strings. This did not constitute a rejection of ordained clergy leadership, who were seen as valuable assets. Leadership was valued as long as it was at the service of empowering others.

\section{Conclusion}

A postmodern approach to the divine and a love of paradox led to the formation and continuation of a congregation, COTA, in which contradictions were relished. The toughest location in the country to start a congregation was chosen to do just that. Two liturgical traditions were called upon to host a completely different, postmodern kind of church that would be simultaneously creedal and orthodox on the one hand, and progressive and freethinking on the other. Belonging was possible before and without believing. Welcome would be radical and yet (perhaps unintentionally) ambiguous, and worship would embrace the ancient and the new, the majestic and the playful.

Leadership would be dispersed, yet clergy would have a major, though indirect impact on the congregation. Young adults were the engine of this congregation despite the transitional condition of their lives. The various aspects of the ethos of the congregation converged with the developmental identity work of young adulthood, and a profound resonance occurred. Ingenious leaders behind the scenes planned some of it, some was co-created by participants, and some, COTANS believe, was simply the result of some sort of mischievous divine intervention. 


\section{CHAPTER 5}

\section{ST. PAUL'S: A VIBRANT, PROGRESSIVE ANGLO-CATHOLIC PARISH}

St. Paul's Episcopal Church is a vibrant and progressive Anglo-Catholic parish ${ }^{35}$ in Uptown Seattle. It was a surprise to many in the diocese ${ }^{36}$ when, after the arrival of the lead priest Mother Vanessa (a pseudonym), a significant number of young adults began attending. I spent a month at St. Paul's, from May 20 through June 20, 2012, engaged in participant observation, document analysis, and interviews with individuals and focus groups in order to discover and describe those webs of significance that were spun by the parishioners and leaders in which young adults found the "intonations of their own language." The data generated were infinitely rich and thick. In a parish so woven together by countless nuances, subtle (and not so subtle) processes, and intriguing individuals, endeavors to sort or categorize the data seemed contrived and reductionist.

The first research question, "What aspects of leadership and translation, if any, were/are exercised to create welcoming space for young adults, and make ancient Christian wisdom and rituals relevant to them?" and the second, "What kinds of resonance, if any, emerged between the leaders and the group (both individual participants and the whole congregation)?" provided the framework for this findings chapter. The young-adult participants' experience of resonance with St. Paul's — as

35 The word parish is used primarily by Catholics and Episcopalians to describe 1) the whole local faith community with all its various worship services and ministries, or 2) the entire neighborhood/community served by the parish. In this chapter it refers to the entire St. Paul's church including the various worship congregations that met at different times, but it does not refer to the neighborhood.

36 The Episcopal Diocese of Olympia, also known as the Episcopal Church in Western Washington, is a diocese of the Episcopal Church in Washington State west of the Cascade Range. It is one of 17 dioceses and an area mission that make up Province eight, one of nine provinces in the U.S. 
discovered directly through interviews and participant observation before I did the review of the literature-will unfold under the following headings: (a) context of the parish, (b) the translation of ancient wisdom and rituals, (c) the creation of welcoming space, and (d) leadership. The third question pertaining to "What kinds of associations, if any, exist between the narratives of participants and theory about the developmental and maturational work of young adulthood?" will be addressed in chapter 7 where I will bring the study data into dialogue with the literature. I will write in the past tense so that it is clear that what I experienced and learned was true at that time. The parish may have moved in different directions since then, particularly since the lead priest was elected as bishop in a different diocese.

I had never heard of about St. Paul's when I decided it would be polite to get permission from the Episcopal bishop to spend time with two other Episcopal communities in Seattle that I had then selected for the study (one of which I did not include in this dissertation). He generously gave his consent but since I was interested in congregations that resonated with younger adults, he encouraged me to also study St. Paul's Parish.

St. Paul's was an Anglo-Catholic ${ }^{37}$ parish, with elaborate worship rituals and practices. All services were, as Mother Vanessa said, "High Church kicked up a notch." There were four services on Sunday; three of them in the morning, and each one with a sung liturgy had a young-adult presence. The service with the most young adults in

\footnotetext{
37 "Rooted in the retention of Catholic Christianity within the English Reformation, Anglo-Catholicism emerged as a dissident movement within an 18th-century church that had so absorbed the rationalism of its time that it had lost sight of the importance of the sacraments and of the centrality of an experience of awe and wonder in the spiritual life" (St. Paul's Profile Committee, 2014).
} 
attendance, though, was the Sunday 5 p.m. service — which, although still Anglo-Catholic in its form, had a circular seating formation and a more participatory feel. Ironically, the entrance to the more "accessible" evening service downstairs could, as I discovered, be a little challenging for newcomers to locate. St. Paul's was not doing most things that others thought would draw young adults; there were no overhead screens or catchy music. In fact, they were the most "High-Church" parish in the diocese.

\section{Context}

\section{Location}

St. Paul's was started in 1892 as a log cabin church in Queen Anne's. In 1903, they moved to the present location within walking distance from Seattle's Puget Sound and the waterfront (known for the Pike Place Market, ferries, cruise ship docks, and various other tourist attractions). The parish is an integral part of the Lower Queen Anne Seattle neighborhood, or Uptown, which is distinct from the wealthier Upper Queen Anne neighborhood up the hill. The Seattle Center and its famous Space Needle border the Lower Queen Anne area to the east. Consequently, theater, opera, and ballet performances, concerts, sports events, ethnic celebrations, and all-city festivals take place in this neighborhood, bringing a diversity of people to the area.

Although the residents of Queen Anne are predominantly educated, white, and single, with a median age of 35 (St. Paul's Episcopal Church, 2012), Lower Queen Anne is a gathering point for a more eclectic mix of people. The varied assortment of people is reflective of other mixes that characterize the area: fast food, local, and fine dining restaurants; high-end apartments, other apartments, subsidized housing, and assisted living facilities; and meeting places for students and busy professionals. There were 
small percentages of unemployed people and homeless people also living in this community.

College-rich neighborhoods. Queen Anne is also home to Seattle Pacific University (SPU) and is not far from the University of Washington (UW, or less formally U-Dub), the Seattle School of Theology and Psychology (the Seattle School), Seattle University (SU), and Northeastern University (NU). Many neighborhood residents are students from these nearby colleges and seminaries. This college-rich environment provided St. Paul's with a rather large pool of young adults, some of whom might be seeking a congregation. Local higher education institutions employed some of the church's leaders, clergy and lay. Mother Vanessa, the lead priest, taught preaching parttime at the Seattle School, and Quinton (a pseudonym), the lay pastor for the afternoon service, was one of the deans of the Seattle School. Other lay leaders taught at various colleges. Numbers of students from SPU attended morning services. Relatively large numbers of the students from the Seattle School attended the 5 p.m. service.

St. Paul's and the city. Part of St. Paul's appeal to young adults was their perception that this Anglo- Catholic parish was also innovative, progressive, and engaged with the community. The mission of St. Paul's deeply connected the parish to their Seattle/Queen Anne location. They had moved from their log cabin building in 1903 when they purchased and built on the present property. According to Mother Vanessa, the Rev. John Lockerby, a former priest at St. Paul's began serving in the late 1950s; a time when the parish had planned to sell its property in Lower Queen Anne and build a new building on a property they had bought in the more affluent Upper Queen Anne. Rev. John Lockerby's belief, she said, was that "the parish should stay closer and more 
urban in its feel, grittier in its connection" to the world beyond the church doors. Therefore, the congregation sold the land it had purchased "up the hill" and stayed in Lower Queen Anne. The current parish building was constructed at the same time that Seattle's Space Needle was developed for the 1962 Century 21 Exposition or World's Fai According to Mother Vanessa, the parish sought "to reflect a certain kind of spirituality for a new time; the engagement of an Anglo-Catholic high liturgy cast into a more modern context — that was the intent." The juxtaposition of the ancient with a progressive present became an identifying aspect of St. Paul's and was almost certainly one of the characteristics that made it so appealing to those who opted to become part of the parish.

This commitment to ministry in the midst of the city had taken a number of forms over the years. In the prevailing climate of prejudice and fear in the late 1970s and 1980s, long before other congregations were willing to do so, for instance, St. Paul's offered church funerals and support for the loved ones of those who had died of complications from HIV/AIDS. This decision drew a substantial LGBTQ-identified community to the parish, and the church even became, for a time, known in the city and the diocese as the gay church.

A significant architectural change in recent years also illustrated St. Paul's commitment to being in the city. A renovation was completed near the end of 2011, after which the narthex ${ }^{38}$ opened onto and was visible from the street, and on the side of the

38 The narthex is an entrance at the one end of a church just in front of the nave (the main area). In the case of St. Paul's, it is the area where baptisms take place and from which processionals begin. 
building there was an outdoor labyrinth ${ }^{39}$ open to anyone- - tourists, locals, parishioners.

The commitment of the church to the neighborhood was also exemplified in its once

monthly "Fatted Calf" meal. This restaurant-quality meal was open to anyone;

parishioners and hungry community folk sat down to eat together as one community.

This and other connections to the neighborhood were important to young adults coming

to St. Paul's, as Mary explained:

I know that this little spot right here in lower Queen Anne, we're in the center of everything. It's not upper Queen Anne. There are a lot of really wealthy people who live on this hill, but down here, you can also reach out to the people who are not wealthy. They don't have much at all, and I think that's a part of St. Paul's identity, and it's something that I personally have really a big heart for.

The story of St. Paul, whose name the parish bore, heightened their commitment to being a city parish. A parish called "St Paul's Church"- - which was almost always abbreviated as "St. Paul's" — could, because of certain problematic New Testament letters attributed (rightly or wrongly) to the biblical writer St. Paul, suggest a place that was uninviting, legalistic, and misogynistic. This parish, however, had identified a different strand of the Pauline tradition in adopting the name. Mother Vanessa referred to the story of the conversion of Paul in the book of Acts:

You know, some people say, "Well, why St. Paul?" Well, many parishes were just named, mindlessly, St. Paul, but he [Lockerby] was the one that invested the parish's name with the biblical passage when Paul became blind and was told to go into the city and he would, you know, meet people and all. So he, he used that passage "Go into the city and you will be shown what you are to do." And so, man, I want to build forever on that one.

39 St. Paul's Centennial Garden Labyrinth is modeled after the medieval original that was inlaid at Chartres Cathedral, France, in the early 13th century. It was the first accessible permanent outdoor labyrinth within the city limits of Seattle. It is a maze-like but flat walking path that takes you through complex twists and turns into the center and then out again. It is meant to provide the support for a walking meditation. 
This instruction to the apostle to "go into the city" where you would be "shown what to do" was understood as the heart of a divine mandate to the parish. The decision not to go up the hill was thus an integral expression of St. Paul's identity as an urban spiritual refuge, deeply embedded in Seattle's Uptown area. The way the parish had both historically and architecturally followed this mandate was a source of pride to the youngadult interviewees, and at least a part of St. Paul's appeal to them.

\section{Mega Mill as Foil}

Just four miles away there was a well-known church drawing thousands of people, young adults in particular, to this and its other "campuses" in the city. Mega Mill $^{40}$ (a pseudonym) was an evangelical congregation with a dominant biblicist pastor. The excellent music bands were "culturally relevant" 41 and young adults flocked there. Mega Mill seemed to be the local success story in terms of young adults and the church. Individuals I interviewed constantly drew a contrast between St. Paul's and Mega Mill. Just as mentioned in chapter 4, there was at St. Paul's also a droll acknowledgement that Mega Mill drew thousands more young adults than did St. Paul's and yet had an almost diametrically opposite set of values when it came to leadership style, participation, and liturgy. Cameron described the difference between what he perceived as the gentle, humble, dispersed leadership style of St. Paul's, and what he saw as the loud, heavy-handed, rigid, authoritarian leadership of the lead pastor at Mega Mill:

40 This section on Mega Mill and evangelicalism is repeated in both findings chapters for those who are not reading the dissertation chronologically, so that each chapter can stand alone.

41 The pastor of Mega Mill cautioned between twin pitfalls of being so culturally relevant that you lose your message or being so culturally irrelevant that you lose your mission. He tried to combine a strongly conservative theological message with culturally "hip" means of communication, e.g. worship music bands, clergy wearing jeans, etc. 
It's interesting though, 'cause [the leadership style] is what keeps me here, but I know so many of my peers are drawn to the opposite, and that's why so many $\mathrm{SP}[\mathrm{U}]$ students go to [Mega Mill]. There's something that's very comforting when you're in a time of transition or doubt or growing up to have someone give you answers, and to tell you how it's gonna be. I've had so many conversations with people about Mega Mill. I think that that's a huge reason that students go there and that young families are there, because they want to be told [what to do and think].

If I was ever tempted to make generalizations about what attracts young adults to congregations, this contrast between the two congregations would set me straight. For those drawn to St. Paul's, the ways ancient Christian wisdom and rituals were translated found resonance with young adults, and it is to this translation that I will now attend.

\section{Translation of Ancient Christian Wisdom and Rituals}

St. Paul's was deeply connected to the Episcopal Church within the Anglican tradition, which according to one of the lay leaders, Nigel, "has always sought the middle way between Protestantism and Roman Catholicism, and that at its best tries to hold both to tradition and innovation." The Episcopal Church in the United States is part of the worldwide Anglican Communion and tends to find unity in being a large extended liturgical family. This unity takes place not as much around a shared theology (there have been significant theological divisions in the denomination since its founding in the sixteenth century which span the range of conservative through progressive) as it does around liturgy, particularly the Book of Common Prayer. ${ }^{42}$ Some young adults

42 The Book of Common Prayer is the official worship book of the Anglican/Episcopal Church, initially created by Archbishop Cranmer in England, and rarely changed. It contains liturgies for daily and weekly worship and other rites. Parishes largely use these liturgies, along with some other approved liturgies, without alteration. 
appreciated the connection with a wider body of people than the parish, the unity-inliturgy that characterized the Episcopal Church. Quinn explained:

St. Paul's is who it is because it is so connected to every other Episcopal Church. I mean you go to any other Episcopal Church and it's going to be doing the same Scripture. It follows the church calendars, very rhythmic, very seasonal and, so, you're connected to so many others, the body, as it were, in that way.

Phoebe also described her enjoyment of the sense of togetherness that came from moving collectively through the church year and liturgy, as opposed to being part of a group in which everyone had essentially the same faith perspective:

You're all moving together, and I think I find that I like all moving together instead of all of us having to be the same; that we're all reading the same Scripture every week, and we're all going through the same cycle of the church calendar.

For Phoebe, then, it was precisely this sense of togetherness in a common movement and rhythm of reading the same Scripture, and going through the seasons of the church year, that enabled her to be part of a group with diverse theologies.

After attending St. Paul's, some interviewees were delighted to discover that certain people they most admired were Episcopalians. Larry said, "I didn’t necessarily associate it until more recently, that those people are part of my same faith tradition, like Desmond Tutu. 'Oh, we're on the same team now, that's awesome."'

The specifics of St. Paul's way of being the church still mattered a great deal, however. Some interviewees who had moved to other parts of the city and tried other Episcopal churches said they did not find the same energy in other Episcopal parishes. Consequently, they found themselves commuting to get back to St. Paul's on Sundays. Phoebe, for example, felt the congregation had a unique vibrancy: 
The liturgy, and just the space, there's just something. [I] went to an Episcopal Church in West Seattle, and it felt so different. It just felt so much more sterile, it didn't feel the same at all. And it's definitely about not just Episcopal, but this specific community.

Even as it reflected the larger Episcopal tradition, we turn now to what it is that made St. Paul's a unique Episcopal parish in Seattle.

\section{Anglo-Catholic Liturgy: Ancient, Mysterious, and Vibrant}

There was nothing humdrum about St. Paul's worship life. Rather than downplaying the High-Church aspects, as some Episcopal Churches do, St. Paul's relished them. According to its website (St. Paul's Episcopal Church, 2012), St. Paul's offered "a style of worship intended to delight and enliven the senses." As Ben explained, "The first time I walked in there was this sensation of being taken to 'a place.' When you walk into St. Paul's, it's almost like an exotic world in a lot of different ways, just this whole other world." There were differences, however, between the various Sunday services. The morning services took place in the nave ${ }^{43}$ at 7:30 a.m., 9 a.m., and 11:15 a.m. with people sitting in the sanctuary in pews. The 5 p.m. Sunday afternoon service took place downstairs in the parish hall, looking onto the memorial garden, where chairs were moved into a circle around the altar. This service tended to be more participatory in its planning and execution and included a shared homily. ${ }^{44}$ All services, however, were sensory and embodied experiences in the Anglo-Catholic tradition.

43 The nave is the part of a church building where most of the congregation worships. In traditional Western churches it is rectangular, and faces the chancel where the officiants preside.

44 In most churches, the sermon or homily involves one person who speaks to the whole group to interpret the Biblical text. The rest are listeners. In a shared homily, someone speaks to the group at the beginning to set the stage for the text and then opens up the conversation so that others share their perspectives or experience. Sometimes the speaker provides a specific question for reflection. 
When I first attended the 11:15 a.m. service, I felt I was wrapped in a flow of alternating sounds: intermittent choir chants and songs; reflective organ music coming from high up behind me; the resonant gong sounding at particular sacred moments; the reading of sacred texts; the calm, intellectual but kindly preaching by clergy; and the prayers both sung and read, sometimes from the front and sometimes by everyone. There were noticeable fragrances as the thurible (a metal censer suspended from chains) was swung on four separate occasions, releasing smoky incense which rose up, clung to the sheer angled wood ceiling, and was colored by the sea blue and forest green hue of the stained glass windows. There was the taste of the wine and bread distributed at an altar rail at the front. There was a visual abundance in this striking sanctuary - the work of various local architects, artisans, and artists - reflective of the Northwest forest. The visual stimulation of the architecture was augmented by the colorful vestments and other sacred objects worn or carried by officiants.

The liturgy was calm and meditative, a carefully choreographed participatory drama in an ebb and flow of movement and stillness, sound and silence, passive and active participation. I noticed that the many physical gestures - kneeling, bowing, holding one's arms facing upward and forward at waist level during the Lord's Prayer, and tracing the cross on one's body by touching the head, abdomen, and left and right shoulders - seemed to be a source of comfort and peace to those familiar with them. Mother Vanessa observed, "We say it is about the prayer through the use of the body, which everybody is about, honestly, in the culture - yoga, tai-chi, all of that kind of embodied spirit." 
The sensory style of worship, during all services, was an intrinsic part of the parish's identity as an Anglo-Catholic Church — although, somewhat uniquely, one with a progressive theology and ethos. Some indeed might feel the term progressive AngloCatholic is an oxymoron. Yet this unusual juxtaposition of a progressive theology in a modern building with an ancient liturgical form was intriguing to people. Ursula explained: "I just feel like this country is just so young, and just has no idea of what it's doing, and I like something that feels a little bit older, and, like, maybe it knows itself a little bit." In a world that seemed so transient, where everything was expendable, there seemed to be, in the context of a progressive theology, a longing for something with deeper roots and a longer history. The church's liturgy was one of the things that addressed this longing. "I would definitely say it's open and affirming and progressive, responsive to society, and relevant issues. It sort of has one foot in tradition, in history, and one in the future," Dante explained.

The parish's unambivalent embrace of the Anglo-Catholic tradition had not always been a given. Although the parish had a "High Church" ethos when Mother Vanessa arrived, she found certain people somewhat nervous about fully embracing this aspect of their parish life. Nigel, one of the lay leaders, explained, "She convinced the parish to boldly use the label 'Anglo-Catholic' as a niche marker and not worry about the possibility of its being misread by folk outside the parish." St. Paul's embrace of AngloCatholicism was, however, eclectic. They rejected the more conservative arguments against women's leadership held by some Anglo-Catholics, and under Mother Vanessa's leadership they went further than that. Nigel remarked, "Ironically, Mother Vanessa as rector eliminated some absolute hallmark Anglo-Catholic practices from St. Paul's 
repertoire - for example, the veiling of statues of the saints and the big altar wall crucifix during Lent." Thus, only certain aspects of Anglo-Catholic distinctiveness became the core of the parish's identity, but of those aspects, Vanessa said, "It is who we are. We want to claim the beauty of that tradition. We're in a location where most people have never heard it. So let's try it out, and let's make everything about it." She then explained how she understood Anglo-Catholicism in terms of its physicality and attention to beauty:

The history of Anglo-Catholicism is a dissident movement in the church that asserted the beauty of holiness and mystery, holiness of life through a pattern to life, the connection between beauty and justice. I mean, who wouldn't want to sign on to that?

The Anglo-Catholic nomenclature, in its St. Paul's version, is now unambiguously the core identity of the parish.

Whether aware of this history or not, young-adult interviewees, when asked what it was about St. Paul's that resonated with them, regularly brought up liturgy. "I love liturgy, and I love the physicality of the service," Lily said. Luke, who had been Catholic before getting involved in a more evangelical context, commented: "Definitely liturgy. That's a big defining factor, which drew me back in." I asked him what liturgy provided that a more charismatic evangelical service did not. He replied:

I'm not even sure how to put that into words. I think that's part of why I like it, because it doesn't has to be explained as much. There is more that is going on that, over time, I might understand more and more, but I don't have to.

The experience of the divine was thus not dependent only on words and music; rather, the sacred was experienced through a multiplicity of senses.

This was a helpful respite from the wordiness of the culture that most Westerners inhabit. Extraneous wordiness was, in fact, avoided during the worship. According to 
Nigel, even sermons were short, because they were not, as in most Protestant worship, the high point. The Eucharist after the preaching was the culmination of the worship experience. In the mornings, even the announcements were kept for coffee time after or before the service. During the service itself, there was no attempt to explain things as they unfolded. Experience was always primary, explanation secondary, an essential understanding within Anglicanism/Episcopalianism.

For many, liturgy created a place to center themselves and slow down, away from the stresses of life and the ubiquitous pull of technology. Kylie reflected on this when she said: "Current young adults are so inundated with newness and with innovation and with technology, that there is, almost, like an undercurrent of longing for a liturgy, and for a restful space, that they don't have to create." At St. Paul's, both the choreography of the morning services and the physical sanctuary, and, in a different, more participatory way, the downstairs Sunday afternoon service with a view of the memorial garden, contributed to this restful space. One young woman went so far as to compare the church to a monastery:

This place reminds me of a monastery, and I'm highly attracted to that. It can often feel like a retreat to be here, like it feels other than what the rest of my week is - even in terms of space, and what happens in that space - and even all the, like the fixed-hour prayers, the rhythms, and all that. [It] feels very monastic to me.

The move beyond evangelicalism. Those without church backgrounds, as well as Lutherans, Catholics, and ex-evangelicals were drawn to this progressive, liturgical church. Some unchurched Queen Anne folk did attend and become part of the parish. The majority of the young adults attending St. Paul's, however, were not so much unchurched as perhaps over-churched. In fact, $66 \%$ of the young adults I interviewed 
were evangelicals who were grappling with their faith and deciding what, if anything, to do with it. Mother Vanessa called them "Evangelicals on the Canterbury Trail," a reference to Wheaton College professor Robert Webber's and Duke professor Lester Ruth's (1985) book ${ }^{45}$ by that name. These young adults were finding a spiritual home not only at St. Paul's but also in the wider Episcopal tradition.

Evangelicals span a wide variety of theologies and practices from conservative to more progressive but generally, according to Bebbington (2003) hold to the principles of crucicentrism (seeing the death and resurrection of Jesus, Son of God, as central to human history and individual destiny), conversionism (believing that people need to be born again or converted, which involves a complete change of life), biblicism (having high regard for biblical authority as a rule of faith and life), and activism (through good works, social justice, or sharing the gospel with others). Although the centrality of the death of Jesus on the cross, conversion, the Bible, and activism are important aspects of most Christian faith traditions, mainstream Christians usually read the Bible in a more metaphorical than literal way. Furthermore, they do not feel the same pressure to ensure that every person they know — even those from other religious traditions — is "saved" by “accepting Jesus as Lord and Savior." The more literal evangelical approach to the Bible tends to result in a need for doctrinal correctness and a perspective that all sexual thought and expression outside of heterosexual marriage is sinful, and that LGBTQ-identified

${ }^{45}$ Webber \& Ruth wrote Evangelicals on the Canterbury Trail: Why Evangelicals Are Attracted to the Liturgical Church, in which Webber described the reasons behind his own gradual shift away from his fundamentalist/evangelical background toward the Anglican tradition. 
people need to be celibate. For many, therefore, evangelicalism can feel oppressively restrictive.

During my research, I became aware that St. Paul's provided a way to move beyond evangelicalism for many of its participants. Some were evangelicals who did not have a negative evangelical experience but had simply found themselves increasingly drawn to the liturgical nature of St. Paul's. Others were LGBTQ-identified folk and their allies who had been hurt by the rejection of their sexual orientation by those in their former congregations. For former evangelicals at St. Paul's, the discovery of the more progressive-thinking liturgical traditions provided a theological breath of fresh air, a sense of the mysterious, and a way to stay connected to what they had found of value in their previous Christian faith experience. Some of those emotionally and spiritually bruised from certain streams of evangelicalism saw themselves as "recovering evangelicals." Many young adults who had grown up Christian were longing for a form of community worship that reflected some of the important values of their culture, in which they could hear "the intonations of their own language."

For some evangelicals, though, the high liturgy was unfamiliar at first. A previous liturgical community or an education in literature, the theater, or the arts at times served to bridge the liturgical gap. Isabel explained how her education had prepared her:

I was learning, at the same time, the significance of acts, and the beauty of poetry and language. I think all of that kind of combines with, now, my experience in the church really, really deeply appreciating rhythm, and liturgy, and the elements of a High Church kind of service. I feel like I can see that more clearly now, especially from my training with literary analysis and archetypal criticism, and drama. I mean, I get the symbolism. 
Exposure to liturgy and the church year at the Seattle School or SPU was the bridge to the St. Paul's liturgical experience for other students. There were those, however, who had to become acculturated to something that initially felt strange. Kylie described her early ambivalence:

A friend had told me about St. Paul's and they wanted to come, and so I came with them. The first time I came there was just something really refreshing about it, and there was also something like, "I don't know that I can do this," because I've never done liturgy, and I've never done a contemplative way of worship. But I found myself wanting to come back.

Various interviewees who came from non-liturgical church traditions explained that they had been prejudiced against liturgical worship because they were taught that it was rigid, or lifeless. Isabel explained:

It is very hard for me because I have so much interference from, you know, the story I was told about mainline churches growing up. I really thought of mainline churches at the time as kind of dead. You know, "We're not those people who stand up, sit down, and that's it."

Their experience at St. Paul's, including their experiences with the authenticity of the leaders, challenged this sort of socialization. Isabel continued:

Here, with Mother Vanessa and Quinton, I feel this sense of the liturgy as very alive, and I don't know how to quantify that. It feels very, mmm, it feels very like, Mother Vanessa is not necessarily encountering it for the first time, because it definitely feels like she has lived deeply into it, but she is definitely encountering it every time, and encountering me as I encounter it. It's very much a presence there in the midst that makes it rhythm instead of routine.

The sense of divine presence seemed to resonate with young adults like Isabel, even when the liturgical form was puzzling. The general warmth of the leadership to all who came, and the ability to build relationships very quickly were also important. Morgan said: 
I knew Quinton outside of this context, before, pretty well, and so his encouragement and presence, and getting to know Mother Vanessa and her being so open from the start, have helped ease me into a world that is more liturgical. I mean, at first it might have seemed too foreign to know where to step in. And so I felt comfortable with asking questions, and with maybe risking not doing it right in ways. I don't feel threatened by stepping in and exploring and experiencing.

The worship leaders of St. Paul's, in short, had the unique ability to pursue excellence within their Anglo-Catholic ways of worship and yet create an atmosphere where newcomers felt no pressure to conform or get it right.

Another way that the leaders of St. Paul's helped people to acclimate to the distinctiveness of the liturgy was through holding "St. Paul's 101" question times after the service for anyone interested. Here people could come and ask one of the leaders any questions they might have. St. Paul's also allowed for a great deal of freedom for personal preference during the worship service. Some people knelt and bowed, and others did not. Some people made hand gestures, but others did not. There was no sense of exclusion based on how one participated. Furthermore, for some evangelicals, the simple motions and rituals of the liturgy provided a helpful contrast to the pressure to participate in the more demanding emotional worship expressions of some congregations. Nick observed:

You don't feel forced to close your eyes and raise your hands. In an evangelical community setting, I definitely felt trained to do that. And yeah, it's hard to gauge the authenticity even for myself, of "am I doing these motions because I have to, or is it totally still that connection?" I think that line's blurry. But I love that it's not even a thought on a Sunday morning anymore for me. Because I'm reading from the hymnal, it's all about the text, and it's not about the show.

Lily, who had been part of an evangelical youth ministry, agreed:

I'm very suspicious of feeling in faith. I look back and I wonder how manipulated some of it was. So there's a lot of security for me in coming to a service where it's not dependent on my emotions, but that I'm worshipping, 
because I am-I am saying the words, and I'm kneeling and I'm getting up and I'm partaking in a sacrament of Eucharist - that doesn't matter what my emotions are. It's something that's happening regardless of how I feel. So that has given me a lot of peace in that regard.

In summary, at St. Paul's, liturgical leaders used two ways of translating ancient Christian wisdom and rituals so that artifacts from the distant past resonated with young adults. First, they created a highly sensory communal immersion into the beauty of the divine mystery through liturgy and invited newcomers to be carried by the community's collective experience of the sacred. Then, and only then, were various opportunities provided, through conversation, St. Paul's 101 's, and various parish formation classes, to discuss, explain, and process with words what it all meant.

Beauty, the arts, and excellence. There was a particular aspect of the AngloCatholic liturgical experience that interviewees mentioned numerous times. As Mary commented, "I think beauty is a really important part of St. Paul's, I think the liturgy is designed to be as beautiful as it can be, and that's really important to the people who come here." Young adults clearly resonated with St. Paul's attention to visual beauty and the arts. Mother Vanessa explained that these were investments the parish made deliberately: "The rhythm of the liturgy, the beauty of it, that's where we invest our [energy], if we do nothing else well, we want to do that well. And that's very much what we're about." Not only did the parish embrace congregational artists, but careful attention to beauty and the arts permeated both the liturgical and architectural aspects of the worship service and the space in which most worship services occurred. Mother Vanessa explained her thinking behind the renovation of the sanctuary. She said, "I said that the aim of our building renovation, if we ever do one, is to make the space as 
beautiful as the liturgy." In the light of the previously stated paradoxical aim of "the engagement of an Anglo-Catholic high liturgy cast into a more modern context" in Lower Queen Anne, Dante affirmed, "I love the remodel, because it just looks more modern." Although important to many members of St. Paul's, the parish's focus on creating beauty through the arts was a powerful draw for artists in particular. Ursula among others appreciated the artistic ethos and support for the arts in general:

It's not a church that has tons and tons of money, but it does feel much more supportive than any other church I've even been to, in terms of artists, so that is definitely part of what keeps me here and makes me love it so much.

Two servers involved in the worlds of literature and theater, respectively, jokingly reminisced about their experiences at St. Paul's. One of them said:

What Vanessa does - a lot of times when we have the prayers of the people, not every week, but she'll still pray when we pray for the artists in St Paul's. She almost inevitably starts with poets and then she'd move on to novelists and painters and sculptors, and I'm somewhere usually on the altar, and I say, "Playwrights, come on, say playwrights. [Laughter] How about graphic artists, all right [laughter], and she gets all the way down to tattoo artists [laughter].

The fact that their art was appreciated and incorporated into the life of the parish was an extra benefit, as Tess explained:

And this is the first church that actually invited me to share my poetry, and I was able to be Artist in Residence [during] Advent of 2010. So that was pretty powerful, too, because in the fundamental evangelical atmosphere where I grew up, poetry was something that, at best, was frivolous and, at worst, was secular. So, yeah, to have poetry at church, my poetry at church!

Various local artists and artisans were commissioned during the renovation. A local artist created the font and altar, and a local architect oversaw the renovation work. These homegrown influences had the effect of ensuring the strong connection of St. Paul's to the region. 
Music. Interviewees also resonated with St. Paul's musical ministry. The music differed greatly from service to service; some preferred the morning music (more classical in its feel) to that at the 5 p.m. service (more jazz-oriented) and vice versa. The 7 a.m. service was the only spoken service with no organ or choir, whereas both choir and organ accompanied the 9 a.m. and 11:15 a.m. services. The 5 p.m. service was different; it had a pianist, and sometimes a flutist, talented musicians who were, as Emma put it, "combining Taizé with Jazz."

Regardless of musical style, however, the music complemented and enhanced the movement of the liturgy, and the quality and sensitivity of the music was appreciated. At most services the priest sang and the congregation sang in response. Emma, who attended both the 11:15 a.m. and 5 p.m. services, noted, "So, a lot of the liturgy is sung, and that somehow makes it more powerful." Ursula, who attended in the mornings, described why music was an important source of her resonance with St. Paul's:

It's really good! As someone who has really devoted themself [sic] to an art form, I believe very strongly that good art is good theology - and that certainly does encompass introducing new people to it, maybe letting people play around in an art form they haven't practiced before - but I also think that it should mean that excellence is promoted. [I am] very staunch about excellence. It's very important to me that a church and the congregation understand that, if you pour everything that you have into making it the best that it can possibly be, that that is part of your worship.

Part of the appeal of the music used in the two morning services where music was employed was what might be described as the music's "otherness." A young man who attended in the morning mentioned his love of the music and the fact that the music he loved in church was different from what he might listen to at home:

Love the music there; love the choir; absolutely the choir. Which I find interesting because, generally, I like new stuff. I like loud music, and you know 
the playing with computers, and high tech stuff and all that, but not at church. Which I know is interesting because a lot of churches play to that, you know. A lot of the ones trying to draw the young adults, and thus play loud music and the big screen up front, you know, and all that. And for me, that's not what I'm looking for.

Like others who attended St. Paul's he was, in fact, looking for a sense of continuity in his experience of the divine, a continuity that, in his mind, seemed to require, if not a lack of continuity with the secular world he inhabited most of the week, at least something that was different. He said:

I'm kind of looking for that kind of, that connection, with the past, with history. I think part of it for me is the idea that I'm being connected with something that's greater than me, you know. There's something about, you know singing the hymns that have been sung for hundreds of years that there's that connection all the way back through.

The music was very much at the service of the liturgy, rather than a performance in itself. The choir loft and the organ were suspended from the ceiling overhead at the back of the sanctuary; the choir thus sang from above and behind the congregation. This "staging" was noticed and appreciated. Nick said:

I love how humble the music is at St. Paul's. It's amazing, it's beautiful but it's sung from up above over your head. It's not, you're not looking at a stage where people are commanding the congregation, you know, it's just a different style and it, yeah it's really a beautiful change for me.

The musician and choir in the mornings and the jazz pianist who accompanied the liturgy at the $5 \mathrm{p} . \mathrm{m}$. service were never the focal point but simply facilitators of worship.

Despite the care taken to make things beautiful, care that was quite evident in the architecture, the elaborateness of the worship choreography, and the music, the participants experienced the services at St. Paul's as a humbler worship expression than that of their former congregations. Nick put it this way: "Yeah, it was my first 
Episcopalian experience, and I was really attracted to the humility of the service, first and foremost. It was just not a show."

Ironically, many who attended St. Paul's saw their previous, less elaborate, evangelical forms of worship with the prolonged periods of singing, preaching, and invitation ${ }^{46}$ often in warehouse-like buildings, as "showy"-more a form of entertainment than a form of worship. By contrast, they saw St. Paul's much more choreographed and intricate high church services as a humbler way to worship. The Anglo-Catholic worship service, permeated by music and scripture, saturated with beauty through liturgy and the arts, tended, over time, to woo the young adults I interviewed.

The Bible. For former evangelicals, the fact that the liturgy was saturated with Scripture was vital. Numerous interviewees mentioned that the Book of Common Prayer was permeated with Biblical language and that four Biblical texts were read each Sunday. There was also a great sense of relief about the more progressive way that St. Paul's engaged with Scripture. Many had experienced the Bible in ways that felt oppressively directive and literal. For instance, Tess explained her aversion to the notion of the Bible as a book of rules or demands rather than sacred literature:

When the Bible is used as a set of rules to live by or a set of platitudes to accomplish, it feels like a weight on the back of my neck. And that is not actually practiced at St. Paul's. And that's a huge piece, how the text is honored or exegeted ${ }^{47}$ is really important, in a space for symbol, and metaphor, and awe, rather than a literalist opinion of the Scriptures. And the churches that I grew up

\footnotetext{
${ }^{46}$ In his article, "From Modern to Postmodern: Worship Changes during the Twentieth Century," Webber (2000) describes evangelical worship from the Romantic era, with some slight changes, as the threefold pattern of Singing, Preaching, and Invitation. The invitation was usually some kind of altar call, which involved people going forward to publically receive Christ as Lord and Savior.

${ }^{47}$ Past tense of the verb to exegete, which means to interpret; to perform an exegesis.
} 
in, and that we went to, took a very literalist opinion to the Scriptures. Being a poet, it's important that poetry is treated like poetry.

Larry explained that the Bible wasn't absent, but present in a different way:

There is a service with readings from the Bible, like the Book of Common Prayer, that puts everything in the seasons of the earth, puts everything in context. And it just doesn't have sermons that are about — not that it's bad to say, "This is how you're going to change your life today, we're going to tell you like these four steps to becoming a better Christian in this area." - It's more, "We will approach the entire canon of the Bible and we will respect tradition" and that's something that I really liked about it.

He was quick to add, though, that he did not think that St. Paul's approach to Scripture was a watered-down version of Christianity. "I know my parents often think that that's what I'm signing up for, to believe what I want to believe. But that's not the case.” In short, formerly evangelical young adults appreciated being part of a church that took the Bible seriously without the perceived oppressive connotations of the past.

The shared homily. One of the innovations at the afternoon service was the shared homily. The shared homily entailed a brief introduction to a Scripture text by one person, followed by an invitation to all present to share their own perspective or experience regarding the text. Many of the people I interviewed appreciated this approach. For example, one young woman, when asked what it was about St. Paul's that resonated with her, said, "Can I say shared homily, shared homily, about five more times, so that it will show up in your [findings]." She went on to say that, because she was not from an Episcopal background, she had no idea how radical the shared homily was within this tradition.

Many Episcopalians, accustomed to preaching only by a theologically trained, ordained priest, might not have felt comfortable with this idea. Yet Mother Vanessa, 
along with Quinton and other leaders, was able to create a space that made this possible. The shared homily ensured that people had a chance not only to hear a biblical text but also to engage and share their experience of it directly.

\section{Focus on the Experience of God}

While many churches run the risk of focusing on the formulas or rituals rather than the reality that the latter are meant to convey, this was not the case at St. Paul's. There was a very tangible sense that the mystery of God was at the heart of all the congregation did, or more simply, the parish understood itself to be about God and God's revelation in Christ, and not about religion for its own sake. Mother Vanessa remembered what a staff person said when he first came to St. Paul's: "He said, 'When I came to St. Paul's what I found was, in the servers [during Holy Communion], the assembly, all of [it], this sense that in the liturgy we were in the hands of something larger than ourselves." Her response was, "There it is! That's what I want! And I want that to be the pervasive experience." That this was the desire of the leaders was clear to participants. Mary, for instance, said, "I think people here are real; I think they strive to make the worship real. I think they really want people to connect with God, and I think that shows." Numerous people talked about sensing the presence of God in the worship. Megan remarked that "Inside I feel slower when I am in place, or I really do feel like there's a loss of time in the midst of being here, like something else takes over." Stephen noted:

Just the silence for some people, it may be the first time they've experienced, in a Christian setting, an awareness that God is present and speaking to us, using that language of silence. I think, too, whether you speak specifically to it or not, [there is] the recognition that there's a love of the mystery, and there's a love of the ancientness, and there's a love of God speaking to us right here and right now. 
This sense of the "Presence in the midst" at St. Paul's through liturgy, silence, or music was another draw for former evangelicals and others for whom experience was critical. It was another factor that enabled the diverse people of the parish to feel connected to each other, and walk alongside each other, even though they came from different backgrounds. This coming together of diverse people for the purpose of worship was made possible, though, by commitments the parish had made about its identity before the newer young adults and others had arrived.

\section{Creation of Welcoming Space for Young Adults}

A great deal of the welcoming at St. Paul's took place, paradoxically, before anyone walked in the door. This happened as the parish went about being the radically hospitable parish that young adults would be proud to join and providing a variety of service times that would appeal to different people. One of the ways that St. Paul's resonated with certain young adults was by starting a 5 p.m. service. The newly implemented service was ideal for those who were involved in other social activities on Saturday nights, or who preferred to sleep in on Sunday mornings. Young people saw

other benefits, as well. Quinn explained: "I really like the morning [service] but with this [afternoon service], I get to know people more, and Sunday mornings are for brunch and coffee and reading." In addition, once a month those at the afternoon service went from the service to the pub, where they enjoyed wine, appetizers, and conversation.

\section{Welcome Through Radical Hospitality}

It was important to most people before they would ever consider joining St. Paul's that the parish espoused values similar to their own regarding inclusivity. The progressive, open, affirming, socially aware nature of the community was important in 
assuring young adults that they, as well as all other people, would be welcome there.

Quinn described her stance on this:

I didn't go to church for a year or two, and my then housemate was going here-I didn't know anything about Episcopal Church — and she said, "You know it's great. They ordain gay people and women, and they have a woman rector," and I decided I couldn't go to any church that didn't - that excluded anyone from leadership, which kind of narrows down [the options].

It was important to the young adults that there were no exclusions from participation or leadership based on gender, sexual orientation, income level, or social status. In this St. Paul's differed from Mega Mill where openly LGBTQ-identified people could not be members and women could not lead

For Catholics who rejected more conservative teachings around women in the priesthood and LGBTQ issues, but valued liturgy, this progressive Anglo-Catholic church felt both refreshing and familiar. When asked how she would describe St. Paul's to others, Morgan cited her partner, an ex-Catholic, saying 'I'd probably describe it how he often does, by saying that it's all of the things of Catholicism that he does like, and not the things that he doesn't." The fact that there was a woman lead priest and one or more gay priests in the parish was very appealing to progressive Catholics and Eastern Orthodox young adults who opted to leave their prior denominational homes and affiliate with St. Paul's version of progressive Anglo-Catholicism.

That the parish was known for being a defender of marginalized people was critical for these young adults. Mary said she had considered leaving the Christian church altogether because of the exclusionary and conservative attitudes of people in her former religious communities, explaining how important it was for her to find a church 
that loved and accepted people where and as they were. She contrasted this approach with the evangelical church/spirituality of her youth:

I guess I had come to believe that in order to live a godly life, it had to be about more than just emotional worship, it had to be about more than that personal relationship with Jesus that you hear about so often in the churches I had been going to. It had to be about loving people, and it had to be about accepting people, because I believe that was what Jesus did, he loved people and accepted them. And if the church can't do that, then it's not the place for me. But St. Paul's does that. There is a quote from our baptismal vows that says, "I will strive to respect the dignity of every human being," and that really, that resonates with me. I think that's at the heart of Christ-centered life.

I found it ironic that the more evangelical emphasis on a personal relationship with Jesus was perceived by these young adults as presenting a narrow caricature of Jesus' actual values.

The inclusive nature of the parish flowed out of a commitment to social justice, human dignity, and peace, not in some abstract or ideological way but in real relationships among diverse people who called the parish home. This sensibility was based in the Episcopal baptismal vow made by both the individual and the congregation in response to the question "Will you strive for justice and peace among all people, and respect the dignity of every human being?" The baptismal candidate and the people replied, "I will, with God's help" (Episcopal Church, 1990). Mary observed:

I think that social justice is a big deal to us. [I] don't think anybody wants to hurt anybody else; I don't think anybody wants to make anybody else feel unwelcome. I think that part of showing God's love in the world is reaching out to people who are oppressed, and I think St. Paul's does that in a number of ways. They are starting to learn how to do it more and to do it in a St. Paul's kind of way [which is] not just supporting a ministry, not just donating food to a food bank, but finding a way to actually be with people, hands on, and not only give them the physical things they need, but give them an experience where they feel like a human being. 
Although St. Paul's expressed a passion for social justice in an assortment of ways, generally it seemed to be less about party politics and the ideological rigidity of some justice-oriented groups, and more about working to ensure that the dignity of all people was valued in the parish's life. The radical hospitality of this parish to visitors, LGBTQ-identified people, women, artists, neighbors, and so on, was a significant reason that so many young adults were able to make St. Paul's their spiritual home.

Healthy diversity. Although I did not gather demographic data on sexual orientation, during storytelling, five interviewees self- identified as LGBTQ. There was a significant diversity of ages also. While 21 interviewees were under the age of 36 , ten were between the ages of 40 and 65. Although most interviewees were Caucasian, there were three interviewees of color in my research sample. The age and ethnicity data were reflective of general demographics in Seattle and lower Queen Anne.

The diversity of the parish around sexual orientation was perceptible to all who entered St. Paul's. What had once been called the gay church continued to feel like home to LGBTQ-identified newcomers because there were still many LGBTQ-identified parishioners and staff. This claim to diversity, though, was no longer the only or even the primary way in which the parish, as a diverse group, identified itself. The lead priest, a heterosexual woman, leaders and parishioners who were gay and straight, married and single, young and old, augmented this diversity. There were families of all kinds, children in the Godly Play ${ }^{48}$ ministry during the services, and the involvement of the broader community, including low-income people who came to eat together at the Fatted

\footnotetext{
${ }^{48}$ Godly Play is a Montessori based children's spiritual curriculum used by the parish.
} 
Calf Café. Having a mixture of people who identified as straight and as LGBTQ, as well as single people and families, seemed very important to everybody at St. Paul's.

LGBTQ-identified congregants were themselves seeking to be part of such diversity. As one man who was gay said, "One of the reasons I'm drawn to this particular parish is that there's a diversity of ages, of ethnicities, of sexual orientation, religious identities in the congregation. They're very visible, and that's appealing." A young woman, who had first tried a parish that was constituted predominantly by men who were gay and older, explained how she felt about the current diversity of ages, marital statuses, and sexual orientations at St. Paul's:

When I came to St. Paul's, there were what appeared to be gay couples and families with small children, and old people, and young adults, and middle-aged people, and it just felt, it felt like a healthy parish, is what it felt like. It felt like I would invite anyone I know to come here because it feels like a whole community, and while there's certainly common characteristics to many St. Paul's goers, I like that it feels diverse in terms of life experience and sexual and gender identification, orientation, but it just seems like a nice healthy diversity. If I had kids, I would love them to go to a church like this, it just feels very balanced.

St. Paul's did not promote strict sexual mores that people were expected to live by, other than the baptismal vow to respect the dignity of all persons. Neither was age a barrier to participation and leadership. There was a mixture of ages at all services at St. Paul's. When I asked if having members of their own age group at St. Paul's was important, interviewees were always quick to say that having a diversity of ages was more important. Phoebe said:

I deeply appreciate the people not like me-the older people that come to the 5 p.m. service and speak up during the shared homily, and hearing their voicesand, just people with all kinds of difference. [I] deeply appreciate that as well. I think one of the things I didn't like of the emerging churches that I tried, or that I had heard murmurings from growing up, or the church that I went to as an undergrad - is that they were all people like me, everybody! 
In fact, Cameron, who attended in the mornings, mentioned that a church filled with people from his school would not be something he would enjoy:

Okay, yeah, so that's like what I like about St. Paul's is that, we are sort of the youngest - I mean, we're not little kids — but there's a wider age range than, say, in this other Church that I went to which was like a lot of SPU students, a lot of young couples. I didn't really wanna go to some sort of Annex of SPU and so that's what I really liked about St. Paul's - there's a few from SPU who come here, but not sort of half of the pews are full of them.

Furthermore, the parish's leadership team included members of a diversity of ages. Everest mentioned this when he was discussing what he valued about the parish:

I think the fact that the leadership is multi-generational, I mean [the senior warden] is our age, right? The fact that both a junior warden and a senior warden [are young adults], and the vestry ${ }^{49}$ is multi-generational, the altar folks are multigenerational. I like that. I think that's different from other congregations where it's the priest and a bunch of kids [and] there are very few adults that actually participate at the altar. And I like that that happens here, and that there are kids who participate, too.

For young adults who attended Sunday services and became involved in the life of the church, it would quickly be clear that the parish respected and utilized the gifts of people of all ages. For young adults at university — who saw many other young adults on a regular basis - the generational diversity in the parish was very important. Not only would they have found a homogenous church made up of only young adults unappealing, but they also prioritized diversity across generations/ages, as well as sexual, gender, cultural, and socio-economic diversity.

\section{Welcome from an extroverted priest and introverted congregation.}

Hospitality was integral to the ethos of St. Paul's. Mother Vanessa, a self${ }^{49}$ A vestry is a committee of those members elected to administer the financial and property affairs of a
parish. 
identified extrovert, was intentional about ensuring that newcomers felt welcome. Dante mentioned that Mother Vanessa "invites people to feel they are not only welcome but [invited them] to participate at whatever level they're comfortable. I think that every new person that walks in is greeted in some way." Mother Vanessa also found ways to put people at ease after the service. Larry noted:

One thing that I've noticed that Mother Vanessa does well; she has such humility in greeting people. And I love how she will sometimes ask; she'll ask a visitor or guest, "Was that crazy for you?" She wants to know what you think and, what can you relate to, and have you ever done anything like this before? And it's a very welcoming way of saying, "I have no idea where you're coming from. This is probably a bit different. If it's not, great. Do you connect? How does it connect to you?"

Undoubtedly, it was the kind of personal relationship that leaders built with participants that made them likely to return. Mother Vanessa also addressed the hospitality goal structurally by ensuring that systems of welcome were in place. She chose one or two people to be the lay pastors for particular services, who could work on building community among the people who attended.

The worship leaders at St. Paul's, while very clear about their Anglo-Catholic identity, were sensitive to the fact that, for many people, Anglo-Catholic traditions such as the liturgy could initially feel very foreign. They did various things to mitigate these sorts of feelings. For example, the following statement appeared on the first page of each worship bulletin: "We're pleased you have come to worship with us today. If you are unfamiliar with the ritual customs of the Episcopal Church, simply relax with the liturgy and let the rest of the congregation carry you in worship." Quinton and Tess shared their initial reaction to this statement: 
So we went that morning, and I remember we just began to cry when we read that, both of us. There was something about that invitation. Also, that the community would carry us until we could stand up. There was also something about - they weren't waiting for us to catch up either. It was like just because we didn't know about it, didn't mean that they were going to stop what they were doing.

It was the clearly defined identity of the parish, as well as its confidence in the liturgy, that enabled newcomers to feel at home and comfortable being carried by the community.

If St. Paul's sought to develop a welcoming ethos, it was nevertheless not overpoweringly welcoming. This was important because the absence of young adults in most mainstream churches creates a potentially awkward environment when young people do visit. Some talk about being welcomed in an over-exuberant way while others feel they were pressured prematurely to come back and get involved in the life of the parish. Students were often unable to participate regularly in any church and appreciated that, at St. Paul's, they were not pushed into commitments - to join the church or participate in activities - that they were not able or willing to make. Opportunities were afforded, but there was no sense of coercion about participating, as Ernest, who was weighed down with the responsibilities of young adulthood, explained:

I'm very busy trying to make sure I have enough money to live, which I don't, and making sure I have, you know, my social things in order, and so there are definitely opportunities to do other things, but [I need] the option and not the enforcement of them. So if I wanted to be more involved in St. Paul's, there are many opportunities and I see them all the time. But they don't force me to, so that's fantastic, 'cause I, I don't want to right now.

Numerous leaders and parishioners also told me the parish had a great many introverts, and so newcomers were not necessarily "pounced upon" when they arrived. In fact, the parishioners had to be trained to welcome people. Quinton remembered:

St. Paul's is an introvert's home, right? And so I think that one of the dynamics is that you have a bunch of introverts. There were times they actually had to 
demonstrate how to go and approach somebody who was new, right, and so they were doing these demonstrations at coffee hour (laughter).

Lily explained what she would say to friends she invited: "It's an introverted parish so you might have to introduce yourself, but I'll go with you, and we'll make friends and it'll be fine." Numbers of the interviewees discussed coming to St. Paul's at the invitation of a friend, or by accompanying a friend. Mia remembered, "We met at the Chocolate Festival. She's, like, 'I'm gonna go to Church after. You wanna come with me?' And I was, like, 'Yeah, I haven't gone to Church in like a year. I don't know. I'll come." Whether they came alone or with others, however, the more reserved character of the parish was actually appreciated by most. Tess explained:

I found a lot of the user-friendliness ${ }^{50}$ of the churches I've been to pretty superficial, and it was a huge turn-off for me, so I don't feel welcomed by people coming after me with all sorts of exuberance at seeing me, because I just discount that as fake. And so, at St. Paul's, when we went there, I didn't feel that superficial exuberance. There was a general feeling that I was welcome, that I could take communion, that I could sing the songs that were being sung, or not. There was nothing in my face that I had to deal with.

Thus the reserve of the congregation, inadvertently but quite beneficially, created an ideal kind of welcome for those young adults not wanting the pressure of premature commitment.

Each story "heard." St. Paul's was seen as a place where, even in the midst of the various group practices, individuals could also have the support and space needed to process their unresolved life and faith issues, a place where their personal stories would be heard and validated. Providing this kind of attention to the individuals is much harder

${ }^{50}$ Some congregations use terms like seeker-sensitive to describe the way a congregation tries to remove all possible strangeness or hindrances to the comfort of newcomers. Religious words might be changed, explanations offered in a pamphlet for everything that happens, etc. 
to do in bigger churches. Isabel explained how, as a former evangelical, this sort of personal support was important to her:

I think the one thing that's come to mind quickly, is, like, our generation is kind of riding the coattails of the, like, mega church, bigger, like cookie cutter programmatic kind of church experiences, especially in the kind of population here in Seattle. What can get lost in some of those traditions is a sense of, like, this sort of unique personal formation, that there's both a sense of, like, communal formation but there's also attention to individual story within that which I think is attended to really well here. How [the two pastors] speak to me based on what they know of where I'm at, what my story has been, where I am looking to go in the future, that to me feels very formative.

One example of attention given to the individual was that of a young couple who were dealing with the repercussions of the husband's realization that he was gay. The parish and clergy were able to provide support to the couple as they worked out an amiable but difficult parting. They were able to gain the space they needed by attending different Sunday services, and they were supported not only personally, but spiritually, through a divorce liturgy Mother Vanessa created to recognize the end of their marriage as well as through their encounters with caring parishioners. St. Paul's thus provided the former wife with support within the context of her own individual life narrative, something that was crucial to this stage of her life. She believed this would have been missing in their previous congregations. Her ex-husband would not have received the same kind of support from people in their former more conservative congregation/s, nor would they have had the same level of care within an impersonal megachurch.

Other participants in this study also valued the sense that each person's narrative/story was known and attended to within the group. Emma noted how important this support was within the broader cultural context of the economic recession that was occurring during the period when data were being collected: 
I've had a tough couple of years. Yeah, the economy has been just terrible. And my family has kind of dealt with it in an unhealthy way. They've kind of turned

to alcohol and drugs. So it's really nice to go to a healthy church, and a lot of the other people that attend sometimes, they have family issues too, so they can definitely relate. And I always have somebody to talk to. So it's very, very good to have a support system there.

The validation of each person's story, along with support from leaders and parishioners, also constituted a powerful source of resonance to these young adults.

Not judgmental or "preachy." Most interviewees commented on the fact that the church ethos was not a judgmental one, nor were the leaders or parishioners overly directive in their engagement with participants. Emma explained:

I found it hard when, you know, people who don't experience what I experience tell me what to do with my life. So it's really hard for [me], like, to reconcile how they tell me what to do, and, you know. So that's why I like St. Paul's. They're not telling me to do something; they're just saying, "Let's share." You know? [There is] less, "This is what you must think."

These young adults wanted and needed the space to work out for themselves what they thought and valued, particularly in terms of their sexuality. Mary explained:

I think that young adults also, they want to see homosexuality be accepted, I think that they want to see like, cohabitation be accepted, and you know people my age just, it feels really good to be in a place where peoples' life choices are accepted, as long as they are loving, you know. And I think that's one thing that is changing in our culture, and I don't know if any other church, certainly no other church I have ever been to, has accepted those things.

Because the church had created a sense that everyone was exploring faith and being human together, each person could feel support as they figured things out for themselves. This sense was further enhanced by the intellectual and questioning culture.

The intellectual climate: Freedom to doubt and question. The Episcopal tradition creates a great deal of room for questioning, doubt, and intellectual discussion and tends to appeal to an intellectual group of people. (I noticed, however, that although 
many parishioners were well educated and intellectual, people were welcome and comfortable regardless of cognitive ability). The more intellectual ethos was a great delight to former evangelicals and Catholics because many felt that their former church communities had stifled dissent, discussion, and the questioning of doctrine or authority - in short, the world of the mind. There was a strong sense that it was not only acceptable to doubt and question but expected and valued. Quinn noted:

I think something, maybe, about our age group, wet] just needs a place where it doesn't feel so "I have to agree to be a part of this community."

Belonging did not require believing, and young adults at St. Paul's felt that the Episcopal tradition was old and strong enough that individuals were not threatened by one another's questions. It was also not threatening if someone was simultaneously exploring another tradition, such as Buddhist meditation, which a couple of interviewees mentioned they also practiced. Paradoxically then, young adults at St. Paul's had the freedom to come or not, to agree or disagree, and to learn from other faith traditions such as Buddhist meditation, and saw this, along with the clear identity of the parish itself, as the reasons for their being able to belong.

\section{Authenticity}

One of the words most frequently used by leaders and young-adult participants in describing their resonance with St. Paul's was authenticity. This term was used in two ways. First, it was used to describe the way St. Paul's had a clear identity and did not try to be everything to everyone. Quinn suggested that it was precisely because St. Paul's had such a clear sense of its identity that it was able to accommodate the questions of its young adults and their own identity struggles: 
I don't have to settle on a certain doctrine. I mean there's a philosophy, and there's a theology at St. Paul's, but it doesn't feel quite so rigid. But it's an odd mix, though, because it [St. Paul's] very much knows its identity. Maybe it's secure enough in its identity that it doesn't have to [defend it]. It allows room and space for people to kind of grapple with that, or question that, or not agree with that.

Tara also saw St. Paul's clarity about its own Anglo-Catholic identity as an expression of authenticity and as the reason young adults were drawn to the parish: "For a while St Paul's really didn't embrace its Anglo-Catholic identity, and as soon as it did (and I think that was soon after Vanessa came), that's when St. Paul's started to grow."

Mother Vanessa described how she led the parish very intentionally into living unapologetically into its progressive Anglo-Catholic identity:

Being who you truly are! The sign of authenticity is that for good or for ill, it kind of brings you to life. When you get close to who you really are and you manifest it, it kind of builds on itself and it, it ends up being, in whatever way it can be, like a magnet.

Authenticity was contagious. Interviewees felt that the leaders were authentic, and this encouraged them to feel that they could be authentic themselves.

Tara agreed that St. Paul's clarity about its identity and its authenticity in living it out was what resonated with young adults, but she fiercely resisted the notion, as did others, that the parish specifically tried to recruit young adults.

This gets back to that authenticity question. St. Paul's [is] authentic about who we were, as a community, and it's that [authenticity] that draws people of all different ages, and different backgrounds. The fact is that there are a lot of people who are younger; there are also a lot of people who are older, and also a lot more people from the neighborhood now. So we don't have any riddles for "reaching the young adults.

Mother Vanessa agreed: "I didn’t actually set out to try to get young adults; I just am where they are. I'm still trying to figure it out authentically." Interviewees asserted 
that this kind of authenticity meant that there was no need for advertising or gimmicks or for pandering to particular groups to attract them. This was also part of an intentional commitment of the leadership, as Mother Vanessa asserted:

The more it [St. Paul's] could live into who it is, the more it's attractive and it does that organically, not by putting ads out there. I cut all the ads when I first came here, I cut all the advertising out of the [budget], and we were doing interesting ads, but I just thought we just need to work right at the center of who we are.

This authenticity enabled newcomers to choose very quickly to be, or not be, part of the community. Like a magnet, St. Paul's could both attract and repel.

When I interviewed one young man who had only came to St. Paul's one time, he said, "I'm glad I came," but quickly added, "Yeah, it's not the kind of service that I would go to on regular basis. It doesn't really fit me." I found this a helpful reminder that there were likely many others who would come and do not return. Kylie explained: "It doesn't have to be seeker-friendly or pretentious. Yeah, it just is who it is, and you either grapple with that or you don't. You know, they don't apologize for that. And that feels very settling." Mother Vanessa was quite comfortable with the fact that St. Paul's would not appeal to everyone and did not feel any need to make everyone happy.

Second, the word authentic was used to explain the space that was created by the parish for people to experiment with their identities and wobble their way toward clarifying, without pressure, what or who they should be in their journey to independent adulthood. What made so many feel welcome was the ability to be on this journey where they could be their real selves without pretense. Nick explained:

There is no element of "fake it "til you make it." I know of some stories where parents would be like arguing in the car and they would get to church and they would tell their children like, "put your happy faces on we're at church," you 
know, so, you know there's no authenticity there. I definitely feel that St. Paul's is an authentic church.

Young adults at St. Paul's appreciated the space to be themselves and define their own beliefs, values, and worldview. In doing so they seemed to need a collective identity stable and clear enough to test their own identities alongside.

In summary, through a balance of radical hospitality, inclusion, and social justice on the one hand, and an absence of pressure, indoctrination, or judgment on the other, St. Paul's had created an environment where people could be authentic, where young adults could figure out who they were, question and doubt freely, and together create a community of which they all felt proud. Even if they had not set out to do so they had created a welcoming space for young adults.

\section{Leadership}

\section{Dispersed and Centralized Leadership}

When I arrived for my first morning service, the narthex was filled with various women and men in albs. ${ }^{51}$ Mother Vanessa, whom I had already met, was out of town. As the service began, nine people processed up the aisle; an older, bearded man, swinging a thurible emitting smoky incense, followed by three rows of people walking side by side. In the first row, one middle-aged man and two young women each carried one of two large lighted candlesticks or one metal cross on a pole. In the second row, a man and a younger woman carried hymnals. In the last row were a man and two women.

\footnotetext{
${ }^{51}$ Alb a white vestment worn by clergy and servers in some Christian churches.
} 
The man and the younger woman each wore over their albs an ornate blue cope. ${ }^{52}$ The third person, an older woman, wore only a stole ${ }^{53}$ over her alb.

I could not tell which albed individuals were clergy and which were laity. The way the leaders were surrounded by others created the perception that worship leadership was a communal matter. Of course, there was an ordained person there, two in fact, along with lay leaders who trained and organized those who were servers, and the whole congregation followed the pattern of the Eucharist laid out in the 1979 Book of Common Prayer. As one lay leader explained, "We relax into, dance with, a shape and rhythm of prayer that we inherit from others - our ancestors in the faith - and the specific mechanisms of the church." The symbolism was of an egalitarian space where leadership roles were shared among numerous people.

In fact, the composition of the procession became, at that moment, a symbol of the way that Episcopal leadership generally holds in tension an authorized ordained priesthood on the one hand, and a dispersed leadership model that draws on the gifts of many, on the other. There was not just one person at the front. As Ursula explained:

The pastor didn't seem to be the center of attention; they were off to the side. The sermon was really short. Ninety percent of the service had very little to do with them, and it seemed like — not to sound harsh, but it seemed like they were put in their place. Whereas the churches I had grown up in, (that's why we were always hopping churches). "Oh, we like the personality of this pastor," or "we don't like the personality of this pastor," or "the pastor has changed, we don't like him now," and it just, it made one person everything, and, in the Episcopal Church, all of a sudden, it just seemed, "Oh it's about us, and our worship!"

${ }^{52}$ A cope is a liturgical mantle or cloak, open in front and fastened at the breast with a band or clasp. It may be of any liturgical color, based on the seasons of the Church Year.

${ }^{53}$ The stole is a strip of colored cloth, three to four inches wide and about eight plus feet long, which is hung around the back of the neck so that the two ends hang down parallel to each other in front. The stole is usually ornamented with a significant religious design or symbol. 
The variety of people in leadership roles on the one hand seemed to create a sense that everyone was important, and that worship was a collective experience. On Sundays, Mother Vanessa was not the only preacher. There were various clergy who could take on this role, including several former priests of the parish, some of whom Mother Vanessa had invited back to serve in various capacities. As a result, those attending St. Paul's for the first time might not have recognized who the lead priest was or even whether there was one. At St. Paul's, leadership was initially embodied in an individual, the lead priest, who had been hired by the vestry, but then dispersed by her to a diverse collection of people of different genders, sexual orientations, and ages.

The fact that leadership was somewhat dispersed and shared on the other hand, did not prevent Mother Vanessa from taking a front and center role in parish life, from being comfortable with the authority she was granted as lead priest, and running the parish in the day to day.

Because of space constraints, I will focus in this leadership section on Mother Vanessa, the lead priest and, and briefly on Quinton the lay pastor at the Sunday afternoon service. These two church leaders had the most involvement with the young adults in the congregation and were mentioned most often by the young adults I interviewed. Both leaders had rich histories and clear gifts, and about each a whole book could be worthily written.

\section{Non-Coercive Leadership: Walking Alongside}

In the earlier comments about Mega Mill, Cameron commented on the way that leaders there told people what to do and think. For those from more authoritarian backgrounds, the remarkable thing about the leadership at St. Paul's was how 
comparatively mild it was. There were no raised voices, no harshness, no compulsion to think, believe, or act a certain way. Mother Vanessa exemplified strong, cheerful, resolute, and calm female leadership.

\section{Leadership and Empowerment: A Healthy Tension}

Mother Vanessa was an energetic woman aged 61. Born and raised in the American South by civil rights activist parents who were not religious, she did not grow up Christian. She brought to her role as priest three primary disciplines: literature, business, and the church. Her undergraduate work in the English Renaissance and graduate work in English led to a career as English and Latin teacher and a passion for literature and poetry. A later call to the priesthood, sponsored by an African-American parish in the South, led to her doing her M.Div. concurrently with an MBA. During this time, she made "a wonderful discovery of all this latent, not so well-mannered capacity that I had around making things happen." Before and after completing her graduate programs, she worked sometimes in business, sometimes in the Church, and sometimes in both simultaneously. She had been a brand manager for a prestigious global consumer products conglomerate and had taught Episcopalian bishops how to be better bishops!

Her life experience and career outside of the church enabled Mother Vanessa to relate to people who worked in business environments. A young former Catholic man who was accustomed to celibate, often lifelong priests, found her refreshing:

I think what impressed me about St. Paul's is, like, "Oh my God, the pastor's a woman," and "Oh my God, she's a woman and she's been divorced, wait a minute, and she worked as a [business executive position] at [company name]" and "she went to business school." So I remember that first homily, "Wow this lady really gets it in a way that, like, I had never [experienced before]." It was like she had education, and the people skills, and the background, the real-life 
[experience]; like “Oh my Gosh, she's a normal person and she's educated, and she can, you know, relate!"

After Mother Vanessa was elected by the vestry at St. Paul's, she started out by listening to the people involved in the parish in order to discover and hear their suggestions about directions the parish could pursue. She described how she gathered congregational feedback and then mapped a way forward:

I put them [the listening sessions] together. And it was like, man, we had everything laid out, and we had their input on how to assess the different aspects of their lives from the get go. And they saw it, and it's not like I presented an agenda. They assessed themselves and we saw what needed to be done.

There was an intriguing balance between this dispersed leadership model and an effective lead priest who was quite comfortable with her own authority. Paradoxically, the variety of liturgical servers I saw at the first service (and all subsequent services) I attended, and the "we're all on this faith journey together" ethos that was the text or subtext of the transcripts of my interviews were actually possible because Mother Vanessa was unequivocally the leader. While she entered into conversations, elicited feedback, and facilitated group processes, she accepted, and the parish recognized, her authority as lead priest. Because her authority was clear, she was able to use it to firmly maintain the space for all to be heard. As one of her colleagues explained:

She is very expressive, very loving, very, filled with energy, but she is the director and that's very clear, and we love it. So it's going to go through her first. I mean she will call me up and she will say, "Do you know we're just not going to do that program in adult education anymore?" Case closed, you know! So I think that, that kind of way of looking at things, looking at a parish as an organization, a flexible moving organization, allows this space for other things to pop up. 
Mother Vanessa, who in fact worked $80 \%$ of the time at the parish and $20 \%$ of the time in a diocesan role, indicated she was sometimes tempted to abdicate the role of effective and decisive leader:

I'm still the person who knows and saw more than anybody else. And I have to remember that. I have to keep reminding myself of that. Sometimes, I like to let myself off the hook about that, "Well, I'm just part-time here, you know." Then I realize, this is BS, and, you know, "You were the one, Vanessa, who said all of the liturgies, whether you're always preaching or not, you see where things are, and you still, even though you've got very talented people here, you need to help them notice, and actually put a stake in the ground on some things that you see."

Since Mother Vanessa was able to hold her leader role firmly but graciously, and since the parish unequivocally supported her in doing so, her style of leadership was very effective. As she said, "This was a place open to what I would bring. You know how some people 'invite in what you need, and then you kill it.' That's just not at all what happened here." Mother Vanessa resisted the temptation to abdicate her authority, and the parish resisted the temptation to undermine it. Because of this leadership model, the parish did not have committees. One young woman, after being coerced onto committees at a former church, valued this about St. Paul's:

Well, one thing personally that resonated with me was the lack of committees at St. Paul's. I mean committees were just like "in groups" and if you weren't in the committee you were in the "out group," and it just felt like a form of bullying, and a form of judging. Who wants to go to a church when you have, you feel like you're being judged by what you are doing or what you are not doing?

Again, a colleague explained the directional role Mother Vanessa assumed

organizationally, including the absence of committees:

It has to do with a kind of theology of God, it is a theology of "move, move, the Spirit wants you to move." So there is this strong kind of orientation toward creating the spaces in which things can move, which is why we don't have any committees. And we haven't fallen apart! 
Mother Vanessa, who had spent a considerable number of years in the business sector, was also able to adjust the nature of her leadership depending on the situation.

It's changed. For me it was, initially, it was strong directive leadership because it was mostly a frightened [group], ready to go, who didn't know what to do next. Now, the leadership is more how to respond, how to notice and respond to what's actually happening in the parish. So the repetition of what came before is not enough. It's too dynamic and changing.

In short, Mother Vanessa adapted her leadership approach to changes in the organization as it developed over time. Yet, at all stages of the parish's development, she used her authority to empower and give voice to others.

Bringing in and developing effective leaders. There was a wealth of effective leadership at St. Paul's. Interviewees mentioned many different individuals as having important roles in the parish. Because Mother Vanessa was not full-time, she deliberately found other leaders to take on vital roles such as the trainer of liturgical servers. By the time I got there, this had moved from including other trained leaders to mentoring new lay leaders. Mother Vanessa said:

And my challenge has been as the, as the size changes, how to go from it's all about Vanessa making it happen, to [involving] more people, which we've really done in the past two years. And now there's another challenge which is, it's not all about them, it's about the true empowerment of laity.

Finding other trained leaders included inviting former clergy back into the parish, and seeking gifted others. A Dominican brother who was teaching at a nearby university and whose own ordered ministry was curtailed because he was gay and remembered when Mother Vanessa said to him, "I think it's important for you to know that I and the parish would be very happy to do anything we could to have your Holy Orders received in the Episcopal Church." Indeed, that happened and he came to work part-time for the 
parish. Those pursuing leadership within the Episcopal Church were also drawn to St.

Paul's. Vanessa explained:

We are a magnet for people in formation for priesthood. We've probably got, in different stages, probably close to fifteen people right now, here. Interns, folks in seminary, transferring, or receiving orders-from Catholics in the first areas of formation, or [those in] discernment for priesthood.

St. Paul's had thus come to see itself as a "training parish," and this had had consequences for how Mother Vanessa altered her own leadership approach over time.

Mentoring. One of the ways Mother Vanessa empowered people preparing for the priesthood and those who were lay leaders was through direct mentoring of potential leaders. As Vanessa identified and mentored new leaders, she had to find a balance between freeing them to explore their own ideas and guiding them within the Episcopalian tradition. She had to walk with them along the fine line between what was negotiable and what was not. The challenge in finding and mentoring new leaders was in helping them to continue to embody and identify with the parish values without feeling stifled by them. She explained the dilemma as,

how to spot and actually help integrate new leaders that really start as new people, just involved, earlier than we would normally do it? How to inculcate within them the identity at its core, not necessarily the way we do things always, but kind of what's the ethic and the value at the bottom there, that usually they easily resonate with?

She explained this dynamic through her relationship with one lay pastor:

And, then, how to stay open to the conversations, like [Quinton] and me figuring out [a particular service], you know, because I was at the very beginning of it. Now it's the two of us kind of, plus a group of people we're trying to bring along, to noodle through it. And, you know, how do I stay open to his suggestions, plural, 'cause they're many, and at the same time help him with what he doesn't know yet?

One of the other lay pastors described the balance Mother Vanessa achieved: 
She will mentor you as long as you need to be [mentored], and then will let people do what they need to do, and so her style has been, has, I think, encouraged a lot of people to take on leadership, and it's made it possible for us to have a part-time rector.

Mother Vanessa herself described her role as mentoring through encouragement, particularly with regard to the many young adults who had started coming to St. Paul's:

I find this age group needs training and encouragement. The reason my age works with them is many of them need a mentor, an encourager, an inspirer, and this is what I do well. I've come to see it's what I really do well, both here in the parish and the diocese. So, the cultivation of a whole group of people in this age group to do significant things in the diocese is kind of what I've been about.

Various lay leaders were also leaders in their own occupations, and there was, therefore, something of a mentoring community at St. Paul's, which resonated with many young adults. As Lily said about some of her professors and others she knew at St. Paul's and outside of the parish, "I think feeling connected to leaders, people who lead within the Church, is really nice, and helps me to feel a little bit more connected and mentored or cared for."

\section{Appreciation for Leadership}

Almost all of the individuals and groups I interviewed had an appreciation for leaders at St. Paul's. Only two interviewees voiced criticisms of the leaders. One person felt that there was so much emphasis on the deconstruction of faith, on doubt and questioning, that there was not enough emphasis on reconstruction, on risking actual answers. The same person would have liked more pastoral care from the lead priest personally. Another was disappointed by what she saw as insufficient group support for personal spiritual formation. These individuals, however, also indicated strong affirmation of the leaders' many gifts. 
Young-adult interviewees appreciated both leaders' personal qualities. I will simply mention some of the words and phrases through which this appreciation took form. Quinton, elicited such affirmations as "salt of the earth," "fun," "family man," "creative and chaotic like me," "keeps people engaged," "people person," "I trust him," and "he listens and joins in my story." He was valued for having made the 5 p.m. group cohesive, for being full of ideas, for community building, and for his appreciation of beauty. Like other members of St. Paul's, he came from an evangelical background and was discovering Anglo-Catholic spirituality as an adult. He and Mother Vanessa were both involved at the Seattle School, and she had asked him to serve as lay pastor because of his community-building skills. His role, particularly in inviting people affiliated with the Seattle School was significant.

Mother Vanessa was admired for her personal, ministerial, and organizational gifts. People valued her ability to connect individually with people. Comments included "she remembers me," "esteems us," "connects with each visitor," "invited me to a coffee date," "delights in, and is excited about, young adults," "her eyes light up when she saw us," "she lets me be in my own story," "she pays attention," "she validates my gifts," "friendly," "an extrovert," "a different kind of clergyperson," "spiritual," "compassionate," "wise," "high energy." The young adults I spoke with admired the fact that she was "not a people pleaser," and "not bossy." All of these comments reflected the capacity of the lead priest to connect on a very personal level with young adults both when they first arrived and during their entire time at St. Paul's.

She was also valued for her organizational skills, as an "expert in parish revitalization," and "able to build momentum." She was seen as having "social smarts," 
"knowing how to get things done." She was characterized as the parish "tone setter," and as a "risk taker." She was experienced as a good preacher (without being preachy) and storyteller, who seemed to quote people's favorite authors and poets. Cameron said:

She's just a really great storyteller and I feel like she does a lot with her comparatively short homilies that not a lot of other people could do in terms of getting you hooked, especially when we read the poems at the end. Like that's what I tell my sort of artsy friends. Like I have a friend who I started grad [school] with who came, and I was like, she reads poetry at the end of her sermons sometimes. Well, she read a good Mary Oliver poem.

Describing what she appreciated about Mother Vanessa’s leadership, Phoebe said, "There's a little bit of mischief, a little playfulness, maybe. I need that." In addition, it should not be surprising, given what was written about authenticity above, that both Quinton and Vanessa were seen as authentic people who exercised gentle and clear leadership. Isabel mentioned both leaders as having a clear sense of themselves:

Her sense of, like, sort of settledness in herself, so that you can tell she is, I mean, I won't say never, but not very often is she trying to please people or trying to be the authority. She just has a centered sense of herself that I think allows her to bring that, without either apologizing for it, or taking over the room. And I think Quinton, very similarly, has that sense of himself, that awareness. That alone helps, because I think there's something really authentic about how they're interacting with people, and how they're choosing to make decisions about things.

Mother Vanessa's ability to be herself, even her imperfect self, created a climate where it was acceptable for others to be their less-than-perfect-selves. I noticed this myself in an evening service. During the shared homily, the preacher (who was not Mother Vanessa) had asked others to reflect on times when they might have felt the need to intervene in someone else's life. After a few people shared, Mother Vanessa acknowledged, “I don’t like it when people intervene in my life, I don't take kindly to it! But when $I$ intervene in my life (laughter).” I felt this was an unusual thing for a spiritual 
leader to admit, because in my experience, the willingness to accept criticism was seen as a sign of spiritual maturity. I could understand, though, why her honesty would lead others into a freedom to share what they really thought and felt about things.

\section{Synchronicity of Stories}

There were many interesting points of connection between the stories of the two leaders, Mother Vanessa and Quinton, and the story of the parish, and all of these relate to the kind of resonance that comes from shared experience. First, a love and passion for the arts and beauty, such a strong value in the parish, was a significant part of their stories, as well. Vanessa's love for the arts has already been mentioned. Quinton described his own experience this way: "I think that's some of what my story has been, as I began to recognize that part of what had saved my life, through all of the multiple experiences I had as a young man, was art and beauty." It was not hard to see why he found a home and role at St. Paul's. A second similarity between the church's story and the stories of the personal stories of its leaders is the way that each leader's story had sources of resonance for the parish as a whole, or for groups within it. Quinton's story involved a journey out of what he described as "a cult." This equipped him with a deep understanding of others making a perhaps less strenuous journey out of their parents' more conservative faith tradition.

Furthermore, St. Paul's was a parish that was all too familiar with loss. The many HIV/AIDS related deaths in the congregation's past, and the grief and loss that surrounded those, had cast a shadow over the parish. Mother Vanessa had experienced in her own story various agonies and losses, as well as restarts and new accomplishments. She had lost her daughter to a terminal illness at an early age, started her career over 
again several times geographically and vocationally, and yet found resources within herself to accomplish significant things. As she told me her story, she mentioned that she had "incredible luck in the midst of incredible pain." St. Paul's was a parish that could only benefit from being tended by someone who had also known the pain of such loss. In the forming and reforming of the mission of the parish, and the ministry of Mother Vanessa and numerous other leaders, the parish also could experience itself as having "incredible luck in the midst of incredible pain." The stories of the leaders and the stories of the parish this seemed to mesh in tantalizing ways, and this too was no doubt a source of resonance for young adults.

In summary, the leaders at St Paul's were refreshing to the young adults interviewed. The lead priest created the space for multiple leaders representing all ages and kinds of people. The lead priest and the lay pastor of the afternoon service, along with other leaders in the parish, were involved in a mentoring role with each other and with young adults, helping all to find their place within the tradition even while being free to innovate. The leadership was one of gentle accompaniment and support as young adults worked out their own faith journeys. Although very different personalities made up the leadership team, there was a profound synchronicity between the stories of the leaders and the congregants at both an individual and a group level.

\section{Conclusion}

This urban parish, embedded firmly within the city of Seattle, was easily accessible to young adults living and going to school nearby. The association of staff and congregants with nearby Christian colleges and seminaries created a reciprocal relationship between these schools and the parish. Many of those at St. Paul's were 
former evangelicals finding their way into a more intellectual and less restrictive faith. The allure of St. Paul's parish was found in the juxtaposition of a progressive, questioning, gentle faith enacted through beautiful, vibrant, ancient liturgical forms where music and Scripture served as facilitators of the experience of the Divine. Here people from Catholic and Lutheran backgrounds could join with "evangelicals on the Canterbury trail" and others to explore faith in an open-minded and openhearted way.

Young adults found welcome through the parish's hospitality to everyone, regardless of '-ities,' '-isms,' and '-ologies,' in an urban monastery-an oasis in the midst of the city. The lack of pressure to join or conform, the non-judgmental ethos of the parish, and the freedom to think for oneself, to doubt and question created a place that felt authentic and welcoming. That the parish was vibrant and open to all, particularly people who identified as LGBTQ and all kinds of families and age groups, created a spiritual community of which young adults could feel proud.

Through the centralized leadership of Mother Vanessa and Quinton flowing into a distributed leadership group of all ages, through their mentoring, gentle accompaniment, and support, young adults at St. Paul's were able to find a sanctuary where they could work out their own spiritual path. The authenticity of the leaders and the synchronicity of their stories with the parish's story led to a resonance with young adults seeking something genuine in a throwaway world.

None of these variables alone, or even all of them together, could fully account for the resonance young adults felt with St. Paul's. The gestalt is always greater than the sum of the parts. Nevertheless, each played some part in the fact that at St. Paul's a significant number of young adults experienced the "intonations of their own language." 


\section{CHAPTER 6}

\section{CROSS-CASE ANALYSIS}

In exploring the reasons that young adults at St. Paul's and Church of the Apostles (COTA) found in those congregations the "intonations of their own language" (Hopewell, 1987), it is important to acknowledge that the young adults at the COTA site might not have found resonance at the St. Paul's site and vice versa. The differences between the congregations were as significant as their similarities. I do not intend to seek a meta-narrative that could account for the appeal of both congregations because amalgamating the narrative would obscure the richness and diversity of factors at play in each context. Because I am not seeking to generalize my findings to congregations and young adults across the U.S. and/or Canada, there is as much value in the differences which make each site unique as there is in perceived commonalities.

Even individual case studies, i.e., the presentation of "another country heard from" (Geertz, 1973) that result from plumbing the uniqueness of each case can lead to conversations that evoke psychological generalizability (Donmoyer, 1990). That term, at least as I am using it here, refers to the uncovering, or it might be more appropriate to say the construction of new cognitive categories that have the potential to promote deeper conversations within denominations, and with and among younger adults. Nevertheless, without seeking to come up with simple ways to "bring young adults back to the churches," I will, even while acknowledging differences, also search for similarities between the two sites in the hope that an awareness of these might provide even more useful topics of conversation to those who hope to engage with their own contexts and create spaces where young people might find resonance. This search for similarities as 
well as differences might also be important for later attempts to build theory that integrates the findings from several cases, including the two reported here, while at the same time differentiating among the very different responses young people can have to their church experience.

It is also important to acknowledge that the rich stories of the young adults and the leaders of the two congregations, and my own experiences as participant observer, were so full of valuable images, ideas, facts, and feelings that no report could fully capture the gestalt of each church, or even their similarities and differences. I am acutely aware of what is not mentioned in the dissertation because of space constraints. Nevertheless, recognizing that there is always much more to tell, I will now analyze the differences and similarities between the two congregations as I see them after doing the analysis, looking in particular at the constructs of context, translation of ancient wisdom and ritual, the creation of a welcoming space, and leadership.

\section{Differences}

Despite both being liturgical in nature the two congregations were remarkably different. This basic finding is important, again, because it is a reminder that there is no single answer to the question of "how to attract young adults to churches, and certainly, that what happens in one successful church cannot be used as a template for addressing the problem in another setting. Even though none of the interviewees mentioned the other congregation, the implicit message here is that it is quite conceivable that what drew certain young adults to one congregation, the music for instance, might repel them from the other. 
That young adults were drawn to two profoundly different congregations should hardly be surprising. After all, other than being in or near the third decade of life between adolescence and the full assumption of adult responsibilities, young adults do not necessarily have a great deal in common. To state the obvious, young adults, even in the distinct culture of the Pacific Northwest, are not a homogenous group, any more than middle-aged adults are. They share all the diversity of character, personality, shapes, sizes, politics, vocations, and so on that any other group shares. Furthermore, there are vast differences between 19, 23, and 30-year-olds which they keenly feel. Finally, it seems obvious that an individual of any age drawn to any specific congregation and its ethos likely finds resonance in what that congregation has to offer, and not necessarily the offering of the congregation down the road. This point was made rather dramatically when people in the two sites studies talked about their bafflement about the appeal to young adults of the evangelical, contemporary-music drenched, and young-person-filled Mega Mill, (but rarely, if ever, about each other).

\section{Context}

There were obvious differences in the ways each congregation presented itself to its neighborhood. On the one hand, COTA's Fremont neighborhood had the fitting motto de libertas quirkas, that is, the freedom to be quirky and the residents, who called themselves Fremonsters, relished their peculiarity. COTA had deliberately chosen this neighborhood to make its life and spent some time operating a café, the Living Room, as very much a part of the community and culture in the neighborhood. Because Carolyn and the first attenders were themselves so appreciative of and embedded in the arts, the congregation founded and developed a Center for the Arts (which later became 
independent). Once COTA and the Arts Center both moved out of the Living Room to share the old church building, which they rented from the Lutheran Church and renamed the Abbey, across the road. At this point COTA lost some of its visibility because the building became known as the Fremont Center for the Arts. Not only did the arts community use the Abbey far more than the congregation did, but at the time I was there, there was no regular sign to mark the existence of a church community in the building. This association with the arts community through the Abbey, however, was a source of resonance not only with the artsy young COTANS who participated in Abbey performances, but with those congregants who felt that being associated with a center for the arts was exciting.

On the other hand, St. Paul's was in a more typical trendy urban young-adultfilled neighborhood, and the building was visibly a church with clear signage. After its renovation, the church entrance was right at the sidewalk so that passers-by could easily see the striking full-immersion baptismal font in the foyer through doors and walls made out of large panes of glass. On Sundays, they would also see the albed servers waiting to process down the aisle.

On the outside of the building towards the east, the labyrinth, modeled after the medieval original at Chartres Cathedral in France, is a flat circular walking path. It is like a maze (but without dead ends), which invites passers-by into a few minutes of walking meditation. It was the first accessible permanent outdoor labyrinth within the city limits of Seattle, and thus a draw to spiritual seekers from all over. For young adults, this location and the general spiritual ambience felt like a monastery or refuge in the middle of the city. St. Paul's has candidly embraced its spiritual visibility and public identity as 
a progressive Anglo-Catholic Church in the neighborhood, taking those who were curious literally from the sidewalk deeply into ancient rituals that were in conversation with socially progressive theology.

To sum up, the one congregation was almost hidden from view, with the Arts Abbey it founded taking center stage, forcing people to work a little harder to find "the congregation." The other congregation clearly positioned itself as a church and spiritual sanctuary in the neighborhood and was hard to miss.

\section{Leadership}

There were quite striking dissimilarities in attitudes toward and exercise of leadership in the two congregations. One leader was functioning mostly behind the scenes, while the other was the major and most visible driving force in the congregation. I will discuss these and other differences under the categories of authority, boundary spanning, and purpose.

Who holds the authority? Although neither congregation embraced the model of having a single authoritative pastor or priest with submissive participants, the ways in which leadership and authority were exercised and understood differed in significant ways. COTA embraced, more strongly than most congregations, the practice of collective or dispersed leadership. In this practice Carolyn saw herself as a curator and mentor, which meant that she worked both to set up experiences for others and to enhance the gifts of others, rather than being the person "up front." During her time there, some visitors had almost a "where's Waldo" experience trying to "find the leader," at COTA. The congregants would simply say to visitors hoping to talk to the priest, "You can talk to me. I can tell you about the congregation!" Carolyn's curator approach 
to leadership appeared to be partly a product of her personality—she mentioned in an email to me that she was a deep introvert—and partly the result of her conviction that the priesthood belonged to all. So, she carefully empowered others to assume leadership roles. It was not just Carolyn as priest, however, who declined a front and center role. No other person led an entire service either. Individuals would come forward to lead some aspect of the service, step up to the microphone, play their part, and return to the congregation. Carolyn would only come forward during the service when it was time to preside over the Eucharist, a role which requires the presence of an ordained priest. The congregation responded to Carolyn's way of leading with a strong sense of ownership of their life together, and this allowed Carolyn to travel extensively to share with people far and wide about the emerging church in general and COTA in particular. Although she was appreciated by many, not a single interviewee named her as a reason they attended COTA.

St. Paul's had a clear and definitive leader, Mother Vanessa, who was, among other things, a self-proclaimed extrovert. Mother Vanessa was clearly, in the minds of congregation members and her own mind, the director of "the organization," who when necessary could make executive decisions. There was no doubt that she was the leader, in charge, and had a front and center role in the life and movement of the parish. Many interviewees saw her as a significant part of why they were at St. Paul's, and she held her leadership role with a gentle, humorous confidence.

At COTA, whether because of having been socialized into the culture or because of their beliefs prior to joining COTA, congregants were actually a little suspicious of those who called or designated themselves leaders. They rejected the notion of anyone 
other than the whole group "pulling the strings," had a fierce resistance to the idea that their presence in the congregation had anything to do with any particular leader, and felt that all could show leadership within their congregational life. The services were planned by the Liturgy Guild, a group that would work together for a season of the church year to plan and curate each Sunday service.

The St. Paul congregation embraced, admired, and respected their lead priest, the associate priests, and their lay leaders, and gave them authority to lead and direct them. The young adults at St. Paul's enjoyed participating in a variety of ways, from serving alongside the priest during worship, reading Scripture on a particular Sunday, to offering a comment during the shared liturgy. Therefore, the clergy exercised their authority and role within the two congregations in different ways. At COTA, authority was exercised quietly and informally; at St. Paul's, by contrast, authority was played out in a more direct, and, even, at times, directive manner.

Boundary-spanning. The founding priest at COTA and lead priest at St. Paul's spanned vocational and cultural boundaries in different ways. The backgrounds of the respective priests were also markedly dissimilar, but both could be seen as boundaryspanners. Boundary-spanners are those people or units in an organization who are most connected to and receptive of the ideas and experience of external sources or groups, and are thus most able to perceive and lead adaptive change (Pawar \& Eastman, 1997). Although I was not able to interview Carolyn, the founding priest of COTA, and have no access to her biography/history, what I know of her from my visits to COTA, her writing and speaking, and from those I interviewed is that she had considerable expertise and infinite creativity around liturgy. Furthermore, while not an artist herself, she was also 
someone who was immersed more fully than most clergy in the music and art forms of the bohemian and postmodern culture around her. She was thus was well suited to animating and guiding the innovative and creative liturgy guild and the musicians who played such an important role in the congregation. It was undoubtedly no accident either that COTA had formed an alliance with the arts community and, in fact, met in what, during the week, was a performing arts center.

The lead priest at St. Paul's, Mother Vanessa, whose initial function, at least, was assisting the congregation with a revitalization process - a process that ended up focusing on embracing their Anglo-Catholic identity_was a boundary-spanner, but with a very different background. Her training in English literature, business, marketing, and organizational development enabled her to weave poetry into her sermons, workshops, and presentations; to connect art and architecture into the liturgical life of the parish; and to apply principles of organizational development in their administrative and structural processes.

The artistic expression at COTA and St. Paul's differed because they connected to different aspects of the wider community. Carolyn's relationship with bohemian culture, music, and art outside of church circles was intrinsic to her ability to blend ancient and future, sacred and secular, in compelling and quirky ways. It certainly was also no accident that St. Paul's appealed to so many artists and writers who loved the experience of literature and poetry that Mother Vanessa brought to her ministry. Mother Vanessa's expertise in organizational behavior and business also gave her insight into the daily lives of many congregants which often took place in business or other organizations. 
Chaos/imperfection and stability/excellence. The organizational cultures at COTA and St. Paul's were truly dissimilar. Leadership and organizational development at COTA were seen to be "organic" because congregants were comfortable with a certain amount of instability and chaos, and a sense that such disruption and imperfection were integral to the authentic nature of congregational processes. One young man asserted at a congregational meeting, "We have no idea what we are doing. Isn’t that GREAT?!" COTANS preferred their worship and collective organizational life to develop organically which meant that there was something of a laissez-faire approach to their development. They tried new things if people had a desire to do so and were willing to take the lead, and if the new idea did not work, they let it expire. They were open to amateurs, most noticeably by having people with no formal theological training do the reverbs (or sermons) or by including less accomplished musicians into the music team, and happy to accept a fair amount of disjointedness in search of participation and authenticity.

St. Paul's, in contrast, expected a polished excellence with regard to their organizational life. Innovation was balanced with stability and intentionality. "Very staunch about excellence," was how one young woman explained St. Paul's. Before servers could serve they were subject to extensive training. The desire for excellence was evident in everything they did, whether liturgical, administrative, or organizational. Their community meal was of restaurant quality, their parish profile looked professional, and their leadership team was established and sophisticated. Their priest taught and consulted in the diocese in the areas of leadership and organizational development. The congregation's desire and need for a more directive leader had likely emerged out of the 
needs and values of their organizational culture. The less and more formal styles of the two congregations may have been due to a difference in size, since St. Paul's was a bigger congregation, and a difference between the types of vocations and average ages of those who attended.

\section{Translation of Ancient Wisdom and Rituals}

Despite the fact that both congregations valued liturgy and church history, there were also obvious dissimilarities in the way that COTANS and members of St. Paul's worshiped. When I walked into the quirky young-adult texture of COTA with its coffee station at the door, couch in the corner, stations with cushions and candles dotted around the walls, people sitting on chairs or the floor, music band with drums and electric guitars, and movable white chairs placed in whatever formation was chosen for that service, I felt surrounded by a very bohemian young-adult energy. When I entered the beautifully furnished sanctuary of St. Paul's with its dark wood pews, high angular ceiling, and suspended choir loft above and behind me, or even in the downstairs hall where chairs were set up in a circle around an altar and lectern and a grand piano to the side, the sense of quiet dignity and formality provided a more consistently contemplative atmosphere. I found my time in worship services at each site a vastly different, though equally absorbing experience.

Liturgy and theology. Although both congregations used certain liturgical forms such as the Nicene or Apostle's creed and a Eucharistic prayer weekly, COTANS appreciated a highly innovative liturgical style that embraced the quirky and experimental. They did not feel themselves bound to any particular liturgical text, such as the Book of Common Prayer, which most Episcopalians believed was the defining 
feature of Episcopal experience. They had permission to experiment, and fail, liturgically. Congregants told others that if they did not like the liturgy or reverb this week, it would likely be very different next week.

Members of St. Paul's savored the weekly use of set texts of ancient liturgies (sung or spoken) through the Book of Common Prayer (or other approved liturgical texts), a celebration of liturgical beauty and a more well-mannered style in their services, which led to a greater sense of awe throughout the worship time. They had with the Bishop's permission, made some changes to the words in the afternoon service's Eucharistic prayer to include metaphors drawing on women's experience, but the same words would then be used in each service.

Therefore, although both congregations could be considered liturgical, celebrated the Eucharist each week, and said or sang the creed, COTA started with the basic building blocks of the tradition each week and created an entirely new liturgy that might involve leaving in the middle to collect trash in the neighborhood, or a Mad Hatters tea party, or breaking into groups for discussion. It might involve having different kinds of stations available during the open space time, or such individual liturgical items as a champagne toast benediction on Easter Saturday eve, or a church "bell choir" using Wii's ${ }^{54}$ to simulate handbells, or any number of options depending on the imaginations of those currently in the liturgy guild. St. Paul's would offer a more reliably similar worship each time, using mostly sung words from the Book of Common prayer or other

54 A Wii is a home video game console released by Nintendo, and in this case, each Wii was configured to emulate the sound of a hand bell. 
approved liturgical texts, and seeking a greater profundity rather than variance in each service.

Paradoxically, COTA, although more innovative liturgically, tended to be a little more orthodox in its theology, perhaps because the congregation was primarily made up of people coming out of evangelicalism. My own litmus test for the theological hue of a congregation starts with whether they use inclusive language for people and God. At COTA during my time there mostly masculine pronouns were used to refer to God. St. Paul's was the reverse. Liturgically, it was more traditional and theologically more progressive, often using feminine pronouns and images to refer to God and including amongst other things, a more historical-critical approach to the Bible in sermons. This may have been because this congregation was first and foremost Episcopal and had a long history of progressive theology. Whereas COTA had a dual Lutheran-Episcopal identity, as well as a connection to the emerging church movement that was predominantly evangelical, St. Paul's embraced an Episcopal character "kicked up a notch" in a wholehearted embrace of its progressive Anglo-Catholic identity.

Music. The musical styles of the two congregations were perhaps the clearest difference between them. Although a love of ancient liturgical forms was integral to the identity of both COTA and St. Paul's, COTA, with its music band, drums, electric guitars, and a mixture of ancient and bohemian music and liturgy, could not have seemed more different than the organ, choir, and more classical (in the morning) or more jazzoriented (in the afternoon) music at St. Paul's. COTA's music depended primarily on one staff musician, usually playing the drums, collaborating with various volunteer and mostly amateur musicians to arrange and play various types of music. Professional 
musicians and some professional choristers, supported by volunteer singers, performed the music at St. Paul's. Much of the music at COTA was of a kind more likely to be encountered in the daily lives of participants (as was the music at St. Paul's 5 p.m. service, at least for those who loved jazz), but this was not so at the morning services at St. Paul's. Numerous COTANS, in fact, talked about how much they disliked organ music and "lame" hymns. The morning services at St. Paul's drew upon a vast store of religious music, primarily the organ and hymns, which, surprisingly, most young adults at St. Paul's loved.

It would be interesting to learn whether the organ and hymns at St. Paul's would, in their uniqueness, be met with the same disdain by COTANS as those "lame" hymns the COTANS mentioned. I mention this because the feel of St. Paul's in no way resembled the "lame" churches to which COTANS might have been referring. Although two congregations did not talk about each other, people I met who had been to St. Paul's often spoke of the energy and hum of the congregation as different from that of most mainstream churches.

To summarize, the congregations implemented their shared respect for both tradition and innovation in very different ways. COTA was more quirky and St. Paul's more urbane. Moreover, ironically, the degree of innovation regarding the theology was opposite to that of the liturgy at each site. COTA was exceptionally innovative liturgically, but relatively traditional when it came to theology. St. Paul's played with ideas, theology, and liturgy, but the liturgical texts were tried and true. 


\section{The Creation of Welcoming Space}

There were also differences between the congregations in the ways they practiced their shared espoused value of radical welcome. The different approaches to welcoming newcomers also resonated in different ways with the young adults in each congregation.

A diversity of ages: Young adults and their children. The two congregations had very different histories when it came to young adults in the congregation. COTA had started out primarily with young adults and later attracted older members in small numbers. Furthermore, the young adults who initially came to COTA were largely single young adults, but as they began to marry and have children, the congregation at that time started a second worship experience — a Sunday breakfast liturgy — to more adequately welcome families and involve their children. At the regular afternoon service, any children who came tended to play in the corners where there was a couch, comfortable chair, and small coffee table.

St. Paul's, historically, had a mixture of ages attending, a mixture that tipped toward older adults, but once Mother Vanessa came, a greater number of single young adults and young families started arriving. The parish then began to develop a formal Montessori based children's ministry, Godly Play, led by trained volunteers in the mornings. This is a carefully planned and structured program with its own room and furnishings. Before and after their program, the children would process out of or into the sanctuary behind an albed person carrying the processional cross on a staff. They would return to the sanctuary to share in the Eucharist with their families.

The congregations had different experiences of intergenerationality. A member of COTA admitted that, because they had started as a new church where no church had 
existed before, they had never had to placate former generations when innovating liturgically or musically. Older adults who came to COTA could choose to stay, but if they did not resonate with what was happening, they were unlikely to remain and agitate for change. COTA's young adult energy and quirkiness was a given. St. Paul's was able to meet the needs of their established members by going more deeply into their tradition and then starting new things such as their afternoon service, that older adults could choose whether or not to attend. Longer term members were still able to choose the morning services, with their "High-Church" feel, without losing anything they treasured, and yet gaining a more intergenerational community. In both cases, a diversity of ages was present and older adults were part of the congregations' life to a lesser or greater degree. The differences reflected the two churches' dissimilar origins and histories.

Social justice. Although both congregations had vibrant collective lives, they went about their understanding of mission and their desire for social justice differently. At the time I visited COTA, the congregation as a whole did not focus on issues of poverty or social justice, although there were some individuals who were intensely committed to social justice agendas and expressed a longing for a more collective involvement with the world beyond the church's front door. Although some might see the Fremont Center for the Arts as an outreach of the congregation, in fact, the center was separate and would continue to exist with or without COTA. There had been an attempt to retain the community energy of the Living Room by starting a café in the Abbey, but various tensions between the Fremont Center for the Arts and the congregation foiled this effort. By contrast, St. Paul's had a more public profile as a justice-oriented parish and offered some small outreach to the community. Among other things, St. Paul's offered a 
monthly restaurant-quality weeknight meal for anyone who chose to attend. As hoped for, most of those who attended from the community were poor and they were joined at table by members of the parish.

To sum up, at first glance, this dissertation focused on two liturgical churches that were very different indeed. Despite the rather obvious differences, however, there were striking similarities. I will now discuss the noteworthy similarities between what, at first glance, might seem to be markedly different congregations.

\section{Similarities}

As I previously indicated, looking at each congregation in depth only has value in terms of psychological generalizability (Donmoyer, 1990), that is, in uncovering new cognitive categories that have the potential to lead to deeper conversations within denominations, and with and among younger adults. The same is true of looking at similarities between sites because common themes from two sites (an $n$ of 2) cannot be used to generalize to all congregations hoping to attract young people, or to all young adults with regard to their religious preferences.

Once again, therefore, the advice is: Proceed with caution! The following discussion of similarities between the two cases, like the two cases themselves, hopefully will have heuristic value by generating new ways to conceptualize the relationship between young adults and the church, and by providing potential conversation points for religious communities that are interested in clarifying their own identity in the context of their environment. They are not necessarily, in and of themselves, specific prescriptions for practice. 
The organizational structure here was, once again, inspired by the research questions. Like the above discussion of differences, this discussion is organized around (a) context, (b) translation of ancient wisdom and rituals, (c) creation of welcoming space, and (d) leadership.

\section{Context}

Though located in particularly nonreligious areas of an already highly secular Seattle, both neighborhoods could be characterized as young adult-filled neighborhoods in which theater, music, and the arts figured prominently. The clergy and the laity of the two churches had good connections with local colleges and the wider church, creating a stream of influence, people, and ideas that flowed in both directions between the churches and the schools, and the churches and the wider Christian community.

Young adults were the largest age group in both the Fremont and Lower Queen Anne neighborhoods. Fremont was more eccentric than Lower Queen Anne, but the arts were central to both communities. Since there are so few support systems for young adults once they are out of school and since churches have a real opportunity to provide much needed connectional space and mentoring for those who desire it, for congregations seeking to build relationships and provide support to young adults, these neighborhoods were ideal locations.

By the time I was collecting data, both COTA and St. Paul's were perceived by those inside and outside the churches as cutting-edge congregations in popular youngadult neighborhoods. Although neither congregation was as famous as Mega Mill, young adults at each site admired the unique and innovative ways their congregations were "being church" in their contexts. Some might argue that their sense of connection could 
be due to their desire to be part of an "in crowd," but it seemed to me that this might be more of a factor at Mega Mill. The genuine faith struggles and desire for authenticity in those I interviewed seemed to refute such a motive. Nevertheless, they took pleasure at being part of an innovative and unique church that felt exciting and energizing. Undoubtedly (and understandably), there would be less resonance with congregations that felt like they were failing. The unanswered question, of course, is: How does a failing congregation turn itself into a cutting-edge one? Ultimately, the answer to that question is beyond the scope of this study, but the similarities below may provide some possibilities, particularly for churches that are situated in young-adult-filled neighborhoods or in college towns and cities.

\section{Translation of Ancient Rituals and Wisdom}

Both congregations were able to translate ancient wisdom and rituals in ways that resonated with young adults, albeit in different ways. As part of the liturgical Episcopal and Lutheran traditions, each week they would use the calendar of the church year to determine:

- what season they were in, for example Easter, Pentecost, Lent etc.,

- what colors to use for banners and stoles, e.g. white for Easter, Red for Pentecost, Purple for Lent etc.,

- which particular Sunday, e.g. Baptism of Jesus, Reign of Christ, or All Saints Sunday etc., it was,

- which lectionary scripture texts to use from the four texts provided for each week. 
From this starting point each week, they then went about creating worship experiences in the unique ways mentioned in the differences section above.

The stability of the ancient. In both congregations, young adults expressed appreciation for the experience of ancient spiritual teachings and wisdom they experienced in the liturgical Episcopal and/or Lutheran traditions. These provided a consciousness of the whole of church history and the unbroken lineage within the Episcopal and Lutheran traditions and gave young adults a sense of continuity in a very discontinuous, uncertain world.

They valued the open-minded and gentle ways in which that wisdom was communicated within the congregations and the sense of ancient rhythm and ritual they discovered in weekly liturgy and the seasons of the Church year. Both sites were influenced by Benedictine monastic spirituality, and both provided opportunities for interested young adults and others to develop a rule of life and practice praying the Daily Office alone or together. For those struggling with the instability and impermanence of their worlds along with the breakdown of tangible generational continuity that results from urbanization and globalization, the connection to something that seems to have stood the test of time, something bequeathed by generations who have gone before, seemed to provide a helpful sense of stability and resonance.

Music. Music, while differently expressed, was in both cases considered to be of exceptional quality and provided the interconnection and sense of flow between the various elements of the liturgy. Rather than viewing musicians and music as performers and performance, members of both congregations understood that the role of music was to serve the liturgy in a modest manner. Even though very different musical genres were 
used in each congregation, almost all interviewees remarked that the music in their location was a key source of resonance for them; without drawing attention to itself the music nevertheless provided a conduit to an experience of the divine.

Personal interaction with texts. Neither congregation provided ready-made interpretations of biblical texts for participants to apply to their lives. Furthermore, in the context of the liturgy, texts were exposited in ways that evoked, rather than shut down, individual interpretation. Each congregation, albeit in quite different ways, provided opportunities for young adults to interact personally and directly with the texts and themes of that particular Sunday of the church year. In this way, they could not only encounter the texts for themselves, but also engage with each other's interpretations even as they developed their own. COTA gave young adults the opportunity to participate in such interpretation through the creation of Open Space, the innovative reverb led by multiple people, group discussion some Sundays, and the prayers of the people. St. Paul's achieved a similar effect in the afternoon service through the shared homily, and in the mornings, through a gentle, storied, and metaphorical style of preaching which evoked creative and critical thinking in the listeners.

Freedom to dissent or disagree. In both congregations, there was less indoctrination and more commitment to creating the space for young adults to explore, question, reject, adopt, or adapt beliefs. Creating a space for young adults to develop their own belief systems was, paradoxically, contingent upon each congregation having a clear sense of collective identity and a set creed. There was plenty of room for dissent and freedom to disagree, but at the heart of these congregations there was a sense of 
identity based in the person and story of Jesus through the weekly reading of Scripture, the Eucharistic prayer, and the recitation of the creed.

Authenticity. The word "authenticity" was extensively used by leaders and participants alike in both congregations. The spirituality of the leaders, the liturgy, and the congregations clearly passed the authenticity test in the minds of the young adults I interviewed. Although the liturgical forms of the two congregations differed markedly, the young people I interviewed were equally passionate about enacting the ancient rituals and wisdom of their tradition in an authentic and sincere way. This sense of authenticity particularly resonated with young adults in that the liturgy, though very important, was not an end in itself. Both congregations saw their most important function as creating space where people could encounter God as directly as possible in a community where they were free to be themselves.

In sum, an authentic experience of a progressive take on the ancient through the liturgy and exceptional music enabled participants to engage with, argue with, and play with sacred texts, theology, and rituals. All of this appeared to complement the faith development and the meaning making of the young adults I encountered in both churches.

\section{The Creation of Welcoming Space}

There were also clear similarities between COTA and St. Paul's regarding the creation of welcoming space for young adults. At both sites, young adults felt that in the absence of a judgmental or overly moralistic environment they were welcomed as they were, with their doubts, questions, and struggles. They were not required to "have it all together." Their ability to belong did not depend on the capacity to believe "the right 
things." This meant that young adults could go through their own psychological/religious rumspringa (Shachtman, 2006), that time of "running around" to determine what form their future faith might take, yet without being completely alienated from a faith community. In the same way that vacations can also be staycations, perhaps rumspringas can be taken as congspringas, where the questioning, struggling, and recentering can take place with the support of a loving congregation around them to the extent that they need it.

Convergence of traditions. The more open, welcoming and progressive theology in these congregations appealed to young adults from a variety of more rigid biblicist traditions. The liturgy and the ancient creeds provided a sense of familiarity for former Catholics, while the saturation of the liturgy with Scripture created a sense of familiarity for former evangelicals. It is also possible that Catholics might enjoy increasing their biblical literacy, and that evangelicals were certainly demonstrating a longing for ritual and the rhythms of the church year. In both congregations, former evangelicals made up the majority of interviewees, and in both congregations there were a few former Catholics. In each case, mainstream progressive liturgical expressions provided a way out of their former spiritual homes, but a way out that enabled former Catholics and former evangelicals to stay tethered to their Christian identity.

Radical hospitality. In both congregations, former Catholic and former evangelical young adults found a new home where their voices and stories were valued and embraced, and where their gifts, including their talents for leadership, contributed substantively to the life of the church. In both congregations, there was a sense of radical 
welcome, often embodied in the welcome of LGBTQ-identified people, which was a kind of code signifying that not just those who were LGBTQ-identified, but all were welcome. At both COTA and St. Paul's then, the Episcopalian baptismal vow to respect the dignity of all people was taken seriously in this radical welcome. At meals and other events, for instance, great care was taken to ensure that all were able to participate as equals. At COTA, there were often meals after the services. Whether these meals happened in community homes or a pub or restaurant, all were welcome. Certain very sensitive members ensured that any who could not afford to pay were still able to participate, and when evening worshippers at St. Paul's went to the pub once a month after the service, the parish paid for some basic items so that all could participate freely.

No pressure to join. Young adults appreciated the fact that members of the congregations did not greet newcomers with an over-exuberant welcome as though the future of the church depended on them.

The young adults I interviewed at both sites further appreciated that, while there were a variety of opportunities, both small and large, to serve and participate in the life of the church, there was no stated or unstated pressure to do so. My interviewees told me they were welcome, but not required to attend services regularly, join the church, or become more actively involved. This lack of pressure was valued in the light of the stresses of student life they faced along with other struggles in their third decade of life as they moved toward full adulthood. Instead, they were offered small, optional short-term ways of contributing almost from the moment they arrived.

In sum, each of these congregations provided a non-judgmental ethos that provided time and space for young adults to go through, at their own pace, a kind of 
cognitive, spiritual, and psychological running-around period, yet within an accepting community. Here former Catholic and evangelical young adults could find a more progressive, open, and welcoming faith practice where all could feel at home and wanted. Regardless of sexual orientation or state of belief, people could be themselves, confident that they were loved, and in this community of acceptance explore and redefine their faith for themselves.

\section{Leadership}

At first glance the attitudes toward and exercise of leadership in the two congregations could not have seemed more different. A closer inspection, however, revealed that there were some important similarities between the two sites. Leaders in both places were committed to engaging participants in the workings of the church. At St. Paul's, although Mother Vanessa was clearly, in the minds of congregation members and her own mind, the director of "the parish," who could make independent decisions in the day to day work of the parish. Ironically, though, the impact of her leadership often seemed to be not all that different than that of the introverted Carolyn. Trust appeared to be maintained because she used the authority she had been given to empower others to use their gifts, find their voices, and exercise leadership within a distributed-leadership model. Furthermore, the boundary-spanning lives of these leaders outside of the church created the kind of networking within the wider culture that built relationships beyond the congregation.

Not trying to attract young adults. A fairly passionate conviction at both sites was that they did not set out to attract young adults in particular, and that their method, if they had one, was to embody the most authentic expression of faith they could, to be 
clear about their own identity, and to communicate that with passion. As has already been noted, authenticity was highly prized in both places. In fact, the word authenticity was probably the word interviewees used most frequently, after liturgy and ritual. Leaders, along with the rest of the faith community and the liturgy, were experienced as "authentic." Young adults in both places celebrated the fact that both of the churches were places where leaders permitted them — indeed, expected them — to "be truly themselves" in the midst of their sometimes messy lives.

Leaders not indoctrinators. In both cases, there was a far gentler, less intrusive form of religious leadership than what young adults from other backgrounds had known before. They experienced the clergy leadership as non-authoritarian as well as relatively non-doctrinaire and particularly appreciated that there was "no yelling" or haranguing of people into religious conformity. These leaders were committed to supporting young adults in the exercise of their gifts and to mentoring them as they developed.

In short, leaders in both churches did not try to tell people what to think or how to behave. Rather, by telling stories and enabling people to bring their own "grappling" to the texts, they created a sense that each young adult brought her or his own unique perspective to scripture and the service and that, when all perspectives came together, faith could be found, rethought, and enhanced for everyone.

Leaders trusted young adults. As young adults learned to operate within an existing liturgical history and culture, there was a strong sense that they were trusted and appreciated. In both churches, for instance, the lead priest was not the only preacher. At COTA, young adults would function as preachers when they did reverbs. At St. Paul's 5 
p.m. service, various leaders would introduce the texts, and all would play a part in the formation of the message by participating in the shared homily.

Leaders not limited by religious culture. The spaciousness where one could be oneself without religious pretense may have been related to the fact that the key leaders in both sites had significant life experience beyond the bounds of the church. The church was not their only world. Carolyn had a strong connection to bohemian music and culture, and she spent time at music clubs and events. She would often know about new musical expressions in the broader culture even before the young music director of the church did. Mother Vanessa had a background both in literature and Renaissance English and in business and marketing. Neither leader was limited by the world of the church. Both applied other lenses through which to view faith and relate to others outside of the religious bubbles in which many clergy find themselves (that is, they did not fall back on pseudo-religious ways of being). As one young man said about Mother Vanessa, "My God, she can relate!" The lives of these leaders outside of the church created the kind of networking within the wider culture that built relationships beyond the congregation.

Narrative leadership. As I listened to the stories of the leaders and the participants during data collection and analysis, it seemed that the leadership approach was a narrative one. In a radio interview (Red Herring, 2006), Carolyn told some of her story and explained that she had always felt that she did not fit in the established church. She went on to indicate that she found in the postmodern, emerging church movement, a sense of connection. She discovered others who felt a similar discontent and came to a wide-ranging understanding of postmodernity and the young adults who felt disconnected from religion. This cognizance undergirded her vision of a church for those who were 
unlikely to fit within the usual church system. It allowed her to connect with other similarly estranged young adults, or those who wanted to be connecting with such, who then together imagined a new kind of church in which they could speak their own "language."

I had heard Carolyn's address to a United Church of Canada conference where she described, before it had happened, the church she envisioned at COTA. As I watched the congregation unfold over time, and when I gathered data in the congregation she had described years before, I kept asking myself and others the question, "How did what she projected would happen in this new church plant, when I heard her speak back in 2002, actually come to pass at COTA, given her introverted nature and leader-as-curator philosophy?" One of the answers I got from those I spoke to was that she was the congregations' theological center, and that she told stories about herself, her life, and the congregation when she was with others in pubs, homes, and during her reverbs. I further realized that she was not predicting a new reality back in 2002 but rather describing a reality that she already understood and had, in some sense at least, lived. That her storyline for the emerging congregation unfolded as she imagined it was likely evidence of the depth of her understanding of the culture of the young adults with whom she would work, an understanding that resulted, at least in part, from a meshing of Carolyn's life story with the stories of her parishioners.

Mother Vanessa also was aware of her own story and how it echoed in and with her parish. Her story of incredible luck in the midst of incredible pain resonated with the parish narrative of losing so many of its members to complications arising from HIVAIDS. She was able, through the gift of gathering and disseminating stories, to embrace 
the congregation's narrative, and then lead the congregation in reframing its story in a way that released new energy. Both leaders thus had clear narrative leadership abilities. They understood the stories of their congregations, and their own life stories reflected their congregations' stories.

In sum, both churches employed leaders with a narrative sensibility, but who had non-authoritarian and non-doctrinaire ways of creating space for young adults to explore their faith, gifts, and identities within their historic faith traditions. Both leaders were adamant that they did not set out to reach young adults, as such, but it would seem that their capacity to relate to young adults and mentor them was enhanced by their engagement with the culture outside of the church, and by their understanding of their own stories and those of participants and the congregation as a whole.

In sum, although COTA made much of the emerging church and postmodernism, and St. Paul's simply embraced their Anglo-Catholic identity, both congregations were able to synthesize apparent binaries in ways that appealed to young adults who gravitated to their two churches. The binaries that were synthesized included progressive and traditional, rationalism and mysticism, clergy leadership and empowerment of lay leaders, and a liturgical tradition that both respected the ancient and responded to the present and future. This confluence of syntheses clearly resonated with the young adults I interviewed.

\section{Conclusion}

The congregations were quite different when it came to their ways of presenting themselves in their neighborhoods, their approaches to liturgy and music, and how they came to welcome young adults and their children. They positioned themselves 
differently when it came to social justice and advocacy. They had different levels of tolerance for chaos and embraced different leadership styles.

Nevertheless, they shared in common their locations in trendy, young adult and college-filled neighborhoods. Both offered a connection to ancient wisdom and rituals in innovative and progressive ways, which provided stability in an unstable world. They encouraged the freedom to disagree, the opportunity to engage personally with sacred texts, and the opportunity, in a world of artificiality, for young adults to be truly themselves. Leaders provided gentle and non-doctrinaire environments where young adults could be mentored and trusted to exercise their own faith and gifts in community. Both churches claim that they did not set out to attract a particular demographic such as young adults. Intentionally or inadvertently, however, these congregations created a space for young adults to be exactly who they needed to be and to embrace and enact the tasks associated with becoming adults during their "rumspringa days" which in this case, could be called congspringa days. The environments created in each case through the authentic expression of their own congregational identity provided a community in which young adults, seeking something authentic upon which to build their lives, found the "intonations of their own language." 


\section{CHAPTER 7}

\section{DISCUSSION}

This final chapter begins with a brief review of the study's purpose and methods, as well as a concise summary of the findings of the study. In the discussion thereafter, I will offer a short reflection on how young adults discovered in two congregations in the Pacific Northwest "the intonations of their own language," and sort these intonations into three main categories; sociocultural, leadership, and adult developmental sources of resonance. I will compare or contrast the literature to the study findings in response to each of the three research questions. The goal of this comparison is to seek patterns that can ignite further conversation and research. I will then discuss the limitations and the implications of the study, first for young adults, Christian congregations, and denominational leaders, and second, for future research.

\section{Overview of Purpose}

The purpose of the study was to gather stories in two progressive mainstream congregations in the Pacific Northwest with significant numbers of participants aged 18 to 35 , (a) to account for why young adults experienced in these two congregations "the intonations of their own language," and (b) to identify and analyze any aspects of leadership and translation that led to the resonance between individual participants and the congregations. 


\section{Research Questions}

Although this was a naturalistic study where I constantly adapted my research plans to the situations being studied, the initial intent was to structure my investigation around answering the following questions:

1. What aspects of leadership and translation, if any, were exercised to make ancient wisdom or rituals relevant to, and create a welcoming space for, young adults?

2. What kinds of resonance, if any, emerged between the leaders and the group (both individual participants and the whole congregation)?

3. What kinds of associations, if any, exist between the narratives of participants and theory about the developmental and maturational work of young adulthood?

\section{Summary of Methods}

This study was a focused ethnography (Knoblauch, 2006) that employed a naturalistic case study/cross-case research analysis design. The primary data gathering occurred intensively over the course of one month at each site, through the recording of interviews/focus groups (with 29 leaders and participants at COTA and 31 leaders and participants at St. Paul's); by observing and recording worship services and other churchrelated interactions; and, to a lesser extent, by analyzing websites, bulletins/PowerPoints, and congregational documents. I encouraged participants in individual and focus group interviews to tell their God/faith stories, especially their stories about involvement or non-involvement with churches in general, and the particular church being studied. In 
this case study/cross-case inquiry, the two churches were treated as the study's two cases. The study employed an "analysis of narrative" approach (Polkinghorne, 1995, p. 5)— both at the individual case level and across the two cases - to seek patterns and themes within and between sites.

\section{Summary of Findings}

Each site in this study encompassed a blend of visionary-actualizing leadership and an authentic expression of faith through a particular religious tradition/identity, in conversation with a unique surrounding context. Although interviewees and leaders in both congregations were adamant that they did not intentionally set out to attract a young adult demographic in particular, there was a congruence between the identities of the young adults who participated and the identity of each congregation, in such a way that these young adults, looking for something trustworthy within which to build their lives, found there the "intonations of their own language."

There were considerable differences between the two congregations. The differences included the ways they chose to engage with their neighborhoods; their completely different liturgical and music styles; the ways young adults and then children first came, and then were included; their different tolerance levels for chaos; and their nearly antithetical leadership styles. Collectively, these differences established unique identities for the two religious communities that were studied.

There were also striking similarities between the congregations, which I have framed below under the headings: (a) the social milieu in which their young-adult participants were engaged; (b) the leadership styles and practices the young adults in both congregations appreciated; and (c) the developmental needs of the young adults who 
were part of both congregations. These findings are relevant to the young adults I studied, but it should be noted that they are likely in direct contrast to what I might have discovered had I studied the young adults who attended the nearby church, Mega Mill. I summarize my findings briefly as follows, and then describe them in more detail in the discussion of findings with regard to the literature:

A. Congruence with the sociocultural milieu of these young adults.

Both these congregations:

- Chose to/happened to be located in the urban context of neighborhoods near to colleges, and offered services at times of day conducive to the lives of single young adults.

- Valued diversity and created a sense of welcoming community in which no one was excluded from participation or leadership based on gender, belief, sexual orientation, marital status, social status, income level, or age.

- Offered the kinds of embodied, sensory, and/or interactive spiritual practices and experiences that were popular in the surrounding culture.

- Offered a middle way between such binaries as rationalism and mysticism; progressive and orthodox theology; biblicism and rejection of scripture; innovation and tradition; ancient and future worship.

- Celebrated beauty through architecture, music, and the arts, in keeping with their artisticly inclined neighborhood communities.

- Provided a more open and positive environment with regard to human sexuality.

B. Congruence with the kinds of leadership valued by these young adults. Both congregations had: 
- Gentle, non-controlling, but influential leaders.

- A different, non-doctrinaire, relationship with Scripture where leaders encouraged people to think for themselves and used the Bible as a resource and conversation partner, rather than an unyielding authority for living.

- Ways of mentoring and authorising young adult leaders which facilitated a distributed leadership model.

- Authentic leaders who were experienced as sincere and who eschewed pretense, false holiness, or gimmicks.

- Boundary-spanning leaders with narrative intelligence who embodied and told evocative stories which empowered the congregation towards their futures.

- Effective visionary leaders who were able to turn their ideas into reality.

C. Congruence with the developmental needs of young adults.

Both congregations:

- Encouraged young adults to think, disagree, and doubt in the pursuit of an intellectually rich, practicing faith.

- Placed no pressure on young adults to believe, belong, or commit to the congregation before they were ready; neither did they welcome them overexuberantly when they first arrived.

- Authorized young adults to be valued as themselves without false holiness or pretense of "having it all together"; to be authentic in a world they often perceived of as inauthentic.

- Offered access in progressive ways to ancient wisdom and rituals that provided continuity in an unstable world.

- Provided young adults with an opportunity to "be part of something" vital, exciting, and with a clear identity. 


\section{Discussion of Findings with Regard to the Literature}

If, as mentioned in the statement of the problem in chapter 1, congregational cultures are constituted by people "suspended in webs of significance they themselves have spun" (Weber, as cited in Geertz, 1973), and if those who look for a congregational home choose congregations where they find "the intonations of their own language" (Hopewell, 1987), both COTA and St. Paul's provided a profusion of webs of significance and intonations of language which created unique cultures in each setting with which young adults resonated. I found these finely spun webs challenging to disentangle and these intonations hard to differentiate completely from each other. I strongly identified with anthropologist Clifford Geertz (1973) who said:

Cultural analysis is intrinsically incomplete. And, worse than that, the more deeply it goes the less complete it is. ... There are a number of ways of escaping this - turning culture into folklore and collecting it, turning it into traits and counting it, turning it into institutions and classifying it, turning it into structures and toying with it. But they are escapes. The fact is that to commit oneself to a semiotic concept of culture and an interpretive approach to the study of it is to commit oneself to a view of ethnographic assertion as ... 'essentially contestable.' Anthropology, or at least interpretive anthropology, is a science whose progress is marked less by a perfection of the consensus than by a refinement of debate. What gets better is the precision with which we vex each other. (p. 29)

Nevertheless, for the sake of communication, the webs must be untangled and the intonations differentiated at least to some degree.

During this study it became clear that the resonance between young adults and the congregations was not always immediately complete. There might be certain aspects of the congregation that were not appealing. For instance, a few young adults at both sites hesitated initially because of the liturgical nature of the services. However, if there were an adequate number of sources of resonance to hold the young adults, they might stay 
tentatively connected and eventually came to appreciate the liturgy as well. In trying to discern what makes up the "intonations of language" that they responded to in various settings, it is necessary to consider the fact that much of what resonates with young adults (or those of any age), may not occur at the level of consciousness. That is, we cannot always explain why we are drawn to some things or people, and repelled by others. Even when we do try to explain, there may be aspects of our attraction/repulsion that we ourselves cannot grasp. It is thus helpful to draw from a variety of disciplines which provide different lenses through which we can investigate the components of a "language."

As I worked with the data in light of the research questions, I found that three categories of resonance (most outside of consciousness) emerged, which I classified as:

(a) the socio-cultural environment of young adults, (b) their instinctive responses to leadership and authority, and (c) their underlying developmental needs. I will now describe briefly how I understand these three repositories of significance or language.

First, Smith (2009) wrote about the "cultural ocean" in which we swim (p. 57), which often shapes our thinking without our being conscious of it. For instance, if spirituality is being practiced commonly in yoga studios, or by doing Tai Chi in the park, or by moving meditation using ringing bells, when young adults hear bells rung or observe spirituality through body movement, even in a church, such physical movement and sounds may resonate either because they feel familiar or because they feel alluringly strange. Thus, embodied spirituality and postmodern thinking, along with church locations in funky neighborhoods, the celebration of diversity as normative, rejection of 
binaries, a positive approach to sexuality, and an appreciation for the arts are examples of what I have named sociocultural resonance.

Second, when Heifetz (2003) wrote that "we can shape [our] the elemental inclinations for dominance and deference ... through learning appropriate to our context and culture" (p. 55), the elemental inclinations he was describing were unconscious biological responses to authority figures. When we encounter authority figures, such as police officers, or teachers, or clergy, we may feel offended by or delighted about the ways they go about exercising their authority. My findings that leaders in the congregations were non-doctrinaire, non-controlling, authentic, visionary people who respected and mentored young adults, and that this kind of leadership appealed to these young adults led me to call this resonance with leaders/authority figures.

Third, when young adults get to their third decade, they begin to solve the mystery of who they really are outside of their family of origin. When they find a congregation that values them personally, that doesn't pressure them to commit, encourages them to question and express doubt, and allows them to be their "work-inprogress" selves, participants may not realize their enjoyment is related to a developmental stage that psychologists call recentering or individuation. I associate this with the adult-developmental tasks working in them often outside of their awareness. Since each of these three kinds of resonance operates to a large degree unconsciously, young adults may only know that the sound of ringing bells and body gestures make them feel peaceful, that they are pleasantly surprised by and heartened by a gentle clergy person, or that they feel a huge sense of relief that they belong without believing, having it all together, or needing to make long-term commitments. 
There were of course countless sources of resonance in the stories of interviewees, all of which signaled the congruence that existed between the ethos of the congregations, on the one hand, and the cultural realities, leadership values, and developmental needs of these young adults, on the other. Rather than addressing all of these under the first research question, (which I could have done), I have grouped the sources of resonance together as they apply to specific research questions, although they flow between these categories to some degree. I will address those sources of resonance specifically related to leadership under the second question, and those specifically related to young-adult development under the third question.

\section{Question 1. What aspects of leadership and translation, if any, were/are exercised to} make ancient wisdom or rituals relevant to, and create a welcoming space for young adults? The first six points describe those sociocultural aspects of congregational life that provided sources of resonance for young adults.

City congregations and young adults. Wuthnow (2010) found that congregations with at least $35 \%$ of regularly attending adults 35 years old or younger, which he called youthful congregations, were located in metropolitan areas where, in today's culture, significant numbers of young adults live. It may seem self-evident, but this study demonstrates that one of the reasons that these two sites resonated with young adults was that they were located in areas young adults frequented, or in which they lived. Although the study indicates that there was more to attracting young people than physical proximity, physical proximity to young adults was a starting point. 
The locations of these two sites allowed an intentional synergistic interaction between the congregations and the neighborhoods in which they were located. For COTA founders, there was real intentionality about choosing Fremont as their location, an act of leadership, in fact, that anticipated the interaction between the artistic quirkiness of the neighborhood and the innovative ancient/future rituals and wisdom they planned to enact there. St. Paul's founders had decided years before to locate themselves in Lower Queen Anne but were very intentional about offering their Anglo-Catholic rituals in the midst of the city.

Both congregations were not only located in places where young adults lived or at least visited regularly, they were also were sensitive to the realities and needs of those who lived nearby. Worship times on Sunday afternoons, for example, were a draw for young adults who tended to go out on Saturday nights, increasing the likelihood that they would want to sleep in on a Sunday morning. As a result, each congregation became, for the transient young adults who arrived at its doors, a spiritual refuge in the city.

Belonging in a welcoming and diverse community. Various points of access were provided at COTA for people to gain a sense of belonging, such as meals after the service, conversations at the Theology-Pub (or T-pub) and other weeknight groups. At St. Paul's, eating or serving at the monthly community meal, weekly coffee/wine times between or after services, and the monthly pub night after the afternoon service, were just a few of the ways people got to know each other. Rituals created for specific life events for individuals helped young adults feel that their stories were valued. Young adults going for coffee with a longer-term member or a leader were a common occurrence at both sites. This provided opportunities for relationships to be built, individual stories to 
be told and heard, and for young adults to feel encountered and received at a very personal level. At both churches, it was often through taking on small, short-term responsibilities that people felt at home. Young adults felt a very real sense of community and friendship in both sites due to a balance between the building of community and the valuing of individual voices and stories.

Furthermore, young adults in these congregations expressed the perspective that "when I know everyone is welcome, I can trust that I am really welcome too." This concept of welcome was connected to an embrace of human diversity in terms of race, sexual orientation, dress, age, and so on. According to Smith and Snell (2009), the "cultural ocean in which young adults swim" (p. 57) includes a much greater appreciation of diversity and difference than ever before, and this point is consistently stressed in other literature, as well (Barry \& Nelson, 2005; Cimino, 2010; Hackett, 2014; Wuthnow, 2010). These authors argue that young adults are simply more comfortable with and accepting of people who are different from themselves than were previous generations. People encountered those who were different indirectly through movies and television and the Internet, and directly through the ease of air travel, the increase of immigration, the migration of sexual minorities to urban areas, and so on.

This study confirmed that appreciating diversity in all its forms was simply a given for these young adult-interviewees. Congregations that were opposed to LGBTQidentified people or the leadership of women were simply not in the running for most of those I interviewed. That both these congregations valued members regardless of sexual orientation and were influenced so significantly by women leaders, and that the visionary founding priest of COTA was an African American woman were significant draws for 
interviewees. These leaders played a vital role in creating space that valued diversity. Diversity at both sites (more evident in a variety of ages and sexual orientations than in terms of race/ethnicity or education levels) was more than just an espoused value.

\section{Embodied, sensory, and/or interactive spiritual practices/experiences.}

Buddhist meditation, Yoga, Tai Chi, and other embodied spiritual practices are now part of the surrounding culture, as are sensory spiritual forms that use ringing bowls, chanting, or drumming (Ferrer, 2015). Flory and Miller (2008) found that worship experiences that engaged both mind and body were found to be important for young adults. The clergy leadership at both sites had an instinctual understanding of the importance of the sensory, interactive, and embodied nature of young-adult spirituality. In this study, the physical gestures, sounds, and smells of Anglo-Catholic worship at St. Paul's; meditating on cushions surrounded by candles and icons at COTA; and the walking of the labyrinth at both sites, corroborated the idea of the importance of this mind-body connection through sacred ritual.

Embracing the middle way between binaries. The Anglican/Episcopal tradition has always sought to forge the via media, starting with its historical attempt to create a faith that was neither Catholic nor Protestant (Taylor, 2014). Consequently, for young adults who were immersed in the cultural ocean of postmodernity with its refusal of exclusive truth claims and the rejection of false binaries (Smith \& Snell, 2009; Gibbs \& Bolger, 2005), the Episcopal via media tradition with its embrace of science and faith, custom and innovation, broadmindedness and traditionalism is appealing to young adults. The ability of the two congregations and their leaders to keep a balance between innovation and tradition, the progressive and the orthodox, rationalism and mysticism, the 
future and the past, affirmation of creeds and critical thinking, were just some of the ways that young adults affiliated with each congregation found resonance in the middle way. Professor of theology from Seattle University, and trainer of liturgists at St. Paul's, Dr. Mark Taylor (2014), described the via media in an enquirer's class at St. Paul's as "both/and, not either/or, faithful to ancient patterns, creative, even daring, in adapting to the present within a communal life of prayer" (p. 1). This resonance between Episcopalianism and postmodern young adults may have been inadvertent, but was for both groups a happy coincidence.

Beauty, music, and the arts. Young adults generally, according to Wuthnow (2010), frequently pointed to art and music as sources of inspiration, and often as the source of their livelihood. When creeds and doctrines failed them, he said, they turned to "the more intuitive lessons of the arts" (p. 48). At both COTA and St. Paul's, a love for the arts was part of the congregational makeup. Each congregation had a vibrant, though unique aesthetic sensibility, which was a clear draw for the local artistic community. Artists in residence were a significant part of the life at St. Paul's, and COTA's symbiotic relationship with its partner, the Fremont Center for the Arts, created a strong link to the arts and the artistic community in the area.

With regard to worship music, I had once assumed that, in most cases, young adults would prefer church music to have a contemporary feel. Wuthnow (2010), however, pointed to a more nuanced reality among young adults who had quite different perspectives. According to Wuthnow, some young adults were indeed more interested in contemporary music, while others wanted to experience music in church that was more religious and unlike what they heard in the everyday. 
Wuthnow's (2010) more nuanced storyline played out in the two congregations studied. Although COTA drew from ancient and contemporary musical sources, the music team looked more like a band with their drums and guitars, and much of the music felt very similar to that of the surrounding culture. At St. Paul's, though, numerous young adults enjoyed both the morning services with the organ, choir, hymns, and other service music that was likely quite different from the music they listened to at home, and the more current feel of the jazz- and Taizé-based afternoon service. In both congregations, music was a primary way of translating ancient faith and wisdom for participants, and, in fact, in both churches, music held the rituals and liturgy together. Music leaders in both churches played pivotal roles in making the rituals accessible to participants, as did other congregational artists and musicians.

Provided a more open environment with regard to human sexuality. Perhaps one of the most obvious ways that western culture has shifted over the last century is in the increasing acceptance of sexual practices and identity outside of the lifelongheterosexual marriage norm. Religion has changed far less than the culture, and there is some tension around sexuality between most religions and modern values. Negotiating sexuality is an important part of identity development in young adults, specifically that of reconciling religious principles with sexual desire and practice. Freitas (2008) encourages colleges, and by extension, we may assume, congregations also to cultivate the high levels of interest in religion and spirituality that young adults have, so that they can be empowered to move their faith from the margins to the center of their life, to see religious faith as a strength rather than an embarrassment, and to view their faith as an avenue for critiquing both the culture of sexual excess in some schools and the culture of 
excessive restraint in others. This way, sexuality does not become associated with guilt and shame. Although COTA interviewees only discussed sexuality in terms of LGBTQ inclusion, at St. Paul's one or two individuals spoke of their appreciation for the nonjudgmental attitude towards sexuality, homosexuality, and cohabitation that allowed young adults to explore this important aspect of their lives and settle any conflicts they may have felt between religious belief and sexual desire.

Once again, the congregations seemed to avoid binary thinking. In this case, the binary that was avoided was the marriage versus celibacy dualism embraced and endorsed by so many other congregations. The two churches that were studied in this dissertation research made it possible for young adults to integrate their sexuality with their religious experiences.

\section{Question 2. What kinds of resonance, if any, emerged between the leaders and the} group (both individual participants and the whole congregation)? This second set of six points describes those sources of resonance derived from attitudes towards leadership and authority espoused by these young adults.

Gentle, uncontrolling leadership. In the political science literature, Welzel (2014) posited that a decline in religious involvement can be found in those nations that have more fully embraced emancipation values, i.e., the desire to be free of domination. The assumption, here, is that religion is perceived as a dominating force that restricts freedom and enforces social rules. It would make sense that, in democratic countries such as the U.S., with strong emancipatory values, religion might be perceived as a dominating force. 
This might explain why the gentle leadership style at both COTA and St. Paul's was appealing to young adults, particularly those who came from more authoritarian church traditions. Participants were already enjoying the absence of constraints brought about by leaving home, and although they appreciated the care and concern of the congregational leaders, they were not looking for alternative parental figures. Replacing parents with similar authority figures could commandeer and further delay two important aspects of their developmental work. First, as young adults mature, they need to respond to the frontal lobe development which supports their burgeoning cognitive skill set known as executive function processes (Isquith, Gioia, and Espy, 2004). These control, supervisory, or self-regulatory functions that organize and direct all cognitive activity, emotional response, and overt behavior must be managed increasingly by young adults themselves. Second, Tanner (2006) described the importance of the recentering process of young-adult development; a three-stage differentiation/individuation process characterized by a renegotiation of the relationship with their parents and a clearer definition of the boundaries between themselves and their families. In this renegotiation, Tanner argued, young adults ideally need to shed reliance on parents without a breakdown in familial relationships. Congregational leaders at COTA and St. Paul's seemed to provide a form of leadership that was respectful of this developmental process and the emancipatory needs of these fledgling adults by empowering and not dominating them.

A different, non-doctrinaire, relationship with Scripture. The cognitive development that takes place during young adulthood creates a need for young adults to think critically, debate, and doubt. Furthermore, the literature has demonstrated the value 
young adults place on autonomy, personal authority, and freedom (Smith \& Snell, 2009;

Twenge et al., 2014, Welzel, 2014). Leaders at COTA and St. Paul's seemed to understand this need intuitively, and to use more of a Socratic and open-ended communication style, which always encouraged young adults to think and act for themselves. This study could provide a challenge to the ways more doctrinaire and authoritarian congregations work with young adults.

\section{Respecting, mentoring, and authorising young adult leadership which} facilitates a distributed leadership model. Leadership and Education scholar Sharon Daloz Parks (2003) outlined practices of mentoring aimed to draw out the dreams and worthy goals of young adults in her book, Big Questions, Worthy Dreams: Mentoring Young Adults in their Search for Meaning, Purpose, and Faith. She suggested a number of potential mentoring communities, including religious congregations, where such mentoring relationships could thrive.

Clergy at COTA and St. Paul's had particular gifts in dispersing leadership by means of respecting, mentoring, and freeing young adults to explore their gifts. The music minister at COTA remembered her experience of being mentored by the founding priest as pivotal to her development as both a person and leader. Mother Vanessa and Quinton, the lead priest and the lay pastor of the afternoon service at St. Paul's, were valued for the personal interest they showed individual participants and the freedom they provided for young adults to take on leadership roles in the church. COTA, in particular, allowed young adults to explore their gifts in various aspects of worship leadership, with no fear of failure, because of the ethos of the congregation where even a less than perfect worship activity, if presented by sincere participants, was valued and celebrated. Both 
congregations were able to mentor young adults in such a way that they felt respected, even as they came to discover and respect the liturgical and historical identity of their congregations.

Authenticity and the absence of gimmicks. In her chapter "Teach Your Children Well: Closing Observations on Constructing Religious Identity in the Next Generation" in the book Passing on the Faith, historian Diane Winston (2006) named authenticity as one of the vital three aspects of young-adult experience. She described her understanding of authenticity as that of "being rooted in a particular historical tradition" (p. 266). Both COTA and St. Paul's embodied this kind of authenticity by firmly locating themselves in the Lutheran/Episcopal/emerging church or Episcopal Anglo-Catholic traditions. Rather than appealing to beguiling gimmicks, the congregations delved deeply into their own histories and rituals which they were both being shaped by, and reshaping. Furthermore, particularly at St. Paul's, the personal sincerity and authenticity of leaders were frequently cited to explain why young adults felt at home. For young adults experimenting with their own identities and faith, the tethering connection to a tradition, combined with the authenticity and deep faith of the leaders, seemed to provide a benchmark against which they could measure themselves.

Boundary-spanning leaders with narrative intelligence. Boundary-spanners are those people or units in an organization who are most connected to and receptive of the ideas and experience of external sources or groups, and are thus most able to perceive and lead adaptive change (Pawar \& Eastman, 1997). Spiritual leaders who have other experience outside the world of the church through exposure to other disciplines or through cultural involvement are thus boundary-spanners. 
In this study, Carolyn's immersion in secular and religious bohemian culture and arts blended with an innovative liturgical sensibility allowed her to embody and tell stories that resonated with the young adults she drew around herself. Mother Vanessa's background in poetry, literature, and organizational development provided her with helpful tools in uncovering the existing story and weaving together a new and hopeful narrative for the parish.

Both Carolyn and COTA and Mother Vanessa at St. Paul's could also both be described as exercising narrative leadership (Salyards, 2009) and exercising narrative intelligence, which Denning (2007, p. 11) defined as the ability to appreciate narrative's presence in all aspects of life as well as to understand that through narrative people express themselves and their worlds. Sparrowe (2005) argued further that leading narratively demands concordance between the story leaders tell members and the one that they live, a story written first in their own narrative self. The leaders in the two congregations exercised narrative intelligence in three ways. First, they deeply embodied in their own lives aspects of the stories of the congregations they served. Carolyn had experienced a sense of alienation from the institutional church, and found herself creating a church from others who felt similarly alienated. Mother Vanessa had come to a church in great pain through loss of valued members to complications from HIV-Aids, and brought her own personal story of loss, her "incredible luck in the midst of incredible pain." Second, they understood the narratives of both the congregation as a collective and the individuals within it. Carolyn had a profound understanding of "postmoderns," (sic) who were disaffected by all things institutional and religious, and of the culture they inhabited. Mother Vanessa understood the story of the parish around its relationship with 
and commitment to the city, embodied in the name St. Paul's, and found ways to weave this narrative into the parish's present sense of mission and hope for the future. Quinton had made the journey out of a more rigid evangelical context into the Episcopal Church, and was able to hear deeply and respect the stories of those who came from different faith backgrounds. Both these and other congregational leaders told and listened to stories in church, and outside of church services over coffee and at the pub. Third, the leaders in both places were able to articulate the new vision of the congregation by helping everyone discover a new and hopeful collective narrative. Carolyn wooed people into the congregation with a vision of a church for those who did not go to church, and a positive engagement with art and culture. Mother Vanessa helped a dispirited congregation find a new future that included people from the city they had committed to serving, including young adults, poor neighbors, and young families. At least to some degree, the narrative intelligence of the clergy was a result of their boundary-spanning natures and experiences.

\section{Effective visionary leaders who knew how to turn their ideas into reality.}

Hayes (2007) asserted that vital congregations provided a community for spiritual seekers (a) in the context of a clearly defined faith tradition, (b) imbued with a strong leader's vision, and (c) responsive to local contexts (p. 11). COTA and St. Paul's exemplified all three of these characteristics. Both the founding priest at COTA and the lead priest at St. Paul's were strong leaders, able to "make things happen" based on the vision that drove them, their particular understanding of their traditions, and within their idiosyncratic neighborhoods. Both leaders were able not only to dream dreams but also to actually see those imaginings become a reality through their equipping and empowering of others. 


\section{Question 3. What kinds of associations, if any, exist between the narratives of} participants and theory about the developmental and maturational work of young

adulthood? Although various studies (Smith \& Snell, 2009; Wuthnow, 2010)

demonstrated that most young adults who attended church tended to be married or married with children, at both research sites the majority of the young-adult interviewees were single (14/22 at COTA; 15/20 at St. Paul's) and none had children. In the following five points, I will attempt to show how the congregations in this study had the remarkable ability to draw single young adults, even during their rocky transitional years, due to the congruence between the ethos of the congregations and the developmental needs of these young adults in or near their third decade.

Freedom to think for oneself, freedom to doubt. The freedom to think and express doubt is related to the cognitive developmental tasks of young adulthood, where substantial cognitive transformations occur during adolescence and young adulthood. In young adulthood for instance, the ability for formal thought, that is, thinking scientifically, meta-cognitively, abstractly, and with complexity (Piaget, 1977), is increased. According to Labouvie-Vief (2006), this ability is enhanced by the ability to exercise postformal thought in the form of dialectical thinking — which involved argument, counter-argument, and debate — as well as practical thinking — which accepted inconsistencies as part of life and thrived on imperfection and compromise. In this study, it was clear that as the ability of young adults to think critically, argue, and accept imperfections matured, supportive congregational environments that encouraged such thinking and allowed the full expression of faith and doubt resonated with young adults. 
It would seem that congregations could thus either stunt this new cognitive ability or help it to thrive. Rather than forcing young adults to reject the church because of doubt, churches such as COTA and St. Paul's provided the kind of intellectual environment where doubts were valued and able to be discussed freely. There was great appreciation on the part of young adults at both sites for the freedom to doubt and think for themselves that had been cultivated there, and for the fact that belonging was possible without believing a set of preconceived religious propositions.

Smith and Snell (2009) described a diversity of young-adult religious attitudes: traditionalists, selective adherents, spiritually open, religiously indifferent, religiously disconnected, or irreligious (p. 57), as though these were discrete categories. They seemed to suggest that only young adults who fall into the first two, or maybe three, categories were likely to attend a church. What was unique about both COTA and St. Paul's, however, was that there was enough permeability for all of these categories of people to feel at home. COTA had the atheist couch for those who liked the community but did not feel inclined to participate in the worship aspect, and one interviewee at St. Paul's described himself as an atheist-Episcopalian. The freedom to doubt and disagree made it possible for all kinds of young adults (as well as those who were no longer young adults) to belong.

No pressure to belong, believe, or commit. The lack of pressure to belong, believe, or commit is related to the task of recentering/individuation. Arnett and Tanner (2006) described the emerging adult period as a time outside of parental control and, given the resulting relative absence of constraints, a time in which emerging adults could explore what values and beliefs they might adopt. Many of the interviewees at COTA 
and St. Paul's were outside of the day-to-day control of parents and, understandably, relished the space, time, and freedom that COTA and St. Paul's provided by not pressuring them to belong, believe, or commit. It was not surprising that to maximize the gifts of this phase; recentering young adults did not want to be controlled by an "alternate parenting system" in the form of the church or other authority figures. This finding supported what Rabbi Matalon (2006) termed as the "asymmetric exchanges of support" (p. 132) offered in his congregation, where a non-judgmental welcome was balanced by low-pressure invitations to deeper involvement.

Authenticity: Free to be me. The level of freedom to be their authentic selves in these two congregations is related to the task of identity development in young adulthood. As previously mentioned, Tanner (2006) suggested that from the time they left home, young adults were engaged in an individuation process called recentering which included the ego development process of differentiating from one's parents to become an individual secure in one's individuality. During this time, young adults explored their experimental self before finding ego constancy, the goal underlying the momentum of adulthood. Hartmann and Swartz (2006) suggested the consolidation of identity that was the task of young adulthood might rely upon the increasing meta-cognitive capacities of this age, namely, the ability to think and explain one's own thinking to others.

This recentering and differentiation period involves separating from both parents and the faith community in which a young adult had been raised. COTA and St. Paul's, in different ways, provided the perfect incubator for this process. They both allowed people the freedom to explore, experience confusion, and go through difficulties, so that young adults felt they could be authentically themselves while trying on and taking off, 
and then retrying, ways of being and beliefs to determine their new identity. This study shows that COTA and St. Paul's were the beneficiaries of young adults migrating from congregations that had expected them to "have it all together" spiritually, sexually, theologically, emotionally, and so on. The contrast both churches provided was both striking to and greatly appreciated by the young adults who affiliated with each of the churches.

Connection to ancient spiritual rituals and forms. The attraction of ancient religious rituals to young adults can be related to the task of identity development as it pertains to generational congruence. Wuthnow (2010) observed that the tendency of American culture to discourage continuity and to push young adults away from the past and towards the future, "does not diminish the need ... for personal coherenceincluding a connection between our present and our past (p. 215).” Anthony Giddens (1991, as cited in Gollnick, 2008) observed that the links between individual lives and the cycle of generations are no longer as apparent as they once were (p. 9). Simultaneously, there is a small body of literature, both peer-reviewed academic and popular culture literature, regarding the resonance of some young adults with ancient liturgical forms (Bates, 2006; Parker, 2015). In this study, it was apparent that, during their journey to ego coherence, young adults at COTA and St. Paul's were seeking connections with the past and found this needed sense of continuity in ancient liturgies and spiritual practices. At both sites, interviewees commented on their need to be part of a lengthier religious history, a need, they noted, that they had not always recognized before. They now acknowledged that they valued singing hymns, songs, and reciting liturgies that had been sung and enacted for hundreds or thousands of years. As they did so, they were able to 
build their identities as part of a contemporary local community, but also a historic one that provided a sense of stability and continuity with the past.

Being part of something good. The enjoyment of belonging to a congregation that is doing something wonderful is related to the young-adult task of meaning making and seeking significance. Daloz-Parks (2011) suggested that the primary developmental task of young adulthood was to learn how to cultivate worthy dreams. Being part of something significant is important to young adults who are investigating their life's purpose and meaning. It may also confirm Twenge's (2014) notion that young adults want to maintain their self-esteem, to feel important and special.

To this end, both congregations were becoming well-known outliers within the diocese, and in COTA's case, was even better known in emerging church circles. People visited both churches, particularly COTA, from far and near to learn about what they were doing. COTA was a widely respected pioneer of ancient-future worship, an emerging church that worshiped in an Abbey, which was also a Center for the Arts. St. Paul's had an historic and contemporary presence in the city as a place for those “wounded by religion” (St. Paul's Profile Committee, 2014). Both congregations had been written about in articles and books.

The sense that something valuable was taking place at these two sites did not only come from outsiders though. There was a general joy and excitement in both churches because people were finding liberation from oppressive religious forms, experiencing community, exploring sacred texts and ancient rituals together, and finding a way to stay connected to faith even in the midst of struggle and doubt. Young adults resonated with 
these congregations because they were sources of energy, and there was an exhilaration about and pleasure in belonging to them.

\section{Back to the Barna Research}

Before concluding this discussion on why young adults resonated with their congregations, we return to the Barna Group's (Kinnaman \& Hawkins, 2011) six major reasons young adults offer for their diminished relationship with Christian churches. COTA and St. Paul's certainly seemed to have avoided these negative factors in the following ways: (1) Neither of these congregations could be described as overprotective. They, in fact, tended to have permeable boundaries; people could come and go as they pleased. (2) Although it was possible to have a shallow faith experience at either site if one chose to do so, there were, nevertheless, opportunities afforded for people to encounter the holy for themselves each week, and to explore their faith in greater depth if they desired. (3) Neither church was antagonistic to science. The congregants in each case were college educated, and many had, or were working toward masters or doctoral degrees, often in the sciences or social sciences. (4) Both congregations created space for people of varying sexual orientations to belong fully and sought to ensure that all types of sexuality were expressed within loving relationships that valued each partner's dignity. (5) Neither congregation demanded that Christianity be embraced exclusively, and members often simultaneously explored other faith traditions as part of their personal explorations. (6) Both churches were friendly to those with doubts; in fact, doubt was expected and seen to be an important part of faith. There is, however, no automatic correlation between congregations that avoid most of the pitfalls Barna (Kinnaman \& Hawkins, 2011) identified and the percentage of young adults within them. A 
congregation that embodied few of these hindrances to young-adult involvement, except perhaps for providing a shallow experience of faith (as is the case with many congregations in my own denomination), might still not resonate with young adults. Furthermore, Mega Mill drew thousands of young adults despite the fact that they were on the wrong side of most of the points above. The issue of resonance between young adults and congregations is clearly more complex than simply avoiding the problems described in the Barna research.

Although not the full picture either, this study suggests that congregations need to be effective in meeting young-adult developmental needs, sensitive to their sociocultural contexts, and responsive to their needs for mentors and leaders who value their thoughts and ideas. Meeting such needs appears to be a necessary, but, clearly, not a sufficient condition, for attracting young adults into the life of a church.

The tentative overarching preliminary assumption (mentioned in chapter 1 ) that leaders and participants in these young-adult-filled congregations (inadvertently or consciously) provided opportunities for young adults to meet their spiritual needs in ways that resonated with their stories/identities, developmental stages, and meaning-making capability, was corroborated by an abundance of evidence. I did, of course, also search for disconfirming evidence but very little was there to be found, perhaps because those who did not have their spiritual needs met in the congregations would be unlikely to stay.

It is remarkable that two congregations who claim they had not set out to attract younger people in particular became so filled with young adults. It would seem that a variety of factors were woven together a) as visionary-actualizing leaders plumbed the depths b) of tradition and innovation to explore c) in radically welcoming communities d) 
an ancient-future oriented experience of the sacred that was worked out e) in dynamic engagement with specific neighborhood communities. The sources of resonance in these two congregations are thus part of a dynamic, complex, and unique whole.

Very few progressive mainstream congregations in the U.S. and Canada have been able to accomplish the task of providing for young adults the spiritual communities that resonate with their sociocultural, leadership, and adult developmental needs. It is my hope that some of the ideas and findings from COTA and St. Paul's will lead readers to important conversations within the mainstream churches as they explore how congregations can provide supportive communities with and for young adults, or basecamps for young-adult experimentation.

\section{Summary}

The absence of young adults is both the result and a cause of the decline of the mainstream church in the US and Canada. Instead of looking at decline, I looked at "outlier" congregations - those that had attracted young adults in significant numbers. After listening to the stories young adults told about their lives, faith journeys, and their churches, I identified sources of resonance between the lives of young adults and their church cultures. After reviewing the literature on young adulthood I discovered that the two congregations were intentionally or unintentionally providing a space in which the usual and unique challenges facing today's young adults could be met. My findings suggest that rather than simply seeking to attract young adults in order to reverse their decline, mainstream churches would do well to understand the developmental and socioeconomic needs of young adults and to ask how they may better meet these needs. 


\section{Limitations}

Case studies are by nature limited, and their findings cannot be simplistically generalized to young adults in the U.S., Canada, or elsewhere. Young adults are not a monolithic group. There are stark differences between a 19 -year-old and a 25 -year-old; 30-year-olds feel they are quite different to 26 -year-olds. Personal tastes and preferences are as diverse in this age group as in any other. The young adults who resonated with these two congregations, therefore, cannot be seen as speaking for all young adults in any way.

I want to specifically acknowledge three kinds of sampling limitations in qualitative research designs mentioned by Patton (2015) namely, (a) limitations in the situations sampled, (b) the time periods during which observations took place, and (c) selection criteria regarding the people sampled. First, in terms of the situations sampled, I chose the Pacific Northwest in the United States because it was close to where I lived and worked. It had further interest for me as an extreme case sample because it had been designated the least religious area in the U.S. for some years. This made it very different from more densely religious areas of the country.

The two sites were selected because they were information-rich outliers. One of them was quite well known in my circles, and the other one was recommended to me by the regional Episcopal bishop as a likely information-rich site for study. The fact that they were both Episcopal and thus liturgical churches (although COTA is both Episcopal and Lutheran) may be a coincidence, or this fact may have been, in itself, relevant. I did not set out to study Episcopal or Lutheran Churches, and yet these were the ones that appeared, in my snowball approach to sampling, to be finding resonance with significant 
numbers of young adults. The congregations were also in or close to the center of Seattle and were, thus, very much urban churches. The young adults in these congregations, though diverse, were primarily Caucasian and college-educated.

Moreover, I deliberately chose congregations that were LGBTQ-friendly because this is simply the cultural milieu within which I operate. In the United Church of Canada, the acceptance of LGBTQ-identified people in leadership and the acceptance of same-sex marriage preceded that of the rest of Canadian society, and indeed, led the way. If I had selected congregations that were not LGBTQ-friendly, I might have acquired different results, but I was never interested in studying these kinds of churches.

Second, in terms of the time period in which the data collection happened, the combination of interviews, focus groups, and participant observation took place over only one month at each site in the spring of 2012. This means that the findings were very much limited to that time, after which the clergy changed in both sites. I have not returned since then and do not know whether I would acquire the same results if I returned today. An encouraging sign as to the fidelity of the findings, however, was that a respected leader at each site (neither of whom had participated in my study) read the findings chapters for their congregation in the month before I submitted my dissertation, and, with only minor and friendly amendments, felt them to be accurate portrayals of was happening at the sites when I was there.

Finally, in terms of the selectivity of people interviewed, in each case I was unable to speak with all congregational leaders or congregants. There might have been different opinions on certain aspects of the church experience if I had interviewed all the leaders involved, particularly at the second site, which had a more formal and larger leadership 
structure. Although I interviewed 22 young adults at COTA, and 21 at St. Paul's, there is no guarantee that I heard all of the stories and storylines that young adults had to tell. The young adults I interviewed signed up to be interviewed on a sheet either that I displayed during the coffee time, or I, specifically, asked them if they might be willing to be interviewed when I came across them after services. In a few cases, someone in the congregation encouraged me to talk to a specific young adult, and I emailed them a request for an interview.

At COTA, 24 out of the 29 interviewees were Caucasians; five were people of color including three bi-racial, one Hispanic, and one African individual(s). At St. Paul's, 28 out of 31 interviewees were Caucasian, one was Asian American, and two were Hispanic. The racial demographics of Fremont (84\% Caucasian) and Queen Ann (83.82\% Caucasian) were relatively similar, however. Other than one young man only two years out of high school, every person interviewed had completed a college degree; some had doctorates, and most had or were obtaining masters' degrees. Although few of the young adults were from Seattle or Washington originally, they had chosen Seattle as a place to study and/or live. The danger of trying to generalize findings from two Episcopal Churches with highly educated, mostly Caucasian participants in the very secular city of Seattle is self-evident. The presence of Mega Mill in the same city at the time of the study with its very different relationship with the cultural milieu, leadership styles, and approach to young adult development strongly negates any generalization to young adults more broadly.

Hayes' (2007) more abstract notion mentioned earlier, however, that vital congregations provide a community for spiritual seekers (a) in the context of a clearly 
defined faith tradition, (b) imbued with a strong leader's vision, and (c) responsive to local contexts (p. 11) could be explored in multiple communities across boundaries of race, class, educational qualifications, and so on. Despite all of these limitations, these context-specific case studies are empirically rich, holistic accounts, which may, I hope, lead to theory building and testing by interested researchers.

\section{Implications for Young Adults, Congregations, and Denominations}

That the two young-adult-filled congregations of the study, and others I heard about, offered alternative worship times in metropolitan areas, particularly where colleges are located, may be disheartening for congregations that are not located in such areas, or those who are wedded to morning services. However, for congregations located in neighborhoods where large numbers of young adults live, having conversations about how to create supportive spiritual community for young adults could be beneficial. It might be fruitful to do an analysis of the needs of young adults by talking to them, especially if the congregations engaged in such conversations might be willing to consider some alternate times of day for worship.

Clearly, denominations that wish to reconnect with young adults need to go where young adults are. For example, colleges and college neighborhoods are important places for denominations to locate progressive Christian communities and ministries.

Abandoning ministries at universities and colleges, because they can generally not be financially self-sufficient, is a self-defeating move. The costs involved are less important than the bridge they build between young adults and congregations.

In addition, congregations vacillating about the full inclusion of women in leadership or LGBTQ-identified people in general might need to clarify their positions. 
At the very least, they may need to clarify, state, and defend their positions with greater confidence. If they are willing to welcome LGBTQ-identified people, they would be more attractive to the majority of young adults for whom such diversity is an expectation. They would do well to go through the necessary education processes to unambiguously welcome people, and say so on their website. If they are opposed to full inclusion, they are unlikely to be able to attract the sort of young adults I interviewed at COTA and St. Paul's. However, there very well may be other young adults who would find a wellarticulated and carefully defended position on such matters attractive.

\section{Developmental Needs of Young Adults}

Those Episcopal and other liturgical churches that combine progressive theologies with ancient forms and are, or could be, geographically placed to support young adults would benefit from learning about young-adult developmental needs in general, and the specific needs of nearby young adults. In doing so, they might be able to provide supports that enable young adults to do the developmental work with which they are engaged, and in so doing to find a spiritual home.

Unfortunately, for many Christians, doubt and questioning are antithetical to faith and must be eradicated. It is perhaps this impasse between the need some congregations feel for unquestioning faith and doctrinal purity in their adherents, and the need many young adults have to exercise their increasing capacity for critical, pragmatic, and postformal thinking that is contributing to the departure of many young adults from religious congregations.

Since young adults are enjoying cognitive spurts that provide the ability to think critically and creatively, congregations need to enhance and not stultify this important 
change. Congregations that demand unthinking adherence to set formulaic doctrines thwart cognitive and identity development and well-being in young adults. If intellectual development is important to such young adults, the congregations may lose their most promising potential members. This study shows that they may find other places where they can flourish and think for themselves such as COTA and St. Paul's. Congregations that support the exciting cognitive processes will find greater resonance with intellectually evolving young adults. Congregations would do well to learn a variety of ways to support young adults in their midst, and have open and honest conversations about what they find life giving and what they find stultifying.

If congregations understand the various developmental needs and tasks of young adulthood, they can better determine how to be supportive during this recentering time. How young adults are welcomed, the ways small short-term opportunities and other possibilities are provided to help with a sense of belonging if desired, the power of ritual and tradition to provide scaffolding for young adults on their recentering journey, the encouragement of critical thinking, and the need to avoid coercing young adults to commit to belief, belonging, or commitment until they are ready are things congregations will have to think about.

Finally, given how many of the interviewees in this study talked about stepping away from the church for a period of time, it may be helpful for congregations to explore whether there is a need for a rumspringa, a period when young adults need to step away from the church completely before they are ready to reintegrate into congregational life. I would encourage congregations to develop rituals that celebrate the period of self and intellectual exploration that young adults will enter into after leaving high school and 
offers them support along the way. It would of course be more ideal if young adults did not have to go through their entire recentering process alone. COTA and St. Paul's to their credit, found ways to become the kinds of congregations that allowed those young adults tentatively re-exploring congregational life, usually after a period of absence, to go through this rocky time in a gently supportive community.

\section{Leadership}

It is important that young adults are free to discover who they are and what they think in relatively uncontrolled environments. Authentic and visionary-actualizing leaders who can support young adults in their developmental journey to autonomous but socially connected adulthood without slipping into the role of parents, and who can mentor and empower young adults into the best use of their skills and gifts, can build relationships and create communities that resonate with young adults. Leaders who have healthy connections outside of the world of the church, who don't feel the need to force others to think the way they do, who understand and use the power of story in their work, and who can hold gently but firmly to their own authority and their spiritual traditions, might find themselves, as Mother Vanessa put it, "where young adults are."

\section{Implications for Further Research}

A fruitful source of research would be to study what is lost to society when churches decline and close. Loss of intergenerational communities, services for vulnerable groups, free training in music and the arts for all ages, the development of a moral inclination in children, cheap space for rent for non-profit groups, are just a few benefits of religious communities to society. It would seem fitting that society should anticipate and plan for such losses. 
Pamela King and various colleagues $(2008 ; 2004 ; 2005 ; 2005 ; 2014)$ have done a number of studies of the positive relationship between congregations on the one hand, and adolescent well-being and identity formation in those youth who are integrated into congregational life, on the other. Extending this research into the developmental supports that congregations could provide to young adults could be fruitful, as could exploration into the relationship between young-adult-filled congregations and the freedom for young adults to think, question, and doubt without fear.

The exodus of evangelicals and Catholics from their churches of origin could be another fruitful source of study. Where they are going; what percentage are moving towards liturgical and progressive congregations; how many are moving into more orthodox congregations; and how many are leaving altogether are interesting questions. This exodus was a striking feature of this research, and an increasing embrace of liturgical traditions by young adults seems to be making its way into the popular literature more quickly than into scholarly articles.

Questions about how many young adults will hesitate or refuse to attend churches that do not celebrate human diversity, that is, who do not welcome women, LGBTQidentified people, or other vulnerable groups into fellowship and leadership might be useful to congregations.

Finally, one of the avenues not explored in this study was the reasons that some young adults are attracted to congregations where they are encouraged to think, reason, and doubt, and others are drawn to congregations that tell them what to think, and eschew doubt. An interesting avenue for research might thus be comparing individuals that go to 
a Mega Mill, and those that go to a COTA or St. Paul's type of congregation, and such developmental theories as Bill Torbert's Action-Logics.

\section{Conclusion}

The exodus of young adults from the church is both a cause and a result of the church's decades' long decline. Instead of being splendid resources for each other, young adults and the aging progressive mainstream church, to all appearances, have needs that are antithetical. Half of the adult population of the United States consists of adults younger than 45 years of age (Wuthnow, 2010), and their absence from congregational life is catastrophic for religious congregations. On the other hand, congregations struggling to survive find it difficult to reimagine themselves, let go of some of the things that are precious to them, and support and empower a new generation in leadership during what can be a transient, unsettled, and difficult period of life for both groups. Although the church and young adults could be of benefit to each other, they are instead heading in different directions.

Most young adults see the church as a place for moral education and leave when they are adolescents to return, if at all, only when they marry, settle down, and have children. Single young adults tend to head into at least a decade-long moratorium on religious attendance. The most impacted religious group, that which has fewest young adults in attendance, is mainline Protestantism. Yet, in Seattle, there are two relatively small congregations that seemed not only to resonate with young adults, but even with the more elusive single young adults who as yet have no children, in a significant way. Although quite different from each other in terms of liturgical style, music, and leadership, they also shared striking similarities. 
In this study, I found that this resonance can be attributed to the congruence between the leaders and young-adult congregants in the study, and the sociocultural realities and developmental needs of young adults who participate in them. This congruence also exists between the styles of the clergy/lay leadership in the congregations and the development needs of young adults, through a gentle, noncontrolling, dispersed, and authentic leadership style facilitated by effective visionary leaders. Because of this congruence, young adults have found, in these two congregations, the "intonations of their own language," and helped to create two congregations that are not only bucking the decline-trend, but also providing a source of community for young adults in search of a vital spiritual home during their explorative or rumspringa years, and a source of hope and inspiration for the rest of the church. 


\section{REFERENCES}

Adler, G., Chaves, M., Anderson, S. L., Martinez, J. H., \& Hoegeman, C. (2008). Dearly departed: How often do congregations close? Journal for the Scientific Study of Religion, 47(2), 321-328.

Ammerman, N. T., Carroll, J. W., Dudley, C. S., \& McKinney, W. (1998). Studying congregations: A new handbook. Nashville, TN: Abingdon Press.

Arnett, J. J. (1998). Learning to stand alone: The contemporary American transition to adulthood in cultural and historical context. Human Development, 41(5-6), 295315.

Arnett, J. J. (2000). Emerging adulthood: A theory of development from the late teens through the twenties. American Psychologist, 55(5), 469-480.

Arnett, J. J. (2010). Oh, grow up! Generational grumbling and the new life stage of emerging adulthood: Commentary on Trzesniewski \& Donnellan (2010). Perspectives on psychological science, 5(1), 89-92. doi:10.1177/1745691609357016

Arnett, J. J., \& Tanner, J. L., (Eds.). (2006). Emerging adults in America: Coming of age in the 21st century. Washington, DC: American Psychological Association.

Arnett, J. J., Trzesniewski, K. H., \& Donnellan, M. B. (2013). The dangers of generational myth-making: Rejoinder to Twenge. Emerging Adulthood, 1(1), 1720. doi: $10.1177 / 2167696812466848$

Astin, A. W., \& Astin, H. S. (2003). Spirituality in college students: Preliminary findings from a national study. Los Angeles, CA: Higher Education Research Institute.

Barry, C. M., \& Abo-Zena, M. M. (2014). Emerging adults' religious and spiritual development. In C. M. Barry \& M. M. Abo-Zena (Eds.), Emerging adults' religiousness and spirituality: Meaning-making in an age of transition (pp. 2138). New York, NY: Oxford University Press.

Barry, C. M., \& Nelson, L. J. (2005). The role of religion in the transition to adulthood for young emerging adults. Journal of Youth and Adolescence, 34(3), 245-255. doi:10.1007/s10964-005-4308-1 
Bates, J. B. (2006). Towards a future church with an ancient faith: "Emerging worship" at the North American Academy of Liturgy. Anglican and Episcopal History, 75(2), 296-301.

Baylor University. (2012). Hearn innovators series: KW. Retrieved from http://www.baylor.edu/ccms/index.php?id=82804

Bebbington, D. W. (2003). Evangelicalism in modern Britain: A history from the 1730s to the 1980s. London, England: Routledge.

Belzer, T., Flory, R. W., Roumani, N., \& Loskota, B. (2009). Congregations that get it: Understanding religious identities in the next generation. In J. Heft (Ed.), Passing on the faith: Transforming traditions for the next generation of Jews, Christians, and Muslims (pp. 115-134). New York, NY: Fordham University Press.

Bosch, D. J. (2003). Transforming mission: Paradigm shifts in theology of mission. Maryknoll, NY: Orbis Books.

Brewer, J. D. (1994). The ethnographic critique of ethnography: Sectarianism in the RUC. Sociology, 28(1), 231-244. doi:10.1177/0038038594028001014

Brooks, D. (2007, October 9). The odyssey years. New York Times. Retrieved from http://www.nytimes.com/2007/10/09/opinion/09brooks.html?_r=0

Bruce, T. (2010). Engaging young adults at a Catholic mega-parish. The Changing Spirituality of Emerging Adults Project Collection. American Catholic History Research Center and University Archives, Washington, DC. Retrieved from http://hdl.handle.net/1961/2041-122334

Cimino, R. (2010). Diversity and spirituality drive young adults at New Life Fellowship. The Changing Spirituality of Emerging Adults Project Collection. American Catholic History Research Center and University Archives, Washington, DC. Retrieved from http://hdl.handle.net/1961/2041-122336

Colby, A., \& Fischer, K. (1983). A longitudinal study of moral judgment. Chicago, IL: University of Chicago Press.

Côté, J. E. (2002). The role of identity capital in the transition to adulthood: The individualization thesis examined. Journal of Youth Studies, 5(2), 117-134. doi:10.1080/13676260220134403 
Côté, J. E. (2006). Emerging adulthood as an institutionalized moratorium: Risks and benefits to identity formation. In J. J. Arnett \& J. L. Tanner (Eds.), Emerging adults in America: Coming of age in the 21st century (pp. 85-116). Washington, DC: American Psychological Association.

Côté, J. E. (2014). The dangerous myth of emerging adulthood: An evidence-based critique of a flawed developmental theory. Applied Developmental Science, 18(4), 177-188.

Coupland, N., \& Nussbaum, J. F. (1993). Discourse and lifespan identity. Newbury Park, CA: Sage.

Cunningham, M. (2009). Physical attractiveness: Defining characteristics. In R. Sprecher (Ed.), Encyclopedia of Human Relationships (Vol. 3, pp. 1237-1242). Louisville, KY: Sage.

Daloz, L. A., \& Daloz Parks, S. (2003). Mentoring big questions and worthy dreams for young adults. Adult Learning, 14(1), 2-22.

Daloz Parks, S. (2011). Big questions, worthy dreams: Mentoring emerging adults in their search for meaning, purpose, and faith. San Francisco, CA: Jossey-Bass.

DeHaan, L. G., Yonker, J. E., \& Affholter, C. (2011). More than enjoying the sunset: Conceptualization and measurement of religiosity for adolescents and emerging adults and its implications for developmental inquiry. Journal of Psychology and Christianity, 30(3), 184-195.

Denning, S. (2007). The secret language of leadership: How leaders inspire action through narrative. San Francisco, CA: Jossey-Bass.

DiMaggio, P. (1998). The relevance of organization theory to the study of religion. In N. J. Demerath III, P. D. Hall, T. Schmitt, \& R. H. Williams (Eds.), Sacred companies: Organizational aspects of religion and religious aspects of organizations (pp. 7-23). New York, NY: Oxford University Press.

Donmoyer, R. (1990). Generalizability and the single-case study. In E. W. Eisner \& A. Peshkin (Eds.), Qualitative inquiry in education: The continuing debate (pp. 175200). New York, NY: Teachers College Press.

Dwyer, S. C., \& Buckly, J. L. (2009). The space between: On being an insider-outsider in qualitative research. International Journal of Qualitative Methods, 8(1), 54-63. 
Dyson, D. W. (2011b). Mending the nets: Towards a Wesleyan ecclesiology as a faithful response to emerging adult faith drift. (Unpublished Dissertation), Princeton Theological Seminary, Princeton, NJ.

Episcopal Church. (1990). The book of common prayer and administration of the sacraments and other rites and ceremonies of the church according to the use of the Episcopal church together with the psalter or Psalms of David. New York, NY: Oxford University Press.

Erikson, E. H. (1968). Identity, youth, and crisis. New York, NY: W.W. Norton.

Ferrer, J. N. (2015). Embodied spirituality: Now and then. Retrieved from http://www.integralworld.net/ferrer2.html

Fischer, K., Rose, L. T., \& Rose, S. P. (2006). Growth cycles of mind and brain: Analyzing developmental pathways of learning disorders. In K. W. Fischer, J. H. Bernstein, \& M. H. Immordino-Yang (Eds.), Mind, brain, and education in reading disorders (pp. 101-123). Cambridge, England: Cambridge University Press.

Flory, R., \& Miller, D. (2008). Finding faith: The spiritual quest of the post-boomer generation. Piscataway, NJ: Rutgers University Press.

Foster, C. R. (2006). Educating clergy: Teaching practices and the pastoral imagination. San Francisco, CA: Jossey-Bass.

Fowler, J. W. (1984). Becoming adult, becoming Christian: Adult development and Christian faith. San Francisco, CA: Harper \& Row.

Freitas, D. (2008). Sex and the soul: Juggling sexuality, spirituality, romance, and religion on America's college campuses. Oxford, England: Oxford University Press.

Fremont neighborhood in Seattle, Washington (WA), 98103, 98107 detailed profile. (n.d.). Retrieved from http://www.city-data.com/neighborhood/Fremont-SeattleWA.html

Funk, C., \& Smith, G. (2012). "Nones” on the rise: One-in-five adults have no religious affiliation. Retrieved from http://www.pewforum.org/files/2012/10/NonesOnTheRise-full.pdf 
Furstenberg, F. F. (1999). Managing to make it: Urban families and adolescent success. Chicago, IL: University of Chicago Press.

Geertz, C. (1973). The interpretation of cultures: Selected essays. New York, NY: Basic Books.

Gibbs, E., \& Bolger, R. K. (2005). Emerging churches: Creating Christian community in postmodern cultures. Grand Rapids, MI: Baker Academic.

Giddens, A. (1991). Modernity and self-identity: Self and society in the late modern age. Stanford. CA: Stanford University Press.

Gilligan, C. (1982). In a different voice: Psychological theory and women's development. Cambridge, MA: Harvard University Press.

Gilligan, C. (2011). Looking back to look forward: Revisiting "In a different voice". Defense Mechanisms, (9). Retrieved from http://chs.harvard.edu/CHS/article/display/4025

Gilligan, C., \& Murphy, J. M. (1979). Development from adolescence to adulthood: The philosopher and the dilemma of the fact. CD New Directions for Child and Adolescent Development, 1979(5), 85-99. doi:10.1002/cd.23219790507

Glesne, C. (2011). Becoming qualitative researchers: An introduction. Boston, MA: Pearson.

Gollnick, J. (2008). Religion and spirituality in the life cycle. New York, NY: P. Lang.

Greenberg, A. (2014). Most young adults value faith, but shun organized religion. Retrieved from http://www.prnewswire.com/news-releases/study--most-young adults-value-faith-but-shun-organized-religion-54239847.html

Hackett, C. (2014). Emerging adult participation in congregations. The Changing Spirituality of Emerging Adults Project Collection. American Catholic History Research Center and University Archives, Washington, DC. Retrieved from http://hdl.handle.net/1961/2041-122311

Handel, A. (1990). Formative encounters in early adulthood: Mentoring relationships in a writer's autobiographical reconstruction of his past self. Human Development, 33(4-5), 289-303. doi:10.1159/000276526 
Hartmann, D., \& Swartz, T. T. (2006). The new adulthood? The transition to adulthood from the perspective of transitioning young adults. Advances in Life Course Research, 11, 253-286.

Hayes, M. (2007). Googling God: The religious landscape of people in their 20's and 30's. Mahwah, NJ: Paulist Press.

Heft, J. E. (2009). Passing on the faith: Transforming traditions for the next generation of Jews, Christians, and Muslims. New York, NY: Fordham University Press.

Heifetz, R. A. (2003). Leadership without easy answers. Cambridge, MA: Belknap Press.

Hendry, L. B., \& Kloep, M. (2007). Conceptualizing emerging adulthood: Inspecting the emperor's new clothes. Child Development Perspectives, 1(2), 74-79.

Holloway, I. (1997). Basic Concepts for Qualitative Research. London: Blackwell Science.

Hopewell, J. F. (1987). Congregation: Stories and structures. Philadelphia, PA: Fortress Press.

Hutchison, W. R. (1990). Between the times: The travail of the protestant establishment in America, 1900-1960. Cambridge, MA: Cambridge.

Isquith, P. K., Gioia, G. A., \& Espy, K. A. (2004). Executive function in preschool children: Examination through everyday behavior. Developmental Neuropsychology, 26(1), 403-422.

Kaell, H. (2010). The Crossing: Worship, community, and action in emergent Episcopal ministry. The Changing Spirituality of Emerging Adults Project Collection. American Catholic History Research Center and University Archives, Washington, DC. Retrieved from http://hdl.handle.net/1961/2041-122345

Kett, J. F. (2003). Reflections on the history of adolescence in America. History of the Family, 8(3), 355-373. doi:10.1016/S1081-602X(03)00042-3

King, P. E. (2008). Spirituality as fertile ground for positive youth development. In R. M. Lerner, R. W. Roeser, \& E. Phelps (Eds.), Positive youth development and spirituality: From theory to research (pp. 55-73). West Conshohocken, PA: Templeton Foundation Press. 
King, P. E., \& Boyatzis, C. J. (2004). Exploring adolescent spiritual and religious development: Current and future theoretical and empirical perspectives. Applied Developmental Science, 8(1), 2-6.

King, P. E., Dowling, E. M., Mueller, R. A., White, K., Schultz, W., Osborn, P., . . . Benson, P. L. (2005). Thriving in adolescence: The voices of youth-serving practitioners, parents, and early and late adolescents. Journal of Early Adolescence, 25(1), 94-112.

King, P. E., Schultz, W., Mueller, R. A., Dowling, E. M., Osborn, P., Dickerson, E., \& Lerner, R. M. (2005). Positive youth development: Is there a nomological network of concepts used in the adolescent developmental literature? Applied Developmental Science, 9(4), 216-228.

Kinnaman, D., \& Hawkins, A. (2011). You lost me: Why young Christians are leaving church and rethinking faith. Grand Rapids, MI: BakerBooks.

Knoblauch, H. (2005). Focused ethnography. Forum Qualitative Sozialforschung / Forum: Qualitative Social Research [S.l.], 6(3), 1-8. Retrieved from http://www.qualitative-research.net/index.php/fqs/article/view/20

Kohlberg, L. (1976). Moral stages and moralization: The cognitive developmental approach. Moral Development and Behavior, 31-53.

Kohlberg, L., \& Hersh, R. H. (1977). Moral development: A review of the theory. Theory Into Practice, 16(2), 53-59. Retrieved from http://search.ebscohost.com/login.aspx?direct=true \&db=eric\&AN=EJ166795\&lo gin. asp $\&$ site $=$ ehost-live $\&$ scope $=$ site

Kosmin, B., \& Keysar, A. (2008, 2008). American religious identification survey: 2008. ARIS. Hartford, CT. Retrieved from http://www.americanreligionsurvey-aris.org/.

Labouvie-Vief, G. (2006). Emerging structures of adult thought. In J. J. Arnett \& J. L. Tanner (Eds.), Emerging adults in America: Coming of age in the 21st century (pp. 59-84). Washington, DC: American Psychological Association.

Labouvie-Vief, G. (2015). Integrating emotions and cognition throughout the lifespan. Champaign, IL: Springer International. 
Lindholm, J. A. (2009). The "interior" lives of American college students: Preliminary findings from a national survey. In J. Heft (Ed.), Passing on the faith:

Transforming traditions for the next generation of Jews, Christians, and Muslims (pp. 75-102). New York, NY: Fordham University Press.

Matalon, J. R. (2009). BJ: A portrait of a revitalised synagogue. In J. Heft (Ed.), Passing on the faith: Transforming traditions for the next generation of Jews, Christians, and Muslims (pp. 125-134). New York, NY: Fordham University Press.

Murray-Swank, N. A., Pargament, K. I., \& Mahoney, A. (2005). At the crossroads of sexuality and spirituality: The sanctification of sex by college students. International Journal for the Psychology of Religion, 15(3), 199-219. doi:10.1207/s15327582ijpr1503_2

Nelson, L. J. (2005). Distinguishing features of emerging adulthood: The role of selfclassification as an adult. Journal of Adolescent Research, 20(2), 242-262. doi: $10.1177 / 0743558404273074$

Newport, F. (2014). Mississippi most religious state, Vermont least religious. Retrieved from http://www.gallup.com/poll/167267/mississippi-religious-vermont-leastreligious-state.aspx

Norris, P., \& Inglehart, R. (2011). Sacred and secular: Religion and politics worldwide. Cambridge, UK: Cambridge University Press.

Olson, D. T. (2008). The American church in crisis: Groundbreaking research based on a national database of over 200,000 churches. Grand Rapids, MI: Zondervan.

Palmer, A. (2010). St. Peter's Catholic Student Center. The Changing Spirituality of Emerging Adults Project Collection. American Catholic History Research Center and University Archives, Washington, DC. Retrieved from http://hdl.handle.net/1961/2041-122341

Parker, E. (2015). Confessions of a high church millennial: Is liturgy a fad? Retrieved from http://millennialpastor.net/2015/03/04/confessions-of-a-high-churchmillennial-is-liturgy-a-fad

Pascarella, E. T., Terenzini, P. T., \& Feldman, K. A. (2005). How college affects students (Vol. 2). San Francisco, CA: Jossey-Bass.

Patton, M. Q. (2015). Qualitative research and evaluation methods: Integrating theory and practice. Los Angeles, CA: Sage. 
Pawar, B. S., \& Eastman, K. K.. (1997). The Nature and Implications of Contextual Influences on Transformational Leadership: A Conceptual

Examination. Academy of Management Review, 22(1), 80-109. Retrieved from http://www.jstor.org/stable/259225

Piaget, J. (1977). The role of action in the development of thinking. In W. F. Overton \& J. M. Gallagher (Eds.), Advances in research and theory (pp. 17-42). New York: Plenum Press.

Piaget, J., \& Gabain, M. (1965). The moral judgment of the child. New York, NY: Free Press.

Pogorelc, K. (2008). The Changing Spirituality of Emerging Adults Project collection. American Catholic Historical Research Center and University Archives, Washington, DC. Retrieved from http://archives.lib.cua.edu/findingaid/changspir.cfm

Polkinghorne, D. E. (1995). Narrative configuration in qualitative analysis. International Journal of Qualitative Studies in Education, 8(1), 5-23. doi:10.1080/0951839950080103

Presidents and Fellows Harvard University. (2008). Foundations of qualitative research in education: Emic and etic. Retrieved from

http://isites.harvard.edu/icb/icb.do?keyword=qualitative\&pageid=icb.page 340911

Price, M. J., Darves-Bornoz, D. Y., Erdey, S. T., Hurst, A. L., \& Walker, K. E. (2011). The hymnal revision feasibility study: A report to the Standing Commission on Liturgy and Music. Retrieved from https://www.cpg.org/linkservid/57003D75DA12-05B2F4FFD5819BE00E5A/showMeta/0/?label=Hymnal\%20Revision\%20Feasibility\% 20Study

Probasco, L. (n.d.). Congregational engagement with young adults: A review of the literature. Retrieved from http://faithcommunitiestoday.org/sites/faithcommunitiestoday.org/files/A\%20Rev iew\%20of\%20the\%20Young\%20Adult\%20Literature.pdf

Red Herring. (2006). E-merg, Podcast, 04. Retrieved from http://yeredherringe.blogspot.ca/ 
Roberto, J., \& Hayes, M. (2007). Best practices in young-adult faith formation. Lifelong Faith. Retrieved from http://www.faithformationlearningexchange.net/uploads/5/2/4/6/5246709/best_pr actices_-_young_adult_faith_formation.pdf

Salyards, W. (2009). Narrative and leadership. Creating Positive Change through Narrative Leadership. Retrieved from www.restory.org

Schoeni, R., \& Ross, K. (2004). Family support during the transition to adulthood: Policy brief \#3. Ann Arbor, MI: National Poverty Center.

Schoon, I. (2015). Diverse pathways: Rethinking the transition to adulthood. In P. R. Amato, A. Booth, S. M. McHale, \& J. Van Hook (Eds.), Families in an era of increasing inequality: Diverging destinies (Vol. 5). New York, NY: Springer.

Schwartz, S. J. (2005). Identity and agency in emerging adulthood: Two developmental routes in the individualization process. Youth \& Society, 37(2), 201-229. doi: $10.1177 / 0044118 x 05275965$

Settersten, R. A., Jr., Furstenberg, F. F., \& Rumbaut, R. G. (2008). On the frontier of adulthood theory: Research and public policy. Chicago, IL: University of Chicago Press.

Shachtman, T. (2006). Rumspringa: Amish teens venture into modern vices. NPR. Retrieved from http://www.npr.org/templates/story/story.php?storyId=5455572

Smith, C., Christoffersen, K., \& Davidson, H. (2011). Lost in transition: The dark side of emerging adulthood. New York, NY, NY: Oxford University Press.

Smith, C., \& Denton, M. L. (2005). Soul searching: The religious and spiritual lives of American teenagers. New York, NY, NY: Oxford University Press.

Smith, C., \& Snell, P. (2009). Souls in transition: The religious and spiritual lives of emerging adults (Vol. 2). New York, NY: Oxford University Press.

Sparrowe, R. T. (2005). Authentic leadership and the narrative self. Leadership Quarterly, 16(3), 419-439.

St. Paul's Episcopal Church - Anglo-Catholic. (n.d.). Retrieved from http://www.stpaulseattle.org/spirituality/anglo-catholic 
St. Paul's Episcopal Church. (2012). St. Paul's Episcopal church. Retrieved from http://www.stpaulseattle.org/our-community/our-building

St. Paul's Profile Committee. (2014). St. Paul's parish profile. Retrieved from http://www.stpaulseattle.org

Tanner, J. L. (2006). Recentering during emerging adulthood: A critical turning point in life span human development. In J. J. Arnett \& J. L. Tanner (Eds.), Emerging adults in America: Coming of age in the 21st century (pp. 21-55). Washington, DC: American Psychological Association.

Taylor, M. (2014). A few more points on Anglicanism as a "middle way": Follow up to October 11, 2012 enquirers' class [class handout]. Seattle. WA: St. Pauls's Episcopal Church.

Trzesniewski, K. H., Donnellan, M. B., \& Robins, R. W. (2008). Do today's young people really think they are so extraordinary? An examination of secular trends in narcissism and self-enhancement. Psychological Science, 19 (2), 181-188. doi: $10.2307 / 40064690$

Twenge, J. M. (2008). Review of emerging adulthood: The winding road from the late teens through the twenties. American Journal of Psychology, 121(4), 682-687. Retrieved from http://0-

search.ebscohost.com.sally.sandiego.edu/login.aspx?direct=true \&db=psyh\&AN= 2008-17600-010\&site=ehost-live

Twenge J.M., Campbell W.K., Gentile B., (2012) Increases in individualistic words and phrases in American books, 1960-2008. Plos One, 7(7), 1-5. doi:e40181. doi:10.1371/journal.pone.0040181

Twenge, J. M., Exline, J. J., Grubbs, J. B., Sastry, R., \& Campbell, W. K. (2015). Generational and time period differences in American adolescents' religious orientation, 1966-2014. Plos One, 10(5), 1-17. doi:10.1371/journal.pone.0121454

United Church of Canada. (2013). Models of board governance/manual 2013. (August). Toronto, ON. http://www.united-church.ca/files/handbooks/models-of-boardgovernance.pdf

United Methodist Communications. (2015). Our Wesleyan heritage: The United Methodist church. Retrieved from http://www.umc.org/what-we-believe/ourwesleyan-heritage 
Vaidyanathan, B. (2011). Religious resources or differential returns? Early religious socialization and declining attendance in emerging adulthood. Journal for the Scientific Study of Religion, 50(2), 366-387. doi:10.1111/j.14685906.2011.01573.x

Valpy, M. (2010). Young increasingly shun religious institutions. Globe and Mail. Retrieved from http://www.theglobeandmail.com/news/national/youngincreasingly-shun-religious-institutions/article1320112

Ward, K. M. (2010). Back to the Future: Visionary, Entrepreneurial, Missional Anglican Leadership for Today's Church. Anglican Theological Review, 92(1), 167.

Webber, R. E. (2000). From modern to postmodern: Worship changes during the twentieth century. Southwestern Journal of Theology, 42(3), 4-21. Retrieved from http://0search.ebscohost.com.sally.sandiego.edu/login.aspx?direct=true \&db=rfh\&AN=A TLA0000911136\&site=ehost-live

Weeks, L. B. (n.d.). Anthony Pogorelc on the Changing Spirituality of Emerging Adults Project. Retrieved from http://www.resourcingchristianity.org/sites/default/files/transcripts/interview/Anth ony_Pogorelc_Changing_Spirituality_Emerging_Adults_Interview.pdf

Welzel, C. (2014). Evolution, empowerment, and emancipation: How societies climb the freedom ladder. World Development, 64, 33-51.

Winston, D. (2006). Teach your children well: Closing observations on constructing religious identity in the next generation. In J. Heft (Ed.), Passing on the faith: Transforming traditions for the next generation of Jews, Christians, and Muslims (pp. 264-274). New York, NY: Fordham University Press.

Wuthnow, R. (2010). After the baby boomers: How twenty-and thirty-somethings are shaping the future of American religion. Princeton, NJ: Princeton University Press.

Yukich, G. (2010). Middle Collegiate Church. The Changing Spirituality of Emerging Adults Project Collection. American Catholic History Research Center and University Archives, Washington, DC. Retrieved from http://hdl.handle.net/1961/2041-122338 


\section{APPENDIX A}

E-MAIL TO CONGREGATIONAL LEADERS TO FOLLOW INITIAL CONTACT 


\section{Dear Friends}

I am a doctoral student at the University of San Diego doing qualitative dissertation research into newer congregations that consist predominantly of young adults (aged 1835). Such congregations will be;

1. mainstream (Presbyterian, Lutheran, United Church, Catholic, or Episcopalian) congregations.

2. attracting and keeping at least 30 young adults between the ages of 1835 who have come regularly for at least 2 years

3. in the Pacific Northwest of North America.

I would like to initially interview the leaders and some interested participants of such congregations in focus groups and individual interviews, attend religious services and other agreed upon congregational events, and look at advertising and other forms of identification literature such as websites, brochures etc. All interview data will be confidential unless the congregation and participants decide otherwise.

Could you let me know if you and your congregation would be willing to participate in my research?

Many thanks!

Blessings to you.

Rev. Bethan Theunissen - Doctoral Student School of Leadership and Education Sciences University of San Diego

Email: 
APPENDIX B

\section{RESEARCH PARTICIPANT CONSENT FORM}




\section{RESEARCH PARTICIPANT CONSENT FORM}

D. Bethan Theunissen is a doctoral student in the School of Education at the University of San Diego. You are invited to participate in a research project she is conducting for the purpose of exploring progressive and mainstream congregations on the Pacific Coast that consist primarily of young adults between the ages of 18 and 30 .

The project will involve up to two interviews with leaders and interested congregations members either individually or in focus groups, followed by providing transcripts to interviewees to check their accuracy. These interactions will involve telling the story of your congregation and your participation in it, as well as my asking your opinion on what makes this congregation attractive to young adults. Each interview will last about 60 to 90 minutes and will include a short demographic form to fill out with some questions about you, such as your age, length of involvement, etc. The interview/focus group will take place at a time and place that is convenient to you, preferably a place that minimizes interruptions and noise. Participation is voluntary and you can refuse to answer any question and/or stop at any time. Should you choose to stop, no one will be offended.

I will analyze the information you provide in a manner that protects your identity. I will use a code number and your real name will not appear on any of the materials. All information you provide will remain confidential and be locked in a file cabinet in the researcher's office and/or kept in a password-protected computer for a minimum of five years before being destroyed.

There is a slight risk that participating in these interviews may be tiring. Remember, you can stop the interview at any time for this and for any other reason. The benefit to participating will be in knowing that you helped religious communities learn how to help clergy and congregations in these changing times. If you have any questions about this research, please contact Bethan Theunissen (_) at 1 or Dr. Robert Donmoyer (_) at the University of San Diego 6192607445. I have read and understand this form, and consent to the research it describes to me. I have received a copy of this consent form for my records. 
APPENDIX C

\section{DEMOGRAPHIC SURVEY}




\section{DEMOGRAPHIC SURVEY}

Code

Age:

Number of years since you started attending the congregation

Mode of transportation to the congregation

Distance from your home to the congregation

How you heard about the congregation

Current religious identity, if any

Number of years of religious attendance as a child

Parents' religious identity1 2

Education (number of school years completed):

Ethnicity

Gender

Do you have children? Y N. Ages?

Are you married, partnered, or single? Please circle ... 


\section{APPENDIX D}

\section{OPEN-ENDED INTERVIEW QUESTIONS: ORIGINAL AND REVISED}




\section{Original Questions}

1. Tell me the story of how you came to be part of this congregation.

2. Can you tell me what you know of the story of how this congregation came to be?

3. Do any of these words (written up on a sheet of paper) have bearing on your story of coming to this congregation, either by their presence or absence? Bible, leaders, music, people like me, theology, parents, friends, location, time of day, ritual, liturgy, special events, etc.

4. Tell me the story of your experience of any leaders, past or present, who are part of why you came to this congregation.

5. Can you tell me any stories of how the leaders of this congregation helped/help young adults feel at home here, or met your needs?

6. Why do you think young adults this congregation attracts young adults?

\section{Interview Questions Revised in Situ.}

1. Could you tell me the story of your spiritual/faith/God (or lack thereof) journey and how that connected you to XXX?

2. Can you tell me the XXX story as you know it?

3. Do any of these words (written up on a sheet of paper) have bearing on your XXX story, either by their presence or absence? Music, peoplelike-me, theology, parents, friends, location, time of day, ritual, liturgy, Bible, leaders, special events, ethos, God, authenticity, safe space, etc. 
4. Are there any leaders in the story of why you are connected to XXX, and who were they, or what did they do, to have an impact on you?

5. Are there any aspects of how leadership is expressed or not expressed at XXX that resonate with those aged 18 to 35 in particular?

6. Can you think of a metaphor for XXX or your experience of it?

7. Why do you think so many young adults resonate with $\mathrm{XXX}$ ? 
APPENDIX E.

DEMOGRAPHIC DETAILS FOR COTA AND ST. PAUL'S 
COTA Demographics

\begin{tabular}{|c|c|c|c|c|c|c|c|c|}
\hline 芯 & \# & 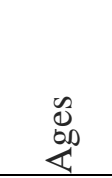 & 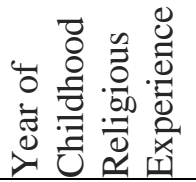 & 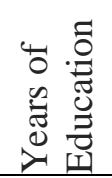 & 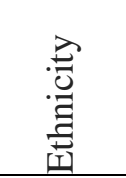 & $\begin{array}{l}\bar{v} \\
\frac{\overrightarrow{0}}{0} \\
\dot{0}\end{array}$ & 过 & 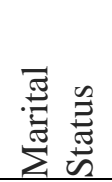 \\
\hline \multirow[t]{2}{*}{ Clergy } & \multirow[t]{2}{*}{2} & 30 & All & 20 & $\mathrm{C}$ & $\mathrm{M}$ & $\mathrm{N}$ & $\mathrm{P}$ \\
\hline & & 34 & All & 19 & $\mathrm{C}$ & M & $\mathrm{N}$ & M \\
\hline \multirow[t]{2}{*}{ Staff } & \multirow[b]{2}{*}{2} & 28 & All & 18 & $\mathrm{C}$ & $\mathrm{F}$ & $\mathrm{N}$ & S \\
\hline & & 30 & All & 20 & $\mathrm{C}$ & F & $\mathrm{N}$ & S \\
\hline \multirow{6}{*}{$\begin{array}{l}\text { Older } \\
\text { Adults }\end{array}$} & \multirow[t]{6}{*}{6} & 44 & All & 16 & $\mathrm{C}$ & M & Y & M \\
\hline & & 57 & All & 16 & $\mathrm{C}$ & M & $\mathrm{Y}$ & M \\
\hline & & 57 & All & 20 & $\mathrm{C}$ & $\mathrm{F}$ & Y & M \\
\hline & & 65 & All & 20 & $\mathrm{C}$ & $\mathrm{F}$ & Y & S-W \\
\hline & & 66 & 2 & 22 & $\mathrm{C}$ & $\mathrm{F}$ & $\mathrm{Y}$ & S-D \\
\hline & & 72 & 13 & 22 & $\mathrm{C} / \mathrm{Ir}$ & $\mathrm{F}$ & $\mathrm{N}$ & S \\
\hline Postulant & 1 & 45 & 18 & 23 & $\mathrm{C}(1)$ & M & $\mathrm{N}$ & S \\
\hline \multirow{8}{*}{$\begin{array}{l}\text { Young } \\
\text { adults }\end{array}$} & \multirow[t]{8}{*}{18} & $23(3)$ & 0 & 14 & C (14) & M (11) & $\mathrm{N}$ & $\mathrm{S}(10)$ \\
\hline & & $24(2)$ & $2(2)$ & 15 & BR (2) & $\mathrm{F}(7)$ & & M (5) \\
\hline & & $25(2)$ & 7 & $16(6)$ & $\operatorname{Afr}(1)$ & & & Girlfr. \\
\hline & & $27(5)$ & 8 & $17(2)$ & $\mathrm{H}(1)$ & & & E \\
\hline & & 28 & 9 & $18(5)$ & & & & $\mathrm{P}$ \\
\hline & & $31(4)$ & 10 & 19 & & & & \\
\hline & & 33 & $17(3)$ & 24 & & & & \\
\hline & & & $18(7)$ & 25 & & & & \\
\hline
\end{tabular}

Note. Ethnicity: Afr, African; A, Asian; BR, Bi-Racial/Multiracial; C, Caucasian; Ir, Iroquois; L, Latina/o; M, Mexican; Ph, Philipino. Gender M, Male; F, Female. Marital Status: S, Single; M, Married; D, Divorced; P, Partnered; Girlfr, Girlfriend. 
St. Paul's Demographics

\begin{tabular}{|c|c|c|c|c|c|c|c|c|}
\hline 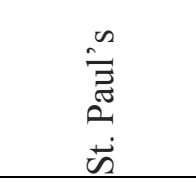 & $\#$ & $\begin{array}{l}\mathbb{J}^{\circ} \\
\mathbb{2}\end{array}$ & 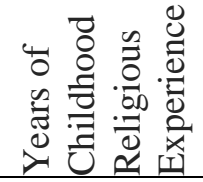 & 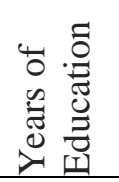 & 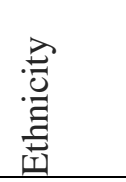 & $\begin{array}{l}\dot{\bar{\theta}} \\
\overline{0} \\
\dot{0} \\
0\end{array}$ & 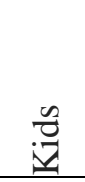 & 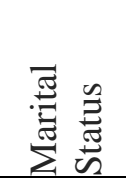 \\
\hline \multirow[t]{2}{*}{ Clergy } & \multirow[t]{2}{*}{2} & 61 & 18 & 22 & $\mathrm{C}$ & $\mathrm{F}$ & $\mathrm{Y}$ & $\mathrm{P}$ \\
\hline & & 61 & 1 & 18 & C & M & $\mathrm{N}$ & S \\
\hline Staff & 1 & 40 & 18 & 12 & $\mathrm{C}$ & M & $\mathrm{Y}$ & M \\
\hline \multirow{3}{*}{$\begin{array}{l}\text { Older } \\
\text { Adults }\end{array}$} & \multirow[t]{3}{*}{3} & 40 & 18 & $16+$ & $\mathrm{C}$ & F & $\mathrm{Y}$ & $\mathrm{M}$ \\
\hline & & 58 & 18 & $16+$ & $\mathrm{C}$ & $\mathrm{M}$ & $\mathrm{N}$ & $\mathrm{M}$ \\
\hline & & 65 & 10 & 18 & $\mathrm{C}$ & M & $\mathrm{N}$ & $\mathrm{M}$ \\
\hline \multirow{4}{*}{$\begin{array}{l}\text { Postulants / } \\
\text { Deacons }\end{array}$} & \multirow[t]{4}{*}{4} & 45 & $1-2$ & $18+$ & C & M & Y & $\mathrm{M}$ \\
\hline & & 48 & 16 & 22 & $\mathrm{C}$ & $\mathrm{M}$ & $\mathrm{Y}$ & $\mathrm{M}$ \\
\hline & & 54 & 18 & 22 & $\mathrm{C}$ & M & $\mathrm{Y}$ & $\mathrm{M}$ \\
\hline & & 57 & 18 & 22 & L-M & M & Y & M \\
\hline \multirow{11}{*}{$\begin{array}{l}\text { Young } \\
\text { adults }\end{array}$} & \multirow[t]{11}{*}{21} & 20 & $18(16)$ & 15 & C (19) & M (9) & $\mathrm{N}$ & S (14) \\
\hline & & 21 & $5(2)$ & $16(7)$ & $\mathrm{A}-\mathrm{Ph}$ & F (12) & $(21)$ & M (2) \\
\hline & & $23(3)$ & 3 & $17(3)$ & L-PR & & & $\mathrm{P}(3)$ \\
\hline & & $24(2)$ & 2 & 18 & & & & S-G (2) \\
\hline & & $25(2)$ & 0 & $19(3)$ & & & & \\
\hline & & $27(3)$ & & $20(3)$ & & & & \\
\hline & & 28 & & 22 & & & & \\
\hline & & $32(3)$ & & $25+$ & & & & \\
\hline & & $33(2)$ & & & & & & \\
\hline & & 34 & & & & & & \\
\hline & & $36(2)$ & & & & & & \\
\hline
\end{tabular}

Note. Ethnicity: C, Caucasian; L, Latina/o; A, Asian; Ph, Philipino; M, Mexican; Afr, African; Gender : M, Male; F, Female. Marital Status: S, Single; M, Married; D, Divorced; P, Partnered; Girlfr, Girlfriend. 


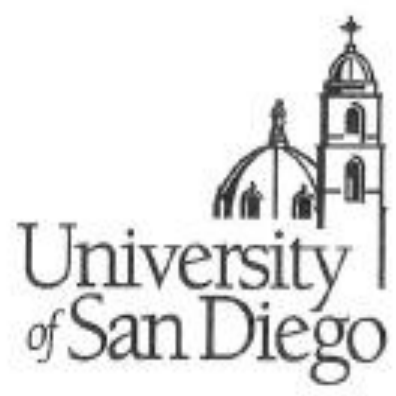

\section{Institutional Review Board Project Action Summary}

Action Date:

Note: Approval expires one year after this date.

Type: _ New Full Review __New Expedited Review X_Modification

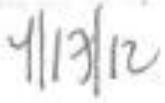

Action:

$$
\text { X_Approved }
$$

Approved Pending Modification

Continuation Review

Exempt Review

Project Number. 2012-03-115

Researcher(s): Denise Bethan Theunissen Doc SOLES

Dr. Robert Donmoyer Fac SOLES

Project Title: $\quad$ "INTONATIONS OF THEIR OWN LANGUAGE": AN ANALYSIS OF LEADERSHIP AND SYMBOLIC RESONANCE IN THREE PROGRESSIVE YOUNGADULT-FILLED MAINSTREAM CONGREGATIONS IN THE PACIFIC NORTHWEST

Note: We send IRB comespondence regarding student research to the faculfy advisor, who bears the ultimate responsibiity for the conduct of the research. We request that the faculty advisar share this correspondence with the student researcher.

\section{Modifications Required or Reasons for Non-Approval}

None

The next deadline for submitting project proposals to the Provost's Office for full review is NA. You may submit a project proposal for expedited review at any time.

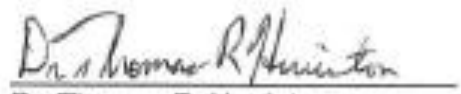

Dr. Thomas R. Herrinton

Administrator, Institutional Review Board

University of San Diego

5998 Alcalá Park

San Diego, California 92110-2492 